\title{
Sustainable jet fuel for aviation
}

Nordic perpectives on the use of advanced sustainable jet fuel for aviation

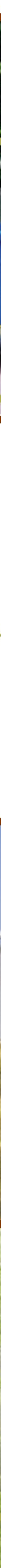







\section{Sustainable jet fuel for aviation}

Nordic perpectives on the use of advanced sustainable jet fuel for aviation

Erik C. Wormslev, Jakob Louis Pedersen, Christian Eriksen, Rasmus Bugge, Nicolaj Skou, Camilla Tang, Toke Liengaard, Rasmus Schnoor Hansen, Johannes Momme Eberhardt, Marie Katrine Rasch, Jonas Höglund, Ronja Beijer Englund, Judit Sandquist, Berta Matas Güell, Jens Jacob Kielland Haug, Päivi Luoma, Tiina Pursula and Marika Bröckl

TemaNord 2016:538 


\section{Sustainable jet fuel for aviation}

Nordic perpectives on the use of advanced sustainable jet fuel for aviation

Erik C. Wormslev, Jakob Louis Pedersen, Christian Eriksen, Rasmus Bugge, Nicolaj Skou,

Camilla Tang, Toke Liengaard, Rasmus Schnoor Hansen, Johannes Momme Eberhardt

Marie Katrine Rasch, Jonas Höglund, Ronja Beijer Englund, Judit Sandquist, Berta Matas Güell,

Jens Jacob Kielland Haug, Päivi Luoma, Tiina Pursula and Marika Bröckl

ISBN 978-92-893-4661-0 (PRINT)

ISBN 978-92-893-4662-7 (PDF)

ISBN 978-92-893-4663-4 (EPUB)

http://dx.doi.org/10.6027/TN2016-538

TemaNord 2016:538

ISSN 0908-6692

(C) Nordic Council of Ministers 2016

Layout: Hanne Lebech

Cover photo: Scanpix

Print: Rosendahls-Schultz Grafisk

Copies: 100

Printed in Denmark

This publication has been published with financial support by the Nordic Council of Ministers. However, the contents of this publication do not necessarily reflect the views, policies or recommendations of the Nordic Council of Ministers.

\section{www.norden.org/nordpub}

\section{Nordic co-operation}

Nordic co-operation is one of the world's most extensive forms of regional collaboration, involving Denmark, Finland, Iceland, Norway, Sweden, and the Faroe Islands, Greenland, and Åland.

Nordic co-operation has firm traditions in politics, the economy, and culture. It plays an important role in European and international collaboration, and aims at creating a strong Nordic community in a strong Europe.

Nordic co-operation seeks to safeguard Nordic and regional interests and principles in the global community. Common Nordic values help the region solidify its position as one of the world's most innovative and competitive.

\section{Nordic Council of Ministers}

Ved Stranden 18

DK-1061 Copenhagen K

Phone (+45) 33960200

\section{www.norden.org}




\section{Contents}

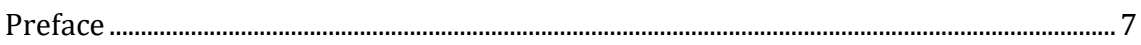

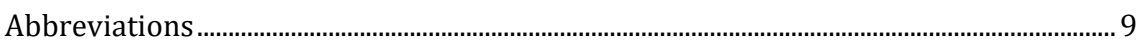

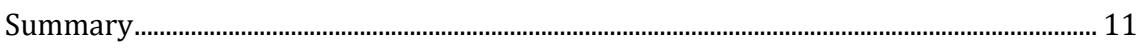

Background and motivation........................................................................................ 11

Market demand and feedstock production .................................................................... 13

Most promising pathway scenarios............................................................................. 16

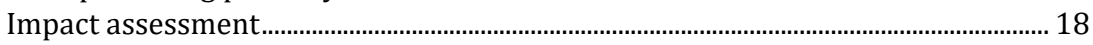

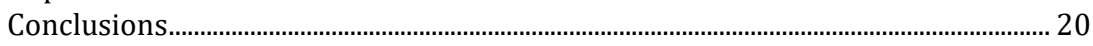

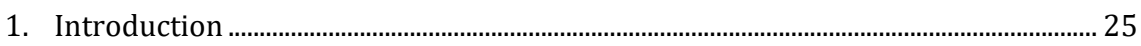

1.1 Process............................................................................................................ 25

1.2 Structure of the report.......................................................................................... 26

1.3 Studies on sustainable aviation fuel.................................................................. 27

Background and Motivations................................................................................................ 33

2. Global status of sustainable jet fuel ........................................................................... 35

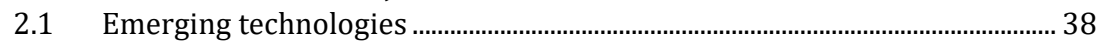

2.2 Multi-stakeholder initiatives ................................................................................ 39

3. Coupling of existing sustainability criteria and policies.............................................. 45

3.1 Criteria for sustainable jet fuel ........................................................................ 45

3.2 International governmental policy frameworks .............................................. 51

3.3 International business policy frameworks ....................................................... 56

4. Legislation and priorities in the Nordic countries and the EU ......................................... 61

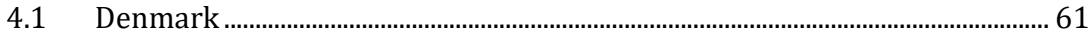

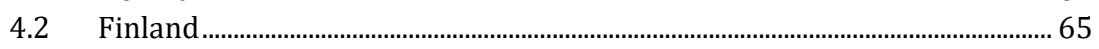

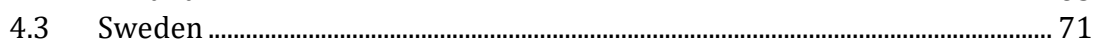

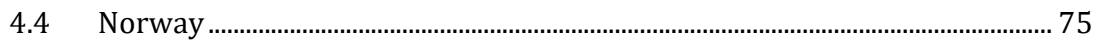

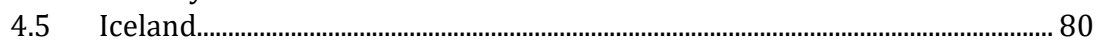

Market and Production Pathways................................................................................... 85

5. Jet fuel Demand and price sensitivity ........................................................................ 87

5.1 Current demand for jet fuel.................................................................................. 87

5.2 Future demand for sustainable jet fuels in the Nordic countries .................. 89

5.3 Future feedstock demand for sustainable jet fuel ........................................... 91

5.4 Price sensitivity ..................................................................................................... 92

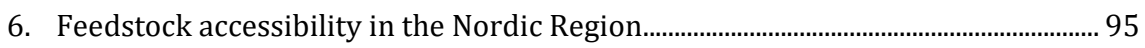

6.1 Types of feedstock ............................................................................................... 95

6.2 Denmark - Feedstock availability ..................................................................102

6.3 Finland - Feedstock availability .......................................................................106

6.4 Norway - feedstock availability ………………..................................................110

6.5 Sweden - feedstock availability ………….........................................................113

6.6 Iceland....................................................................................................................116

6.7 Import of feedstock ........................................................................................117 
7. Nordic Energy Infrastructure ....................................................................................119

7.1 Nordic Airports: infrastructure, supply chain and logistics .........................121

7.2 Petroleum refineries............................................................................................125

7.3 Biorefineries and production facilities .................................................................126

7.4 Introduction of new fuels in the supply chain .................................................132

8. Technology pathways...........................................................................................................137

8.1 Introduction to a sustainable jet fuel technology pathway............................137

8.2 Recognized pathways ...........................................................................................139

8.3 Conversion efficiencies and product distribution ...........................................148

8.4 Technical complexities in sustainable jet fuel production ..............................151

8.5 Nordic technologies, role in pathways and maturity ……………...................152

Most Promising Pathway Scenarios ......................................................................................163

9. Most promising pathway scenarios for Nordic collaboration ..................................165

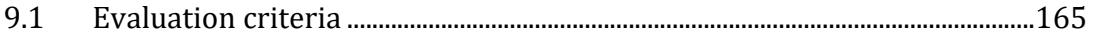

9.2 Most promising feedstock ..................................................................................167

9.3 Most promising conversion technology pathways............................................169

9.4 Identification of the most promising scenarios .................................................169

9.5 Scenario 1: HEFA/HEFA+ .................................................................................170

9.6 Scenario 2: FT Forest industry integration......................................................175

9.7 Scenario 3: Lignocellulosic AtJ .............................................................................179

9.8 Comparison of the three scenarios ..................................................................184

10. Nordic comparative advantages...................................................................................187

10.1 Nordic strengths on feedstock and infrastructure ...........................................187

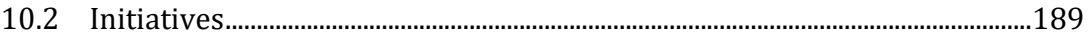

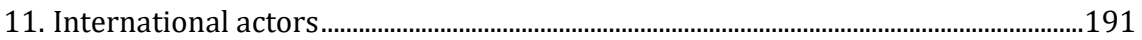

11.1 Experience from other countries....................................................................193

Impact on Climate Change and Economy..........................................................................197

12. Climate change mitigation impact................................................................................199

12.1 How to measure the climate impact of aviation fuel.......................................199

12.2 Non- $\mathrm{CO}_{2}$ climate effects of sustainable jet fuels .............................................203

12.3 Climate impacts of the three pathway scenarios ............................................204

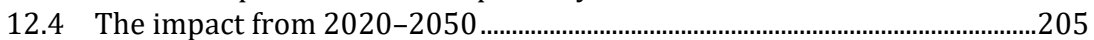

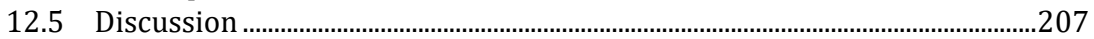

13. Socio-economic and business impact ............................................................................20

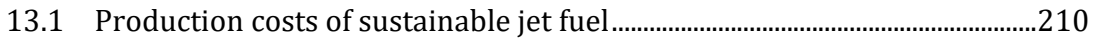

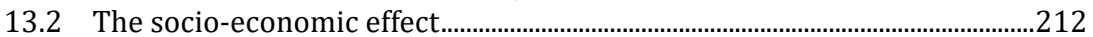

13.3 The impact on business sectors........................................................................215

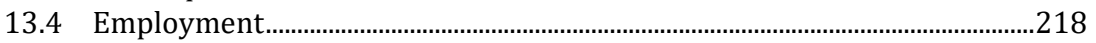

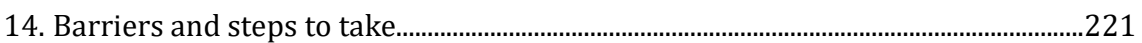

14.1 Price differential on fossil and sustainable jet fuels......................................222

14.2 Lack of congruent sustainability requirements...............................................222

14.3 Business challenges................................................................................................226

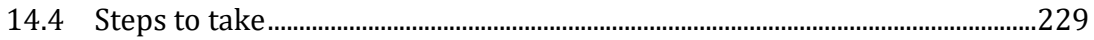

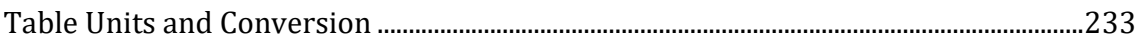

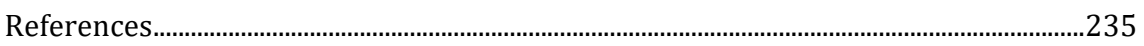




\section{Preface}

In the effort to meet its international commitments in reducing its share of the global GHG emissions from international aviation, the aviation sector in the Nordic countries have initiated a series of developing processes towards new sustainable jet fuel solutions.

At present the aviation sector has managed to improve its fuel efficiency, although these results are far from sufficient to deliver the required reduction path. Therefore, the aviation sector is increasingly focusing on developing the technical standards, the legal framework as well as a production infrastructure for a commercial production of sustainable jet fuel.

This report presents an overview of the current state in the Nordic countries of the development process for the sustainable jet fuel. The overall aim is to assess to what extent the use of advanced sustainable jet fuel may contribute to GHG reduction and mitigation, as well as identifying the extent of the commercial potential for initiating and scaling up advanced sustainable jet fuel production at a Nordic level. The report explores as well on how to most efficiently use the available Nordic know-how, feedstock and production facilities. The report draws on the latest available reports and statistics, as well as interviews with stakeholders and experts across the Nordic countries, concludes on identifying the most matured technologies, the Nordic opportunities and challenges, and ideas to mitigate the barriers within the Nordic private and public sectors.

The report is divided into four main sections. The first describes the current background knowledge and policy framework for the development process of the sustainable jet fuel. The second discusses the market basis, including the demand and supply. The latter includes an indepth mapping of the existing feedstock and available technology in the Nordic countries, as well as the feedstock pathway. The third section identifies the most promising production scenarios and explores the Nordic comparative advantages for these. The fourth section concludes on the possible consequences for the Nordic climate objectives and business and social economy of scaling-up the identified pathway scenarios. The main conclusions and suggestions are summarized in section 1.5. 
The content and recommendations of this report is the sole responsibility of the Consultant, but the report has been subject to review and discussion in a Steering Group consisting of:

- Marie Kjellén, Nordic Energy Research.

- Lars Hasselager Olsen, Danish Energy Agency.

- Anders Lewald, Swedish Energy Agency.

- Anna Lilja Oddsdottir, National Energy Authority, Iceland.

- Anita Makinen, Ministry of Communication and Transportation, Finland.

- Ágústa Loftsdóttir, National Energy Authority, Iceland.

- Arnhild Wartiainen, Norwegian Ministry of Transport and Communications.

- Jens Erik Ditlevsen, Danish Transport and Construction Agency.

- Jonas Lindmark, Swedish Energy Agency.

- Suvi Anttila, Minestry of Communication and Transportation, Finland.

- Martin Porsgaard, NISA, Nordic Initiative for Sustainable Aviation .

The report has been developed from August 2015 to June 2016 by a project team with technical, economic and environmental specialists in NIRAS A/S and its partners in ÅF (Sweden), SINTEF Energy Research (Norway) and Gaia Consulting OY (Finland). 


\section{Abbreviations}

$\begin{array}{ll}\text { ADAM } & \text { Annual Danish Aggregate Model } \\ \text { ASTM } & \text { American Society for Testing and Materials } \\ \text { ATAG } & \text { The Air Transport Action Group } \\ \text { ATM } & \text { Air Traffic Management } \\ \text { AtJ } & \text { Alcohol to Jet } \\ \text { BDL } & \text { Brancheforeningen Dansk Luftfart (Danish Aviation) } \\ \text { CAAFI } & \text { Commercial Aviation Alternative Fuels } \\ \text { CHP } & \text { Combined heat and power } \\ \text { CH } & \text { Catalytic Hydrothermolysis } \\ \text { DCA } & \text { Danish Centre for Food and Agriculture } \\ \text { DSHC } & \text { Direct Sugar to Hydrocarbons } \\ \text { EOF } & \text { Energi- og Olieforum } \\ \text { EPA } & \text { Environmental Protection Agency } \\ \text { ETS } & \text { Emissions Trading System } \\ \text { EU RED } & \text { European Union Renewable Energy Directive } \\ \text { FAME } & \text { Fatty Acid Methyl Esters } \\ \text { FAO } & \text { Food and Agriculture Organization of the United Nations } \\ \text { FCC } & \text { Fluid Catalytic Cracking } \\ \text { FRL } & \text { Fuel Readiness Level } \\ \text { FSC } & \text { Forest Stewardship Council } \\ \text { FSRL } & \text { Feedstock Readiness Level } \\ \text { FT } & \text { Fischer-Tropsch } \\ \text { FTE } & \text { Full Time Equivalents } \\ \text { GHG } & \text { Greenhouse Gas } \\ \text { GFAAF } & \text { Global Framework for Aviation Alternative Fuels } \\ \text { GWP } & \text { Global Warming Potential } \\ \text { HDCJ } & \text { Hydrotreated Depolymerized Cellulosic Jet } \\ \text { HEFA } & \text { Hydrotreated Esters and Fatty Acids } \\ \text { HTL } & \text { Hydrothermal Liquefaction } \\ \text { IATA } & \text { The International Air Transport Association } \\ \text { ICAO } & \text { International Civil Aviation Organization } \\ \text { ILUC } & \text { Indirect Land Use Change } \\ \text { IPCC } & \text { Intergovernmental Panel on Climate Change } \\ \text { ISO } & \text { The International Organization for Standardization } \\ \text { LCA } & \text { Lifecycle Assessment } \\ & \end{array}$




$\begin{array}{ll}\text { LHF } & \text { Liquid hydrocarbon fuels } \\ \text { LUC } & \text { Land Use Change } \\ \text { LULUCF } & \text { Land Use, Land Use Change and Forestry } \\ \text { MASBI } & \text { Midwest Aviation Sustainable Biofuels Initiative } \\ \text { MEC } & \text { Maabjerg Energy Concept } \\ \text { NISA } & \text { Nordic Initiative for Sustainable Aviation, Nordic Countries } \\ \text { NREL } & \text { National Renewable Energy Laboratory } \\ \text { OECD } & \text { Organization for Economic Co-operation and Development } \\ \text { PEFC } & \text { Programme for the Endorsement of Forest } \\ & \text { Certification schemes } \\ \text { PJ } & \text { Petajoule (equivalent to 1.015 Joule or 2.78·105 MWh) } \\ \text { RSB } & \text { Roundtable of Sustainable Biomaterials } \\ \text { SAFUG } & \text { Sustainable Aviation Fuel Users Group } \\ \text { SARPs } & \text { Standards and Recommended Practices } \\ \text { SAK } & \text { Synthetic Aromatic Kerosene } \\ \text { SES } & \text { Single European Sky } \\ \text { SESAR } & \text { Single European Sky ATM Research } \\ \text { SK } & \text { Synthetic Kerosene } \\ \text { SKA } & \text { Synthetic Paraffinic Kerosene with Aromatics } \\ \text { SMEs } & \text { Small and medium sized enterprises } \\ \text { SPK } & \text { Synthetic Paraffinic Kerosene } \\ \text { TJ } & \text { Terajoule (equivalent to 1,012 Joule or 278 MWh) } \\ \text { USGS } & \text { United States Geological Survey } \\ \text { WWF } & \text { World Wildlife Fund } \\ & \end{array}$




\section{Summary}

This report studies the background and current state of the Nordic countries' effort to develop sustainable jet fuel solutions based on biofuel technologies, as well as assesses to which extent scaling up these solutions may contribute to GHG mitigation in the sector and the commercial potential for initiating and scaling up production at a Nordic level. The study has focused on solutions on how to make use of Nordic know-how, feedstock and production facilities.

The study is divided into four main sections, including the background and motivations for the Nordic countries to engage in developing sustainable jet fuel solutions, an identification of the market and production pathways, a section on perspectives for the most promising production pathways in the Nordic countries, as well as an impact assessment of scaling up the production in terms of socio-economic factors and climate change mitigation. Additional to the analysis, the study includes thorough introduction to a series of terminologies, as well as political framework, technical discussions and identification of challenges and opportunities. The main conclusions, identified barriers and recommendations are presented in the last chapter (14).

\section{Background and motivation}

The world has yet to see a fully functioning commercial supply chain for sustainable jet fuel. However, an increasing number of commercial flights operate worldwide on a blend of commissioned biofuels. Nordic countries have been the leader on this field in Europe. Since January 2016, biofuel has been available on the Oslo airport in Norway. The delivered fuel is produced at a refinery in Porvoo, Finland. There are promising developments elsewhere as well. In US four producers: Fulcrum Bioenergy, GEVO, Red Rock Biofuels and AltAir, have established agreements with airlines for the supply of larger fuel amounts on a long term basis. This collaboration is likely to lead to a stable commercial production in the US in the near future. In addition to the established producers of alternative jet fuel, a number of companies are supplying and developing technologies that are either commercially used to some extent or 
could see increased future potential given technological development. While such technologies may seem to offer promising new solutions, they are generally on a lower level of maturity.

In the last decade, the world has seen more than 80 multi-stakeholder initiatives. Some of them have terminated, due to various challenges facing the commercial markets for the sustainable jet fuel producers. However, the increasing number of initiatives demonstrates a growing interest in sustainable jet fuels on both the producers and buyers side, as well as from the states, organizations and other stakeholders.

\section{Criteria for sustainable jet fuel}

There is currently a variation of several internationally agreed upon criteria of what defines sustainability, in sustainable jet fuel. Although, the terminology points on many different aspects of the production and consumption, including environmental and socio-economic factors, the issue of accountable GHG-emissions reductions, biodiversity and land usage are most common.

The Nordic countries do not have one common definition of what constitutes sustainable jet fuel. However, they are members of international organizations who have. The Nordic EU members are politically committed to the Renewable Energy Directive, which defines sustainability jet fuel as fulfilling a number of land-use criteria and has less direct GHG emissions over the full life cycle as compared to the fossil fuel. The GHG emission reduction criterion is currently $35 \%$, but increases to $50 \%$ from 2018 and $60 \%$ for new production sites after the 5th October 2015. GHG emissions from e.g. indirect land-use changes are not included.

ICAO, the International Civil Aviation Organization of the UN, is also likely to provide a similar definition, as it is planning to launch a global, market-based mechanism to promote reductions in GHG emissions from civil aviation. Besides the intergovernmental frameworks constituted by the UN and the EU, the business community itself has formed a range of organizations, which engage themselves in sustainable aviation including setting criteria for sustainability, including the work of the International Air Transport Association (IATA), the Sustainable Aviation Fuel User Group (SAFUG) and the Nordic Initiative for Sustainable Aviation (NISA).

In the debate the question is not as much whether the fuel is sustainable, but whether it also is advanced. This indicates that the fuel at least is produced using a so-called 2nd generation technology and feedstock and cultivation. However, dividing feedstock into generations is largely historical, based on the progression of technology. 


\section{Nordic policy framework for sustainable aviation fuels}

The current EU GHG emission reduction targets do include aviation. However, any GHG emissions from aviation exceeding $6.18 \%$ of total national emissions are excluded from from the national GHG accounts of the EU countries.

The Nordic countries are known for their ambitious environmental policies and for leading the position in the fight against climate change. Yet, the Nordic policy framework for sustainable jet fuels is fragmented. While Finland has introduced national initiatives aimed at the promotion of sustainable jet fuel, and Norwegian domestic aviation is also subject to $\mathrm{CO}_{2}$ taxation, the remainder of the Nordics has not yet introduced targets nor any national initiatives aimed at sustainable aviation specifically. ${ }^{1}$

On the other hand, the Nordic countries have all implemented quota obligations for biofuels in road based transport and rather comprehensive support schemes for energy production using renewable energy, such as biomass. Thus, there exists a precedent for political support of renewable energy and of carrying political commitments in this area.

Yet, this precedent might prove to be a double-edged sword for sustainable jet fuels, as existing support schemes may incentivice the use of biomass in road transport and energy production over the production of sustainable jet fuel. This will however depend on the design of the scheme. Norway has an investment support scheme for production of biofuel and biogas, where also sustainable jet fuel production can apply for investment support.

\section{Market demand and feedstock production}

Because of the international competition, the majority of fossil jet fuel consumption in the Nordic countries is covered through maritime imports from overseas producers. However, 11 Nordic petroleum refineries are in operation to meet the demand of gas and oil for mainly building heating and train and road transportation. Because of the planned green energy transition of train and road transportation, these existing facilities are likely to experience an increasing factor overcapacity, which can be included into the value chain of local sustainable jet fuel production in the future.

\footnotetext{
${ }^{1}$ At the moment (June, 2016) Norway is discussing quota obligations and rebate in landing fees and Sweden is working on a national aviation strategy.
} 
Dedicated refineries for biofuels and intermediates already exist in the Nordic countries. Most are dedicated to producing either bioethanol, renewable diesel, but also other fuels such as DME or gaseous fuels. Only one facility exists capable of producing sustainable jet fuel.

\section{The Nordic market demand of sustainable aviation fuels}

Over the past five years, the Nordic countries aggregate consumption of jet fuel has gradually increased from roughly 4 million $\mathrm{m}^{3}$ in 2010 to 4.5 million $\mathrm{m}^{3}$ in 2014, of which jet A-1 fuel accounts for $99 \% .^{2}$ Projections of the future demand for jet fuel shows a continuation of this gradual increase up until 2025, where the Nordic demand for jet fuel peaks at roughly 5.7 million $\mathrm{m}^{3}$. Subsequently, the demand stagnates reaching a steady state of an aggregate annual demand of 5.4 million $\mathrm{m}^{3}$ in 2030 and onwards.

Currently, there exists a price gap between sustainable and conventional jet fuels, which is primarily attributable to the high production costs of the former. This price gap has been further augmented by the historically low contemporary oil prices. Thus, sustainable jet fuel currently exhibits costs ranging from EUR 0.8-2.2/l, compared to a fossil reference of EUR $0.25 /$ l. As a consequence of this gap, a market for sustainable jet fuels has yet to emerge, both in the Nordic region and globally.

Based on assumptions pursuant to the global aviation industry's GHG emission targets and the industry's four pillar strategy (see section 3.3) for meeting set targets, the future demand for sustainable jet fuel in the Nordics has been estimated in this report. Assuming that commercial production can take place in a Nordic supply chain from 2020, initial annual demand for sustainable jet fuel could reach 65 million $\mathrm{l}$ in 2020equivalent to about $1.2 \%$ of the total demand in the Nordic countries. As the demand for sustainable jet fuel is assumed to make up an ever increasing fraction of total fuel consumption, owing to the aforementioned targets of the global aviation industry, the demand for sustainable jet fuel should not stagnate in 2030, but will continue to increase over the period of analysis, reaching 2 billion l in 2050, corresponding to $37.5 \%$ of total Nordic jet fuel demand.

The market's supply of sustainable jet fuel depends on several variables. Firstly the factor availability, including the feedstock and technology. Secondly, the market competition for input factors, which is determined by the factor's ability to substitute and complement with other products.

2 The remaining $1 \%$ is covered by avgas, which is not considered further in this report. 


\section{Feedstock availability}

Several domestic feedstock candidates for sustainable jet fuel exist in the Nordic countries. The most ideal candidates in the foreseeable future, with respect to availability and price, are wood residuals, wheat straw and organic waste fractions. All the feedstocks face heavy competition from alternate uses in production of heat and power and biofuels for road transport.

Wood residuals from logging-, pulp, paper and timber industries are used in vast amounts in Finland, Norway and Sweden. Estimates of the total potential range well over $250 \mathrm{PJ}$ annually. The price for wood residuals range between EUR 5-8/GJ and is highly dependent on the specific source and region of origin.

Wheat straw is left to compost at fields in large amounts in Denmark and Sweden amounting to a potential of $37 \mathrm{PJ}$ annually. The price for wheat straw ranges between EUR 5-6/GJ.

All organic waste fractions can in theory be used in sustainable jet fuel production, in particular vegetable and animal waste oils are highly suited. The total potential is complex to estimate. Prices are highly variable, with negative estimates for fractions with a gate-fee and up to EUR 5/GJ. There exist no available data on the cost, but import of waste fractions from outside the Nordic countries may even show to be a cost effective solution (including transportation costs) and is therefore also considered as an option.

Other sources of feedstock are also possible, but not currently available in any significant amount in the region. These include energy crops and marine resources, such as seeweed and algae. In the longer term, these feedstocks may become available, given developments in their cultivation.

Many of the feedstock candidates can potentially be imported from countries outside the Nordics, though the same issues of competing markets are expected to limit availability.

\section{Technology availability}

The Nordic countries have strong competencies in biorefining technology. Within a biochemical conversion route, this includes suppliers for pre-treatment of lignocellulosic biomass by enzymatic hydrolysis, as well as yeast cultures for fermentation, and within a thermochemical route it includes gasification of biomass and reforming of syngas. A range of suppliers also provide technologies for producing intermediates, currently used in Nordic production of other biofuels such as re- 
newable diesel, which can potentially also be used for sustainable jet fuel production. Finally refining technologies, relevant for all biofuels are also part of the Nordic technology portfolio.

A handful of firms are currently in active pursuit of a sustainable jet fuel production. With the exception of Neste, who has the capacity and technology to produce sustainable jet fuel, all of these actors are at a lower technological maturity and require significant development before they can be considered part of a possible commercial scale production.

\section{Most promising pathway scenarios}

The most promising pathway scenarios for a Nordic production of sustainable jet fuel is HEFA/HEFA+ based on waste-oils and oil crops; Fischer-Tropsch (FT) on wood residuals and Lignocellulosic Alcohol-to-Jet (At)). These pathways have a maturity level in terms of technology and infrastructure which can make production realistic in the short to medium term. The scenarios involve a more available and affordable feedstock production in comparison to other pathways. They are also already available to some extent in two or more of the Nordic countries. Lastly, all of the three pathway scenarios have potential Nordic suppliers of technology and their roles in the different stages of the scenarios are identified.

\section{Comparative Advantages}

Comparing the three scenarios, the HEFA-based scenario is superior to the two other scenarios when it comes to maturity and cost efficiency. Also, it has the lowest production complexity and is therefore most attractive as an initial technology. This scenario is thus likely to be initiated first, from around 2020 (provided that the demand is increased), while the FT and the AtJ scenario are expected to be initiated towards 2025-2030. The downside of HEFA is the limited availability of waste oils as a feedstock in the Nordic countries and generally poorer conditions for cultivating oil crops like jatropha or camelina compared to warmer countries.

The FT scenario has an international comparative advantage, as it utilizes the forest biomass in Finland, Norway and Sweden, which represents the largest forest resource in Europe, with an existing, wellestablished industry and infrastructure for collection and utilization of the feedstock. Most Nordic forests are also in a state of net growth, and this extraction can be increased if economically and sustainably viable. 
In terms of life cycle GHG reductions, the FT-scenario is most likely to achieve the highest performance out of the three scenarios. ${ }^{3}$

The AtJ scenario is in comparison the most immature technology, as well as the most expensive production process.

All technologies have different levels of production foot prints in each country. The downstream of the HEFA-based scenario will most likely be physically located in Finland, due to the already existing infrastructure. However, long term expansion could in principle be located in any of the Nordic countries. The FT based scenario is likely to be produced in Norway, Sweden or Finland, close to available forest biomass and forestry/pulp and paper production infrastructure. The AtJ scenario will especially benefit Denmark or Sweden, due to the utilization of straw. Iceland has large acces to low cost energy, which could be utilized for hydrogen production, though any other production processes are unlikely to be located physically in Iceland.

The location of the final processing steps of refining for all scenarios can, theoretically, also be located in any of the Nordic countries, as the transportation costs of the more energy dense intermediate products are low, compared to the costs of transporting pure feedstocks.

In comparison to the rest of the world, the study identifies the following comparable advantages for the Nordic region in engaging in sustainable jet fuel production:

- Commercial scale production facilities already exist.

- Availability of an increasing over-capacity in refining caused by placing the refining steps of biofuel production in retrofitted units or integrated close by.

- Knowledge and feedstock capacity to let the three most promising scenarios exist in parallel.

- The biorefinery concept is already well-established in Nordic energy production and is closely linked to an increasing awareness of circular economy and the utilization of by-products.

- The Nordic countries have strong competencies and technological know-how within:

- Advanced utilization of forest biomass, such as gasification and extraction of higher value products in biorefining. 
- Production synergies and increasing the production differentiability between biofuels and biochemical.

- Fermentation and enzymatic hydrolysis technologies, with similarly strong technological competencies and know-how. Impact on climate mitigation and socio-economy.

- Catalytic technology for refining of fuels and reforming/conditioning of syngas.

\section{Impact assessment}

\section{Climate change mitigation}

Aviation is annually responsible for about $11 \%$ of all transport associated $\mathrm{CO}_{2}$ equivalents (CO2e) emissions, which is equivalent to $2 \%$ of all anthropogenic $\mathrm{CO}_{2}$ emissions. Studies from the industry indicate that the industry's emissions are estimated to almost triple by 2050 (relative to a 2005 baseline) in the absence of fuel efficiency gains and other mitigation measures. Sustainable jet fuel has therefore been recognized as a key measure for mitigating this development.

The climate mitigation impact of introducing sustainable jet fuels by one of the three most promising pathway scenarios equals marginal annual savings of $150-170 \mathrm{kt}$ of CO2e in the early years. By 2050, it is estimated that annual marginal CO2e savings in the Nordic countries will amount to 4,700-5,300 kt, corresponding to total CO2e savings of 43-85 Mt CO2e over the period of analysis.

The analysis shows that the FT scenario on average is likely to create the highest climate impact. The aggregate GHG mitigation impact in 2050 is estimated to around 76-85 Mt CO2e for the FT scenario, 43-62 Mt for the AtJ scenario and 57-85 Mt for the HEFA scenario.

The climate impacts from aviation are usually measured in tonnes $\mathrm{CO}_{2}$-equivalent. However, other climate impacts from aviation exist, known as non- $\mathrm{CO}_{2}$ effects, though their significance on the overall climate impact is still under scientific debate.

\section{Economic and commercial potential}

Studies indicate that an increased feedstock production will have a multiplication effect on a broad range of sectors across the Nordic region. The study does not quantify the total effect, but shows through an illustrative example how the net socio-economic benefit of the production of a liter 
sustainable jet fuel is likely to be in the range of EUR 2.6-4.4 for the three most promising scenarios, deducted from the loss of benefits from downscaling of fossil fuel. Extrapolating this to a 2050-level of production in the Nordic countries with a blend-in level on $37.5 \%$, the socio-economic net impact would annually be between EUR 5.2-8.8 billion, depending on the mixture of the three pathway scenarios and assuming that all sustainable jet fuel will be produced within the Nordic region.

The derived impact on employment of a sustainable jet fuel production is likely to be between 7 and 11.2 annual full-time employed per 1 million liter. This will on a 2050-level of production with a blend-in level on $37.5 \%$, generate $14,000-22,500$ additional employed in the region, depending of the production mixture of the three pathways. The rough estimates do, however, not include future likely productivity effects of scaling-up production to a Nordic level. For example, scaling up production is likely to affect the farmers' (and forest owners') production level and choice of crop, depending on future price on fossil fuel and biofuel.

If the feedstock is entirely imported, the benefit to the Nordic sectors will, however, be much lower, since it is only the downstream part of the value chain, such as the transportation and refining which will benefit the region.

The analysis on the business impact shows, that transition to sustainable jet fuel is likely to especially create jobs for the feedstock processing and production in the agriculture and forestry sectors. The employment impact in these sectors alone is in the illustrative example estimated to be between 6,000 and 10,000 new jobs. More than $50 \%$ of the job creation is likely to require a vocational training background. The second highest job-category is likely to be low-skilled jobs for people without tertiary education levels.

Between 2,500 and 4,000 full time jobs, with a short-to-medium term high education background, are likely to be created in a $37.5 \%$ blend-in scenario, depending on the combination of the three scenarios. Similarly, $700-1,200$ jobs with a long-term higher education background are a likely estimate for the same production level. These jobs are especially expected to be generated in the energy, industry and construction sectors. 


\section{Conclusions}

The conclusions of the study are that Nordic production of sustainable bio jet fuels has potential benefits stemming from the reduction of GHG emissions and negative environmental impacts, the development of new technology, as well as economic growth and job creation.

Furthermore, the Nordic countries possess a series of comparative advantages with regards to producing sustainable jet fuels, including:

- The vastest forest resource in Europe, with a well-established industry and infrastructure.

- Strong competencies and technical know-how with regards to utilization of forest biomass.

- Strong competencies in fermentation and enzymatic technologies, relevant for production under e.g. the AtJ pathway.

- Already existing commercial scale facilities for production under a HEFA pathway, combined with technical expertise in converting lipids to jet fuel.

- Strong competencies in refining technology, relevant for all pathways.

- Existing infrastructure poised for retrofitting to production of sustainable jet fuels.

- Airlines companies show a high willingness to introduce biofuel in aviation.

\section{Barriers and challenges}

A number of barriers and challenges to implementing such a production exist, which are deemed practically insurmountable without proper political action to support market creation and investment in sustainable jet fuels.

Challenge 1: High price gap between fossil and sustainable jet fuels A main barrier is the cost of sustainable jet fuel, which falls within a price range that is currently roughly $2.5-8$ times higher than conventional jet A-1. This price gap is likely to diminish step-by-step in the future, following the annual reduction of the implementation of the ETS system's free allocated allowances. Also, an agreement on ICAO's Global Market-Based Mechanism as a globally extended compatible ETS system will further contribute to this development, as it can reduce the carbon 
leakage potential of the current ETS market as well as establishing a global price on fuel.

\section{Challenge 2: Lack of congruent sustainability requirements}

The current lack of global consensus with regards to what constitutes sustainability creates hesitation and disincentives for the industry to commit to certain technology pathways. It is a necessity for producers of sustainable jet fuel worldwide to have an internationally agreed upon standard to adhere to, in order to ensure the production of truly sustainable jet fuels. Secondly, regional asymmetries with regards to the sustainability standards that producers should achieve could result in an asymmetrical competitive situation. Thus, producers of sustainable jet fuel within the EU could face unfair global competition.

\section{Challenge 3: Lack of coherent policy across Nordic region}

The Nordic policy framework for sustainable jet fuels is fragmented. The unaligned support schemes cause different levels of incentive/ disincentive in different countries.

\section{Challenge 4: Low access to risk-capital}

Many businesses fail in making the transition from demonstration to commercial scale production, due to the commercial risks and difficulties in attracting investors. The lack of explicit policy goals for sustainable alternatives for aviation fuels reduces investor confidence in the future market. The uncertain future demand forms the basis of an environment which is detrimental to investments for first-movers. As a consequence, it becomes necessary to find a way to pool risk between the various stakeholders of the industry.

\section{Challenge 5: Competing uses for feedstock}

Feedstock constitutes at least part of the substantial production cost of sustainable jet fuels. This makes the production highly vulnerable to fluctuations in feedstock prices and thereby demotivation for investments.

\section{Recommendations/Initiatives to be taken}

In order to improve the Nordic potential to develop and use sustainable jet fuel, the Nordic countries need to target the identified market barriers, including the price structure, the feedstock supply, the technology development and the financial availability, as well as the very definition on what constitutes sustainable alternatives for aviation fuels. Some of 
the optional recommendations are best implemented on a national level and others internationally in a Nordic, EU or global policy context.

A commercialization of the sustainable jet fuel market, which can meet the sector's blend-in commitments from 2020 and onwards, and at the same time can position the enterprises in the Nordic countries with a first-mover advantage, is dependent on stimulus from the public and private sector. A series of recommended actions are listed below to further the introduction of sustainable fuels for aviation.

The recommendations are divided into steps to take for national policy makers, public-private partnerships and international action.

Recommendations to national policy makers:

- Recognize that focused jet fuel targeted strategies are needed to kick start and develop a market for sustainable fuel alternatives in the Nordic countries.

- Launch national and international initiatives which can kick-start and stimulate the maturing and upscaling of the market for sustainable jet fuel. An example could be to tie economic benefits to the use of sustainable jet fuel in order to reduce the cost differential. An inspiration could be the proposed Norwegian reduction of owed landing fees for airplanes using a minimum blend-in of $25 \%$ sustainable jet fuel. Iceland has lowered VAT on sustainable fuels. Other initiatives could be to give prioritization to national biomass resources into sectors, which does not have any sustainable alternatives.

- Explore possibilities to make specific targets for the share of RES in aviation on global, European and Nordic level in order to create a strong signal value to private investors and design a more streamlined incentive structures.

- Explore and stimulate possibilities for co-processing with existing facilities, especially oil refineries.

Recommendation to policy makers and private sector in terms of enhancing public-private collaboration:

- Organize the individual technologies and their developers in collaboration around specific production pathways throughout the value chain and with a strong lead partner to facilitate and drive the development. 
- Intensify innovation and research on sustainable jet fuel across the Nordic countries. For example, launch initiatives which can enable the collaboration between the forestry industry and R\&D institutions to enhance the utilization of by-products and raw materials. Also, initiatives to bring professional entrepreneurship assistance to startup companies in the sustainable jet fuel value chain.

- Promote public-private partnership, between the aviation sector, jet fuel producers, universities and other public entities, in order to increase transparency and lower the risk in investing in sustainable business models.

- Explore new, sustainable business models in support of the development of sustainable jet fuel supply chains, such as the Fly Green Fund and the multi-stakeholder initiative BioPort.

- Policy makers should explore possibilities for establishing a loan guarantee mechanism for producers of sustainable jet fuels, in order to secure transition investment capital.

Recommendations for policy makers directed towards of international collaboration:

- Nordic collaboration and policy makers should work on the international level through ICAO and other channels, towards an incentive structure for the use of sustainable jet fuel.

- Nordic collaboration and policy makers should continue work towards globally applicable standards for sustainability, in line with current policies for climate change mitigation.

- Explore the possibility to develop globally accepted mandatory blending levels.

- Support and advocate for more streamlined and time-efficient ASTM acceptance processes of new pathways in support of sustainable jet fuel. 



\section{Introduction}

The focus area for the study is the potential to develop and use sustainable jet fuel for aviation in the Nordic countries, including Denmark, Finland, Norway and Sweden. Iceland is as well included in the analysis. However, because of the limited feedstock available in Iceland, specific sections to the country in some of the analytic chapters have been reduced of editorial reasons.

The main purpose of the report is to assess to what extend the use of advanced sustainable jet fuel may contribute to GHG mitigation in the sector at both European and global level; and to assess the commercial potential for initiating and scaling up production at a Nordic level, making use of Nordic know-how, feedstock and production facilities, and identify barriers and steps to take to remove the barriers.

\subsection{Process}

The study has been developed as an iterative process, involving desk studies, interviews and dialogue with key experts and stakeholders. A way to further ensure updated knowledge about the stakeholders and the current state of biofuel production in the Nordic region, was to put together a project team of four organisations, NIRAS, ÅF, Gaiai Consulting and Sintef Energy, which all of them separately had produced recent national studies on sustainable jet fuel pathways in respectively Denmark, Sweden, Finland and Norway.

The sources of information for the desk studies included national studies from each of the Nordic countries, policy and legislation on sustainable biofuels and related fields, reports from the aviation industry, voluntary certification schemes, industry-driven policy development, as well as reports on international initiatives. A comprehensive reference list of the findings is found in the appendix.

The interviews and continued dialogue has been a key activity in order to both map existing knowledge, opportunities and challenges, as well as gathering input on sketched development pathways and effects. The process involved developing guides and semi-structured qualitative interviews of key stakeholders. 
To activate the knowledge gathered during the desk studies and challenge key stake-holders with the results, an online meeting ha been held with identified experts and stakeholders relevant to Nordic perspectives on the use of advanced sustainable jet fuel for aviation. The focus for the meeting was barriers and possibilities of scaling up the biofuel production targeting each country.

A steering group was established prior to the project. Their main purpose was to provide feedback to the synopsis and the working documents, which were produced along the project development. One meeting was held with the steering group, including a kick-off meeting and a commentary meeting.

The systematic approach served to prevent premature conclusions on i.e. opportunities and challenges and ensures the inclusion of multiple views on the identified most efficient pathway scenarios. The outcome of the interviews was compared with the desk studies in order to ensure an iterative verification towards the study's end goal.

\subsection{Structure of the report}

The study has been divided into four main sections. The first section, entitledbackground and motivations, focus on the global status of sustainable jet fuel (chapter 2), the exisiting criteria and policies relevant for sustainable jet fuel in the Nordic countries (chapter 3), and the legislation and priorities in the Nordic countries (chapter 4). The second section, the market and production pathways, identifies the current and future demand for sustainable jet fuel (chapter 5), the supply side, including the feedstock accessibility in the Nordic countries (chapter 6), the relevant infrastructure (chapter 7) and the technology pathways (chapter 8). In the third section, the most promising pathway scenarios are disidentified (chapter 9), followed by an identification and discussion on the Nordic comparative advantages (chapter 10) and how international actors may contribute to strengthen the development of sustainable jet fuel in the Nordic countries (chapter 11). The last section discusses the consequenses of scaling up the production in terms of climate change mitigation (chapter 12) and socio economic factors (chapter 13). The report concludes with a perspectivating chapter, on the challenges and steps to take (chapter 14). The conclusions of the report have also been extracted in a short form in section 1.5 above. 


\subsection{Studies on sustainable aviation fuel}

A great deal of information exists on the development and adoption of sustainable jet fuel, including national studies in most of the Nordic countries. The studies document, that the Nordic countries are all producing biofuels. All with the exception of Iceland are involved in developing capacity for the production of sustainable jet fuel. The Nordic countries all have different prerequisites for developing production capabilities for sustainable jet fuel. Factors such as production capabilities, technical know-how, geographical properties, biomass potential, etc. differ greatly for each country. As pointed out in the Danish report, this provides an opportunity for cooperation with each country finding a role in a Nordic production of sustainable aviation jet fuel.

Production already exists within the region, but sustainable jet fuel cannot yet compete with its conventional counterpart. To achieve competitiveness the price of sustainable jet fuel must be reduced considerably, through development of technologies, production capabilities and predictable supply. Furthermore, a demand for fuels that may not be able to compete on prices alone needs to be created. Hopefully a new Nordic study can help providing a foundation for further development of the industry within the Nordic countries.

The findings from most recent Nordic studies are presented in the following.

Sustainable Fuels for Aviation - An Analysis of Danish Achievements and Opportunities, Denmark 2014: A national study from 2014 provisioned by Danish Aviation and the Danish Transport and Construction Authority, was conducted by the consultancy company NIRAS (NIRAS 2014). It was concluded that sustainable jet fuel is a cardinal measure in order for the aviation industry to significantly reduce its negative environmental impact. A national production of sustainable jet fuels will also give rise to other side-benefits outside of reduced environmental impacts, such as technology development, economic growth and new employment opportunities.

While the study found that the aviation industry is aware of the opportunities and advantages of substituting fossil fuels, it still emphasizes a need for further incentives to encourage a transition.

The study addresses that Denmark possesses a certain expertise in pretreatment technologies, but there are no companies in Denmark capable of supplying a complete pathway from feedstock to jet fuel. An actual Danish production thus necessitates stakeholder- and crossindustry collaboration along with substantial investments. The study 
recommends facilitating matchmaking between industry actors in order to attain a national production capability. In the future the study expects that many benefits can be gained by expanding collaborations to also include stakeholders in other Nordic countries, or countries in the rest of the world, as these countries have different strategic advantages than Denmark. As with the other Nordic studies the Danish study sees AtJ, HEFA and FT as the most promising technological pathways.

It is recommended that a discussion of the political priorities for allocating the limited biomass resources is initiated. This requires the proper involvement of all relevant ministries and other stakeholders, taking into account that aviation has no other options than the use of (sustainable) biofuels in order to reduce the negative environmental impact substantially.

Future Transport Power Sources, Finland: A working group under the Finnish Ministry of Transport and Communication published a 2013 report on the "Future Transport Power Sources". (MTC, 2013) The task was to determine, based on the existing fleet of transport vehicles and their projected rate of replacement, what power source options will be available in Finland in the future, and to make recommendations for implementation measures. The working group recommends that Finland, at a minimum, should follow the EU target of $40 \%$ sustainable alternative jet fuel in 2050. It is recommended that by 2020 Finland will have established a distribution infrastructure for alternative power sources. According to the report Finland should aim at a production capacity for sustainably produced biofuel that can cover all domestic demand. The report also states that innovations in fuel technology plays an important part of lessening the outflow of capital to oil producing countries and boosting export of Finnish clean tech. It is also pointed out that Finland has national subsidy schemes specifically reserved for biofuels.

Deployment of aviation biofuels, Finland 2014: Another report, commissioned by the Finnish Ministry of Transport and Communication, finds that Finland is "extremely well-positioned to be among the first in the world to start extensive, continuous use of biofuels in aviation" (MTC, 2014). However, there is an issue in covering the additional costs of the more expensive biofuels. The report examines different business models for making biofuels profitable and proposes a possible concept for the next 3 years. In the first two years the additional price will primarily be covered by forerunner businesses and public sector clients, with public subsidies covering $45 \%$ of the increased costs. Private air passengers will play a big role in financing the production costs the following third year. Furthermore, the report sees a possibility of lowering the costs through 
the introduction of a new type of bio-kerosene, ${ }^{4}$ similar to renewable diesel produced by Neste that can replace the current method.

Biofuel production in Iceland, 2010: In 2010, an Icelandic project on investigating the future potential of biofuels on Iceland was initiated. The project was a partnership of a group of actors managed by the University of Akureyri, examining a possible biofuel production from household- and industrial waste. A report on the total potential biomass usable for biofuels and yields with different technologies up to 2030 was published (ME, 2010).

Green methanol from hydrogen and carbon dioxide using geothermal energy and/or hydropower in Iceland or excess renewable electricity in Germany, 2015: A 2015 article, "Green methanol from hydrogen and carbon dioxide using geothermal energy and/or hydropower in Iceland or excess renewable electricity in Germany", examines the potential for using Iceland's inexpensive renewable energy in the production of methanol. The explored process is an Emission-to-Liquid technology, from Carbon Recycling International (CRI), in which hydrogen and $\mathrm{CO} 2$ is combined to create methanol. While methanol in itself is unsuitable as an aviation fuel, it may provide a feedstock for further processing. The article finds a total maximum potential of 2,150 million $\mathrm{l} / \mathrm{y}$ if all available geothermal energy and hydropower is used, and 340 million l/y if only CO2 from geothermal plants is used (Kauw, et al., 2015).

Utredning - Bærekraftig biodrivstoff for luftfart, Norway, 2013: A national study commissioned by Avinor and Norsk Luftfart was conducted by Rambøll and published in 2013. Realizing that sustainable jet fuel is the only way to significantly reduce the negative environmental impact from aviation, the project investigates the possibilities for a profitable and sustainable production of Jet A-1 in Norway within the years 2020-2025. The study seeks to find out which technology and feedstock is the most suitable for a Norwegian production. The study found that forest feedstock is the most suitable from a Norwegian perspective and concludes that Fischer-Tropsch (FT) and Alcohol to Jet (At) production of sustainable jet fuel can be competitive by 2020-2025. This conclusion relies heavily on the possible income from byproducts from the production.

Benchmark of conversion and production technologies for synthetic biofuels for aviation, 2012: In a 2012 report by SINTEF Energy AS, FT and AtJ were similarly found to be the most suitable Norwegian production pathways. This report was provisioned by Avinor to investigate the most

${ }^{4}$ This is referred to as HEFA+ throughout this report, though the term HEFA+ is sometimes used in other literature. 
promising and suitable technological pathways and biomass resources for the production of sustainable jet fuel in Norway by 2020-2025.

Pursuing Aviation Biofuels - A Diagnostic Analysis of the Swedish Biojet Innovation System, Sweden, 2014: A study from 2014 by Raffaele Rossi, MSc in Environmental Management and Policy from Lund University, used the concept of an innovation system framework, ${ }^{5}$ aiming to identify actors and institutions involved in the Swedish bio jet innovation process, the required steps to establish a regional bio jet chain, and the most effective actions to promote it.

The study identified a large number of actors and institutions that can influence the innovation process, but also that only a very small fraction of all the stakeholders drive the development in Sweden. The difficulty to reach market competitiveness creates a demotivating state of uncertainty causing investors to stay away. The conclusion suggests that significant innovative progress could be made, if the observed stakeholder interest is directed into further proactive involvement.

Aviation Biofuel Production in Sweden, 2014: Another study from 2014 by Ben Fethers, MSc in Environmental Management and Policy from Lund University, investigates the opportunities and barriers to the production of sustainable jet fuel in Sweden using forestry biomass as feedstock. The study proposes that there is a need for producer incentives favoring sustainable jet fuel production. The main barriers identified are production costs and the lack of political ambition. The study strongly emphasizes the need for linkage between research institutions, governments and other actors in the bioenergy field, in order for the field to grow.

Outside of the Nordic region, many studies similar in nature to the ones presented above have been published. Likewise, they address the required components for a full sustainable jet fuel supply chain, as well as challenges and opportunities in the respective countries or regions.

Annual report, IATA: The International Air Transport Association (IATA) publishes an annual report on the current state of alternative aviation fuels, accounting for the current production and market status, technological developments, certifications and stakeholder initiatives. Each annual IATA report on alternative fuels is followed by a contributing update from the International Civil Aviation Organization (ICAO). ICAO also produces a number of other reports including a report on "The challenges for the development and deployment of sustainable alternative fuels in

${ }^{5}$ The innovation system framework stresses that the flow of technology and information among people, enterprises and institutions is the key to an innovative process. 
aviation." from, 2013 and "Approaches to the Sustainability of Alternative Fuels in Aviation", a look on sustainability criteria from 2014.

Global Framework for Alternative Aviation Fuels, ICAO: ICAO has developed the Global Framework for Alternative Aviation Fuels (GFAAF), a comprehensive database of multi-stakeholder initiatives and R\&D support and commercial supply or cooperation agreements between alternative jet fuel producers and airlines. 



\section{Background and Motivations}

This section focus on the why the considerations for establishing a future production of sustainable jet fuel in the Nordic region makes sense. First (chapter 2), we discuss the current status of developing sustainable jet fuel. Then, the exisiting criteria and policies is explored, relevant for sustainable jet fuel in the Nordic countries (chapter 3). Lastly, we provide an overview over the existing legislation and policy priorities in the Nordic countries is (chapter 4). 



\section{Global status of sustainable jet fuel}

In recent years, many initiatives on sustainable jet fuel have emerged from both existing and new stakeholders. In particular, feasibility studies and roadmaps for establishing supply chains in the EU and individual countries like Germany, the UK, the United Arab Emirates, Japan and Brazil have been produced.

In 2014, ASTM International approved a new production pathway, the "Synthetic Iso-paraffin (SIP)" in in 2016 the approval of AtJ from isobutanol arrived (biomassmagazine 2016). The following years may see the certification of other new pathways, such as the and HEFA+, which could open up for new production and supply options (IATA 2014; Reuters 2014). Since the end of 2015, 22 airlines (including three of the biggest Nordic Airlines have been listed using alternative fuels for commercial flights (IATA 2015), though large-scale production of sustainable jet fuel for commercial use is still non-existent. However, 2014 and 2013 saw four major supply agreements between airlines and producers. Finally, new technologies and feedstock are also emerging, such as wastestreams and algae, and on a longer time scale hydrocarbon production from photosynthetic microorganisms or power to liquid technology.

This section will focus on highlighting initiatives, production and development of sustainable jet fuel that could be inspirational for a potential Nordic production.

Since 2011, the number of commercial flights operated on a blend of biofuels has increased to more than 2,000 in 2015 (IATA 2015). Despite this development, there is currently no dedicated production of sustainable jet fuel at a large scale level, and all used fuel have been produced in smaller amounts on commission (IATA 2015), though larger and larger amounts are being commissioned.

Below is a (non-exhaustive) list of commercial producers of alternative jet fuel, accounting for the used production pathway, feedstock and example of agreements with airlines.

Recent development has seen four US-based producers, Fulcrum Bioenergy, GEVO, Red Rock Biofuels and AltAir, making agreements with airlines for the supply of larger fuel amounts over longer periods of time. 
Such large scale production is expected to be ready from 2017 and could potentially constitute a transition towards a dedicated and stable commercial production.

\begin{tabular}{|c|c|c|c|c|}
\hline Producer, Country & $\begin{array}{l}\text { Production } \\
\text { pathway }\end{array}$ & Capacity & Feedstock & $\begin{array}{l}\text { Example of } \\
\text { airline agreement }\end{array}$ \\
\hline $\begin{array}{l}\text { Neste } \\
\text { Finland }\end{array}$ & HEFA & - & $\begin{array}{l}\text { Natural oils and } \\
\text { animal fats }\end{array}$ & Lufthansa \\
\hline $\begin{array}{l}\text { Amyris/Total } \\
\text { US/France }\end{array}$ & SIP & $47 \mathrm{mio} \mathrm{l} / \mathrm{yr}$ & Sugarcane & GOL, AirFrance \\
\hline $\begin{array}{l}\text { Fulcrum Bioenergy } \\
\text { USA }\end{array}$ & FT & $35 \mathrm{mio} \mathrm{l} / \mathrm{yr} *$ & MSW & Cathay Pacific \\
\hline $\begin{array}{l}\text { Gevo } \\
\text { USA }\end{array}$ & AtJ & $68 \mathrm{mio} \mathrm{l} / \mathrm{yr} *$ & $\begin{array}{l}\text { Lignocellulosic } \\
\text { (straw, wood } \\
\text { residuals) }\end{array}$ & Alaska Airlines \\
\hline $\begin{array}{l}\text { Red Rock Biofuels } \\
\text { USA }\end{array}$ & FT & $11 \mathrm{mio} \mathrm{I} / \mathrm{yr} *$ & Wood residuals & Southwest Airlines \\
\hline $\begin{array}{l}\text { AltAir } \\
\text { USA }\end{array}$ & HEFA & $113 \mathrm{mio} \mathrm{l} / \mathrm{yr}$ & $\begin{array}{l}\text { Camelina, agricul- } \\
\text { tural residues }\end{array}$ & United Airlines \\
\hline $\begin{array}{l}\text { UOP Honeywell } \\
\text { USA }\end{array}$ & HEFA & - & $\begin{array}{l}\text { Natural oils (Came- } \\
\text { lina) }\end{array}$ & GOL, LAN \\
\hline $\begin{array}{l}\text { Sinopec } \\
\text { China }\end{array}$ & HEFA & - & Waste oils & Hainan \\
\hline $\begin{array}{l}\text { Solazyme } \\
\text { USA }\end{array}$ & HEFA & - & Microalgae & United Airlines \\
\hline
\end{tabular}

Note: "*" denotes that the capacity is planned rather than existing.

"_" denotes that the production capacity (of jet fuel) is unknown.

Fulcrum Bioenergy is an upcoming commercial producer of jet fuel made from municipal solid waste (MSW). In 2014 they were funded 70 million USD from the US Department of Defense (DoD) to construct a biorefinery (IATA 2014). Fulcrum has since then partnered with Spanish based Abengoa to build the first biorefinery capable of turning MSW into jet fuel by FT-gasification (Abengoa 2015) and expects commercial production to begin in 2017 (Fulcrum BioEnergy 2015). Cathay Pacific Airlines has made a significant equity investment and long-term deal with Fulcrum for the supply of 375 million US gallons of fuel over 10 years (Cathay Pacific 2014), the largest of any such agreement today (IATA 2014), and more recently United Airlines has entered a similar agreement with Fulcrum over a smaller amount of fuel (United 2015).

Gevo is the first commercial producer of Atj fuel. Biobased feedstock are processed into isobutanol by fermentation, which is then refined into 
synthetic iso-paraffinic kerosene. Gevo states that their technology can produce isobutanol from grains, sugar cane and lignocellulosic feedstock, such as wood-residuals. The isobutanol is currently produced at a retrofitted corn ethanol plant in Luverne, $\mathrm{MN}$, with a planned capacity of 68 million l pr year. In 2014, Lufthansa entered an agreement with Gevo to test the AtJ fuel (Lufthansa 2014). In an attempt to fuel the first commercial flight on AtJ, Alaska Airlines entered a supply agreement with Gevo in 2015. In April 2016, Gevo's AtJ fuel was ASTM approved eligible for up to $30 \%$ blending in commercial flight (biomassmagazine 2016).

Red Rock Biofuels have similarly to Fulcrum Bioenergy received 70 million USD from the US DoD (IATA 2014) in addition to investment from a partnership with Flagship Ventures to build a commercial refinery in Lakeview, Oregon (Biofuels Digest 2015b). The refinery will convert wood biomass into jet fuel by the FT process. Red Rock Biofuels has entered an agreement with Southwest Airlines, who will buy all produced fuel (IATA 2014). Production is expected to start in 2017 with about three million US gallons per year produced through 2024 (Biofuels Digest 2015c).

AltAir produces jet fuel based on feedstock of non-edible natural oils (in particular Camelina) and agricultural residuals. AltAir has partnered with Alon Energy to retrofit an existing petroleum refinery with HEFAbased process technology developed by Honeywell UOP (AltAIR 2015). In 2013 AltAir established an agreement with United Airlines to supply 15 million gallons of jet fuel (Biofuels Digest 2013). The fuel will be mixed with conventional jet A-1 in a 30/70 blend ratio (Biofuels Digest 2015d).

In collaboration with Amyris, Total is currently the only commercial producer of the newly ASTM-certified SIP-SPK fuel, with a capacity of $40 \mathrm{kt} / \mathrm{yr}$ (IATA 2014). Total/Amyris converts sugarcane into the farnesene molecule by fermentation with engineered yeast, which is then upgraded by hydroprocessing into diesel and jet fuel. Due to the homogenous hydrocarbon composition of this fuel, blending with conventional jet A-1 is currently limited to $10 \%$ (IATA 2014).

UOP Honeywell is, in addition to being a producer themselves, also one of the largest licensors of their HEFA-based process technology, e.g. to companies like AltAir, and the upcoming Petrixo Oil \& Gas commercial scale refinery scheduled to begin production of renewable jet fuel in 2017 in the United Arab Emirates, with a production capacity of $1 \mathrm{Mt} / \mathrm{yr}$ of biofuels (UOP 2014).

Dutch $S k y N R G$ has supplied fuel to more than 20 different aviation customers, but is as such not a producer of sustainable jet fuel, but a broker. They are technology agnostic, but currently only deliver HEFA 
jet fuel. SkyNRG is also involved in a number of initiatives and international activities with efforts to increase demand and create a stable market for sustainable jet fuels. In particular, the BioPort demand centres, the first of which was established in 2013 in Brisbane airport and the BioPort Holland. Recently, SkyNRG Nordic was also established, as a partnership aiming to commercialize sustainable jet fuel and create a supply chain in the Nordic countries, for example by supplying sustainable jet fuel to Bioport Karlstad and Oslo airport.

\subsection{Emerging technologies}

In addition to established producers of alternative jet fuel, a number of companies are supplying and developing technologies that are either commercially used to some extent or could see increased future potential given technological development. While such technologies may seem to offer promising new solutions, they are generally on a lower level of maturity, either at the research, pilot or demonstration phase at most. Their potential role in a near future commercial production of sustainable jet fuel is therefore deemed unrealistic. Instead, the technologies represent possibilities available in the longer term. At such time they could, however, prove a vital role in filling in the gap created by an increasing demand for sustainable jet fuel following the industry's aspiration of a $50 \%$ net $\mathrm{CO}_{2}$ emission reduction by 2050 .

Pursuing the production of AtJ fuel, Lanzatech is of particular interest, developing a technology for converting industrial waste gases into high value chemicals and ethanol by fermentation and then chemical conversion into jet fuel. In 2014, Lanzatech joined a partnership with Virgin Atlantic and the UK bank HSBC aspiring to develop AtJ demo-scale fuel production from steel industry waste gases (Biofuels Digest 2014a).

Using microalgae feedstock, Solazyme has produced the world's first $100 \%$ algae-derived jet fuel. The fuel is produced from algae oil by fermentation and with UOP HEFA process technology. Solazyme's jet fuel has been tested by the U.S navy (PR Newswire 2010) and Quantas has stated intent to buy an unspecified fuel amount (Biofuels Digest 2014b).

Utilizing sunlight and concentrated $\mathrm{CO}_{2}$ source to drive hydrocarbon production by photosynthesis in microbial organisms, Joule Unlimited has produced both diesel and jet fuel products known as Sunflow-D and Sunflow-J respectively. The jet fuel has met ASTM specifications D-1655 for blending with jet A-1 fuel by up to $25 \%$ (Joule Unlimited? 2014). Currently no partnership for further development of Joule's Sunflow-J is in 
place, though Joule has partnered with Audi on further developing and commercializing Sunflow-D (Biofuels Digest 2012).

SOLAR-JET is an EU-funded research project acting to develop a carbon-neutral production pathway for jet fuel. $\mathrm{CO}_{2}$ and water is split into hydrogen and CO (syngas) by a two-step solar thermochemical process, which can then be processed into jet fuel by the FT process. The technology is currently lab-scale, but in 2014 the first synthesized jet fuel was produced, demonstrating the entire production chain (EUCommission 2014). In a similar process, German Sunfire uses renewable electricity sources to produce hydrogen, which is then combined with $\mathrm{CO}_{2}$ from ambient air capture and converted to syngas (a process known as Power to Liquid). Sunfire has produced diesel fuel by processing the syngas in a new pilot plant in Dresden (Sunfire 2015). Diesel fuel is chemically similar to jet fuel, and Sunfire's fuel could potentially be upgraded to meet criteria as a drop-in fuel.

\subsection{Multi-stakeholder initiatives}

A synthesis of the GFAAF database reveals over 83 multi-stakeholder initiatives created from 2006 to the end of 2014 (some of which are now terminated), focused on many purposes to advance sustainable jet fuels, either as research and development, assessment of production possibilities and setting up value-chains, as well as networking and coordination between national stakeholders. The many initiatives demonstrate a growing interest in sustainable jet fuels and an increasing engagement from many states, industries, organizations and other stakeholders. The initiatives also highlight the many challenges facing a commercial market for sustainable jet fuel, which emphasizes the continued need for such multi-stakeholder initiatives. Following below is a list of some of the recent major initiatives which can serve as inspiration for establishing a Nordic production chain for sustainable jet fuel.

\subsubsection{NORDIC, NISA, Nordic Initiative for Sustainable Aviation}

Partners: Airlines (SAS, Finnair, Norwegian, Icelandair, Air Greenland, Malmo Aviation and Atlantic Airways), Airports (Copenhagen Airports, Swedavia, Avinor, Finavia and Isavia) transport authorities of Denmark, Sweden and Finland as well as Airbus and Boeing, Organisations 
(Brancheforeningen Dansk Luftfart, Svenskt Flyg, Svenska FlygBranschen, NHO Luftfart and IATA.)

The partners have come together to form an association to facilitate the development and uptake of sustainable aviation fuels in the region. Focusing on bringing together stakeholders throughout the supply chain - researchers, agriculture, technology suppliers, investors, regulators, producers and oil suppliers - to find the best and most energy efficient solutions.

\subsubsection{Norway 2015: Gardermoen Biohub}

Partners: SkyNRG Nordic, Avinor, Statoil, SAS, KLM, Lufthansa, Neste, Air BP.

Gardermoen Biohub is a collaboration between various stakeholders, aiming at supplying sustainable jet fuel to airplanes at Gardermoen airport, Norway. The fuel is produced by Neste and delivered from Gardermoen's main fuel farm.

Becoming operational on 22nd January 2016, the project marks the first time sustainable bio jet fuels are delivered through existing airport infrastructure (SkyNRG, 2016).

\subsubsection{EU, 2011. European Advanced Biofuels Flightpath (EUABF)}

Partners: EU Commission, Airbus, Airfrance, KLM, Biomass Technology Group, British Airways, Lufthansa, Neste Oil, UOP.

An initiative of the European Commission in collaboration with Airbus and selected alternative jet fuel producers with the aim to use 2 million tons of sustainable fuel per year in the EU civil aviation sector by 2020 , identifying possible pathways and actions for establishing production in the EU (EUC 2011.)

\subsubsection{EU, 2012: Initiative Towards Sustainable Kerosene for Aviation (ITAKA)}

Partners: EU Commission, SENASA, Airbus Group, École Politechnique Federale de Lausanne, Embraer, The Manchester Metropolitan University, Neste, SkyNRG.

A research project with the aim to support development of sustainable jet fuel in Europe, in particular towards the fulfilment of the short term objectives of the EUABF. ITAKA has focused on camelina, grown as a rotation crop in arid regions (with no LUC or ILUC impacts) as the most promising feedstock that can timely be grown and processed in the 
EU. Large plantations have been cultivated in Spain and Romania and test production of fuel has been initiated (IATA 2013).

As a part of the ITAKA initiative, Neste is producing 4,000 tons of sustainable jet fuel. The primary feedstock used in this production is Spanish Camelina (biodiesel magazine, 2012).

\subsubsection{Germany, 2011. Aviation Initiative for Renewable Energy in Germany (AIREG)}

Partners: Air Berlin PLC \& Co. Luftverkehrs KG, Bauhaus Luftfahrt, Boeing, Deutsche Energie-Agentur, Deutsche Lufthansa AG.

AIREG is a German initiative by a group of aviation and petroleum industry representatives, research institutions and other partners acting to support the development of sustainable jet fuels. Achievements to date have been the publication of a strategy paper for climate friendly aviation in Germany, with the aim of $10 \%$ alternative fuels in 2025 (AiREG 2012), and signing U.S-German bilateral agreement for the development of sustainable fuels.

\subsubsection{Holland, 2013: Bioport Holland}

Partners: KLM, SkyNRG, Schiphol Airport, Neste Oil and Port of Rotterdam, The Dutch State Secretary of Infrastructure and the Environment and the Minister of Economic Affairs.

A stakeholder action group of Dutch aviation and alternative jet fuel industry and governmental institutions. Bioport Holland is working to strengthen the market for sustainable jet fuel and secure continuous production for Europe by creating long-term demand, new conversion technologies and price competitive production.

\subsubsection{USA, 2012: Midwest Aviation Sustainable Biofuels Initiative (MASBI)}

Partners: United Airlines, Boeing, Honeywell's UOP, the Chicago Department of Aviation and the Clean Energy Trust, .US. Department of Agriculture, U.S. Department of the Navy.

MASBI was a stakeholder organization aiming to advance sustainable jet fuel in the Midwest 12-state region. MASBI focused on delivering an evaluation of the regions biofuel potential, focusing on feedstock, technology and commercialization, in addition to mapping out a plan for support- 
ing the regional development of biofuels. The evaluation concluded in June 2013 with the report "Fueling a Sustainable Future for Aviation".

\subsubsection{United Kingdom, 2006: Sustainable Aviation Group}

Partners: AOA, ADS, Airbus, Bata Boeing, British Airways, NATS, Virgin Atlantic.

Sustainable Aviation (SA) is a UK cross sector industry group of airlines, airports, manufacturers and other organizations working for a long term strategy of sustainable UK aviation. SA facilitates research initiatives and has made a number of publication, such as a Roadmap towards a 30\% take-up of sustainable alternative jet fuels in 2050 in the UK (SA 2014), in addition to annual progress reports on the use of sustainable jet fuel in the UK.

\subsubsection{USA, 2006: Commercial Aviation Alternative Fuels Initiative (CAAFI)}

Partners: Federal Aviation Administration, Airlines for America, Airports Council International, Aerospace Industries Association.

CAAFI is a US coalition of a wide range of stakeholders representing airlines, aviation industry, fuel producers as well as many organizations and non-sponsor stakeholders, aiming to promote the development of commercially viable alternative jet fuel.

CAAFI is both feedstock- and technology-neutral. Their efforts are focused in the four areas of Fuel Certification, R\&D, Environment and Business and Economics. CAAFI's major achievements include the collaboration with ASTM International for the approval of the production pathway FT-SPK in 2009, HEFA-SPK in 2011, SIP-SPK in 2014 and the pending approval of AtJ-SPK and FT-SPK/A expected in late 2015. CAAFI has also developed the Fuel and Feedstock Readiness Level assessment tool.

\subsubsection{United Arab Emirates 2014; Biojet Abu Dhabi (BAD)}

Partners: Etihad Airways, Boeing, Takreer, TOTAL, Masdaar Institute.

An initiative investigating how to set up a biofuel supply chain in UAE by a consortium of stakeholders. The initiative has produced the report Biojet Abu Dhabi: Flight Path to Sustainability The Roadmap (BAD 2015), identifying possible feedstock, technological pathways and recommendations for developing a supply chain. 


\subsubsection{Japan, 2014: Initiative for Next Generation Aviation Fuels (INAF)}

Partners: University of Tokyo, Boeing, Japan Airlines, Nippon Cargo Airlines, Nippon Airway, Narita International Airport, Japan Petroleum Exploration.

A Stakeholder action group of Japanese airlines, universities, petroleum industries and other organizations with the aim of developing commercial sustainable jet fuel ready for use during the 2020 Tokyo Olympics. INAF has produced a roadmap for establishing a supply chain in Japan (INAF 2015).

\subsubsection{Brazil, 2012: Brazilian Biojetfuel Platform (BBP)}

Partners: ABEAR, UBRABIO, Boeing, GE, Gol Airlines, Curcas Diesel.

BBP is a collaborative stakeholder platform promoting greater implementation and R\&D of biojet fuel and developing a value chain, based on a multi feedstock supply (macauba, jatropha, camelina, waste oils and fats). BBP has established a private-sector interface for a US-Brazil Biojetfuel Bilateral Agreement, and launched the Flying Green carbon footprint offset program in 2014. 



\section{Coupling of existing sustainability criteria and policies}

This chapter discusses existing sustainability criteria and policies, which can have an effect on the commercial production of sustainable jet fuel in the Nordic countries.

\subsection{Criteria for sustainable jet fuel}

Though the term sustainability is commonly used, there is currently no internationally agreed upon definition of what constitutes sustainable jet fuel. There are several sustainability initiatives worldwide, with varying definitions. Thus, the following section will seek to outline what aspects of sustainability that should be included in the assessment of biofuels for aviation in this report.

Adverse environmental effects from the use of sustainable jet fuel can stem from greenhouse gas emissions from combustion of fuel and the production of feedstock, including the leaching of nutrients, land use and land use change, the use of pesticides, damage to biodiversity, water usage and the choice between annual and perennial feedstock. These effects are explained in the following.

\subsubsection{Greenhouse gas emissions}

Climate Change and Greenhouse gas (GHG) emissions are of special concern to the aviation industry, as non-CO2 GHGs emitted at a higher altitude contributes more to global warming than GHGs emitted near the land surface (Lee et al., 2010). Consequently, the GWP ${ }^{6}$ in question is also multiplied by an additional factor known as the Radiative Forcing In-

${ }^{6} \mathrm{GWP}$ (Global Warming Potential) is a factor used to convert a concentration of any given $\mathrm{GHG}$ into $\mathrm{CO}_{2}$-eq 
dex (RFI). RFI, in turn, is dependent on the aircrafts combustion composition, which makes it difficult to measure. ${ }^{7}$

The most well-known GHG is $\mathrm{CO}_{2}$, which primary anthropogenic source is the combustion of fuels. Yet, other gasses contribute to global warming. Besides carbon dioxide, nitrogen oxides (NOx) are the most significant air emission arising from flying. NOx emissions arise in combustion processes that take place at high temperatures. Nitrogen oxides contribute to the formation of ozone in the lower atmosphere, but destroy methane, which is a powerful greenhouse gas, in the atmosphere. The impact of nitrogen oxides is complex and in many respects still not fully understood (NASA, 2016).

Methane $\left(\mathrm{CH}_{4}\right)$ is another GHG, which is also primarily associated with agriculture, predominantly from ruminants that produce $\mathrm{CH}_{4}$ as a part of their metabolism. Globally, about $60 \%$ of $\mathrm{CH}_{4}$ emissions are estimated to stem from anthropogenic sources.

The combustion of biofuels has traditionally been considered to be $\mathrm{CO}_{2}$ neutral, due to the assumption that the $\mathrm{CO}_{2}$ emitted is considered equal to the amount of $\mathrm{CO}_{2}$ that the feedstock has removed from the atmosphere through photosynthesis over its lifecycle. While this is true for annual plants, where the $\mathrm{CO}_{2}$ released from combustion of biofuels is absorbed by a new plant the following year, the combustion of biofuels made from perennial plants/feedstock will remain in the atmosphere for a longer time, as the plant takes time to replace. ${ }^{8}$ Consequently, the emitted $\mathrm{CO}_{2}$ contributes more to global warming, as it remains longer in the atmosphere before it is absorbed by new plants. Furthermore, the harvesting, processing and other parts of the biofuel's supply chain consume energy, the production of which could emit GHGs through combustion of fossil fuels. Thus, biofuels are not technically $\mathrm{CO}_{2}$ neutral. This problem can possibly be exacerbated through the use of genomic engineering of feedstocks.

It should be noted that the issue of emissions from biofuels is still contested and that there is a lot of ongoing research in the field. Furthermore, the results of said research are dependent on the methodological choices made by researchers. Thus, the $\mathrm{CO}_{2}$ emission impact of biofuels can vary greatly, depending on the level of analysis (for instance stand vis-à-vis landscape level), which serves to complicate the issue (Cintas, et al., 2015).

${ }^{7}$ The Intergovernmental Panel on Climate Change (IPCC) estimates RFI to be equal to a factor of 2.7 with an uncertainty of at least \pm 1.5 , dependent on the type of aircraft, fuel, etc. (IPCC, 1999). Thus, the RFI falls within a range from 1.2-4.2. More recent research suggests that the RFI should operate with a factor of 1.6, falling within a range of 0.6-2.4 (Ribeiro et al., 2007)

8 Perennial plants are plants that live for more than 2 years. 


\subsubsection{Direct and indirect land-use change}

When an uncultivated land area is cultivated, a net change in the carbon stock stored in the area's vegetation is incurred. Land use change (LUC) from carbon rich vegetation, such as forests, to less carbon rich vegetation, such as fields, decrease the amount of carbon that can be stored in the land and results in a net increase in $\mathrm{CO}_{2}$ emissions. Such effects of LUC should be kept in mind, when selecting feedstock and technological pathways for the production of biofuels for aviation, if such a production is to be sustainable.

Indirect land use change (ILUC) refers to the shift in the use of a crop, e.g. from food to feedstock. For instance, if the crop of a maize field, which was formerly used to meet food demand, is redirected to be used as feedstock, the demand for food needs to be satisfied elsewhere. This may lead to a displacement of food production to other land areas, which undergo LUC as described above. In practice, emissions from ILUC are difficult to quantify, because they occur at a different site than the actual production of feedstock, which makes the emissions difficult to trace. ILUC should be taken into account, for example, in the manufacturing of biofuel by ensuring that arable land used for growing food crops is not used to produce raw material for biofuel, which would result in either the clearing of forests or wetlands to create space for food production or a decline in food production. The effects of LUC and ILUC are futher discussed in chapter 12 .

\subsubsection{Nutrients}

From an environmental perspective, phosphorous (P) and nitrogen $(\mathrm{N})$ are the most important nutrients. The nutrients are present in high concentrations in many fertilizers, including animal manure.

If $\mathrm{P}$ and $\mathrm{N}$ are leached from fields into lakes and streams, they can cause eutrophication, which can cause depletion of oxygen in the water, which in turn can cause death of aquatic animals. The unintended release of nutrients can cause damage to local ecosystems and thus impair future generations' use of these. However, nutrients (especially P) are also valuable resources that have relatively few mines. P has many uses, e.g. in fertilizers, metallurgy (such as steel production), flame retardants and soft drinks (Greenwood and Earnshaw, 1997). Thus, the recirculation of nutrients is important to consider when choosing feedstock and technological pathways for the production of sustainable jet fuel. 


\subsubsection{Pesticides}

Pesticides ${ }^{9}$ are chemicals used to protect crops from pests, such as weeds, fungi and insects. The use of pesticides is associated with a range of benefits, such as improved crop yields and quality (Cooper and Dobson, 2007). However, pesticides have also been shown to have adverse effects on the environment and human health, e.g. if they leach into water sources. Changing how land is utilized can either increase or decrease the demand for pesticide use. For instance, perennial crops have a lower pesticide requirement than annual crops, as they are more competitive towards weeds.

\subsubsection{Biodiversity}

Biodiversity refers to the flora and fauna in an ecosystem, i.e. the variety and proliferation of plants, animals and other organisms in an area. Biodiversity effects the ecosystem services delivered in a given area, i.e. the benefits that an ecosystem provide to humanity. Such benefits are associated with a range of industrial sectors, such as agriculture and human health, as well as business in general, which relies on ecosystems for a multitude of raw materials, e.g. water, timber, rubber and fiber (IUCN WRI, 2007).

Utilizing land areas, such as forests, for feedstock can potentially harm the biodiversity of these areas due to the loss of natural habitats. Thus, the exploitation of such land areas for feedstock can cause harm to the ecosystem services. The anticipated health risks of climate change are closely related to the loss of biodiversity, through changes in vectorborne diseases, the availability of fresh water and food resources.

However, biomass production can be planned in such a way as to facilitate improvements in biodiversity, e.g. by cutting of vegetation in meadows and carefully removing the cut-off, which can be used as biomass, more vulnerable species of vegetation can achieve better growth conditions.

\subsubsection{Water usage}

As feedstock production can pollute existing water resources, water usage refers both to the amount of water used in the production of biomass and the quality of water resources. Iceland and Denmark rely pri-

${ }^{9}$ In this report, the word pesticides cover herbicides, fungicides and insecticides. 
marily on groundwater sources, whereas Sweden, Norway and Finland also are reliant on surface water.

While water stress and scarcity is projected to increase worldwide, freshwater resources are abundant in the Nordic countries (OECD, 2012; Nordic Council of Ministers, 2012; UN, 2004). However, such resources are vulnerable to pollution from nutrients and pesticides, as outlined above.

\subsubsection{Generations of feedstock and biofuels}

This report will utilize a separation of biofuels into different generations, dependent on the fuels carbon resource, i.e. the feedstock used in the biofuels production. Four different generations are used to categorize biofuels:

- 1st generation (1G): Food and feed crops.

- 2nd generation (2G): Lignocellulosic and waste materials.

- 3rd generation (3G): Micro-, macro-algae and engineered feedstocks.

- 4th generation (4G): Algae, microorganisms and microbes, which absorb and convert $\mathrm{CO}_{2}$ to biofuels.

The definition of $1 \mathrm{G}$ and $2 \mathrm{G}$ biofuels is rather well-established. $1 \mathrm{G}$ biofuels are based on feedstock that is either actually or potentially in competition with food production (EU, 2015). Such feedstock could for instance be rapeseed, sugarcane, palm oil and maize. 2G biofuels, also known as Advanced Biofuels, are produced from lignocellulosic or cellulosic materials, such as residues from agriculture and forestry, grasses, and industrial or communal waste (EU, 2015). Advanced biofuels exhibit zero (or low) LUC impacts.

The division of biofuels into generations does not necessarily imply that older generations are less sustainable than newer generations. For instance, certain crops exhibit overlap between different generations of feedstock. An example of one such crop could be cereals, where the cereal itself would be considered a $1 \mathrm{G}$ feedstock, whereas the inedible stock of the cereal would be considered agricultural residue and thus a $2 \mathrm{G}$ feedstock. In addition, the use of residues as $2 \mathrm{G}$ feedstock might incentivize the "production" of waste, which would induce the very ILUC effects that $2 \mathrm{G}$ seek to mitigate. The technologies available to convert feedstocks into biofuel suitable for aviation vary greatly in maturity and commercial availability. Therefore, the choice of feedstock is not only dependent on its theoretical environmental sustainability, but also on its suitability for jet fuel production and market sustainability. 
In summation, there is currently no singular recognized definition of what constitutes a biofuel as sustainable. GHG emissions and reductions are largely a question of the choice of feedstock generation. However, the division of feedstock into generations is largely historical, based on the progression of technology. As shown in this chapter, there are certain problems with such a division. Thus, the definition of feedstock generations should change over time in tandem with technological progress in the field. Extending upon this argument of traditional $2 \mathrm{G}$ becoming de facto $1 \mathrm{G}$, it can be argued that LUC and ILUC are not as much issues of sustainability, as they are issues of smart land-use planning. For instance, the use of previously "unused" lands for feedstock production should not be prohibited, insofar as it does not clash with protection of vulnerable land-areas, biodiversity, etc.

Setting up criteria for biofuel is a complicated matter. At present the focus is on 2. generation biofuels although only a very small quantity of fuels come to the market. The developments are in progress, but still some way to go before we will see full scale commercial production at competitive prices. We have developed technologies that enable us to produce edible sugar extracted from straw and pine - sugar that is similar to sugar from sugarcane or beats.

In a global perspective and especially in a long time perspective, we need to produce more food, feed and biochemical as well as biofuel. Especially for aviation as no other alternatives are likely to meet the demands if aviation is going to be fossil-free. We can either wait for the ongoing developments of 2nd generation fuels for aviation, until they become as fully commercialized as 1 st generation fuels, or we can choose to start to use 1st generation fuels and then gradually turn the production towards 2 nd generation, when such are commercially competitive.

The discussion is very difficult and many aspects have to be considered i.e.:

- The production of biomass needs basic availability of land, water and nutrients.

- Several analyses have proven that we do see a linear correlation between the prices of food versus the production of fuel.

- Hunger is in most cases caused by drought, conflicts or poverty - not by the lack of global production.

- The production of seed crops versus perennial crops creates a lot of $\mathrm{CO}_{2}$ from plowing thus oxidize the carbon in the field. 
- The production of biomass per area per year is very different from different crops.

- Some crops can be separated or refined with a combination of products i.e. proteins and starch.

- Effects of iLUC from production of crops and feedstock need to be better understood

- A lot of land is used for non-food purposes i.e. wine, tea, coffee, flowers, Christmas trees etc.

- A lot of land is used for towns and roads, and the green areas between housing or industrial complexes are not used for food production.

- Solar panels are placed on land instead of on buildings in order to produce another kind of sustainable energy.

Our perception of what is both technically and commercially possible and our perception of sustainability, i.e. the choice between 1.G and 2.G, are thus not entirely compatible. Perhaps we should allow for a timeline of development from technically and commercially possible towards sustainable: "Perfect is often the enemy of good".

\subsection{International governmental policy frameworks}

The international agreements relevant to sustainable jet fuel are formulated through the UN and the European Union. The following presents the policy frameworks deemed most relevant with regards to sustainable aviation in the Nordic Countries.

\subsubsection{The European Emission Trading Scheme (EU ETS)}

The EU ETS (EU Emission Trading Scheme) is a system of tradable allowances for companies covering selected industrial sectors (including power and heat generation, energy-intensive industries and, since 2012, aviation). The system is based on a "cap and trade" principle, where the cap is gradually reduced over time, in alignment of the overall GHG targets of the participating partners. The EU became operational in 2005 and has since been a cornerstone of the EU GHG mitigation instruments, covering today about $45 \%$ of the total EU emissions.

Emissions from aviation were included in the ETS system from 2012. It includes trade with emissions from, to and within the European Eco- 
nomic Area (EEA) (including Iceland and Norway as EFTA members). Like industrial installations covered by the system, airlines receive tradeable allowances covering a certain level of $\mathrm{CO} 2$ emissions from their flights per year. Although the EU ETS only covers the EEA, the scope is that it, after 2016 will be linked to a ICAO induced Global Market Based Measures (see the following section for more details on this). In order to support progress being made in the ICAO on its development of a GMBM, the EU has introduced a temporary derogation from the application of the EU ETS compliance obligations for flights to and from countries outside the EEA (as well as flights to and from outermost regions). This is a temporary measure that will expire at the end of 2016, where after the scope of the EU ETS in the period after 2016 will be linked to the development and adoption of the GMBM.

The aviation sector cap remains the same in each year of the 20132020 trading period and set to $5 \%$ below the average annual level of aviation emissions in the 2004-2006. Around $82 \%$ of emissions are allocated as "free allowances" to the aviation sector and the remaining 18\% (as well as emissions above the cap) have to be offset with carbon certificates.

The current ETS carbon price is however far below what is needed to incentivise emissions cuts and drive low-carbon technologies investment. After reaching a peak in 2015 on almost EUR 9/ton CO2, the price has decreased and carbon certificates are currently priced at roughly EUR 6/t CO2 (as of june 2016), corresponding to roughly EUR 0.025/l conventional jet A-1. This corresponds to a cost for the airlines of about $10 \%$ of the current price of fossile jet fuel for the intra-european flights.

\section{International Civil Aviation Organisation}

The International Civil Aviation Organisation (ICAO) is a specialized agency within the UN. ICAO works with the aviation industry to create international Standards and Recommended Practices (SARPs), which the member states translate into legally binding, national regulation of civil aviation.

ICAO operates in multiple areas of the civil aviation industry. Following years of pressure by especially the European countries, the ICAO agreed in 2013 to develop a global market-based mechanism (GMBM) to address international aviation emissions by 2016 and apply it by 2020. The GMBM is part of a basket of measures including also, amongst others, a global certification scheme for $\mathrm{CO} 2$ emissions from aviation, based on a common metric for evaluating GHG emissions from aircraft of different sizes. While the initiatives from ICAO are not yet finalized, it is safe to assume that aviation in the Nordic Countries, which are all ICAO member states, will be subject to the GMBM. The 
use of sustainable alternative fuels is intended to give rise to reduction of obligations under the GMBM.

\subsubsection{The Renewable Energy Directive}

In 2009, the EU issued Directive 2009/28/EC on the promotion of the use of energy from renewable sources, the so-called Renewable Energy Directive (RED). A cornerstone of the RED is the target of renewable energy sources (RES) making up a $20 \%$ proportion of total energy production in the EU by 2020, compared to 2005. Included in this target is the sub-target that $10 \%$ of the total energy used in transportation, should be made up of renewable sources, e.g. biofuels.

The 20\% overall RES target is computed as an EU average. Thus certain Member States can have lower targets for renewable energy, whilst others have higher targets. The $10 \%$ target for transport is the same for all member states. All Nordic countries have rather ambitious goals set by the RED directive:

- Norway has a target of a $67.5 \%$ share of RES of gross final consumption of energy by 2020 , including a $10 \%$ share of RES in energy for transportation (MPE, 2013).

- Denmark's target share of RES is $30 \%$ of gross final consumption of energy by 2020 , including a $10 \%$ share of RES in energy for transportation (KEM, 2010).

- Sweden has set a target of 50\% RES of gross final consumption of energy by 2020 , including a $10 \%$ share of RES in energy for transportation (Regeringskansliet, 2010).

- Finland's target share of RES is $38 \%$ of gross final consumption of energy by 2020 , including a $10 \%$ share of RES in energy for transportation. Finland has unilaterally increased the target share of RES in transportation to $20 \%$ by 2020 (MEE, 2010).

- Iceland has set a target share of $73 \%$ of gross final consumption of energy by 2020 , including a $10 \%$ share of RES in energy for transportation (MII, 2014).

The RED applies to sustainable biofuels used in aviation. Thus, the use of sustainable biofuels in aviation can help the Nordic countries achieve the goals listed above. Yet, special provisions exist for aviation under the RED, due to the sectors special circumstances with regards to technological development and lack of commercially viable alternative fuels. 
Member States are allowed to disregard energy consumed in aviation that exceeds $6.18 \%$ of the country's total energy consumption..$^{10}$

The goal of $10 \%$ renewable energy in transportation includes the aviation sector. However, the target is not split into separate targets for different transport modes, as e.g. road transport and aviation.

The RED sets out sustainability criteria for biofuels, to ensure these fuels are produced in a manner, which guarantees carbon emission reductions and protect biodiversity. These criteria include:

- A biofuel must exhibit direct GHG emission reductions of minimum $35 \%$, compared to fossil fuel reference. When calculating GHG reductions, the total emissions of a biofuels life-cycle must be taken into account, including emissions from cultivation of feedstock, processing and transport. ${ }^{11}$

- From 1st January 2018, the target reduction is increased to 50\%

- The target reduction is $60 \%$ for facilities built after 5 th October 2015.

- Biomass cannot be produced in areas converted from land with high carbon stock, such as wetlands or forests.

- Biomass cannot be produced from land with high biodiversity, such as primary forests or highly biodiverse grasslands.

In addition to the criteria listed above, feedstock producers are also required to submit documentation of the status of land-use prior to 2008 in order to trace LUC.

The ILUC directive amended the RED by limiting the share of the $10 \%$ transport target that can be achieved by biofuels from food crop feedstocks to a maximum of $7 \%$, and by setting an indicative target of $0.5 \%$ advanced biofuels. The ILUC directive also introduces values for GHG emissions from indirect land-use changes, but these values are only to be reported and not counted in the GHG emissions criterion of the sustainability criteria.

\footnotetext{
${ }^{10}$ I.e. when a Member State calculates national energy consumption, it can ignore any energy for aviation that exceeds 1.5 times the national average of energy related to aviation in the EU. The national average of emissions stemming from aviation was $4.12 \%$ in 2005 , thus the maximum percentage of energy from aviation that must be included in national accounts was set to $1.5 * 4.2=6.18 \%$. Malta and Cyprus must include only $4.12 \%$.

11 GHG emission reductions must be calculated based on a methodology presented in Annex V of the RED.
} 


\subsubsection{The Fuel Quality Directive}

The 2009 version of the Fuel Quality Directive (FQD, 98/70/EC as amended by $2009 / 30 / E C$ ) did not include the aviation sector. Article $7 \mathrm{a}$ of the directive requires fuel suppliers to reduce the greenhouse gas intensity of fuels per energy unit by $6 \%$ in 2020 compared to the EU average of 2010. By an amendment to the FQD by the ILUC directive, member states can decide nationally to allow suppliers of biofuels for aviation to participate in the fulfillment of this requirement. In that case, only the biofuel part of the aviation fuels is counted. The sustainability criteria for biofuels in the FQD are equivalent to those in the RED.

\subsubsection{Sustainability certification and voluntary schemes}

Under the RED and FQD, it is mandatory for companies who wish to market their products as sustainable, to provide proof of adherence to the sustainability criteria of the directive. For the biofuel industry, this means that a producer of sustainable jet fuel must be able to document compliance to the RED/FQD not only in their own production processes, but throughout their value chain, i.e. the sustainability of suppliers, biomass producers, etc. Voluntary schemes are sustainability certification companies that evaluate value chains according to the RED/FQD requirements. Thus, companies participating in the value chain for biofuels for aviation can use certification by voluntary schemes as proof of sustainability requirements.

The Commission has approved 19 voluntary schemes to date (COM, 2015b). In section 3.3, the voluntary scheme of the Roundtable on Sustainable Biomaterials, which is considered the most comprehensive of the schemes, is briefly introduced.

\subsubsection{The Nordic Council of Ministers}

The Nordic Council of Ministers is the official forum for cooperation between the governments of the Nordic countries. ${ }^{12}$

The Nordic Environmental Action Plan is a policy document serving as a framework for the Nordic Council of Ministers for the Environment from 2013-2018 (Nordic Council of Ministers, 2012). The Action Plan builds on four pillars of cooperation, namely:

12 Originally, the Nordic countries included Denmark, Finland, Iceland, Norway and Sweden. Greenland, the Faroe Islands and the Aland Islands, has later been added, as these regions were awarded autonomous rule. 
- Inclusive green development.

- Climate change and air pollution.

- Biodiversity, ecosystems and ocean acidification.

- Health and environmentally hazardous chemicals.

It is explicitly stated that cooperation within these areas should rest on "the principles of Nordic synergy and added value [...] and the export of Nordic environmental technology" (Nordic Council of Ministers, 2012: 7).

Of special interest with regards to sustainable jet fuel production is the pillar of climate change and air pollution, which seeks to reduce GHG emissions so as to maintain global warming below $2^{\circ} \mathrm{C}$, thereby limiting negative environmental and human health effects of climate change. This is to be achieved through increased energy efficiency and the use of sustainable renewable energy in all sectors, including aviation (Nordic Council of Ministers, 2012).

\subsection{International business policy frameworks}

Besides the intergovernmental frameworks constituted by the UN and the EU, the business community itself has formed a range of organizations, which engage themselves in sustainable aviation. The following introduces the work of the International Air Transport Association (IATA), the Sustainable Aviation Fuel User Group (SAFUG) and the Nordic Initiative for Sustainable Aviation (NISA).

The Air Transport Action Group (ATAG), ${ }^{13}$ an umbrella organization for global aviation sector associations has set forth targets to help reduce the aviation industry's negative imprint on the environment. These targets include:

- Fuel efficiency improvements averaging on $1.5 \%$ per annum from 2009-2020.

- A cap on net $\mathrm{CO}_{2}$ emissions from aviation from 2020, i.e. carbonneutral growth.

- A reduction in net $\mathrm{CO}_{2}$ emissions from aviation of $50 \%$ in 2050 , compared to 2005.

${ }^{13}$ ATAG is comprised of stakeholders to the aviation industry. It members span a range of different actors, including airlines, airports, pilot and traffic controller unions, chambers of commerce, industry associations, etc. 
The three targets are to be achieved through a four-pillar approach, encompassing technologic improvements including biofuels, more efficient aircraft operations, improvements to infrastructure, and a market-based measure to close remaining emission gaps (ATAG, 2013).

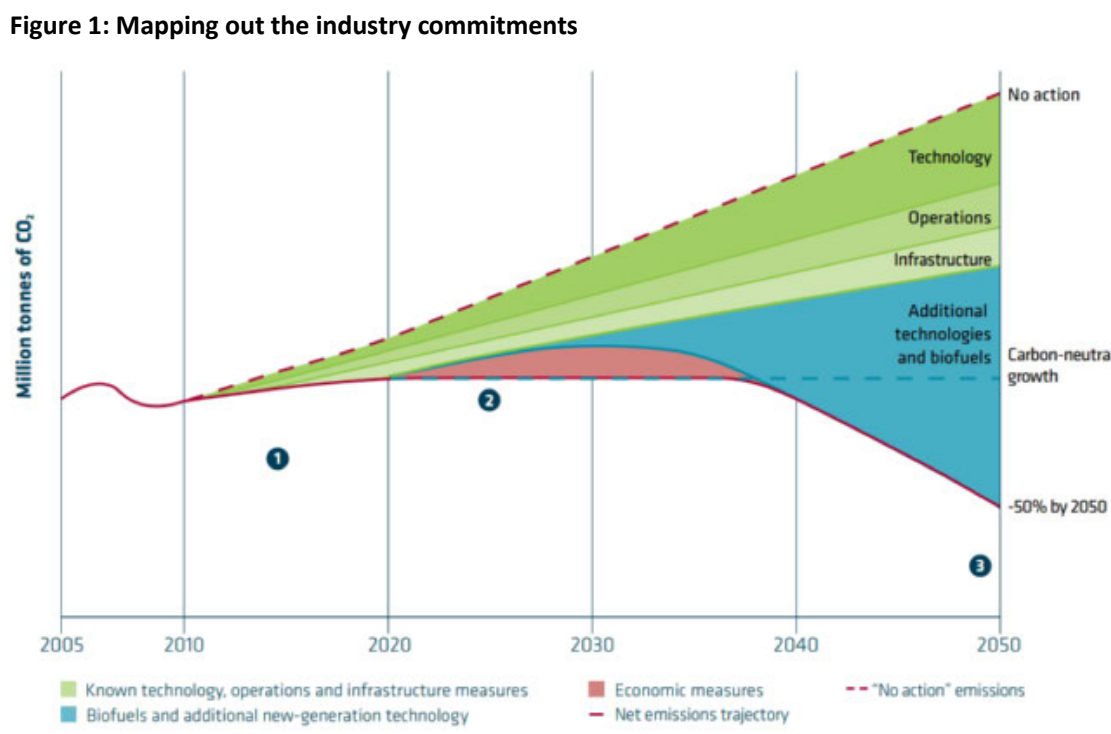

Source: ATAG, 2013.

As shown above, the aviation industry acknowledges that the commercialization of sustainable jet fuel will play a vital role in attaining their goal of a $50 \%$ net reduction in $\mathrm{CO}_{2}$ emissions by 2050 . Thus, the association work to promote sustainable jet fuels, in order to make them costcompetitive vis-à-vis conventional jet fuels.

SAFUG was founded in 2008, with the objective of accelerating the development and commercialization of sustainable drop-in biofuels for aviation (SAFUG, 2015).14 The group consists of air carriers and other aviation industry organizations, representing around 33\% of commercial demand for aviation fuels.

${ }^{14} \mathrm{~A}$ drop-in fuel is a biofuel that can substitute conventional fuels, without any special handling of the fuel or changes to engine design. I.e. a biofuel, which, for all intends and purposes, acts like the fossil fuel it is meant to replace. 
SAFUG defines sustainable biofuels as fuels that

- exhibit a minimal impact on biodiversity

- meet a sustainability standard with respect to land, water and energy use

- do not displace or compete with food and feed crops

- provide a positive socioeconomic impact

- do not require any special fuel handling equipment, distribution systems or changes to engine design.

SAFUG refers to the Roundtable on Sustainable Biomaterials, with regards to which sustainability standards should be followed (SAFUG, 2015).

NISA was established in 2013. Like SAFUG, NISA works to promote the development and proliferation of sustainable jet fuels. NISA agrees with SAFUG's definition of sustainability criteria, but proceeds to include aviation's impact on local air quality as a parameter in sustainability. Thus, broadening the traditional focus on GHG emissions to also include ultrafine particles (NIRAS, 2014).

\subsubsection{The Roundtable on Sustainable Biomaterials}

The Roundtable on Sustainable Biomaterials (RSB) is an independent multistakeholder coalition founded in 2007. The coalition has formed a voluntary certification scheme for biomaterials, based on sustainability criteria covering environmental, economic and social principles (RSB, 2015a). The RSB is widely recognized as the most robust and comprehensive certification scheme for the sustainability of biomaterials (see for instance NRDC, 2014; SSI, 2014; WWF, 2013; IUCN NL, 2013).

The sustainability criteria are divided into 14 principles, 15 each encompassing a range of minimum and progress requirements, where minimum requirements are mandatory to achieve certification (RSB, 2011).

15 The 14 principles of the RSB are: Legality; planning, monitoring and continuous improvement; GHG emissions; human and labour rights; rural and social development; local food security; conservation; soil; water; air; use of technology, inputs and management of waste; land rights (RSB, 2011). 
The RSB certification scheme identifies four types of operators in a biofuel's supply chain:

- Feedstock producers.

- Feedstock processors.

- Biofuel producers.

- Biofuel blenders.

The four types of operators may face different requirements under the 14 principles. Yet, the scheme has been constructed to encompass the entire value chain of biofuel production (RSB, 2011).

Since its inception, the RSB has revised its sustainability criteria to incorporate those set forth in the EU RED of 2009. This adaption includes the approval by the RSB to use EU default values for GHG emission reductions, as well as the allowance of products and materials in the production process, certified by other EU approved voluntary schemes (RSB, 2014; RSB, 2015b). However, the RSB requirement for a minimum GHG emission saving of $50 \%$ compared to a fossil fuel reference has not changed and is currently more ambitious than the EU RED for production sites from before 5 th October 2015. This RSB requirement will correspond to the EU RED from 2018.

The RSB counts a range of aviation industry stakeholders among its members. These include, but are not limited to, IATA, SAFUG, Boeing and Airbus as well as a series of sustainable biofuel producers and airline companies (RSB, 2015c). During 2014, the RSB has been involved in nearly all major biofuel for aviation initiatives, where it has witnessed advanced biofuel for aviation deployed at a commercial scale. RSB has given sustainability certifications to certain bio jet projects, including the Project Solaris in South Africa (Project Solaris, 2016).

\subsubsection{ISO - 13065/Standards for Bioenergy}

The International Organisation for Standardisation (ISO) published an international standard on sustainability criteria for bioenergy (ISO 13065:2015) in September, 2015. The standard specifies principles, criteria and indicators of sustainability for bioenergy, with regards to the environmental, economic and social aspects of sustainability. The standard is applicable to single processes, parts of the supply chain or the supply chain in its entirety. Furthermore, it can be used for any type of bioenergy, regardless of feedstock, geographic region of origin/ production and conversion technology. Finally, the standard does not 
specify any thresholds or limits. Thus, the objective of the standard is not to ascertain sustainability per se, but to facilitate comparability between various types bioenergy and processes by harmonizing crosstopic issues - such as terminology, verification and auditing - and definitions (ISO, 2015).

Seeing as all the Nordic countries are Member Bodies (full members) of ISO, it is assumed that an ISO standard on assessment of the sustainability of bioenergy will be applied to the Nordic countries.

The initiatives outlined above all presents sustainability criteria that a Nordic production of sustainable jet fuel to some extend should take into consideration. However, the task of complying with these frameworks and schemes is not as daunting as it may initially appear, as most of these initiatives are already aligned. For instance, SAFUG (and NISA by extension) refers to the RSB with regards to measureable targets for GHG emissions, etc. The RSB in turn incorporates, and even extends upon, the requirements of the EU RED. IATAs set targets for increased energy efficiency, carbon neutral growth from 2020 and ultimately emission reductions are more or less in line with the requirements of the EU RED as well and the targets have become a common point of reference across the aviation industry, being cited by both SAFUG and NISA. 


\section{Legislation and priorities in the Nordic countries and the EU}

This chapter sets the national scenes for the Nordic aviation sector and the policy development towards sustainable jet fuel. This includes an overview of the market situation for jet fuel and policy objectives for each country, an introduction to the relevant national initiatives in the context of sustainable jet fuel, the stakeholders and the relevant legislation and upcoming policy initiatives.

\subsection{Denmark}

The direct impact of the aviation industry in Denmark has been estimated at EUR 2.55 bill and 30,000 jobs. If the indirect effects of the industry are taken into account, the total effect is estimated at EUR 4.16 billion and 50,000 jobs. In 2013, 32\% of Danish exports measured in value were reliant on transportation by plane (Copenhagen economics, 2015).

However, the aviation industry is reliant on a relatively large use of resources, most notably jet fuel. The Danish demand for sustainable jet fuel can be derived from the current consumption of conventional jet fuels, assuming that potential sustainable fuels are drop-in fuels.

The Danish consumption of jet fuel can be divided between two types of fuel; avgas and jet A-1. The vast majority of fuel demand relates to jet A-1, which made up 99.8\% of total demand in 2013 (Danish Energy Agency, 2014). The total use of fuels for transportation was $202.25 \mathrm{PJ}$ in 2013. Of this, aviation made up 37.35 PJ ${ }^{16}$ (Danish Energy Agency, 2013). The majority of fuel consumption in Denmark is made up of diesel oil and gasoline, accounting for 96.29 and 57.73 PJ respectively. Sustainable fuels and electricity on the other hand, account only for 8.71 and 1.39 PJ respectively. Thus, there is a potential for increased use of drop-in fuels across the transportation sector. This potential across the 
transportation sector can cause competition for biomass. Thus, it is paramount that the limited supply of biomass is managed according to different industries' needs. For instance, use of renewable energy in aviation is more dependent on liquid sustainable fuels than land transport, because of a lower potential for electrification in the foreseeable future.

\subsubsection{Policy objectives and priorities}

In the Energy Policy Report it is stated that Denmark in 2015 will spend around EUR 134 million (DKK $1 \mathrm{bn}$ ) on research, development and demonstration-projects within the energy sector (KEBMIN, 2015).

The 2050 goal is to have a transport sector that is completely independent of fossil fuels (Danish Energy Agency, 2012). Because aviation is very different from land transportation due to its transnational operations, Denmark does not have specific targets for e.g. GHG reductions, outside of those agreed upon in the international organizations in which Denmark partake, such as UN Framework Convention on Climate Change (UNFCCC), ICAO and the EU.

In 2014, the Danish Energy Agency released a report describing five different scenarios for the Danish energy supply up until 2050 (Danish Energy Agency, 2014). Each scenario, with one exception, includes the previous government's targets of fossil free production of electricity and heat by 2035 and an entirely fossil free energy system by 2050 .

Three out of five scenarios assigns the largest part of biomass input in the transportation sector to aviation, due to an assumption of high levels of electrification in land-based transportation. Thus, it seems evident Denmark prioritize the use of biomass for aviation over other modes of transportation in the long term. ${ }^{17}$

The Danish Resource Strategy (2013-2018) focuses on the reuse of waste, as opposed to incineration. Thus, it is a target that households should increase the share of organic waste that is reused from $22 \%$ in 2013 to $50 \%$ in $2022^{18}$ (Regeringen, 2013). The strategy explicitly mentions the use of organic waste to increase bioenergy production. Thus, a strategy aimed at increasing the sorting and reuse of waste materials might serve to increase the amount of available biomass.

\footnotetext{
17 Each scenario assign a little less than $40 \mathrm{PJ}$ input to the aviation sector, while total consumption of fuels range from $192 \mathrm{PJ}$ to $710 \mathrm{PJ}$ across the different scenarios.

${ }^{18}$ While the resource strategy is in effect from 2013-2018, special provisions exists for households, extending targets to 2022 .
} 


\subsubsection{National initiatives relevant to sustainable fuels for aviation}

Currently, Denmark does not have any national initiatives targeting the advancement of sustainable jet fuel specifically. However, a range of private and public Danish entities are members of transnational initiatives, such as NISA.

\subsubsection{National stakeholders}

Danish Aviation (Brancheforening Dansk Luftfart) works as an agent for the stakeholders in the Danish aviation industry. The purpose of the organization is to give the Danish aviation sector the best framework to become a central player in the political development.

BioRefining Alliance is an organization with the goal of strengthening the Danish position as a producer of bioenergy. The alliance consists of Dong Energy, the Danish Agriculture and Food Council, Novozymes, Haldor Topsoe, Aarhus University (AU), the Technical University of Denmark (DTU), Danish Straw Suppliers \& Danish Contractors and Entrepeneurs, the University of Copenhagen (KU), NIRAS, and Vestforsyning.

The Sustainable Biofuels Network is an informal network under Copenhagen Capacity (an organization for investment business development in Copenhagen), with the objective of gathering and disseminating knowledge of sustainable biofuels in the transportation sector, as well as creating political awareness and action in the field.

The Danish Transport and Construction Agency (Trafik- og Byggestyrelsen), the Ministry of Transport and Building (Transport- og Bygningsministeriet), and the Danish Energy Agency (Energistyrelsen) are the main public authorities in aviation. Their role is to propose regulation and supervise the civil aviation industry.

Copenhagen Airport is the largest airport in Scandinavia. The airport accounts for roughly $87 \%$ of annual Danish consumption of jet fuel, with 7 minor airports and a range of airstrips accounting for the remaining fraction. Copenhagen Airport is planning to expand its capacity, servicing an additional 40 million passengers annually. If this goal is to be realized, the airport will require more jet fuel than it does today.

Aalborg University (AAU), DTU, KU and AU all make research within the field of bioenergy. Furthermore, private companies do research in the field, e.g. Haldor Topsoe A/S, Novozymes A/S, Biogasol, Dong Energy New Bio Solutions, Steeper Energy, Cumulus Bio and TK Energy ApS. 


\subsubsection{Relevant legislation at the national level}

The Danish Law on $\mathrm{CO}_{2}$-quotas ${ }^{19}$ implements the EU ETS in Denmark and seeks to reduce GHG emissions in a cost efficient manner, through a system of quotas and credits on $\mathrm{CO}_{2}$-eq. The law includes aviation quotas, which determine the amount of GHG that can be released from air transport. The law is applicable to all flights stemming from, or destined to, airports within the EU, insofar as Denmark is the administrative Member State of the aircraft's operator. Under the regulation, biofuels that are certified as sustainable are considered to be carbon neutral. Aviation for certain purposes, such as scientific progress, e.g. test flights of new technology, are exempt from this regulation.

The Danish Law on the Advancement of Renewable Energy, ${ }^{20}$ implements EU legislation into Danish law, and aims to promote the production of energy from renewable sources. This is done through a series of subsidies. Such subsidies could serve to misalign the distribution of available biomass in favor of electricity production. It should be noted, that the government has approved subsidies for biogas used for other purposes than electricity generation, such as transportation, on par with the current subsidy-scheme. However, these subsidies are still awaiting approval by the EU and are consequently not yet in operation (Danish Energy Agency, 2015).

The Law on Sustainable Biofuels and Reduction of Greenhouse Gasses from Transportation ${ }^{21}$ introduces support systems for certain uses of biomass. This regulation implements the EU requirement of a 5.75\% blend of biofuels into gasoline and diesel for land transportation. In congruence with the EU RED, this requirement will increase to $10 \%$ by 2020 and $2 \mathrm{G}$ biofuels counts double towards achieving the target. The result is a potential bias towards the use of available biomass.

The Order on the Sustainability of Biofuels ${ }^{22}$ incorporates the EU RED definitions on sustainable biofuels into Danish legislation. The law requires producers of sustainable products to submit documentation on the sustainability of its products to the Danish Energy Agency each year. An audit, from an EU-approved voluntary scheme (see topic 3, section 1.2.3), can serve as documentation of compliance with the sustainability criteria.

Such legislation as the blending requirements for land transport fuels is potentially a double-edged sword for sustainable jet fuel. On the

\footnotetext{
${ }^{19}$ Lov om $\mathrm{CO}_{2}$-kvoter [LOV 1095 28/11/2012].

20 Lov om Fremme af Vedvarende Energi [LBK 122 06/02/2015].

${ }^{21}$ Bekendtgørelse af lov om bæredygtige brændstoffer og om reduktion af drivhusgasser fra transport [LBK $67421 / 06 / 2011$.

22 Bekendtgørelse om biobrændstoffers bæredygtighed [BEK. 1403 15/12/2009].
} 
one hand, it shows a precedence for support of green initiatives and technologies. On the other hand, support for one specific technology could serve to skew the allocation of available biomass.

\subsubsection{Upcoming policy initiatives that could affect sustainable fuels for aviation}

The Danish objective is to lower Danish GHG emissions reduction targets for 2020 from $40 \%$ to $37 \%$. The government has suspended the previous objective of $100 \%$ GHG reductions in 2050 , in favor of adopting the EU target of $80-95 \%$ reductions.

Furthermore, the energy research program (EUDP) has had its budget halved in the state budget for 2016 (Dansk Energi, 2015). This reduction of available funds for research in clean energy solutions could affect research in pathways for sustainable jet fuels negatively.

As outlined above, the Danish government assigns a significant proportion of biofuel energy inputs to the aviation sector in its future plans for the Danish energy system. However, the recent fiscal budget agreement indicates that the exemption of electric cars from the taxes and levies might be retracted. Thus, the price for electric cars will increase, which is likely to cause a shift in consumer behavior towards more fuel efficient, fossil-fueled cars. This could, in turn, cause a shift in the assigned distribution of biofuels towards land transportation, in order to meet EU requirements for a $10 \%$ share of RES in this sector.

\subsection{Finland}

Since Finland is mainly separated from the rest of Europe and further destinations by the Baltic Sea, air traffic is of major importance and cannot be replaced by other forms of traffic. A study conducted by Oxford Economics estimated that the aviation sector, including closely related industry sectors, produce $3.2 \%$ of Finland's GDP, and employed around 100,000 persons directly or indirectly in 2014 (Finnish Transport Safety Agency, 2015). A total of 19.7 million passengers and 194,475 t of air freight went through Finnish airports in 2014 (Trafi, 2015).

Neste has been a global forerunner in developing advanced technologies for biofuel production and demonstrated the ability to produce biokerosene in large scale already in 2011, when the ASTM certification of the HEFA process made it possible. However, Neste has not started continuous production of aviation biofuel, because the demand for bio- 
fuel has so far been insufficient to make the investments in modifying the production facility and logistics profitable.

Finnair has been flying several flights with sustainable jet fuels. In 2014, it operated a flight from Helsinki to the UN Climate Summit in New York. The sustainable fuel mixture was partly manufactured from recycled cooking oil. Finnair first flew with sustainable jet fuel in 2011.

\subsubsection{Policy objectives and priorities}

Finland's long-term objective is to be a carbon-neutral society (Ministry of Employment and the Economy, 2014). The latest National Energy and Climate Strategy concludes that previously decided measures will suffice to meet the renewable energy target set by EU for 2020, which is $38 \%$ of final energy consumption (National Energy and Climate Strategy, 2013). The use of renewable energy has increased in a frontloaded manner.

While the EU has set the obligation of a $10 \%$ share of renewable energy in road transport fuels for 2020, Finland has set a higher national target of $20 \%$ and uses blending obligations to reach this target.

According to Finland's Air Transport Strategy 2015-203023 the $\mathrm{CO}_{2}$ emissions from Finnish domestic flights have been estimated to be 0.3 million $t$ per year whereas emissions from international flights amounted to 1.9 million t in 2013 (Ministry of Transport and Communications, 2015; Trafi, 2015). Renewable aviation fuels are mentioned as an important tool in the reduction of $\mathrm{CO}_{2}$ emissions from aviation. The goal is to reach a $40 \%$ share of sustainable fuels in aviation by 2050 (Trafi, 2014).

The Ministry of Transport and Communications' report on Alternative fuel's infrastructure recognizes a need to review the plan for a renewable jet fuel distribution network, technical and administrative processes required, as well as relevant legislation impacting the distribution of alternative fuels, in accordance with the EU requirements (EU, 2014).

In developing the markets for alternative fuels the aim in Finland is to decrease the dependency of transport on fossil oil, improve the security of supply, support economic growth, improve the competitiveness of the Finnish industry, decrease energy consumption in transport, and reduce greenhouse gas emissions (Ministry of Transport and Communications, 2015).

The report of the Ministry of Transport and Communications on Future Power Sources reaffirms the vision that $40 \%$ of aviation fuel should be from renewable sources by 2050 and that transport in airports and

${ }^{23}$ Air Transport Strategy 2015-2030, 2015. 
port terminals should be nearly emission free by 2030 (Ministry of Transport and Communications, 2013).

Furthermore, the objective of the Finnish Bioeconomy Strategy is to push the bioeconomy output up to EUR 100 billion by 2025 and to create 100,000 new jobs (The Finnish Bioeconomy Strategy, 2014). In September 2015, the government allocated EUR 300 million for projects regarding expertise and education as well as in bioeconomy and clean energy solution focusing, for example on piloting and demonstration in biobased value chains.

\subsubsection{National initiatives relevant to sustainable fuels for aviation}

As described in chapter 1.4.1 several Finnish actors are already involved in developing the production and use of alternative aviation fuels.

In 2014, Finnair, Finavia, Neste, the Finnish Ministry of Transport and Communications, and the Finnish Ministry of Employment and the Economy collaborated to compile a set of business models that could enable the profitable use of sustainable jet fuel (Gaia Consulting, 2014). The report presents a concept, in which trendsetter companies can act as trailblazers by favoring sustainable fuels in their business travel. Private air passengers would also be able to choose sustainable fuels. In the implementation stage, the project would receive government subsidies, but customers' interest and willingness to pay would determine the extent of sustainable jet fuel use.

The report concludes that there are existing domestic production technologies and potential capacity for resuming continuous sustainable jet fuel production to meet the demands of the aviation sector. HEFA+ is viewed as an opportunity when it is ASTM approved for use as a blendin jet fuel.

Finland is evaluating the possibility of establishing a biofuel hub at Helsinki Airport. Project is led by the Finnish Ministry of Transport and Communications in collaboration with Finnair, Finavia and Neste Oil as partners. Finland is very well positioned to be among the first countries in the world to introduce biofuels in broader and continuous use in aviation. The survey conducted by the project identified renewable biobased diesel as a potential alternative to biokerosene, due to its lower investments required for continuous production, and therefore lower costs. Renewable biobased diesel has not yet received international approval for use as aviation fuel, but the approval process is underway. Estimates 
indicate that, if the process progresses smoothly, renewable biobased diesel could be approved for aviation use in 2016.

From 2007-2012, the Innovation Funding Agency (Tekes) financed a EUR 242 million BioRefine Programme to support the development of innovative new products, technologies and services based on biomass refining and biorefineries focusing primarily on biofuels. Research and development resulted in technically successful piloting and demonstration and readiness for production on a commercial scale and introduction of the products to the markets, but the biggest barrier has been the economic feasibility of the concepts. ${ }^{24}$ NSE Biofuels, a joint venture of Neste and Stora Enso, abandoned plans to build a renewable diesel plant in 2012. The work done during and after the effort to develop a commercial-scale plant was technically successful, but the companies could not find a solid basis for the profitability of the substantial investments needed. The unprofitability has also made Vapo decide to put the diesel plant planned in Kemi, Finland, on hold.

\subsubsection{National stakeholders}

The Ministry of Transport and Communications prepares acts, decrees and decisions, participates in the EU legislation process and in international work carried out at ICAO. Other relevant authorities are the Finnish Transport Safety Agency (Trafi) and the Energy Authority.

Finnair is the national carrier and largest airline of Finland, with its main hub at Helsinki-Vantaa Airport. Finnair and its subsidiaries dominate both domestic and international air travel in Finland. Its major shareholder is the government of Finland, which owns more than $50 \%$ of the shares.

Finavia maintains and develops a network of Finnish airports, which cover the entire country. Finavia also maintains an air navigation system and provides air navigation services. Finavia is a public limited company fully owned by the Finnish State. The Ministry of Transport and Communications is responsible for Finavia's ownership steering.

Several research and universities have strong expertise on sustainable fuels and their processing technologies, including sustainable aviation fuels, including VTT, Natural Resources Institute Finland and Aalto University.

\footnotetext{
${ }^{24} \mathrm{An}$ indication of the excellence by international standards of the concepts developed was the shortlisting of two Finnish consortiums to the EU's limited NER300 demonstration funding.
} 


\subsubsection{Relevant legislation at the national level}

Most of the legislation at the national level is based on EU legislation including, among others, renewable energy targets and sustainability requirements. Under the Act on the promotion of the use of sustainable fuels for transport (446/2007), a distributor of transport fuels liable to pay tax must distribute sustainable fuels for consumption. In 2011-2014, the energy content of sustainable fuels had to account for at least $6 \%$ of the total energy content of the fuels delivered by the distributor for consumption (distribution obligation). ${ }^{25}$ After that, the distribution obligation rises steadily up to $20 \%$ in 2020 . No such obligations exist for aviation.

The act on sustainability of biofuels and bioliquids (393/2013) lays down provisions on the sustainability criteria of biofuels and bioliquids made for energy purposes other than transport. It also specifies procedures to be complied with in verifying compliance with sustainability criteria.

As the Emissions Directive was amended in 2008 to include aviation in the EU's Emissions Trading System, it was implemented nationally by an Act on Aviation Emission Trading (34/2008). Statutory tasks in Finland are undertaken by Finnish Transport Safety Agency (Trafi) and the Energy Agency.

Aviation fuel used for commercial flights is exempt from excise tax in Finland. ${ }^{26}$ The tax for jet fuel for recreational flights is EUR 0.675/l. ${ }^{27}$

The production of renewable energy is subsidized with a variety of measures, such as subsidies for electricity produced on biomass, biofuels and biogas. Such subsidies have impact on the use of available biomass in favor of electricity production. The feed-in tariff paid for electricity produced in a forest chip fueled power plant is designed to retain the competitiveness of the use of forest chips as fuel in the cogeneration of power and heat. It should be noted that the subsidies can change from year to year according to political priorities and budgetary constraints.

\footnotetext{
25 The biofuels included in the distribution obligation must meet the sustainability criteria specified in the EU RED.

${ }^{26}$ http://www.tulli.fi/fi/suomen_tulli/julkaisut_ja_esitteet/asiakasohjeet/valmisteverotus/ tiedostot/026.pdf

27 http://www.tulli.fi/fi/yrityksille/verotus/valmisteverotettavat/energia/
} 


\subsubsection{Upcoming policy initiatives that could affect sustainable fuels for aviation}

Recent strategies and reports predict an increasing role for sustainable fuels in aviation in the long-term future. The Ministry of Transport and Communications' report on Alternative fuel's infrastructure recognizes a need to review the renewable jet fuel distribution network and related legislation. The Ministry's report on Future Power Sources reaffirms the vision that $40 \%$ of aviation fuel should be from renewable sources by 2050. Furthermore, the objective of the Finnish Bioeconomy Strategy is to push the bioeconomy output up to EUR 100 billion by 2025 and to create 100,000 new jobs.

Also preparations of a new national energy and climate strategy which will be ready by the end of 2016 are on the way. The outcome will be affected by future EU decisions on biomass sustainability and state aid rules for energy and environmental aid but is likely to build on the following principles:

- The use of emission-free, renewable energy will be increased in a sustainable way so that its share will rise to more than $50 \%$ by the end of 2020 s and the self-sufficiency to more than $55 \%$, also including peat.

- Coal will no longer be used in energy production and the use of imported oil for the domestic needs will be cut by half by the end of 2020s.

- The share of renewable transport fuels will be raised to $40 \%$ by 2030.

- Finland will create new support programmes for renewable energy. Aid will be based on technology neutrality and ranking of economic priorities.

However, it will be yet to be seen what will be the concrete ways and measures that will have an impact on the aviation fuels. Due to the low oil price the price gap between biofuels and fossil fuels has been too wide in the past years. This has discouraged taking action towards introducing aviation biofuels to the market. 


\subsection{Sweden}

There are a number of ongoing initiatives in Sweden involving sustainable jet fuels, and research in the area is also taking place. The current market share for sustainable aviation fuels is still small, but there is a huge potential to increase the use of sustainable jet fuel, and the great interest from the industry in sustainable jet fuel is promoting and facilitating a further introduction.

The Swedish airline industry employs around 44,000 people in Sweden and contributes with approximately EUR 2.77 billion (SEK 26 bill) to Swedish GDP. In 2012, 38 million passengers arrived and departed from Swedish airports, and approximately $175,000 \mathrm{t}$ goods were sent from the airports. Sweden is, compared to an EU average, very export dependent: $50 \%$ of Swedish GDP originates from the export of goods and services and air freight is therefore important for the economy (Oxford Economics 2011, Svenskt Flyg, 2014). During 2014, 35.7 million people travelled to and from the largest airports in Sweden. This corresponds with a passenger growth of $7 \%$ compared to 2013 .

In 2014 Sweden consumed about $40.5 \mathrm{P}^{28}(930,690 \mathrm{t})$ of jet fuel in total (Statens Energimyndighet, 2015). In a projection made by the Swedish Energy Authority, they expect the consumption of aviation fuel to be between 39.6 PJ and 43.2 PJ in 2030 (Statens Energimyndighet, 2014).

\subsubsection{Policy objectives and priorities}

Sweden has a number of policy objectives which affect renewables in the energy system, namely 50\% renewable energy, $10 \%$ renewables in road transport by 2020 (according to Renewable Energy Directive); Fossil independent vehicle fleet by 2030 and thirdly, a sustainable and resource efficient energy supply with zero net GHG emissions in 2050.

Sweden has already reached the first target stipulated in the Renewable Energy Directive (directive 2009/28/EC). In 2013 Sweden had the highest share of energy from renewable sources in its gross final consumption in the EU-28 with renewables reaching 52.1\%. Moreover, Sweden reached the target with renewables in the transportation sector (aviation excluded) ${ }^{29}$ with 16.7\% in 2013 (Eurostat, 2013).

\footnotetext{
${ }^{28}$ Assuming an energy content of $40.5 \mathrm{GJ} / \mathrm{t}$

${ }^{29}$ How the shares are calculated can be seen by following the link; URL:

http://ec.europa.eu/eurostat/web/energy/data/shares [Accessed 20th November 2015]
} 
On a country level, a number of measures have been prioritized to promote the use of bioenergy: carbon and energy taxes, electricity certificate system and specific measures targeting sustainable fuels for transport such as the "pump act", ${ }^{30}$ car taxation measures and a range of subsidies promoting sustainable fuels and vehicles using renewable fuels or electricity.

The use of renewable fuels increased in 2014 and accounted for roughly $12 \%$ of the fuels used in land transportation. Fossil gasoline accounted for $35.7 \%$, fossil diesel for $51.5 \%$, and natural gas less than $1 \%$ (SPBI 2015).

To summarize, a range of policies and subsidies intended to support renewable fuels in the ground transportation sector have been introduced and withdrawn during the last 10 -year period. Nevertheless, today there are no governmentally introduced policies in place to promote a transition to sustainable jet fuels in Sweden. Targets for sustainable jet use and initiatives for sustainable jet introduction in the area are mainly driven by the aviation industry itself, by voluntary initiatives, and market mechanisms.

\subsubsection{National initiatives relevant to sustainable fuels for aviation}

There are at the time of writing no national government-backed initiatives or support schemes that promotes the use or production of sustainable fuel for aviation per se. However, there are several nongovernmental and industry driven projects and initiatives that support the emerging sustainable jet market such as the Fly Green Fund initiative and the sustainable jet fuel station located at Karlstad Airport. Moreover, Sweden's major airline operator takes part in international organizations such as NISA.

\subsubsection{National stakeholders}

The Swedish Transport Agency (Transportstyrelsen) is involved in providing accessibility, quality and security in rail, air, sea and road transport. The Civil Aviation and Maritime Department formulates regulations and monitor developments in the aviation market (Transportstyrelsen, 2015).

\footnotetext{
${ }^{30}$ In December 2005 the Swedish Parliament decided to adopt a new act on the obligation to supply renewable fuels. As of 2006 the major filling stations are obliged to supply renewable fuels such as ethanol or biogas.
} 
Civil Aviation Administration (Luftfartsverket, LFV) is a state enterprise that operates air navigation services in Swedish air space. Services are given to both civil and military customers throughout the country. Together with airlines and airports LFV ensures air safety and costeffective air navigation (LFV, 2015).

Svenskt Flyg (Swedish Aviation) is a member-owned organization with the purpose of working politically for the Swedish commercial airline and aviation industry. Members of Svenskt Flyg are e.g. Luftfartsverket and Swedavia.

Energimyndigheten (Swedish Energy Agency) is a government agency working with national energy policy issues. As such, the Swedish Energy Agency is an important Swedish stakeholder in the field of biofuels in general, especially considering national biofuel policy and research. The agency channels more or less all state funds into energy research, amounting to around SEK 1,300 million, or roughly EUR 140 million annually.

Swedish universities involved in sustainable jet research and development include e.g. Lund University, Royal Institute of Technology (KTH) and Chalmers University. Swedish Biofuels is a private company involved in a Swedish-US cooperation program on sustainable jet production and testing. Non-governmental entities involved in sustainable jet activities include e.g. Swedish Bioenergy Association (Svebio) and regional consortia and business clusters such as Paper Province.

The Swedish Bioenergy Association (Svebio) is a NGO advocating optimal conditions for bioenergy in Sweden and internationally. Around 300 Swedish businesses are members of Svebio.

\subsubsection{Relevant legislation at the national level}

Sweden's integrated climate and energy policy is guided by two governmental bills (2008/09:162 and 163) with the following targets (IEA 2013):

\section{Short-to medium targets for $\mathbf{2 0 2 0}$}

- $40 \%$ reduction of greenhouse gases compared to 1990 (for sectors outside the EU-ETS).

- $50 \%$ share of renewable energy in gross final energy consumption (RED). ${ }^{31}$

- $10 \%$ renewable energy in the transportation sector (RED).

- $20 \%$ more efficient use of energy compared to 2008 .

${ }^{31}$ Renewable Energy Directive (2009/28/EC). 


\section{Long-term priorities}

- A vehicle fleet independent of fossil fuels by 2030 .

- No net emissions of greenhouse gases by 2050 .

The target of 50\% renewable energy and 10\% renewable energy in the transportation sector does not cover aviation, as the aviation sector is not included in the RED.

Moreover, Sweden launched an action plan for renewable energy as part of the integrated climate and energy policy mentioned above. The action plan includes an increase in ambitions for the electricity certificate system with an increase of 25 TWh in 2020 as compared to 2002 (IEA, 2013). Sweden also adopted a comprehensive energy efficiency program with a total of EUR 156.2 million during a five-year period. Activities under the energy efficiency program aim to strengthen regional and local initiatives and to support green procurement etc. In total, the energy efficiency activities amount to EUR 61 million per year, mainly targeting energy-intensive industries.

Sweden is covered by the EU-ETS system. In 2013, 17 airline operators applying for emission allowances (EUAs) in Sweden have been granted EUAs. In 2012 the aviation sector's emissions were equivalent to 97\% compared to the average emissions per year from 2004 to 2006. For the period 2012-2020, the number of EUAs is reduced to $95 \%$ compared to the average emissions in 2004-2006.

The Swedish government has introduced a number of incentives for ground transportation and for privately and state owned cars. The taxation system has supported, and supports, the purchase of environmentally friendly vehicles.

The abovementioned types of incentives, together with requirements for filling stations to supply renewable fuels have boosted the market for flexi-fuel cars and sustainable fuels in general during the period 2008-2010. The combination of subsidies, tax exemptions and investments in biofuel infrastructure ensured a reliable supply and availability. From 2010 and onwards some measures and incentives has been withdrawn, postponed or changed, such as the $20 \%$ tax reduction for flexi fuel cars, which has negatively affected the Swedish biofuel market and industry. 


\subsubsection{Upcoming policy initiatives that could affect sustainable fuels for aviation}

This section gives an overview of possible measures discussed in Sweden in relation to sustainable jet fuel. Currently there are no mandatory measures to increase the share of sustainable jet fuel in Sweden.

The possibility of introducing a renewable fuel quota system in the jet fuel market in Sweden has been under investigation by the Swedish Energy Agency and the Swedish Transport Agency. Recent studies, however, conclude that implementing quota obligation systems in line with the ICAO regulations would lead to higher ticket prices. Higher ticket prices will not per se impact the demand, but it would make Swedish airlines less competitive (Rossi, 2014).

Based on the long-term Swedish strategy for reducing greenhouse gas emissions and increase renewable energy, airport operators are striving to achieve sustainability through the daily operations. The stateowned airport operator Swedavia strives to reduce the environmental impact of both air and ground operations. Examples are the use of biogas-driven snow removal equipment, and the airport vehicle fleet that mostly uses electricity, and to support airlines in the transition to sustainable fuels. One aim is to replace fossil fuels with sustainable fuels in airport operations on the ground.

Today voluntary initiatives such as the FlyGreen-fund mechanism initiated by the industry are gaining momentum in Sweden, attracting attention from industry stakeholders and media.

\subsection{Norway}

Norway is a country with long distances, scattered population and challenging terrain. This means that Norway is more dependent on aviation as a mode of transportation compared to other European countries. Norway's oil and petroleum industry is strongly dependent on aviation, in order to carry goods and workforce to oil installations at sea. Of all domestic travels half is occupational, of which a quarter is carried out within the petroleum sector (Avinor, 2014). Other important travels are within the service sector, where experts make their way to customers for immediate problem solving, maintenance and development. In Norway aviation plays an important role in healthcare as well, especially for people who cannot reach hospitals in other ways.

The Norwegian aviation industry provides $60,000-65,000$ jobs. Overall, the aviation sector accounts for 4\% of Norway's GDP (Avinor, 2014). 
The industry is growing steadily; from 2013 to 2014 the air traffic increase was $2.2 \%$. 891,000 t (1.1 billion liters) of Jet-A1 was sold in Norway in 2014, which is an increase of 2.1\% from 2013. From 2010 to 2014 the average growth rate in jet fuel consumption has been a little over $3 \%$ per year (Statistics Norway, 2015). About 50 million passengers entered or left a Norwegian airport in 2014 (Statistics Norway, 2015).

The national bioenergy strategy published in 2008 (Regjeringen.no, 2015) describes a Norwegian ambition of increasing the sustainable fuels share in road transport to reach the $5 \%$ goal by 2009 and $7 \%$ from 2010. These goals were, however, changed/removed due to sustainability concerns regarding $1 \mathrm{G}$ biofuels on the market.

The Climate Cure 2020 study, that assesses scenarios and policy instruments in order to reach Norway's climate targets, recommends sustainable fuels as part of the solution for reducing GHG emissions and estimates potential annual $\mathrm{CO}_{2}$ reductions from transportation in Norway of 1.7 million $t$ in 2020 and 2.6 million $t$ in 2030, depending on the scenarios' biofuel shares (Statens vegvesen, 2010).

\subsubsection{Policy objectives and priorities}

A quota obligation for biofuels in road transport was introduced at $2 \%$ in 2009 and increased to $3.5 \%$ in 2010. In the 2012 Climate Agreement, the Norwegian Parliament stated that it wanted to increase the quota obligation to $5 \%$, provided that the sustainability criteria were considered sufficiently strong. The Government also stated that it wanted to establish a complete value chain for the production of $2 \mathrm{G}$ biofuels in Norway (Stortinget, 2012). Although sustainable fuels were mentioned in the 2012 Climate Agreement, sustainable fuels for aviation were not targeted specifically. The quota obligation only covers road transport. Due to weaknesses of the EU sustainability criteria, especially concerning ILUC, the quota obligation was kept at 3.5\%.

In 2012, an expert commission nominated by the Government in order to assess and provide policy recommendations for the further development of the energy system in Norway delivered a report (NOU, 2012: 9). The report offers some assessment of the potential of biomass for energy purposes in Norway (chapter 11.8). However, the report did not stipulate or recommend any specific or reinforced role for sustainable fuels in Norway (Knudsen et al., 2015). Sustainable fuels for aviation is not targeted specifically, although it is mentioned that sustainable fuels is the only option for heavy transport, such as aviation, to cut $\mathrm{CO}_{2}$ emissions in the short term. 
In the 2013 Government platform, the Government stated that it wants Norway to be a pioneer in sustainable energy use and production, both in hydropower, wind power, bioenergy and other renewable forms of energy. Although bioenergy is mentioned, and the Government stated it would develop a strategy for biogas, biofuels for aviation were not targeted explicitly.

Sustainability criteria and double counting of advanced biofuels were introduced from 2014.

\subsubsection{National initiatives relevant to sustainable fuels for aviation}

The greatest initiative in Norway was started by Avinor in 2015. It aims to make Oslo airport a hub for handling and distribution of sustainable jet fuels (Aviationbenefits.org, 2015). Over a trial period of 12 months, $2,025 \mathrm{t}$ (2.5 million liters) of sustainable jet fuel will be handled in existing fuel infrastructure and sold at Oslo airport, Gardermoen. The airport is operated by Avinor. The aim of the project is to assess the handling and use of sustainable jet fuel blends in the existing infrastructure as well as to find long-term solutions for further operations and financing (O.M. Larsen, 2015).

Enova provides financial support for producers of bioelectricity and -fuel, in order to help mitigate the price gap between bio- and fossil energy, thus increasing the feasibility of producing bioenergy on a commercial scale (Enova, 2016).

In addition, there are a few initiatives in the planning phase. These are mentioned jointly with the stakeholders in the next chapter.

\subsubsection{National stakeholders}

Avinor is the greatest stakeholder in aviation as well as sustainable aviation fuels in Norway. Avinor is a state owned company under the Ministry of Transport and Communications. Avinor is responsible for the 46 state-owned airports as well as navigation services both for civil and military aviation. Avinor has a mission of developing and operating a safe, efficient and sustainable aviation system in Norway (Avinor, 2014). In this mission, sustainable aviation fuels play a central role. 
Silva Green Fuel A/S is a company formed by Statkraft (51\%) and Södra (49\%) (Statkraft, 2015). ${ }^{32}$ The company will establish production of $2 \mathrm{G}$ biofuels, where aviation biofuels can be included depending on profitability. The first task of Silva Green Fuel is to find a suitable technology for commercial industrial $2 \mathrm{G}$ biofuel production based on feedstock from forestry. The production is planned to take place at Tofte, an industrial area previously owned by Södra.

Treklyngen which is a subsidiary of Viken Skog is also evaluating technologies for biofuel and other bioproducts production at Follum industrial area (Viken skog, 2015).

SINTEF jointly carries out research with a broad consortium consisting of Norwegian and international industry, research institutes and universities. One of the projects aiming at sustainable aviation fuels is Gasification and FT synthesis of lignocellulosic feedstock (GAFT) funded by the Norwegian Research Council and industrial partners (SINTEF, 2015). NTNU is doing active research in catalysts relevant for sustainable fuels production (Norwegian Research Council, 2015). They have several projects; one is aiming at solving the issues of producing fuels from syngas while another project aims at proofing a high pressure fast pyrolysis followed by catalytic upgrading of vapors to fuels.

Finally, Enova, the Norwegian Research Council and Innovation Norway all provide support schemes for producers of biofuel and -energy.

\subsubsection{Relevant legislation at the national level}

Generally, there are few economic incentives concerning the phase-in of sustainable fuels (Knudsen et al. 2015). Biofuels are exempted from the CO2 tax. In October 2015, the Ministry of Finance removed the road use tax for sustainable fuels. This applies to sustainable fuels that surpass the blend-in requirement - which was increased from 3.5\% to $5.5 \%$ from the same date (regjeringen.no 2015). The aviation sector is subject to $\mathrm{CO}_{2}$ tax, landing charges and the EU ETS. Many stakeholders in aviation have underlined the need for defining the concrete framework conditions. In addition to this, generally high $\mathrm{CO}_{2}$-taxes provide indirect support for sustainable fuels.

\footnotetext{
32 Statkraft is a leading company in hydropower internationally and Europe's largest generator of renewable energy. The Group produces hydropower, wind power, gas power and district heating and is a global player in energy market operations. Statkraft has 3,700 employees in more than 20 countries.

Södra is a group with extensive forestry operations and a leading producer of paper pulp, sawn timber and bioenergy. The Group is owned by 50,000 forest owners in southern Sweden, has 3,500 employees and revenue of SEK 17 billion assessed October 2015.
} 
In 2015, the Parliament asked the Government to consider a model for tax changes or an incentive scheme, which will contribute to increased profitability for airlines that use sustainable fuels (stortinget.no 2014). However, several stakeholders have criticized the Government for not following up on this and requested that suggestions for such a model are developed (skogeier.no 2015). A differentiation of landing taxes has also been suggested by some actors (nrk.no 2014), as well as the expert panel SKOG22 (SKOG22, 2015). ${ }^{33}$ In December 2015 the parliament made a request to the government on landing fees, see below.

\subsubsection{Upcoming policy initiatives that could affect sustainable fuels for aviation}

In early 2015, the Government decided that it will develop a national strategy for bioeconomy. The bioeconomy strategy will be developed in a partnership with all relevant ministries. Funding agencies, businesses, organizations and research institutions will also be involved in the work. The strategy is scheduled to be completed in 2016.

The SKOG22 report will likely be an important input into the Government's efforts with a national bioeconomy strategy. Here, it is stated that the Government needs to send clear signals that it wants to replace fossil energy carriers with sustainable fuels in transport and aviation. The report suggests increased $\mathrm{CO}_{2}$ tax on fossil fuels, a differentiated landing fee for aircraft using sustainable fuels, production support for forest-based biofuels and transfer of funds administered by Investinor to other policy measures which stimulate projects in early stages (SKOG22, 2015).

Following the negotiations for the state budget of 2016, the parliament asked the government to increase the blend-in requirement of biofuels for road transport to $7 \%$ in 2017. In addition, the parliament has asked the government to plan further increases in the blend-in requirement up until 2020 and a transition from 1G fuel to more advanced fuels with better sustainability. The plan should be published together with the proposal for the state budget 2017 (Stortinget, 2016).

Another request from the parliament to the government is the requirement that all biofuels sold in Norway are sustainable, in accordance with the principals set forth in the EU RED (Stortinget, 2016).

\footnotetext{
${ }^{33}$ The Norwegian government established an expert panel in 2013 in order to provide recommendations for an improved resource management and increased industrial activity related to Norwegian forest resources. This strategic activity was called Skog22 (Forest22).
} 
Finally, parliament has asked for a $25 \%$ reduction of the landing fees for airplanes, insofar as the plane use a minimum blend of $25 \%$ sustainable jet fuel. The plan is that this measure should be replaced by a blendin requirement for sustainable jet fuel by 2018 (Stortinget, 2016).

\subsection{Iceland}

The Icelandic energy sector is unique in many ways, not the least because of its isolation from other European networks and the share of renewable energy in the total primary energy budget. Iceland has ample reserves of renewable energy in the form of hydro and geothermal energy. Due to this, the energy profile has $80 \%$ of the primary energy supply from renewable resources; the remaining $20 \%$ comes from imported fossil fuels. The renewable energy sources are mainly used for district heating and the production of electricity, whereas the fossils are mainly used in transportation and fisheries. Thus, Iceland has already surpassed its declared goal of a 73\% share of RES in its energy mix by 2020 (Icelandic Ministry of Industries and Innovations, 2014).

All petroleum derived fuels currently used in Iceland are imported (NEA 2015). The table below shows the oil consumption in different sectors from 2011-2013. About $96 \%$ of the total oil consumption was by transportation and fishing in 2013, and fuel for aviation form around $25 \%$ of the total consumption. 


\begin{tabular}{lrrr} 
Table 2: Icelandic oil consumption & & & \\
\hline $\mathbf{( 1 , 0 0 0 ~ t )}$ & $\mathbf{2 0 1 1}$ & $\mathbf{2 0 1 2}$ & $\mathbf{2 0 1 3}$ \\
\hline Automobiles and equipment & 277 & 276 & 280 \\
Domestic fishing vessels & 159 & 154 & 151 \\
Aviation & 140 & 147 & 164 \\
Other $^{34}$ & 48 & 39 & 54 \\
Total $^{4}$ & 624 & 616 & 649 \\
\hline
\end{tabular}

Source: Statistics Iceland.

\subsubsection{Policy objectives and priorities}

In the Icelandic National Renewable Energy Action Plan (MII, 2014), the main areas of emphasis in the field of energy, fuel in particular, are to boost research, development and production of domestic, sustainable fuel and increase the number of alternative energy outlets. The aim is to enable Iceland to lead the way in coming years in experiments and production of sustainable energy sources, in part by supporting research and development and building up infrastructure.

The share of renewable energy in the transport sector is currently $0.35 \%$. However an ambitious goal of $10 \%$ for transport, for the year 2020 in line with the EU RED, has been put forward by the Government. This target is one of the Government's main targets, which are set forth in the policy document Iceland 2020.

\subsubsection{National initiatives relevant to sustainable fuels for aviation}

There has not been identified any national initiatives with regards to sustainable jet fuel in Iceland.

\subsubsection{National stakeholders}

The Science and Technology Policy Council (STPC) is the governmental body of Iceland in charge of developing R\&D policy, including budgetary expenditures programmes to support certain technologic developments. Eco-innovation has been identified as a priority area in Iceland.

The Ministry of Industry and Innovation (MII) covers all sectors of ordinary economic activity in Iceland. Among other things, the MII is responsible for overall energy policy (OECD, 2014).

34 Other includes industry and other vessels. 
The Ministry of Environment and Natural Resources (MENR) formulates and enforces the Icelandic climate policy (MENR, 2015). Given the overlaps between climate and energy, the work of MENR is carried out in close cooperation with the MII (OECD, 2014).

The National Energy Authority regulates the energy market. This includes issuance, and monitoring, of operating licenses for energy producers.

The Icelandic Centre for Research (Rannís) and Innovation Centre Iceland (ICI) are the main providers of funding for R\&D in Iceland (OECD, 2014). Rannís also provides information and research and technology developments to the STPC, monitors resource allocation and performance in R\&D and evaluates results of scientific research. ICI advocates and pioneers new technologies in chosen fields of research, such as biotechnology and -energy. It also provides support services and financial assistance to start-up companies within its chosen fields, as well as facilitating transnational cooperation in R\&D.

CleanTech Iceland (CTI) is a special industry group operating within the Federation of Icelandic Industries. Established in 2010, CTI works to accelerate the growth of environmentally aware companies and green technology (CTI, 2015). The group supports green enterprises through various means, including financing and staff training. In addition, CTI works to establish a favorable regulatory framework for the development of green technology. The group place special emphasis on renewable energy in transportation (Althingi, 2011).

The tourism industry is one of the fastest growing sectors of the Icelandic economy. The industry is heavily reliant upon aviation, the nature, history and culture of Iceland. Thus, the industry is keen to preserve the resources that it first and foremost builds upon, and a heavy emphasis has been placed on a greening of the travel industry (Althingi, 2011).

\subsubsection{Relevant legislation}

In 2010, Iceland introduced a carbon tax on most fossil fuels. ${ }^{35}$ The tax rate reflected the price of emissions allowances under the EU ETS at the time. It should be noted that this carbon tax fully applies to fuel used in the fishing fleet. This is unusual, as most countries hardly even tax fuel used by their fishing fleet (EOCD, 2014). Taxes levied on petrol and diesel in Iceland are the lowest in the Nordic countries (OECD, 2014). However, the inclusion of fuels used in the fishing industry into the tax regime could

\footnotetext{
35 The carbon tax does not include natural gas and coal, which respectively is not used in Iceland and is exclusively used in sectors covered by the EU ETS.
} 
cause a shift in the use of biomass towards production of fuel for the maritime sector. In line with the EU Energy Tax Directive, ${ }^{36}$ fuels used for aviation are exempted from the carbon tax, as of 2012 (OECD, 2014).

Act 99/2010 on Incentives for Initial Investments in Iceland authorizes the Icelandic government to issue general incentives to enterprises with regards to environmental protection and eco-innovation (Althingi, 2011). Such incentives include, but are not limited to, support for R\&D in connection to new investments in Iceland.

Act 156/2010 changed the tax regime for motor vehicles in two ways. Firstly, it introduced an ad valorem for vehicles based on $\mathrm{CO}_{2}$ emissions per kilometer (OECD, 2014). Vehicles emitting less than $80 \mathrm{~g}$ $\mathrm{CO}_{2} / \mathrm{km}$ are exempted from this tax, thus providing incentives to shift fuel consumption towards low-carbon, or carbon-neutral fuels, such as sustainable fuels. This in turn could cause a shift in the use of biomass towards production of biofuels for land transport. Secondly, it authorized the waiving of excise duties for vehicles that prior to their first registration was modified to run on methane rather than petrol or diesel (Althingi, 2011). New cars (less than 6 years old), which are retrofitted to run on methane, are eligible to receive a reimbursement equivalent to $20 \%$ of the cost of the retrofit, up to a maximum of approximately EUR 704 (ISK 100,000) (Althingi, 2011).

Vehicles that are either electrically powered or run on hydrogen are exempted from VAT, up to a value of approximately EUR 10,775 (ISK 1.53 million). Additionally, plug-in hybrid vehicles also receive an exemption from VAT, yet only up to a value of approximately EUR 7,183 (ISK 1.02 million) (OECD, 2014). While such incentives are not strictly in line with the intention to power the vehicle fleet using biomass, such regulation should ceteris paribus cause a shift towards use of electricity and hydrogen in land transport, allowing a larger proportion of Iceland's scarce biomass to be directed towards the production of sustainable jet fuel.

Iceland joined the EU ETS in 2007, yet due to the country's unique energy mix, its partition in the scheme has been limited, up until the inclusion of aviation and aluminum production in 2012 (OECD, 2014). Under the EU ETS, sustainable fuels used for aviation are considered carbon neutral.

${ }^{36}$ EU 2003/96/EC. 


\subsubsection{Upcoming policy initiatives that could affect sustainable fuels for aviation}

In 2011, a Parliamentary Committee has proposed to lower VAT from approximately $25 \%$ to $7 \%$ for environmentally certified products, such as sustainable fuels certified by a voluntary scheme. As of 2014, this proposal had yet to be enacted (OECD, 2014).

Furthermore, the Parliamentary Committee has proposed to exempt RES used for land transport from VAT, until a share of $20 \%$ of RES in transportation has been achieved (Althingi, 2011). While a lower VAT for certified sustainable products might be beneficial for the production of sustainable jet fuel, an exemption from VAT for RES in land transport could serve to reduce the benefits of such a rebate, causing a shift in the use of available biomass towards land transportation.

The National Renewable Energy Action Plan identifies the use of sustainable fuels as a key driver in attaining the previously mentioned goal of a $10 \%$ share of RES in transportation. The NREAP attributes $75 \%$ of this share to biogas and vegetable oil, 15\% to biodiesel and the remaining $10 \%$ to electricity. Yet, given the scarcity of available biomass in Iceland, the OECD deems this large-scale deployment of sustainable fuels for land transport to be unrealistic, asserting that the use of electric vehicles would be a more appropriate means of attaining a $10 \%$ share of RES in land transportation (OECD, 2014). 


\section{Market and Production Pathways}

This section focuses on the current Nordic market situation in terms of demand and supply of sustainable jet fuels. The section will provide the basis for identifying the potential for a future production of sustainable jet fuel in the Nordic region. First (chapter 5), we identify the current and future demand for sustainable jet fuel, then we explore the supply side, including the feedstock accessibility in the Nordic countries (chapter 6), the relevant infrastructure (chapter 7) and the technology pathways (chapter 8). 



\section{Jet fuel Demand and price sensitivity}

The market for sustainable jet fuel alternative has not developed by itself especially due to the existing price differential between available biofuels and fossil-based jet A-1. Sustainable jet fuel could be produced at a price of EUR 0.8-2.2/liter, dependent on choice of pathway and the feedstock-to-fuel efficiency (see sections 9.2 to 9.4 for more details on the cost estimates). Compared to a fossil reference of EUR 0.25/liter, the cost of sustainable jet fuel falls within a price range that is roughly 3-9 times higher than conventional jet A-1.

The current ETS carbon price is also below what is needed to kickstart the market by itself. After reaching a peak in 2015 on almost EUR 9/ton CO2, the price has decreased and carbon certificates are currently priced at roughly EUR 6/t CO2 (as of June 2016), corresponding to roughly EUR $0.025 / \mathrm{l}$ conventional jet A-1. This corresponds to a cost for the airlines of about $10 \%$ of the current price of fossil jet fuel for the intra-European flights.

In this chapter we explore the aggregated demand of sustainable jet fuel in the Nordic market in order to project the future demand for sustainable jet fuel in the region. The chapter will afterwards examine price sensitivity in the aviation industry, estimating the effect an increase in fuel prices will have on the demand for the industry's services and by extension on the demand for sustainable jet fuel.

\subsection{Current demand for jet fuel}

The historic jet fuel demand of the Nordic countries is illustrated below. The data has been extracted from various national statistics agencies and triangulated with data available from Eurostat. ${ }^{37}$

\footnotetext{
${ }^{37}$ Eurostat's numbers tend to be slightly higher than those of the national statistics, due to i.e. the inclusion of lesser aviation fuels, such as avgas, rather than reporting solely on jet A-1. Yet, as the national statistics tend to report their figures in different units of measurement and also include different units of jet fuel (as some national data tended to gravitate more towards the Eurostat data than others), the Eurostat data has been chosen, in order to ensure comparability of data.
} 
Table 3: Aggregated Nordic demand for jet fuel

\begin{tabular}{lrrrrr} 
million I & $\mathbf{2 0 1 0}$ & $\mathbf{2 0 1 1}$ & $\mathbf{2 0 1 2}$ & $\mathbf{2 0 1 3}$ & $\mathbf{2 0 1 4}$ \\
Denmark & 1,092 & 1,139 & 1,114 & 1,113 & 1,196 \\
Sweden & 1,050 & 1,136 & 1,087 & 1,118 & 1,014 \\
Norway & 1,014 & 1,004 & 1,041 & 1,159 & 1,184 \\
Finland & 849 & 957 & 923 & 931 & 906 \\
Iceland & 163 & 184 & 187 & 211 & 243 \\
Total & 4,169 & 4,419 & 4,353 & 4,532 & 4,543 \\
\hline
\end{tabular}

Source: Own estimates, based on extracts from Eurostat.

The table shows that the jet fuel consumption has fluctuated across the years for the different countries. The total demand is estimated at 4.5 billion 1 in 2014, divided almost equally between the Nordic countries except Iceland that has a much smaller consumption. Out of the annual consumption, almost $99 \%$ accounts for A1 jet fuel.

A projection of future Nordic demand for jet fuel is shown in the table below. It is based on projected growth rates for energy demand in the aviation industry by the Danish Energy Agency and the PRIMES ${ }^{38}$ model of the EU.

The model assumes growth in the industry's energy demand of $2 \%$ per annum up until 2015. From 2016-2020, energy demand is projected to grow by 3\% per annum. From 2021-2025, the growth in energy demand slows to $1 \%$ per year and from 2026-2030, growth rates of $-1 \%$ are projected. From 2030 onwards, energy demand is projected to reach a steady state, i.e. to exhibit annual growth rates of $0 \%$.

The model simulates dynamics of sectoral change based on consumer choice; estimated rate of technological change, refueling infrastructure and policy instruments aimed at enables these changes. Furthermore, sectoral growth is based on projected growth in population and the macro economy, based on Eurostat data.

${ }^{38}$ The PRIMES model simulates energy systems and markets on a country-by-country basis within the EU on five-year intervals (E3M-lab, 2016). 
Table 4: Projection of Nordic demand for jet fuel up until 2050

\begin{tabular}{lrrrrr} 
Million I & $\mathbf{2 0 1 4}$ & $\mathbf{2 0 2 0}$ & $\mathbf{2 0 2 5}$ & $\mathbf{2 0 3 5}$ & $\mathbf{2 0 5 0}$ \\
Denmark & 1,196 & 1,414 & 1,487 & 1,414 & 1,414 \\
Sweden & 1,014 & 1,199 & 1,260 & 1,199 & 1,199 \\
Norway & 1,184 & 1,400 & 1,471 & 1,399 & 1,399 \\
Finland & 906 & 1,072 & 1,126 & 1,071 & 1,071 \\
Iceland & 243 & 287 & 302 & 287 & 287 \\
Total & 4,543 & 5,372 & 5,646 & 5,369 & 5,369 \\
\hline
\end{tabular}

Source: Own estimates, based on extracts from Eurostat.

Applying these growth rates to the aggregated Nordic demand estimated above, Nordic demand for jet fuel will increase steadily over the coming decade, peaking in 2025 at 5.6 billion l. Then, demand will decrease for a short period, before reaching a steady state of 5.4 billion 1 per annum in 2030.

Section 7.1 lists the ambitions of the major Nordic airports to significantly increase the number of passengers. If these airports prove successful in realizing their ambitions by becoming larger connecting hubs, a significant number of international flights will be diverted away from other European airports towards the Nordic airports. As a result, the jet fuel consumption will increase accordingly, possibly at a higher rate than projected in Figure 5.

\subsection{Future demand for sustainable jet fuels in the Nordic countries}

Having established the projected demand for jet fuel in the Nordic countries over the coming decades, this section proceeds to estimate the demand for sustainable jet fuel, based on the projections listed above.

There are a number of assumptions tied to the following estimations. Firstly, it is assumed that the aviation industry will seek to uphold its $\mathrm{CO}_{2}$ emission reduction targets. Thus, it is assumed that the industry's $\mathrm{CO}_{2}$ emissions will have been reduced by $50 \%$ in 2050 and that half of these reductions will stem from the use of sustainable jet fuel. According to IATA (2014), a 3\% blend-in of sustainable jet fuel corresponds to a $2 \%$ reduction in GHG emissions. Thus, in order to reach a GHG emission reduction of $25 \%$ through the use of biofuels, a blend-in ratio of $37.5 \%$ is required by 2050 . Furthermore, it is assumed that airline carriers will gradually implement blend-in of sustainable fuels. This is represented 
through a linear progression from 2020-2050, towards the target of $37.5 \%$ blends.

Secondly, as the price of sustainable jet fuel is likely to be much higher compared to the fossil alternative, it is assumed that the aviation industry will seek to minimize their costs by blending lowest possible fraction of sustainable fuels into their energy mix.

Thirdly, it is assumed that sustainable and conventional jet fuels are assumed to be fungible, given the aviation industry's demand that sustainable fuels are drop-in, i.e. that their energy content is similar to their fossil counterparts and that they can be used directly, without adaptation of existing infrastructure.

Fourthly, assumptions about the prices of conventional fossil fuel and the various sustainable jet fuels covered in the analyses, are based on the cost estimates presented in chapter 9 .

Finally, it is assumed that airline carriers will not shift routes away from the Nordic countries as a result of the introduction, and gradual increase of blend-in requirements. This assumption is based on the fact that the assumed blend-in requirements are founded in the aviation industry's own, international goals for GHG emission reductions.

Based on these assumptions, blend-in of sustainable jet fuels should commence in 2020, where the production pathway for the sustainable jet fuel is estimated to be sufficiently matured. To reach the 2050 level and following a linear growth pathway, the blend-in level must be of $1.21 \%$ in 2020 , corresponding roughly to a total of 65 million 1 in the Nordic countries.

Table 5: Future demand for sustainable jet fuels in the Nordic countries

\begin{tabular}{lrrrrrrr} 
million I & $\mathbf{2 0 2 0}$ & $\mathbf{2 0 2 5}$ & $\mathbf{2 0 3 0}$ & $\mathbf{2 0 3 5}$ & $\mathbf{2 0 4 0}$ & $\mathbf{2 0 4 5}$ & $\mathbf{2 0 5 0}$ \\
Denmark & 17 & 108 & 188 & 274 & 359 & 445 & 530 \\
Sweden & 15 & 91 & 160 & 232 & 305 & 377 & 450 \\
Norway & 17 & 107 & 186 & 271 & 355 & 440 & 525 \\
Finland & 13 & 82 & 143 & 207 & 272 & 337 & 402 \\
Iceland & 3 & 22 & 38 & 56 & 73 & 90 & 108 \\
Total & 65 & 410 & 714 & 1,039 & 1,364 & 1,689 & 2,014 \\
\hline
\end{tabular}

Over time, the demand for sustainable jet fuel in the Nordic countries will gradually increase. It should be noted, that unlike the demand of conventional jet fuel, the demand for sustainable fuels will neither stagnate after 2025 nor reach a steady state in 2030. This is because these effects reflect the other three pillars of the aviation industry's strategy to reduce GHG emissions, such as increased fuel efficiency and optimized infrastructure. Thus, the demand for sustainable jet fuels should contin- 
ue to increase, until it reaches the target of a $37.5 \%$ blend-in, corresponding to an estimated total demand of 2 billion 1 in 2050 in the Nordic countries.

\subsection{Future feedstock demand for sustainable jet fuel}

To satisfy the Nordic demand for sustainable jet fuel projected in the section above, the amount of feedstock required per year can be calculated. This is reported in the unit of PJ which allows for comparing amounts of different feedstock despite varying water content. The amount depends on how effectively the energy content in the feedstock can be converted into jet fuel. For this calculation, three conversion efficiencies are assumed, a low efficiency of $5 \%$, a medium of $15 \%$ and a high of $25 \%$ (section 8.3 has more info on this topic). First the feedstock amount required is calculated in terms of energy content. Assuming an average energy content of $15 \mathrm{GJ} / \mathrm{t}$, the feedstock demand can then be calculated in tonnes:

Table 6: Feedstock demand for sustainable jet fuel from 2020-2050

\begin{tabular}{lrrrrrrr} 
& $\mathbf{2 0 2 0}$ & $\mathbf{2 0 2 5}$ & $\mathbf{2 0 3 0}$ & $\mathbf{2 0 3 5}$ & $\mathbf{2 0 4 0}$ & $\mathbf{2 0 4 5}$ & $\mathbf{2 0 5 0}$ \\
& & & & & & & \\
Feedstock demand [P] & & & & & & \\
Low efficiency: 5\% & 45 & 285 & 497 & 723 & 949 & 1,175 & 1,401 \\
Medium efficiency: 15\% & 15 & 95 & 166 & 241 & 316 & 392 & 467 \\
High efficiency: 25\% & 9 & 57 & 99 & 145 & 190 & 235 & 280 \\
Feedstock Demand [‘000 Tons] & & & & & & & \\
Low efficiency: 5\% & 3,015 & 19,015 & 33,152 & 48,220 & 63,289 & 78,358 & 93,427 \\
Medium efficiency: 15\% & 1,005 & 6,338 & 11,051 & 16,073 & 21,096 & 26,119 & 31,142 \\
High efficiency: 25\% & 603 & 3,803 & 6,630 & 9,644 & 12,658 & 15,672 & 18,685 \\
\hline
\end{tabular}

From the table above it is seen that higher conversion efficiency results in the lower demand. The total amount also depends on the energy content of the feedstock. Feedstock like dried wood residuals will have values around $20 \mathrm{GJ} /$ ton, while feedstock like waste will have lower values around $10 \mathrm{GJ} /$ ton. The total amount required in tons will thus be lower, if using a feedstock of high energy content. 


\subsection{Price sensitivity}

The following section discusses the effects of higher fuel prices, when shifting the aviation industry away from conventional jet fuels towards increasing blend-in requirements, as outlined above.

Assuming that higher fuel prices will be passed on to the consumer, in the guise of higher ticket prices, the theory of price cross-price sensitivity posits that the higher cost of sustainable jet fuels should inter alia decrease the demand for the services of the aviation industry, as consumers shift their travel towards alternate modes of transport, such as trains or ships.

IATA (2008) developed an econometric model, which used data input from the US Department of Transport, IATA's Passenger Intelligence Service and the UK International Passenger Survey to estimate general demand elasticities for air travel on various level of aggregation. The levels of aggregation used in the model include the Route level, the National level and the Supra-national level. The route level measures cross price elasticity between different airlines flying the same routes. The National level denotes the price elasticity of demand when travel from country to country, rather than by specific city-city routes. Finally, the Supra-national level quantifies the price elasticity of demand for intra-regional travel, for instance travel from the USA to the EU. IATA's results support the following price sensitivities on the different level of aggregation:

- The Route level: -1.4

- The National level: -0.8

- The Supranational level: -0.6

The results reveals a rather high cross price elasticity of demand on the Route level, meaning that a $1 \%$ price increase on any given route serviced by Airline A, would lead to a more than proportionate shift in demand towards Airline B, servicing the same route. However, at the National- and Supranational level, the price elasticity of demand is inelastic, meaning that an increase in the price of jet fuel would cause a less than proportionate response from consumers.

In addition to the results above, it should be noted that the price of jet fuel only makes up around $30 \%$ the price of airline services. Thus, a $1 \%$ change in the price of jet fuel would probably trigger a lesser effect on demand than that suggested in the above. For instance, NIRAS (2014) found that a blend-in ratio of sustainable jet fuel of $2.5 \%$, corresponding to a $2 \%$ increase relative to the price of jet fuel, would only increase the 
price of an airline ticket by $0.6 \%$. Likewise, a blend-in ratio of $20 \%$, causing a price increase of $16 \%$ for fuel, would only increase ticket prices by $4.8 \%{ }^{39}$ Thus, low quota obligations of sustainable jet fuels are expected to have a negligible effect on the demand for air travel services and thus for the quantity of jet fuel demanded in the future.

39 These calculations are based on the assumption that fuel makes up $30 \%$ of airlines' operating costs, as reported by IATA (2013), and an average price of sustainable biojet fuel of 47 eurocent/liter. 



\section{Feedstock accessibility in the Nordic Region}

This chapter summarizes the feedstocks suitable for a sustainable jet fuel production and discusses the availability and price. For a sustainable jet fuel production to be feasible, it must rely on a cheap feedstock available in sufficient quantity. The potential feedstocks for sustainable jet fuel are also potential feedstock for other renewable fuels, such as biodiesel or -ethanol. Thus, there is no feedstock base exclusive to jet fuel production, but rather a base shared with processes for producing sustainable fuels for road transport. Therefore, it is important to be aware of which other sectors currently utilize the feedstock and hence are in direct competition of demand. Furthermore, feedstock logistics influence the price of the final jet fuel price and is hence relevant to consider. The Nordic countries have a number of potential domestic feedstock, though imported feedstock are also discussed in this chapter. Finally, feedstock sustainability according to the criteria described in chapter 3 is essential to consider when planning a supply chain for sustainable jet fuel.

\subsection{Types of feedstock}

Feedstocks can roughly be divided into four categories, based on their composition: Lipids, sugars/starch, lignocellulosic and organic waste.

- Lipid feedstocks are oil-rich and include palm oil, rapeseed oil, jatropha, camelina, tall oil, micro algae and waste oils, both vegetable and animal (also commonly referred to as used cooking oil).

- Sugar/starch feedstocks contain mainly glucose, and can be fermented and converted into alcohols which can be chemically processed further into jet fuel. Alternately, the sugars can be converted by microorganisms to lipids. Sugar/starch feedstocks include sugarcane, wheat, maize, sugar beet and macro algae (seaweed). 
- Lignocellulosic feedstocks are rich in cellulose (glucose polymers), hemicellulose (polymers consisting of different sugar monomers with both five and six carbon atoms), and also contain a significant amount of lignin. Lignin increases the rigidness of the feedstock and complicates the conversion to biofuels. Examples of lignocellulosic feedstocks are wood, straw and energy crops

- Organic waste, such as municipal solid waste, manure or other waste fractions is composed of a wide range of compounds, including lipids, sugars and lignocellulosic and can be converted to jet fuel by a variety of processes, such as gasification.

The following section includes a presentation of different feedstocks relevant to a Nordic production of sustainable jet fuel including a brief introduction to their main composition, environmental aspects of production, special considerations in terms of logistics and other issues relevant to a Nordic supply chain. This is following by country specific information such as national production and import of the different feedstocks as well as country specific considerations.

\subsubsection{Energy Crops}

Cultivation of energy crops is generally considered a means to substitute fuels and energy derived from fossil sources with more sustainable alternatives. Theoretically, a variety of techniques exist for energy crops to enter into a production of sustainable jet fuel, so the question becomes what makes energy crops a more viable feedstock than other sources of input, such as household waste or agricultural residues. From a Nordic perspective, it is especially the yield potential in combination with the environmental performance that is of interest when assessing energy crops as a potential feedstock for producing sustainable jet fuel.

Generally, lignocellulosic energy crops such as willow, poplar or miscanthus are often considered to cause lower environmental impacts while yielding more biomass per hectare than a conventional cropping system. Less depletion of the soil carbon stock, reduced nitrate leaching, lower $\mathrm{N}_{2} \mathrm{O}$ emissions and reduced application of fertilizer are some of the factors reported in the scientific literature (Parajuli et al., 2015a; Eriksen et al. 2014). When grown on land otherwise left fallow or unsuited for cultivation of traditional food crops such as cereal, energy crops do not compete with food production. Moreover, scientific literature suggests that cultivating certain energy crops, such as miscanthus may even cause net savings in GHG emissions due to the buildup of soil 
carbon (Parajuli et al. 2015c). However, if energy crops displace agricultural production effects of iLUC may occur reducing the sustainability, though these effects are difficult to quantify and compare individually across feedstock.

\subsubsection{Marine feedstocks}

Marine feedstocks, such as different types of micro and macro algae (seaweed), benefit from not occupying land area usable for cultivating other crops. Microalgae have potential, but require a large area and vast amounts of sunlight to grow, making them difficult to grow in the Nordic region. Naturally occurring macro algae typically grow in protected areas. However, they can be grown on lines much like mussels, and are capable of increasing its own weight by $100 \%$ annually.

There are various environmental impacts associated with the cultivation and harvest of marine seaweed. (Skjermo et al., 2014):

- Seaweed uses nutritients from surface waters and thus can alter the nutrient access for planktons and other surface organisms. Large scale seaweed farming is likely to reduce marine productivity. The European environmental legislation (The Water Framework Directive) covers this and is implemented in Norway.

- Both farmed and wild seaweeds produce organic wastes which will spread downwards influencing the seafloor ecosystem. This influence is two-fold, as the waste serve as nutrient but at the same time too much waste can contribute to the oxygen depletion in seafloor sediments. When seaweed is harvested, less organic waste will be produced. More research is needed to quantify these effects and understand the local significance. The extent and the nature of the organic waste's influence on seafloor ecosystems depend on other conditions (depth, hydrodynamics, biological state, etc.) as well.

- Seaweed forests serve as habitat for many sea organisms that will be affected upon harvesting.

\subsubsection{Straw}

Straw is traditionally considered a byproduct from cereal production. Thus, crop fertilization and pesticide use remain unchanged when solely using straw otherwise left for decomposition. As long as straw utilized for the production of biofuel remains a byproduct of conventional farming practice, no negative effects from LUC/ILUC or increased threats to 
biodiversity should be expected. Moreover, assuming no changes in the type of seeds used and standard harvesting methods, grain production in itself will be unaffected.

It is well known that removing additional biomass from cereal fields can negatively impact the soil carbon stock which is why additional straw should not be harvested from areas with a high Dexter-index 40 (Jørgensen et al. 2013). Thus, depending on the location of a potential biofuel plant, the amount of regionally available straw can vary depending on the Dexter-index of the surrounding areas. It should be noticed that carbon can be returned to fields after energy and fuel production. This is the case for e.g. the digestate from biogas production.

\subsubsection{Wood biomass}

Wood biomass is common within all Scandinavian countries, and is well suited for use as a feedstock in the production of biofuels. However, wood biomass is an essential commodity and is being utilized to great extend in particular in the timber, pulp and paper industries. Apart from the parts essential to the primary productions most of the byproducts are utilized in some way, for example as an internal power source within production plants or for production of biofuels such as renewable diesel. Therefore, use for sustainable jet fuel production is in competition with many existing utilizations.

The process of logging leaves a wide range of wastes and residues including stems from tops, branches, roots and foliage from trees. These residues play a part in the ecological cycles of the forests, which should be considered if they are to be used for fuel production. Furthermore, some logging residues are difficult to collect, increasing the price of collection.

Residues from wood processing industries, i.e. timber-, pulp and paper, leave behind residuals such as wood chips, sawdust and bark, but also other products like tall oil and black liquor. All these residuals, both from logging and the industries, are well suited for production of sustainable jet fuel, though competing utilizations limits the total potential.

40 The Dexter-index is the ratio between clay and organic carbon in soil. A high Dexter-Index indicates a low organic carbon concentration. 


\subsubsection{Organic waste fractions}

In this study the term organic waste fractions cover a broad range of products including:

- Organic household waste.

- Organic industrial waste (e.g. from fishery, slaughter houses, super markets and restaurants).

- Biomass from land management and parks.

- Scrap tires.

- Industrial rubber and plastic waste.

- Municipal solid waste (MSW).

These feedstocks can have both sugar/starch, lignocellulosic and lipid compositions and can be processed to biofuels by many different conversion pathways. In the Nordic countries, the organic waste fractions listed here are currently either incinerated, anaerobically digested to biogas, landfilled or recycled. The fractions are also suited for the production of biofuels.

Some of the fractions have the possibility of recycling into new products hence reducing fossil fuel consumption, which from an environmental point of view can be more favorable. However, as an alternative to incineration, liquid fuel production offers a utilization of higher value with the possibility to store and transport the energy produced. Furthermore, there are no LUC and ILUC effects from these fractions as they do not require cultivated land for their production.

\subsubsection{Other inputs: Energy and hydrogen}

In addition to the feedstock component of jet fuel production, other inputs are required in all conversion pathways, in particular energy and hydrogen, the origin of which is highly important for the sustainability of the production. Hydrogen is traditionally produced from steam reforming of fossil methane or alternatively from biomass gasification. Another source is electrolysis of water, which is an energy intensive process and reduces the sustainability if based on a fossil dominated electricity source. Using surplus electricity from renewable peak production, e.g. from solar or wind can negate this disadvantage but is also associated with a number of challenges. First, the capital investment of the electrolysis units increases as if the full capacity is only utilized during peak production. Second, technical problems arise when operating the elec- 
trolysis units sporadically, including efficiency and safety issues. However, the technology is still relatively young and it is quite possible that these challenges might be overcome as the technologies mature (UK SHEC, 2012).

Nuclear electricity production in Sweden and Finland provides an additional potential for the production of hydrogen. Both in the utilization of off-peak production and the use of excess heat. Excess heat enables the use of hydrogen production technologies with high temperature demands, and can also be used to optimize electrolysis processes (UK SHEC, 2012). Finally, Iceland has a unique renewable energy supply compared to the other Nordic countries, available at very low cost and high quantities, which could allow for a cheap sustainable production of hydrogen.

If the required supply of sustainably produced hydrogen is unavailable in the short term at least, it may be advantageous to locate biofuel production near existing fossil refinery infrastructure, where surplus hydrogen can be accessed (though of fossil origin), which also provide possibilities for synergy effects of production and mitigation of capital investment costs.

Table 7: Summary of feedstock accessibility

\begin{tabular}{|c|c|c|c|c|}
\hline & Denmark & Finland & Norway & Sweden \\
\hline $\begin{array}{l}\text { Energy } \\
\text { crops }\end{array}$ & $\begin{array}{l}\text { Low potential (short } \\
\text { term) } \\
\text { Limited cultivation of } \\
\text { willow and poplar, } \\
\text { corresponding to less } \\
\text { than } 1 \mathrm{PJ} / \mathrm{yr}\end{array}$ & $\begin{array}{l}\text { Not available in } \\
\text { significant amounts }\end{array}$ & $\begin{array}{l}\text { Not available in } \\
\text { significant amounts }\end{array}$ & $\begin{array}{l}\text { Low potential (short } \\
\text { term) } \\
\text { Cultivation of around } \\
11,000 \text { ha of willow, } \\
\text { corresponding to } 1.5 \\
\mathrm{PJ} / \mathrm{yr}\end{array}$ \\
\hline Straw & $\begin{array}{l}\text { Promising potential } \\
\text { Up to } 1.5 \text { million } \\
\text { tons, corresponding } \\
\text { to } 22 \mathrm{PJ} \text { may be } \\
\text { available } \\
\text { Competition with } \\
\text { heat and power } \\
\text { production. }\end{array}$ & $\begin{array}{l}\text { Not available in } \\
\text { significant amounts }\end{array}$ & $\begin{array}{l}\text { Not available in } \\
\text { significant amounts }\end{array}$ & $\begin{array}{l}\text { Some potential } \\
\text { Around } 1 \text { million tons } \\
(15 \mathrm{PJ}) \text { may be avail- } \\
\text { able, though in com- } \\
\text { petition with other } \\
\text { uses. }\end{array}$ \\
\hline $\begin{array}{l}\text { Wood } \\
\text { residuals }\end{array}$ & $\begin{array}{l}\text { Not available in } \\
\text { significant amounts }\end{array}$ & $\begin{array}{l}\text { Promising potential } \\
8 \text { million } \mathrm{m}^{3} \text { of log- } \\
\text { ging residues was } \\
\text { used in } 2014 \text { for } \\
\text { energy production. } \\
\text { A part of this fraction } \\
\text { could be diverted } \\
\text { towards biofuel } \\
\text { production, along } \\
\text { with other logging } \\
\text { residues which are } \\
\text { not currently har- } \\
\text { vested from forests. }\end{array}$ & $\begin{array}{l}\text { Promising potential } \\
\text { Around } 69 \text { PJ of } \\
\text { logging residues is } \\
\text { technically available. } \\
\text { Large amounts of } \\
\text { secondary wood } \\
\text { residuals could be } \\
\text { diverted towards } \\
\text { biofuel production }\end{array}$ & $\begin{array}{l}\text { Promising potential } \\
\text { Between } 54-130 \text { PJ of } \\
\text { logging residues are } \\
\text { technically available. } \\
\text { Over } 86.4 \text { PJ of sec- } \\
\text { ondary wood residu- } \\
\text { als was used in ener- } \\
\text { gy production, some } \\
\text { of which could be } \\
\text { diverted towards } \\
\text { biofuel production. }\end{array}$ \\
\hline
\end{tabular}




\begin{tabular}{|c|c|c|c|c|}
\hline & Denmark & Finland & Norway & Sweden \\
\hline $\begin{array}{l}\text { Tall oil and } \\
\text { black liqour }\end{array}$ & $\begin{array}{l}\text { Not available in } \\
\text { significant amounts }\end{array}$ & $\begin{array}{l}\text { Some potential } \\
\text { Most tall oil is used } \\
\text { for chemicals and } \\
\text { renewable diesel } \\
\text { production, but use } \\
\text { may be diverted to } \\
\text { jet fuel production. } \\
\text { Most black liquor is } \\
\text { used for heat and } \\
\text { energy production } \\
\text { but use may be di- } \\
\text { verted to jet fuel } \\
\text { production }\end{array}$ & $\begin{array}{l}\text { Not available in } \\
\text { significant amounts }\end{array}$ & $\begin{array}{l}\text { Some potential } \\
\text { Most tall oil is used } \\
\text { for chemicals and } \\
\text { renewable diesel } \\
\text { production, but use } \\
\text { may be diverted to } \\
\text { jet fuel production. } \\
\text { Most black liquor is } \\
\text { used for heat and } \\
\text { energy production } \\
\text { but use may be di- } \\
\text { verted to jet fuel } \\
\text { production }\end{array}$ \\
\hline $\begin{array}{l}\text { Waste } \\
\text { fractions } \\
\text { Waste }\end{array}$ & $\begin{array}{l}\text { Low potential (short } \\
\text { term) } \\
\text { Total production of } \\
11 \text { million tons in of } \\
\text { waste in } 2014 \text {, with } \\
93 \% \text { either incinerat- } \\
\text { ed or recycled. } \\
\text { Improved sorting } \\
\text { technology may free } \\
\text { up a part of the } \\
\text { organic fraction for } \\
\text { jet fuel production. }\end{array}$ & $\begin{array}{l}\text { Some potential } \\
\text { Total production of } \\
\text { around } 9.5 \text { million } \\
\text { tons waste in } 2013 . \\
\text { No large-scale incin- } \\
\text { eration of waste. } \\
\text { Some organic frac- } \\
\text { tions are already } \\
\text { utilized for biofuel } \\
\text { production } \\
\text { Long transportation } \\
\text { distances limits the } \\
\text { total potential }\end{array}$ & $\begin{array}{l}\text { Low potential } \\
\text { Large use of waste in } \\
\text { inceration, including } \\
\text { import from Norway } \\
\text { Long transportation } \\
\text { distances limits the } \\
\text { potential }\end{array}$ & $\begin{array}{l}\text { Low potential } \\
\text { Total production of } \\
\text { 11.2 million tons in } \\
\text { 2013. Large export of } \\
\text { MSW to Sweden. } \\
\text { Long transportation } \\
\text { distances limits the } \\
\text { total potential }\end{array}$ \\
\hline $\begin{array}{l}\text { Marine } \\
\text { feedstock }\end{array}$ & $\begin{array}{l}\text { Not available in } \\
\text { significant amounts }\end{array}$ & $\begin{array}{l}\text { Not available in } \\
\text { significant amounts }\end{array}$ & $\begin{array}{l}\text { Low potential (short } \\
\text { term) } \\
\text { Some sea-weed } \\
\text { harvest today, } \\
\text { though not for biofu- } \\
\text { el production. } \\
\text { Large scale cultiva- } \\
\text { tion increases the } \\
\text { potential in the long- } \\
\text { er term }\end{array}$ & $\begin{array}{l}\text { Not available in the } \\
\text { short term }\end{array}$ \\
\hline
\end{tabular}




\subsection{Denmark - Feedstock availability}

In Denmark the most important feedstocks in a production of sustainable fuels for aviation are:

- Straw.

- Energy crops.

- Organic renewable and fossil waste fractions.

A 2012 study from Gylling et al. estimates the potential for increasing the Danish biomass for energy production. This is through efforts such as increasing straw collection and changing crop types. The potential is calculated for three different scenarios: A business-as-usual, a biomass optimized and an environment optimized scenario. From the biomass optimized scenario it is estimated that the feedstock production for energy purposes can be increased by 9.5 million $t$ (dry weight). In the environment optimized scenario the annual biomass production is potentially increased by 7.9 million $t$ (dry weight) compared to 2009. In addition to the increase in biomass production, leaching of nitrate to surface waters is predicted to decrease by $23,000 \mathrm{t} \mathrm{N}$, corresponding to around $14 \%$ of the total amount leached in 2007 , by, among others, increasing the amount of perennial crops and forestry.

In addition to biomass yield, logistics can be optimized by changing the type of trucks collecting the biomass or how the biomass is packed. As a result transportation costs can be significantly reduced. For instance straw has a high volume relative to its mass, which limits the distances it is economically feasible to transport it. This can be overcome by pressing the straw differently into bales or pellets.

The figure below illustrates a rough mass balance of biomass in Denmark (in 1,000 t/year) which includes the environment optimized scenario from Gylling et al. (2012). From the mass balance it is evident that the majority of biomass produced and imported is fodder for the meat production industry. Thus, mass wise the export is rather limited as meat production has a relatively poor conversion of energy in the feedstock. 
Figure 2: Biomass balance of Denmark

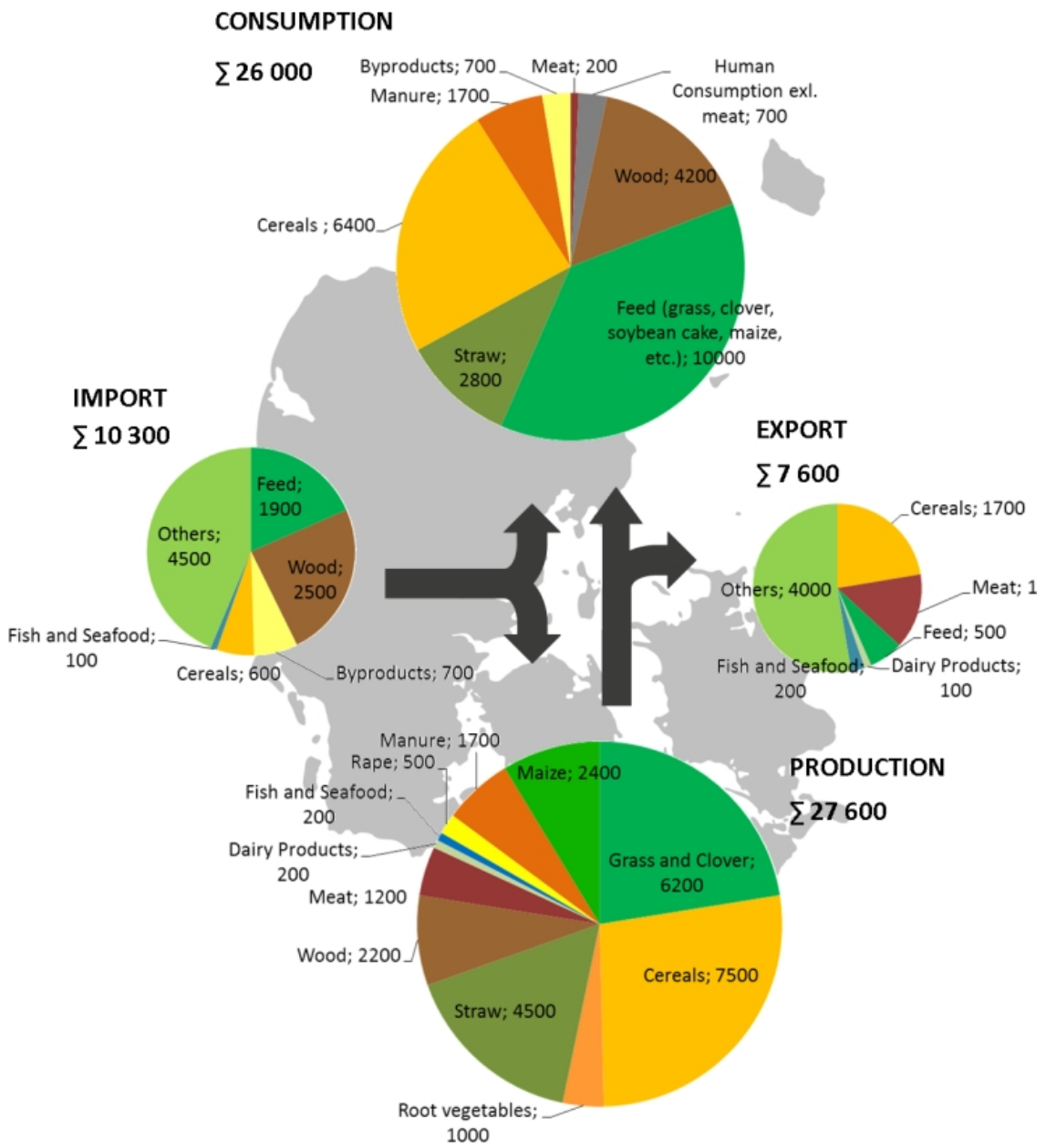

Note: Based on data from 2011 [1,000 t dry weight unless otherwise stated]. The areas of the circle diagrams represent the ratios between the total mass imported, exported, produced and consumed (NIRAS, 2014).

In June 2015 a EUR 13.4 million research project was initiated involving researchers from Aarhus University. The goal of the project is to increase the efficiency of Danish agriculture while maintaining an environmentally friendly production method. This is done through the introduction of decision support systems utilizing data on local geography, meteorological data, etc. This will allow the farmer to plant and fertilize more efficiently according to actual local conditions, increasing yields and mitigating effects on the environment (AU, 2015). 


\subsubsection{Energy Crops}

In Denmark, willow was grown on 5,800 ha, poplar on 3,250 ha and miscanthus on 68 ha in 2014 (NaturErhvervsstyrelsen, 2014). These crops are currently mainly grown for incineration in combined heat and power (CHP) plants across the country. As the numbers indicate, only willow and perhaps poplar are grown on a large enough scale to actually obtain reliable yield estimates. The limited experience with growing energy crops on a larger scale in Denmark makes it difficult to predict their future potential as a biomass source for sustainable fuel production.

The yield per hectare will likely be the key factor determining whether energy crops grown in Denmark can be utilized for sustainable jet fuel production. Crops that apply C4-photosynthesis convert solar radiation more effectively than C3-crops, implying a higher yieldpotential (Beale and Long, 1995). Currently, maize (corn) is the only C4crop grown on a larger scale in Denmark with miscanthus, another C4plant, only being grown on about $70 \mathrm{ha}$. Since virtually all arable land in Denmark is cultivated already, the potential of energy crops to serve as biofuel feedstock in Denmark depends on the economic viability of growing these crops.

The Danish BioM-project involved large-scale trials of cultivating willow from 2009-2012 (BioM, 2015a). The observed yields were often lower than anticipated (4-7 tDM/ha/y), with weed-control and correct application of fertilizer being two major factors influencing the total biomass yield. Under improved growing conditions, yields of up to $14 \mathrm{tDM}$ per hectare per year are expected. The BioM-trials revealed that keeping harvesting costs to a minimum greatly influenced the profitability of growing willow for energy purposes in Denmark (BioM, 2015b).

Experience with growing miscanthus in England shows that the correct harvesting technique can improve yields, and that the choice of harvest in the spring had no effect on overall yields during the harvest window from March to the end of April (Meehan et al., 2013). This is of importance for potential widespread cultivation of miscanthus in Denmark since weather conditions during the spring can vary greatly. A flexible harvest window maximizes the chances of harvesting the crop under favorable weather conditions, avoiding soil compaction. 


\subsubsection{Straw}

The amount of straw harvested in Denmark has been fairly constant over the past years, ranging between 5 and 6 million tons from 2006 to 2014. Currently, the harvested straw is primarily used for heat production as well as animal feed and bedding.

An average of $40 \%$ of biomass has been left behind on the fields as agricultural residue in the period 2006-2014. In 2014, the amount of biomass left as residue was 3.2 million $t$, which should be considered an upper (theoretical) estimate of the amount available for fuel production. Gylling (2015) assessed that up to 1.5 million additional t of straw can be utilized under current market conditions. Most of the straw available in Denmark can be attributed to growing winter wheat (about $50 \%$ of the straw available) and spring barley (25\%). Generally, the amount of straw available for future biofuel production will depend on which crops are grown, as each crop has its own ratio of straw and cereal/grain.

The Danish market for straw is currently characterized by a supply of domestically produced (harvested) straw delivered to central and decentral CHP ${ }^{41}$-plants for incineration. For 2015, the Danish Energy Agency predicts an average price of EUR 5.70/GJ straw delivered to a decentralized CHP-plant (ENS, 2014). It should, however, be noted that the current supply of straw is limited by the amount each CHP-plant is willing to take in for use of co-firing, i.e. with wood chips. Thus, if jet fuel production facilities can generate enough value per ton of straw to open up for a new market, then this may drive up prices. A steady supply of straw at foreseeable prices could be ensured through long-term contracts between fuel production facilities and biomass suppliers.

\subsubsection{Organic waste fractions}

In 2013, Denmark produced around 11 million t of waste. Out of this $66 \%$ was collected for recycling, $27 \%$ was incinerated, and the rest was either landfilled, moved to temporary storage or required special treatment. Recycling does not specify treatment and part of the recycled waste end up incinerated or in landfills (Miljøstyrelsen, 2015).

Waste fractions typically used as feedstocks in biofuel production such as: 404,000 t biodegradable waste, 253,000 $\mathrm{t}$ wood, 19,000 $\mathrm{t}$ wooden packaging, and $817,000 \mathrm{t}$ garden waste. Furthermore, 23,000 t of

${ }^{41}$ Combined Heat and Power. 
used tires, though fossil based and nonrenewable, may be utilized for fuel production through processes such as pyrolysis.

Paper and cardboard, two separate fractions both at 328,000 t, are possible feedstocks for biofuels but are currently recycled for new paper production. The use of paper and paperboard may therefore benefit from further research into their best utilization. The plastic fractions, $44,000 \mathrm{t}$ of plastic and 30,000 $\mathrm{t}$ of plastic packaging, also have potential for use in biofuel production. However, plastic has a potential for material recycling which is usually preferred over recovery of energy for fuel production. While thermoform plastics separated in very clean fractions are well suited for material recycling, the quality decreases rapidly when fractions are mixed. This makes recycling of waste plastics difficult. The composition of the plastic fractions is unknown but it can be assumed that it is mostly mixed, which makes recycling highly inefficient and energy recovery through fuel production more feasible.

The two largest waste fractions usable in biofuel fuel production are domestic general waste at 1,440,000 $\mathrm{t}$ and waste for incineration at $1,409,000 \mathrm{t}$. Both of these are highly mixed and include the aforementioned fractions. In addition to recycling, the Danish reliance on waste incineration may inhibit the use of waste as feedstock in the short term. Waste to energy is an important element in the Danish energy system and the fractions usable in fuel production provide crucial feedstocks for district heating. Further sorting of the incinerated waste may impact the energy system, and may lead to increased import of waste and biomass to fill plant capacity, negating the benefits from utilizing waste.

\subsection{Finland - Feedstock availability}

In Finland the feedstocks with the most potential in a production of sustainable fuels for aviation are:

- Wood-based feedstock.

- Waste and residues. 
Several Finnish industry activities are already based on bio-based feedstock including wood products, pulp and paper, chemicals, heat and power as well as transport fuels. Wood and wood-based residuals from Finland's large-scale pulp and paper industry, including black liquor derived from pulp-making processes, account for $97.5 \%$ of the bioenergy produced in Finland. Solid recovered fuels, biogas, and energy crops like reed canary grass and organic liquid fuels make up the remaining $2.5 \%$.

\subsubsection{Wood biomass}

Finland possesses a significant amount of renewable resources, especially forestry resources, and bioeconomy is one of the key sectors on which the Finnish government aims to base the future economy (MEE, 2014).

The state owns $26 \%$ of forests, private individuals and families $60 \%$, industries $10 \%$ and municipalities and parishes 9\% (Finnish Forest association 2016). The majority, around $80 \%$, of wood used by the forestry industries is harvested from private-owned forests, of which there is around 347,000 private holdings of at least two ha (Ibid).

The largest users of wood energy are the forest industry companies, who produce large quantities of energy from residual wood such as bark, sawdust and woodchips, as well as the wood-based by-products of pulp and paper making processes, including black liquor.

In 2014, 57 million $\mathrm{m}^{3}$ of domestic roundwood and 10 million $\mathrm{m}^{3}$ of imported wood were used and processed in Finland. In addition, about 8 million $\mathrm{m}^{3}$ logging residues were used for energy production. Figure 3 illustrates the multiple uses of the wood along with the side streams it produces. Logging residues, bark, and sawdust are often seen as the sources of feedstock with the most potential for bioenergy and biofuel production. 
Figure 3: Use of forestry biomass and side streams in Finland in 2014

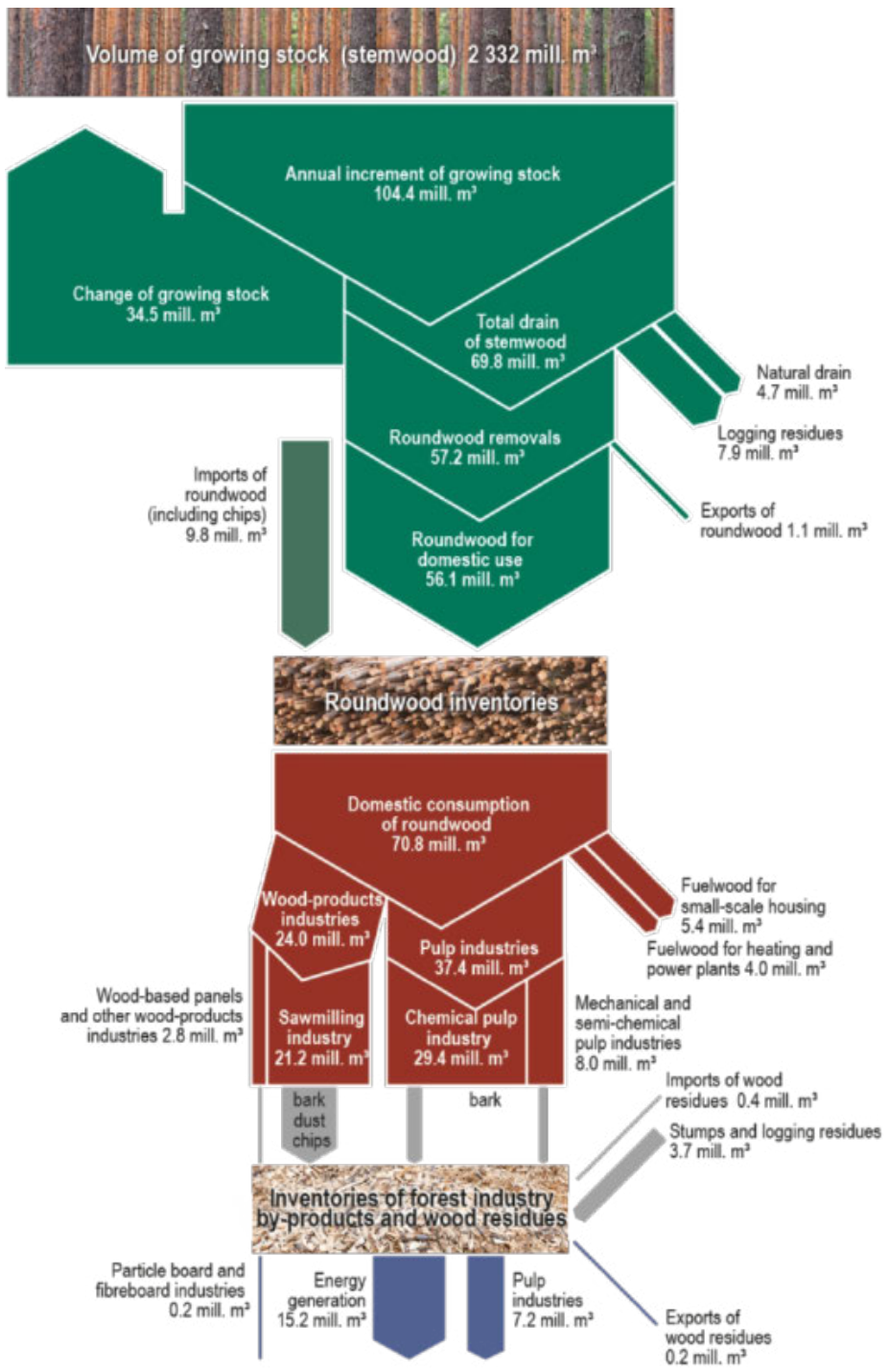

Finnish Statistical Yearbook of Forestry 2014

Source: Natural Resources Institute Finland, 2014. 
In 2014, heating and power plants consumed a total of 18.7 million $\mathrm{m}^{3}$ (129.2 PJ) of solid wood fuel (Natural Resources Institute Finland, 2015). The most important solid wood fuel used in CHP plants was forest chips. Almost half, 3.7 million $\mathrm{m}^{3}$, of the forest chips consumed by the heat and power plants were manufactured from small-sized trees (pruned and unpruned stems). The second most common source was logging residues ( 2.6 million $\mathrm{m}^{3}$ ). The use of stumps as raw material for forest chips decreased from the previous year by nearly a third to 0.8 million $\mathrm{M}^{3}$. This means that there are already many competitive uses for forest biomass in Finland, and many heat and power plants are regulating their use of forest biomass based on the price and availability.

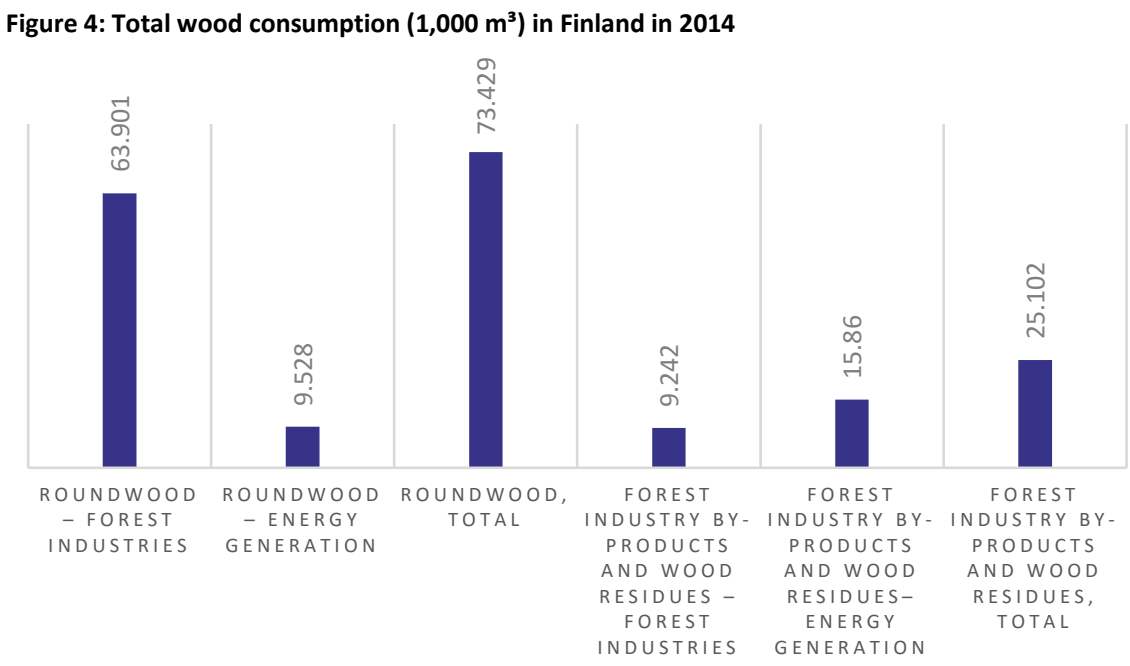

Source: Natural Resources Institute, 2015.

In October 2015 the market price of wood chips (forest residues, saw dust and bark) was EUR 18.21/MWh. Existing subsidies have an impact on the price and attractiveness of utilizing the wood biomass in different uses. For example, the use of forestry biomass for heating has increased rapidly with the financial support provided by the government for biobased energy production (feed-in tariff).

\subsubsection{Organic waste fractions}

According to Statistics Finland, around 1 million $\mathrm{t}$ of animal and vegetal wastes, 2.9 million $t$ of mixed ordinary wastes and 0.7 million $t$ of sludge were generated in Finland in 2013. 
Figure 5: Wastes produced in Finland in 2013

Different types of wastes produced in 2013, in ton

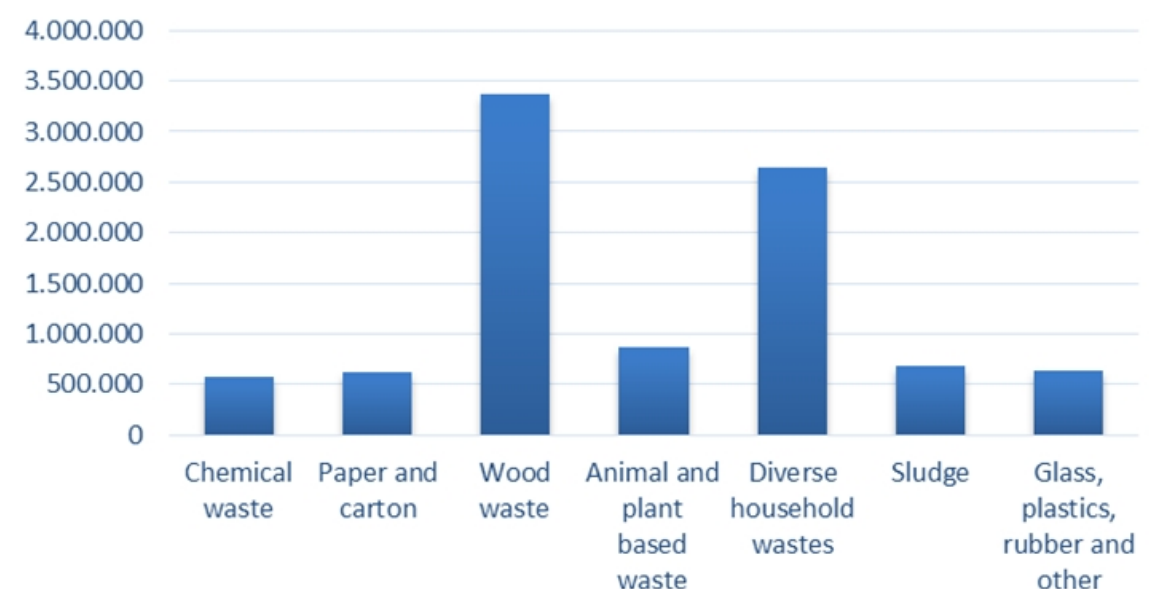

Source: Statistics Finland.

In contrast to many other countries, waste in Finland is not used for heat and power production at a large scale. However, there are several alternative uses for the feedstock streams, including biogas production and biofuels for road transport. A significant barrier for using waste fractions as feedstock is complex logistics and long transportation distances.

\subsection{Norway - feedstock availability}

In Norway the most important feedstocks in a production of sustainable jet fuel are:

- Wood-based feedstock.

- Organic waste fractions.

- Marine feedstock.

Currently around two thirds of Norway's bioenergy production (61.2 PJ) is based on forest resources such as firewood and wood chips, while the remaining third derives from byproducts from either the forest industry or from waste used in district heating plants (Lindegaard et al., 2014). At the same time, most of the bioenergy use in Norway is for stationary purposes, namely domestic and district heating. The Norwegian government has clearly stated their ambitions of establishing a bioeconomy 
where a wide range of high-value, carbon based products will most likely compete for the same biomass feedstock as that one currently used for energy purposes. In addition, there are around 120,000 forest-owners in Norway, which make individual decisions based on different terms, such as price, expected market development or other incomes to mention some. Thus, even though Norway has an abundance of renewable biomass, both land and marine based, a major bottleneck for the production of sustainable biofuels is the availability of sufficient quantities of sustainable raw materials.

A recent Norwegian study by Trømborg et al. (2012) that investigated and assessed the biomass availability for a profitable production of sustainable jet fuel in Norway states that forestry biomass (mainly pulpwood and forest residues such as tops and branches) has the largest potential for the production of biofuels, including biofuels for aviation in the coming decades. The estimated sustained yield of forest biomass for bioenergy and biofuels in Norway is 17 million $\mathrm{m}^{3}$. Logging close to the sustained yield with wood chip price of EUR 5.43-7.24/kJ, means a doubling of today's use. This represents a potential of 57.6 PJ, where $36 \mathrm{PJ}$ comes from logging residues.

\subsubsection{Marine resources}

The amount of wild seaweed is estimated to $80 \mathrm{Mt}$ which grows on an area of $8,000 \mathrm{~km}^{2}$ along the Norwegian coastline (Gundersen et al., 2011). Norway currently harvests around 150,000 to 190,000 t/yr wild seaweed though its use is clearly focused towards high value products (alginate, food and feed).

Cultivated seaweed is expected to be a major contributor to medium and long-term bioeconomy. It is estimated that at least $170 \mathrm{t}$ wet weight (26 t dry weight) can be cultivated per hectare (Broch et al., 2013), representing a large biomass yield with many applications. One driver in the Nordic region is Integrated Multitrophic Acquaculture (IMTA), in which seaweeds are used to alleviate the dissolved effluents from fish farms (Skjermo et al., 2014). This development is expected to increase the availability of seaweed and conversely lower the price. In Asia the seaweed farmers breed their species in order to achieve hybrid strains with high carbohydrate productivity. In Norway, however, deployment of only region specific natural strains is allowed. The high economic costs associated with the cultivation and harvest of this feedstock make its use for exclusive production of biofuels a challenge. Therefore, a much more attractive approach to using seaweed for biofuel production is through a 
holistic multiproduct biorefinery concept where biofuels are only one of several products.

\subsubsection{Wood biomass}

In Norway, a large fraction of logging residues are currently not in use and thus representing the largest biomass potential ( $\sim 36$ PJ) for energy applications in the short and medium term. In 2014, 8,160 $\mathrm{m}^{3}$ logging residue chips were sold (Norwegian Agricultural Agency). Trømborg et al. estimated the annual potential of logging residues to $49 \mathrm{PJ}$ (at 12 million $\mathrm{m}^{3}$ total logging) and $69.1 \mathrm{PJ}$ (at 17 million $\mathrm{m}^{3}$ total logging). However, it is not technically possible and economically viable to remove all the logging residues. Considering the technical and economic viability as well as environmental restrictions (nutrient balance) the real potential will be 50$60 \%$ of the theoretical potential. The biomass price for chipped logging residue delivered to terminal is estimated to be > EUR 4.92/GJ based on $35 \%$ moisture content (NVE, 2014). The price of chips from stumps and roots delivered to terminal is estimated to be > EUR 5.82-6.43/GJ based on 35\% moisture content (NVE, 2014). Stumps are unused resources in Norway and it is not considered technically viable to utilize stumps as a resource in the short and medium term.

Tellnes et al. (2011) mapped the main flows of wood resources into and out of the Norwegian sawmilling industry in 2010. According to their publication, the Norwegian sawmill industry used about 4.8 million $\mathrm{m}^{3}$ of roundwood including bark.

Around $12 \%$ of Norwegian forest areas are under public ownership, $80 \%$ private (of which the majority is owned by individuals), and $8 \%$ under other categories of ownership (Follo, et al. 2015).

\subsubsection{Organic waste fractions}

11.2 Mt waste was generated in the Norway in 2013 (Statistics Norway, 2015). $23 \%$ of this amount is generated in the manufacturing industry, $22 \%$ is household waste while construction and demolition industry stands for $20 \%$. Looking at the categories, the major waste material in 2013 was mixed waste, which had $22 \%$ of the total, followed by wood waste with $12 \%$ and hazardous waste with $11 \%$. The material and energy recovered are 35 and $40 \%$ respectively leaving only a small amount of waste going to landfills (Becidan et al., 2015). The Norwegian waste to energy (WtE) plants have a small average size $(60,000 \mathrm{t} / \mathrm{y})$ compared to other countries. They process 1.70 million t MSW while producing 14.4 PJ 
heat for mainly district heating as well as industrial steam and some electricity. Statistics Norway reported that in 2014 around 1.3 million t of household waste was incinerated which is a doubling compared to 2004.

Rambøll estimated the potential and costs for wastes from Norwegian industry (NVE, 2014). They emphasized that the costs are very uncertain due to bilateral agreements and exports to Sweden. They estimated the industrial waste potential to $2.2 \mathrm{PJ}$ and the cost without collection and transport to EUR $0.08-4.04 / \mathrm{kJ}$. Norwegian energy producers that use household waste as a feedstock face the same competition with Swedish plants using industrial wastes. The gate fee for household waste is EUR 2.72-6.64/kJ (NVE, 2014).

\subsection{Sweden - feedstock availability}

In Sweden the most important feedstocks in a production of sustainable jet fuel are:

- Energy crops.

- Straw.

- Wood-based feedstock.

- Organic waste fractions.

The biofuel market in Sweden is intrinsically linked to its forests, which cover over $60 \%$ of the Swedish landscape, and forestry biomass accounts for roughly $85 \%$ of the bioenergy produced, most of which is heat and power. Sweden has invested heavily in the development of $2 \mathrm{G}$ feedstock for biofuel production, from wood-biomass, such as in 2015, when the Swedish Energy Agency granted EUR 7.6 million to a pilot plant for the production of gasoline and diesel from lignin. In addition to woodbiomass, biofuels used in the ground transportation sector is also produced from grain and organic waste.

\subsubsection{Energy Crops}

Willow plantations amounts to around 11,000 ha, or roughly $0.4 \%$ of the total arable land and has been grown in Sweden since the 1990s, corresponding to about 1.5 PJ per year, which is used for local heating purposes. Despite the long-term Swedish experiences of growing willow and governmental and R\&D support in terms of financial incentives, the cultivation of Salix is still in its infancy. The yield is typically 5-7 dry t/ha pr. 
year even though new clones produced under the national breeding program could produce 10-20 dry t/ha pr. year. The current planted area of 1,000 ha is considerably below the expectations 20 years ago, when it was expected to contribute significantly as feedstock for energy production. The example in Sweden clearly indicates the difficulties in estimating future potentials for short-rotation crops given changes in agricultural policies, trade and viability of different crops for the farmer.

\subsubsection{Straw}

A large amount of the straw produced is used for feed and bedding in animal husbandry, and large volumes are left in the field to increase the amount of organic matter in the soil. A more extensive production of grain and oilseed generates more straw which could be used for energy purposes. Previous estimates on the potential of straw in Sweden amounts to $100 \mathrm{PJ}$ per year, without considering to technical issues. Taking into consideration technical, economic and ecological restrictions it is estimated that the actual potential from straw equals $15 \mathrm{PJ}$ per year which is around 3\% of the current biomass supply in Sweden. The estimated straw potential in Sweden is illustrated below.

Figure 8: Straw potential in Sweden

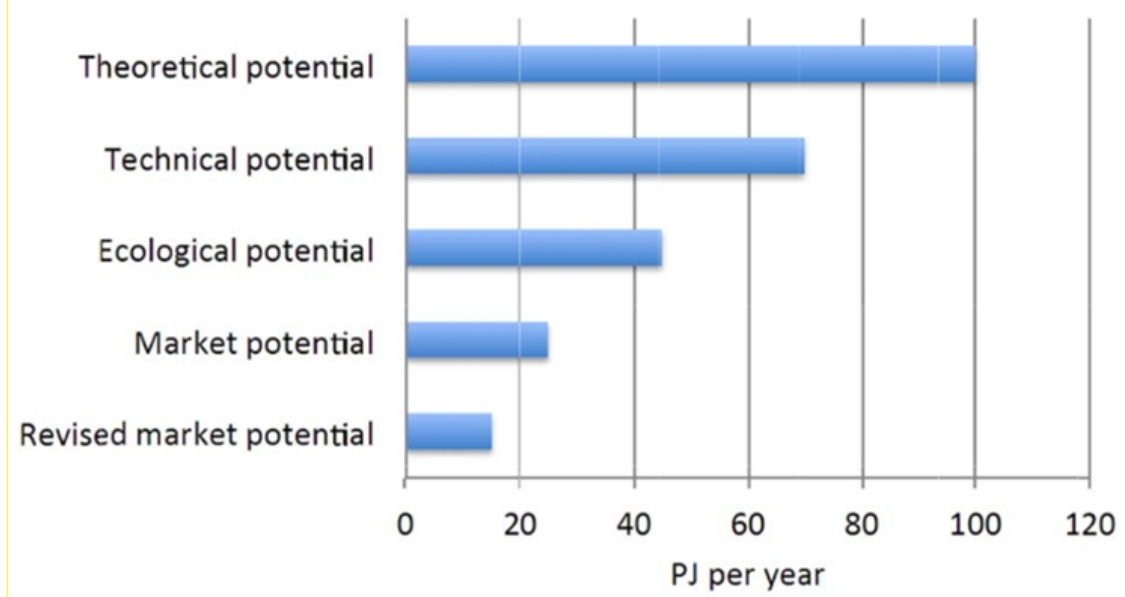

Source: IEA 2012. The table shows actual potential (15 PJ) in relation to the theoretical potential (100 PJ). 


\subsubsection{Wood biomass}

The annual volume of gross logging in 2013 was 86.3 million $\mathrm{m}^{3}$ standing volume (The Swedish Forest Agency), and the total annual growth was around 116 million $\mathrm{m}^{3}$ on productive forest land, resulting in a net growth of forest. Ownership in Sweden's forest is 50\% private owners (with over 200,000 individual owners), 25\% State owned companies and 25\% public owners. Around $10 \%$ of the forestland is protected for biodiversity purposes (mainly in Northern Sweden) (Fethers et al., 2014).

Every year about $27 \mathrm{PJ}$ of logging residues (equivalent around to 1.5 Mt dry substance) is in Sweden used mainly for heat and energy production. Estimating the total potential is a complex issue and the availability is dependent on location, transportation distance etc. One estimate made by the Swedish University of Agricultural Sciences and the Swedish forest agency estimated the ecological potential to be $306 \mathrm{PJ}$, with technical potential estimates ranging range between 54-129.6 PJ, or about 3.2-7.4 Mt (Staffas et al. 2013).

The consumption of wood fibre in the Swedish forest products industry amounted 81 million $\mathrm{m}^{3}$ solid volume (excluding bark). This wood fibre was used in the pulp and paper industry (46.4 million $\mathrm{m}^{3}$ ), in sawmills (33.6 million $\mathrm{m}^{3}$ ) and in the wood-panel industry (0.8 million $\mathrm{m}^{3}$ ). Of the wood fibre going to sawmills, 10.8 million $\mathrm{m}^{3}$ was generated as by-products for use in the pulp and wood-panel industries. (The Swedish forest agency, 2015). Almost all pulp and paper mill residues are utilized for plant energy and heat purposes.

The prices of wood residuals, both from logging and from the industries range from EUR 5.1-5.8/GJ (Swedish Energy Agency 2015).

Marked-based instruments and financial based incentive mechanisms affect the use of black liquor for internal use. The most significant of these are the EU emissions trading system (EU ETS). In 2003, an electricity certificate system was introduced that gives industries incentives to produce their own renewable electricity, making it difficult to secure wood-residuals, but also tall oil and black liquor at a low price for the production of sustainable jet.

\subsubsection{Renewable organic fractions}

Household waste is an important feedstock for heat and power plants and district heating in municipalities across the country. About 56.2 PJ was produced from waste in 2013. The amount of waste produced is not enough to satisfy demand for incineration which resulted in the import of $830,000 \mathrm{t}$ of waste for energy recovery purposes in 2013 , mainly from 
Norway. The amount of domestic household waste treated was 4.4 million $\mathrm{t}$ which is an increase of $1.1 \%$ compared to $2012.711,000 \mathrm{t}$ went to biological treatment. The amount of food waste collected in 2013 amounted to $370,000 \mathrm{t}$. The total volumes of treated household waste are illustrated below in the table.

Table 9: Utilization of waste in Sweden 2013

\begin{tabular}{lrr} 
Treatment & $\mathbf{1 , 0 0 0 ~ T}$ & KG/CAPITA \\
Material recycling & 1,467 & 152.1 \\
Biological treatment & 711 & 73.8 \\
Waste to energy & 2,236 & 231.8 \\
Landfill & 33 & 3.5 \\
Total & 4,449 & 461.2 \\
\hline
\end{tabular}

Anaerobic digestion is the most common method of treating food waste in Sweden. The biogas produced is used as vehicle fuel in municipalities' transportation fleets, but can also be used for generation of heat or electricity.

\subsection{Iceland}

Iceland does not possess the same amounts of biomass as the other Nordic countries due to the country's size and climate. They do however have access to cheap renewable energy due to their unique geography, which provides other opportunities for the production of biofuels. Thus, the feedstocks in focus in this section are renewable energy and biomass in general.

\subsubsection{Renewable energy}

The Icelandic electrical power generation is primarily based on hydroand geothermal power, with hydropower being the dominant energy source, providing $72 \%$ of the total installed capacity in 2013 and geothermal providing $24 \%$. While Iceland does have a potential for other renewable energy sources it remains largely unexploited, with wind providing less than $1 \%$ of the total energy production (Statistics Iceland, 2015).

The vast amounts of cheap renewable energy available in Iceland, makes looking at alternative pathways to producing aviation biofuel relevant. One such pathway is Emission-to-Liquid (ETL) fuel production. In 2012 Carbon Recycling International (CRI) opened the George Olah plant, which produces methanol from hydrogen and $\mathrm{CO}_{2}$. Power for the 
electrolysis of water for hydrogen production is supplied by the nearby geothermal power plant in Svartsengi. Svartsengi also supplies $\mathrm{CO}_{2}$ captured from emissions already released by the geothermal plan. While methanol in itself is unsuited for use as an aviation fuel, it may be used as a feedstock in production of aviation biofuel.

ETL is an interesting pathway as it relies on $\mathrm{CO}_{2}$ as the carbon source instead of organic carbon from biomass, hence having no LUC and ILUC effects. However it is limited by its supply of feedstocks; power and $\mathrm{CO}_{2}$. Kauw et al. (2015) examines the potential for ETL methanol production in Iceland through different scenarios. The study finds that the total maximum potential for production is 2,140 million liters of methanol pr. year. However, both geothermal plants and industry emissions would only be able to provide around $80 \%$ of the $\mathrm{CO}_{2}$ needed for this scenario. The capture of $\mathrm{CO}_{2}$ from industry will also be a lot less energy effective than from geothermal plants and provide logistical problems. Furthermore this scenario requires the production and installation of more than 1,000 alkaline bipolar electrolyzers. While this is technically possible, this type of electrolyzer has only been built once and at an extremely high price. If only $\mathrm{CO}_{2}$ from geothermal plants is used, the production potential is limited to around 340 million liters pr. year.

While the technology is still young, the George Olah plant is producing around 2 million liters per year, and CRI is looking to construct a 50 million liter pr. year plant (Mannvit, 2015).

\subsection{Import of feedstock}

Many of the feedstocks described in the previous sections are also imported or exported as commodities to a wide extent. Hence, a Nordic production of sustainable jet fuel might be more economically feasible utilizing imported feedstocks. Furthermore, producers might want to acquire feedstock from different sources (also internationally) to eliminate risks related to feedstock availability and price fluctuations. The overall economic viability of importing feedstock will depend heavily on the specific properties of the biomass considered. Low energy density or difficulties with storing biomass will likely influence trade patterns. However, the world-wide trade with palm oil and soy proves that agricultural commodities can be utilized far away from their origins at competitive prices. Promising candidates suitable for the relatively wellestablished HEFA-pathway include waste oils and oil crops, such as 
camelina and jatropha, but neither are cultivated successfully on a large scale as of yet.

\subsubsection{Camelina}

Camelina can be grown in semi-arid areas where other crops cannot be grown. Oil yields of $35-38 \%$ in combination and the ability to thrive on marginal lands make this crop a promising option. LUC and ILUC effects are significantly mitigated compared to other crops which to some extent can outweigh an increase in GHG emissions from additional transportation of feedstock. (Bansal, et al., 2015).

Currently, a large EU funded project called ITAKA is assessing the entire value chain of Camelina converted to bio-SPK. The project has not yet been concluded, but the results are likely to have a significant impact on the further development of camelina grown for sustainable fuel in Europe.

\subsubsection{Jatropha}

Another possible energy crop is jatropha - a plant which produces oil containing seeds and seedpods typically containing around 35\% oil, which is highly suited for use in production of biofuels. As with camelina, jatropha is capable of growing in conditions under which it would be difficult to cultivate crops for food. However, ability to grow does not equal high yield, and jatropha does not produce high yields in less than optimal conditions. A main problem is that it is essentially a wild plant, but this also open up for crop improvements, which may be able to increase yields as well as reduce negative LUC and ILUC effects (FAO, 2010). Just like camelina, fuels produced from Jatropha have been used in both demonstration and commercial flights.

\section{Waste and residues}

Pathways capable of utilizing different waste fractions may also use imported waste oils. One example is Finnish Neste which imports residues from e.g. corn ethanol production. While sourcing waste internationally gives access to additional feedstocks and quantities not available within the Nordic region, the consequences of importing wastes and residues should not be overlooked. 


\section{Nordic Energy Infrastructure}

This chapter reports on the Nordic infrastructure, relevant for a sustainable jet fuel production. This covers airports (and their fuel supply chain), petroleum refineries and biorefineries. How this infrastructure can be utilized and integrated in the supply chain of a sustainable jet fuel production is discussed further in chapter 8 and in chapter 9. The following graph places the different infrastructure components on the Nordic map. 
Figure 1: Map of the Nordic infrastructure relevant for a sustainable jet fuel production scenario

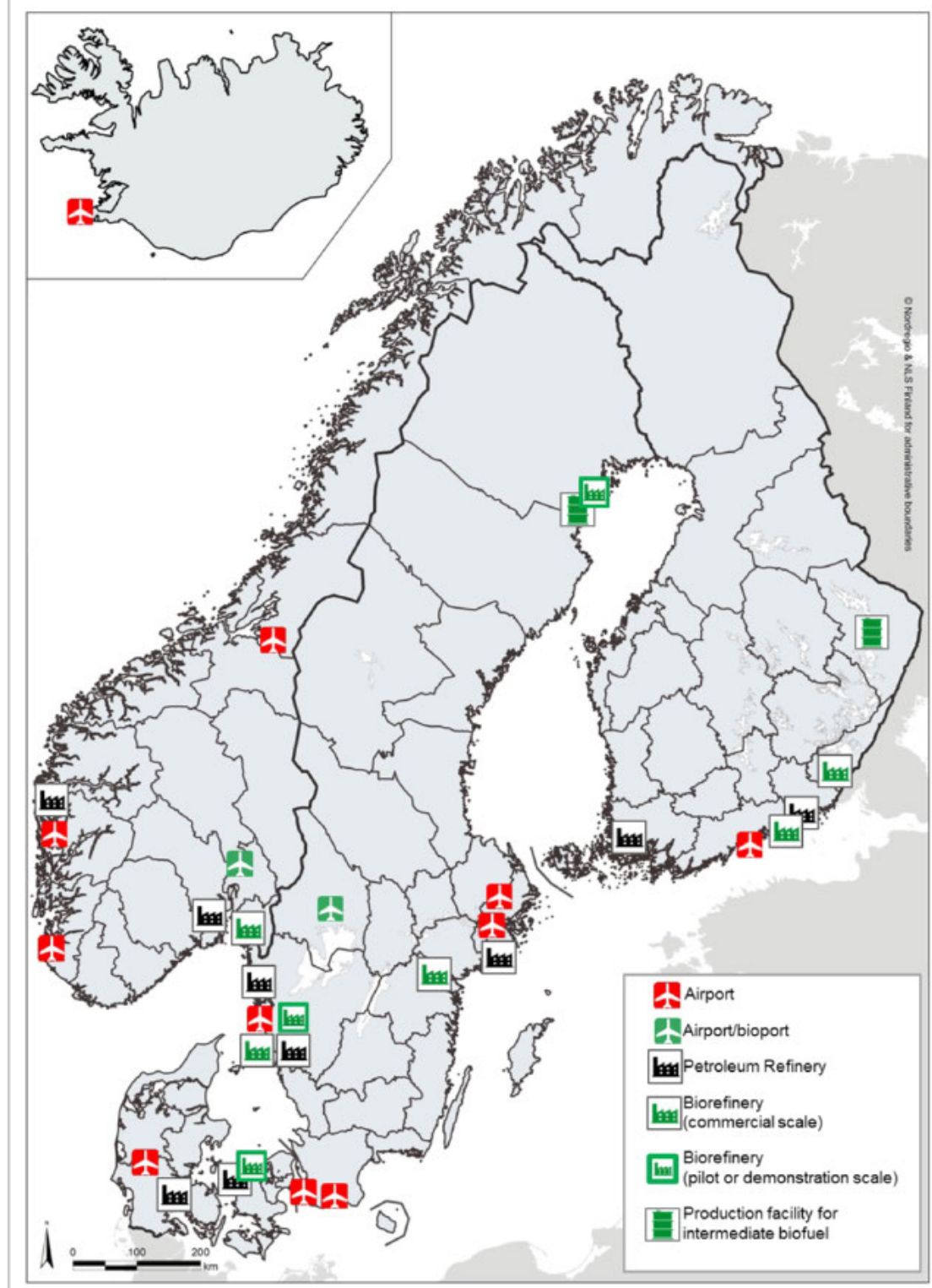

Note: Legend Explanation

Airports: This category includes only airports with more than 2 million passengers annually. Airport/Bioport: This includes airports where sustainable jet fuel can already be fueled, currently limited to Oslo Airport (NO), and Karlstad Airport (SWE).

Biorefinery: This includes relevant biorefineries, where biofuels and other byproducts are produced.

Production facility for intermediates: This includes facilities where intermediate biofuels are produced 


\subsection{Nordic Airports: infrastructure, supply chain and logistics}

\subsubsection{Denmark}

All jet fuel currently used in Denmark is imported by sea to oil terminals located around the country. From the terminals the fuel is distributed either by direct pipeline, or in the case of smaller airports, by truck and rail transport.

In Denmark there is currently 15 airports with facilities for tanking jet fuel, though the vast majority of traffic, both commercial and freight, is handled at the three airports in Copenhagen, Billund and Aalborg. Consequently, almost all jet fuel is fueled at these airports, with Copenhagen being the biggest consumer by far.

\section{Copenhagen Airport}

Copenhagen Airport (CPH) is the largest airport in Scandinavia, handling around 26.6 million passengers and 0.37 million t cargo in 2015. (CPH, 2016). The airport accounts for $87 \%$ of the annual national consumption of jet fuel. Due to its size CPH is the only Danish airport relevant in this study. In January 2014, CPH introduced the strategy "Expanding CPH" with the goal of 40 million passengers annually (CPH, 2014), which will further increase demand for sustainable jet fuel.

After the merger of Statoil Fuel and Retail Aviation (SFRA) and BP there are four different companies supplying fuel in $\mathrm{CPH}$. Apart from supplying fuel, they operate the fuel supply chain through a number of jointly owned companies.

The fuel itself is imported by sea through the off-field import terminal at the nearby Prøvestenen, also called the "Gasoline Island". Here it is stored before it is transported by pipeline to the airport's on-field storage, which has a capacity of 4.5 million l, or around 24 hours of operation. Some of the fuel stored off-field is shipped on to other airports, and the fuel from SFRA is pumped directly into the pipeline as it leaves the "gasoline island". From the on-field storage the fuel is transported to the parked planes through the airports hydrant system, where it is loaded onto the planes through specialized dispenser vehicles. 


\section{Other Danish Airports}

The other commercial Danish airports are considerably smaller, but also store and service fuel on site. However, the last part of the fuel delivery to the airport storage tanks is done by either truck or rail, with the exception of some military airports.

\subsubsection{Finland}

The Finnish airport network is dense: there are 24 airports, though the vast majority of traffic, both commercial and freight, is handled in Helsinki Airport. There are three fuel distributors operating over the country, including Avifuels, Neste and Shell. The fuel is distributed by trucks to the different airports. All distributors buy the fuel from Neste, who either imports it or produces it in its own refinery in Porvoo. Porvoo refinery also has a large port where 20-23 million tons of crude oil and petroleum products pass through annually. In total, 297 million l of kerosene was imported in 2014 (12.5 million I was exported). ${ }^{42}$ All three fuel distributors supply jet fuel to Helsinki airport and have separate logistics for deliveries, including separate trucks for transport to the airport, storage tanks at the airport and supply trucks at the airport.

\section{Helsinki Airport}

Helsinki Airport (HEL) is the fourth largest airport among the Nordic countries handling around 16.4 million passengers in $2015.4^{43}$ It also handled 0.2 million $\mathrm{t}$ freight and mail in 2014. Finavia has outlined a development programme for increasing transfer traffic capacity at the Helsinki Airport. The objective of Finavia's EUR 900 million programme is to strengthen the position of Helsinki Airport among international airports and as an important hub between Europe and Asia. As a result of the expansion, Helsinki Airport will be capable of serving 20 million passengers in 2020.

\footnotetext{
42 Source: Statistics Finland. In 2010-2014 the amount of imported kerosene has varied between 112,300 and 237,300 t. In 2010-2014 the amount of exported kerosene (including biokerosene) has varied between 0 and $72,000 \mathrm{t}$.

43 Finavia Statistics 2014
} 


\section{Other Finnish Airports}

The other Finnish airports are considerably smaller, but some fuel is also stored and serviced on their sites. At present, it is mostly Shell that distributes fuel to the smaller airports, as the fuel demand in the smaller airports is too low to support multiple suppliers with separate logistics and infrastructure.

\subsubsection{Norway}

Norway has a large number of airports distributed over the country, with two thirds of the population having access within one hour's worth of transportation. This is particularly important in a sparsely populated country like Norway situated in the outskirts of Europe with long internal distances and challenging topography. The total number of commercially operated airports in Norway is 52. Oslo airport (Gardermoen) accounts for around $50 \%$ of the air traffic in Norway.

The first two flights with bio jet fuel (blend of 45\% used HEFA-SPK jet fuel and 55\% fossil jet fuel) were conducted in November 2014, flying from Bergen to Oslo and from Trondheim to Oslo.

\section{Oslo Airport}

The largest Norwegian airport, Oslo Airport, handled 24.7 million passengers in 2015 (Avinor Statistics 2016) and 9,062 t freight. In 2014 an expansion was initiated to accommodate up to 28 million passengers annually by 2017 .

The jet fuel is provided by a designated fuel train, with a capacity of 1.1 million 1 fuel, between the port of Oslo and Oslo Airport. Only a small part of the jet fuel delivered to Oslo Airport comes from the Mongstad refinery. Most of it is imported by tankships from foreign oil refineries, mainly from the Netherlands, the Middle East and the US.

By the beginning of 2016, Oslo Airport became the first hub in the world to receive regular deliveries of bio jetfuel, based on partnership with AirBP, SkyNRG, Lufthansa Group, KLM and SAS, delivering 2.5 million 1 of sustainable bio jet fuel in total. The goal is, however, to receive regular deliveries of sustainable jet fuel. The fuel is HEFA-SPK made from camelina oil, produced in Finland by Neste and supplied by Air BP (PC Avinor, 2015). The fuel has been integrated in the hydrant system and allows aircrafts to refuel in the usual way, without the need for specialized fuel trucks travelling from one aircraft to another. 


\section{Other Norwegian airports}

The other three major airports are Stavanger airport (Sola), Bergen airport (Flesland) and Trondheim airport (Værnes). The jet fuel to these airports is exclusively coming from Mongstad, delivered by tankship to local storage tanks and then trucks to the airports.

\subsubsection{Sweden}

Sweden has a large number of airports, with the majority of traffic being handled in the four major airports of Stockholm (Arlanda and Bromma), Göteborg (Landvetter) and Malmö. Most of the domestic flights are going to and from Stockholm and most international flight departs from Stockholm.

The fossil jet fuel used in Swedish airports is imported to major ports in Sweden, such as the Port of Gävle (Gävlehamn). At the Port of Gävle different producers deliver Jet-A1 which after storage and reesterification is loaded onto the train, which is then transported by railway to Stockholm Arlanda Airport or by truck transport to the airports. Several actors are involved in the handling and transportation of jet fuel.

\section{Stockholm Arlanda Airport}

Stockholm Arlanda Airport is the largest airport in Sweden, with 23.2 million passengers in 2015. The fuel for aircrafts (Jet-A1) is transported by train from the harbor in Gävle, $13 \mathrm{~km}$ north of Stockholm, to storage tanks located close to Brista heat and power plant in Märsta, $4 \mathrm{~km}$ from Arlanda Airport. From the storage facility in Brista the fuel is transported by pipeline to storage tanks at the airport. From the storage tanks, the fuel is further distributed to the aircraft at the airport through the hydrant system (an underground pipeline system). The hydrant system is connected to the piers at the airport where aircraft can be refueled.

The fuel storage system at Arlanda Airport and Brista is owned and operated by AFAB, jointly owned by the oil companies delivering fuel to the airport.

\section{Karlstad Bioport}

At Karlstad Airport, which is a relatively small airport near the city of Karlstad, a permanent storage tank for sustainable jet fuel is located (storage capacity 30,000 l). The sustainable jet fuel in the tank (made from used cooking oil) was imported from North America. The blending ratio of the fuel can be between $10-45 \%$. The facility is the result of cooperation between Karlstad Airport, Karlstad municipality, Air BP and SkyNRG Nordic. The purpose of the project is to show that biojet is available today and to develop and learn from the concept. The sustain- 
able jet fuel available at Karlstad Airport is imported by SkyNRG Nordic and is handled and blended by BP. A number of flights have been carried out in Sweden with a low blend-in ratio of biofuels. There are currently no sustainable jet fuel production facilities in Sweden and the sustainable jet fuel used is imported.

\subsection{Petroleum refineries}

The Nordic countries hold 10 petroleum refineries in operation, with two in Denmark, two in Finland, two in Norway and four in Sweden. The refinery capacities range from about 2 million t crude oil annually to 12 million $\mathrm{t}$ for the largest.

Table 10: Nordic petroleum refineries

\begin{tabular}{|c|c|c|c|}
\hline & $\begin{array}{r}\text { Capacity million } \mathrm{t} . \\
\text { crude oil/yr }\end{array}$ & $\begin{array}{l}\text { Production of } \\
\text { jet fuel }\end{array}$ & Other remarks \\
\hline $\begin{array}{l}\text { Denmark } \\
\text { Kalundborg Refinery } \\
\text { Statoil }\end{array}$ & 5.5 & $\begin{array}{l}\text { None } \\
\text { (has previously } \\
\text { produced jet fuel) }\end{array}$ & \\
\hline $\begin{array}{l}\text { Fredericia Refinery } \\
\text { Shell }\end{array}$ & 3.4 & $\begin{array}{l}\text { None } \\
\text { (has previously } \\
\text { produced jet fuel) }\end{array}$ & $\begin{array}{l}\text { In } 2014 \text { Shell announced plans to sell the } \\
\text { refinery, but as of mid-2016 no buyer has } \\
\text { been found }\end{array}$ \\
\hline $\begin{array}{l}\text { Finland } \\
\text { Porvoo Refinery } \\
\text { (Neste) }\end{array}$ & 12 & Yes & $\begin{array}{l}\text { The refinery also has the capacity to } \\
\text { produce sustainable jet fuel from waste } \\
\text { vegetable and animal oils }\end{array}$ \\
\hline $\begin{array}{l}\text { Naantali Refinery } \\
\text { (Neste) }\end{array}$ & 3 & Yes & \\
\hline $\begin{array}{l}\text { Norway } \\
\text { Mongstad Refinery, } \\
\text { Statoil }\end{array}$ & 12 & Yes & \\
\hline $\begin{array}{l}\text { Slagentangen Refin- } \\
\text { ery, Statoil }\end{array}$ & 6 & None & \\
\hline $\begin{array}{l}\text { Sweden } \\
\text { Lysekil Refinery } \\
\text { (Preem) }\end{array}$ & 11.4 & Yes & \\
\hline $\begin{array}{l}\text { Gothenburg Refinery, } \\
\text { Preem }\end{array}$ & 6 & Yes & $\begin{array}{l}\text { A hydrotreatment unit of the refinery has } \\
\text { been retrofitted to co-process tall oil into } \\
\text { diesel with renewable content }\end{array}$ \\
\hline $\begin{array}{l}\text { Gothenburg Refinery, } \\
\text { St1 }\end{array}$ & 4 & None & $\begin{array}{l}\text { An ethanol plant running on organic } \\
\text { waste has been integrated within the } \\
\text { refinery complex }\end{array}$ \\
\hline $\begin{array}{l}\text { Nynäshamn Refinery, } \\
\text { Nynas }\end{array}$ & 2 & None & \\
\hline
\end{tabular}


The petroleum refineries can play an important role in a sustainable jet fuel scenario. In the coming decades, the refineries are likely to experience an increasing over-capacity, and they will thus look to the market of biofuels for new opportunities, such as co-processing renewable feed, retrofitting units (such as hydrotreatment units) to handle only renewable feed or constructing full biorefineries integrated into the fossil refinery complex. Such concepts can utilize the existing infrastructure and distribution channels to airports and can reduce investment costs for biofuel production as well as reduce risk. Among the Nordic, three examples are worthy of note:

- In the Preem refinery in Gothenburg, a hydrotreatment unit has been revamped to co-process tall oil to produce diesel with renewable content for road transport.

- In the St1 refinery in Gothenburg, a bioethanol plant has been constructed and integrated within the refinery complex.

- The Neste refinery in Porvoo can produce refined fossil oil products, as well as renewable diesel and sustainable jet fuel from vegetableand waste oils.

So far, the interest from the refineries have been limited and mostly focused on renewable diesel and bioethanol, which is in high demand for the market of road transportation. However, if demand for sustainable jet fuel increases, the petroleum refineries could be seen as key players in realizing a Nordic production of sustainable jet fuel.

\subsection{Biorefineries and production facilities}

Several production facilities/biorefineries for biofuels and intermediates exist in the Nordic countries. Most are dedicated to produce either bioethanol, renewable diesel, but also other fuels such as DME or gaseous fuels. Only one facility exists capable of producing sustainable jet fuel. This section introduces all the existing facilities, which could be relevant in a Nordic jet fuel production scenario, either directly or as a source of know-how. The focus is on facilities of a significant size, and thus anything smaller than demonstration scale is not considered. 


\subsubsection{Denmark}

\section{Inbicon - Bio-refinery (demonstration scale)}

A bio-refinery was constructed in Kalundborg in 2009 by the biotechnology company Inbicon, which is part of the Dong Energy New Bio Solutions (DENBS). At the time of initiation it was the world's first 2G strawbased bio-refinery. The conversion technology uses enzymatic hydrolysis to break down lignocellulosic material into $\mathrm{C}_{5}$ and $\mathrm{C}_{6}$ sugars which are then fermented to cellulosic ethanol. In collaboration with Danish Terranol a new $\mathrm{C}_{5} / \mathrm{C}_{6}$ yeast was tested in 2014 with reported conversion rates of $90 \%$ of sugars into ethanol (Dong Energy 2014), which effectively eliminates $\mathrm{C}_{5}$ molasses as a by-product (in favor of higher ethanol conversion). The refinery has a treatment capacity of $100 \mathrm{t}$ dry feedstock per day yielding about 10 million L cellulosic ethanol per year.

In 2015 the plant has ceased production and remains idle. DENBS has reported that the technology is, however, mature and ready for industrial scale, and the 2015 cessation is due to resource allocations towards larger scale development, as well as the Maabjerg Energy Concept. Despite suspended operations, the Inbicon refinery itself or the technological know-how may prove to be an integrated element in a Nordic production of sustainable jet fuel from straw and wood residuals, either by the AtJ or the SIP pathway.

\section{Maabjerg Energy Center (commercial scale)}

Maabjerg Energy Center (MEC) is a joint venture between multiple stakeholder companies, among them Dong Energy A/S and Novozymes A/S. The concept of MEC is a large scale bioethanol production facility coupled with a CHP-plant and a biogas plant. Annual production of bioethanol and biogas is scheduled to yield 80 million $\mathrm{l}$ and 50 million $\mathrm{m}^{3}$, respectively. The first two legs of MEC, a biogas and CHP-plant have been established and the bioethanol plant is scheduled to be finished in 2018. The market conditions for bioethanol are highly variable, and consequently the planning partners of MEC are requesting a national requirement of a $2.5 \%$ bioethanol blending in gasoline before a large-scale production is launched. Alternatively, in the absence of a national gasoline blending requirement, MEC's bioethanol facility may still be constructed, if the bioethanol can be utilized by further processing to jet fuel.

The integrated concept behind MEC makes it an interesting case in the context of sustainable jet fuel production. Several key factors that govern the economic viability of a large-scale production facility such as the MEC will likely be of no less importance when establishing a sustainable jet fuel production. The application of an integrated technology concept that uti- 
lizes several byproducts from the different production processes and facilities can help bring down costs. In the MEC, production of bioethanol will mainly use straw feedstock undergoing hydro-thermal pretreatment and enzymatic hydrolysis, while the vinasse, a byproduct from the ethanol production, is used as feedstock by the biogas plant.

\section{Other facilities}

In addition to the biorefinery concepts mentioned above, two biodiesel producers exist in Denmark. Emmelev A/S process rapeseed oil and convert this to biodiesel and a range of other products with an annual capacity of 80,000 t biodiesel. Daka Denmark A/S likewise produces biodiesel and other products, however, their feedstocks are animal fats and slaughterhouse waste. The annual production of biodiesel is 55 million l. In a HEFA pathway, either based on vegetable or waste oils, the capacity and technical know-how of existing biodiesel production facilities may be integrated in a potential Danish sustainable jet fuel production. Several companies also have smaller facilities, such as Biogasols bioethanol pilot plant and Steeper Energy's hydrothermal liquefaction pilot plant.

\subsubsection{Finland}

\section{Neste Porvoo Biorefinery (commercial scale)}

Neste is a global forerunner in aviation biofuels and currently one of the few companies in the world capable of producing renewable aviation fuel in industrial scale. The Porvoo refinery produces renewable diesel, but also has the capacity to produce sustainable jet fuel, which has so far only been done in batches. In the upcoming years, the intention is to make use of the running renewable diesel production capacity infrastructure at the refinery to also produce sustainable jet fuel. The technology produces biofuels from a wide range of feedstocks, including crude palm oil, waste and residues (waste animal fat, waste fish fat, vegetable oil fatty acid distillates, technical corn oil) and other vegetable oils (e.g. rapeseed and camelina oils).

\section{St1 Bioethanol plants (demonstration scale)}

St1 has five bioethanol plants in Finland (capacity around 10-20 million l per year). The bioethanol is produced from waste and residues including bio-waste from households, leftover dough from bakeries, waste from beer and other beverage production and starch- and sugarcontaining waste from the food industry. St1 also has plans to build up 
an ethanol plant using saw dust in Kajaani, North of Finland (planned capacity 10 million l per year, likely to start operating in 2016).

\section{UPM Tall oil Diesel Biorefinery (commercial scale)}

Forest company UPM produces $2 \mathrm{G}$, wood-based renewable diesel on a large-scale in Lappeenranta located on the same site as the UPM Kaukas pulp and paper. Operations started in January 2015. The feedstock used is crude tall oil, a residue of pine wood pulp and a by-product of pulp manufacturing supplied from its own pulp mills located in Finland. The total biorefinery investment was EUR 175 million, and annual renewable diesel production 120 million 1 .

\section{Other facilities}

In addition, other companies are producing liquid and gaseous biofuels for transportation and energy production. A bio-oil plant integrated with Fortum's CHP plant in Joensuu, Finland, utilizes fast pyrolysis technology and is the first of its kind in the world on an industrial scale (capacity $50,000 \mathrm{t}$ of bio-oil per year). Chempolis has a biorefinery in Oulu for testing raw materials and producing sample batches of bioethanol and biochemicals. VTT also has a piloting plant for biomass fractioning, fast pyrolysis, and chemical pilots.

\subsubsection{Norway}

\section{Borregaard Biorefinery (commercial scale)}

Borregaard owns and operates the only existing biorefinery in Norway located in Sarpsborg. The company focuses on sustainable production of biochemicals, biomaterials and biofuels from wood. In particular, Borregaard's main products are speciality cellulose, lignin, vanillin and bioethanol. Borregaard has been producing ethanol by fermentation of wood sugars since 1938 and has during a long time been the world's largest manufacturer of $2 \mathrm{G}$ bioethanol, with an annual production of around 18-20 million liters. At present, around 5-6 million liters of these are used as biofuels for transportation purposes (heavy duty vehicles, buses and cars) whereas the rest is devoted to biochemicals (PC Borregaard, 2015). In terms of biofuels, Borregaard and Statoil have entered into an agreement to deliver 44,000 liters of bioethanol per month. If the market for biofuels would be economically more favorable than today's situation, Borregaard would possibly consider increasing the share of their bioethanol for the transport sector. 


\subsubsection{Sweden}

\section{SunPine Tall oil diesel production facility (commercial scale)}

SunPine uses tall oil (extracted from the black liquor which is a byproduct from several pulp and paper plants, both in close area and further away), converts it into tall oil diesel by fractionation (annual production and capacity is 100 million l tall oil diesel), and then ships the oil to a Preem refinery in Gothenburg where it is co-processed with fossil oil into Preem ACP Evolution Diesel for road transport (SunPine, 2015). The tall oil diesel plant is located in Piteå and was the first facility of its kind in the world (SunPine, 2015).

\section{Preem refinery - Gothenburg (commercial scale)}

The Preem refinery in Gothenburg allows renewable primary products to enter the refinery. Today the refinery accepts tall oil diesel from SunPine which is processed into Preem Evolution Diesel. The Preem Evolution Diesel consists of up to $35 \%$ of renewable resources; $28 \%$ is tall oil diesel and the remaining $7 \%$ are RME. The plant will be expanded in order to double the production of Preem Evolution Diesel, based on a decision in 2015. (Preem, 2015).

\section{St1 refinery - Gothenburg (demonstration Scale)}

In Gothenburg, St1 has built an ethanol plant adjacent to St1's refinery. The plant has been granted project funding via the European Commission and the LIFE+ fund. The main objective is to demonstrate the potential for production of ethanol for blending in road transport. Raw materials for ethanol in this plant are by-products from the food industry. The facility is fully integrated to the processes and logistics of the St1 oil refinery, with synergies in terms of using residual heat and cooling. The ethanol will use the refinery's existing logistic chain to reach out to customers in the transport sector.

The expected result from the demonstration project is to show the potential for sustainable production through integration with the production of an existing oil refinery. The expected produced amounts are 5 million 1 of ethanol per year for use as a fuel for transportation.

\section{GoBiGas: Gothenburg-Energy Biomas Gasification Project (demonstration scale)}

GoBiGas is a demonstration scale gasification facility for biomass and residues from the forestry. The project is a partnership between Gothenburg Energy and E.ON and is also closely linked to the Chalmers University of Technology in Gothenburg. In 2020, the aim is to produce 
biogas corresponding to 1 TWh (Chalmers Technical University, 2015). The end product is synthetic biomethane, to be used in either road transport or for power/heat generation. In 2015 Gothenburg Energy assessed the opportunities for producing sustainable jet fuel, through Fischer Tropsch synthesis, as part of the GoBiGas project, though no plans for realization has been put in motion as of yet.

\section{Chemrec gasification plant (Pilot scale)}

The process for gasificiation of black liquor (forest industry residue) to produce syngas is developed by Chemrec. The produced syngas has been converted into dimethyl ether, methanol, synthetic diesel or synthetic gasoline (Chemrec, 2015). Chemrec itself has no operation today, but the pilot gasifier is located in Piteå, Sweden, and is operated by LTU Green Fuels. Currently, only BioDME and biomethanol is produced. The future of the plant is currently uncertain due to a lack of funding (Luleå Technical University, 2015).

\section{The Lantmännen Agroetanol, Norrköping (Commercial scale)}

The Lantmännen Agroetanol production plant is located at Händelö outside Norrköping, Sweden. Production of ethanol takes place in close collaboration with the adjacent combined heat and power plant which supplies electricity and process steam to the ethanol plant. Waste heat from the ethanol plant is returned to the heat and power plant and used for district heating in the city of Norrköping. Raw materials in the ethanol production are wheat, rye and barley. Around $550,000 \mathrm{t}$ of grain are required to produce 210 million $\mathrm{l}$ of ethanol. After the production stage the residue, thin stillage, goes to a nearby biogas plant to produce vehiclequality biogas.

Lantmännen Agroetanol ethanol is sold to oil companies in Sweden for low admixture in petrol or exported to Germany. In Sweden, 5\% of ethanol is low-blended into conventional petrol.

\section{Biorefinery Demo Plant (SEKAB), Örnsköldsvik (Demonstration scale)}

An ethanol pilot-plant was inaugurated in 2004 as part of the Domsjö chemical plant in Örnsköldsvik. In April 2013, SP, the Technical Research Institute of Sweden took over the overall responsibility for sales and customer contacts for the plant with the goal of expanding the operations to develop more sustainable products from various types om biomass. The plant was renamed the Biorefinery Demo Plant. SEKAB ETechnology is, on behalf of SP, responsible for the planning and implementation of demonstration tests as well as the maintenance and adap- 
tation of the plant to new applications. Current production capacity of ethanol is around 0.2 million l annually.

The SEKAB's biorefinery demo plant can use a wide range of feedstock. Today residues from agriculture and forestry are mainly used, but energy crops can also be used.

\subsection{Introduction of new fuels in the supply chain}

The existing Nordic energy infrastructure contains components which can to some degree be integrated and utilized in a full sustainable jet fuel supply chain, though several key challenges must be addressed, both upstream (feedstock and transportation), midstream (conversion and refining) and downstream (distribution and storage).

\subsubsection{Upstream - feedstock, preparation and transport}

Chapter 6 presented and discussed a number of possible feedstocks for a sustainable jet fuel production. Finding the right feedstock in ample supply may be complicated by requirements of sustainability, competition with existing biomass production and utilization, as well as the economic feasibility of cultivation or sourcing.

In contrast to the upstream supply chain of fossil jet fuel, a large number of producers will likely be involved in supplying feedstock to the conversion facilities. This will entail a more complex coordination with regards to transport of feedstock and storage. Depending on the choice of feedstock it may also be necessary to standardize the condition of feedstock delivered to the conversion facilities.

Many of the existing and future planned Nordic biofuel production facilities are located in areas with access to large amounts of forestry biomass. It is reasonable to think that significant amounts of the biomass processed in these production plants will be local biomass situated within short to medium distances. In this situation, the biomass will be transported by either heavy duty trucks or train, similarly to the logistics used in the old pulp and paper mills located in the same industrial areas. Whereas train is economically more advantageous for long to medium distances heavy duty trucks are the best solution for short distances, both in terms of economy and flexibility. 
Table 11: Supply-chain stage

\begin{tabular}{|c|c|c|}
\hline & Existing infrastructure & Challenges \\
\hline \multicolumn{3}{|l|}{ Upstream } \\
\hline Feedstock & $\begin{array}{l}\text { Nordic forestry/pulp and paper industry } \\
\text { (wood-biomass) } \\
\text { Various industries for sources of waste } \\
\text { fractions (oils and animal fats, } \\
\text { organic waste) } \\
\text { Danish/Swedish farmers (straw) }\end{array}$ & $\begin{array}{l}\text { Complex coordination with many feedstock } \\
\text { suppliers } \\
\text { New facilities for pre-treatment of } \\
\text { feedstock } \\
\text { competing uses for many feedstock }\end{array}$ \\
\hline Transportation & $\begin{array}{l}\text { Trucks for short distances } \\
\text { Trains for longer distances }\end{array}$ & $\begin{array}{l}\text { Complex logistics for transportation } \\
\text { Long transportation distances }\end{array}$ \\
\hline \multicolumn{3}{|l|}{ Midstream } \\
\hline Conversion & $\begin{array}{l}\text { Neste's biorefinery in Finland can produce } \\
\text { sustainable jet fuel } \\
\text { Renewable diesel production can serve as } \\
\text { inspiration for integration with forestry } \\
\text { industry } \\
\text { Bioethanol production can be diverted } \\
\text { towards further processing into jet fuel }\end{array}$ & $\begin{array}{l}\text { New facilities and production capacity } \\
\text { required } \\
\text { Location of facilities, close to feedstock } \\
\text { source and in connection with industry } \\
\text { infrastructure } \\
\text { Economic incentives for biofuel producers } \\
\text { before sustainable jet fuel is considered an } \\
\text { attractive option }\end{array}$ \\
\hline Refining & $\begin{array}{l}\text { Petroleum refineries can be retrofit- } \\
\text { ted/revamped to refine renewable feed } \\
\text { into jet fuel }\end{array}$ & New refining capacity likely required \\
\hline \multicolumn{3}{|l|}{ Downstream } \\
\hline Distribution & $\begin{array}{l}\text { Jet fuel producing petroleum refineries } \\
\text { may have existing distribution infrastruc- } \\
\text { ture to airports }\end{array}$ & \\
\hline Storage & $\begin{array}{l}\text { Off-field and on-field storage facilities at } \\
\text { the largest airports }\end{array}$ & $\begin{array}{l}\text { Blending ratios of sustainable jet fuel with } \\
\text { fossil jet can be restricted depending on } \\
\text { composition of existing fossil based supply } \\
\text { and the type of sustainable jet fuel } \\
\text { New storage tanks may have to be con- } \\
\text { structed (at airports or off-field) } \\
\text { Airport fueling system may have to be } \\
\text { expanded }\end{array}$ \\
\hline
\end{tabular}

Several possibilities for optimization of feedstock logistics exist depending on how the feedstocks are transported and if they are processed prior to transportation. Transportation can for instance be optimized using specially constructed lorries with a higher biomass capacity or shifting to e.g. freight train transportation. The feedstock can also be pre-treated to increase its energy density and hence decrease transportation costs. Straw can for instance be pelletized instead of conventional straw bales, and many feedstocks will require some kind of drying or heat treatment. 


\subsubsection{Midstream - pre-treatment and conversion}

Only Neste in Finland possesses existing conversion facilities for sustainable jet fuel production. This infrastructure constitutes an essential part for a scenario based on vegetable and waste-oils. The remaining conversion facilities are mostly focused on bioethanol and renewable diesel. All the Nordic produced bioethanol is used in ground transportation, though a fraction could in theory be diverted towards further processing into jet fuel via an alcohol-to-jet pathway if facilities for such are created. The renewable diesel production is not directly compatible with sustainable jet fuel production in the same way, though wood-biomass based diesel production may serve as a source of inspiration and knowhow on integrating production with forestry and pulp and paper industry. The existing fossil oil refineries may also be integrated, by drawing upon inspiration from other existing petroleum refineries which have been retrofitted towards biofuel production, such as the Gothenburg Preem refinery, or an overseas example of the partnership between $\mathrm{Al}$ tAir and Alon Energy to retrofit idle parts of the Bakersfield refinery in California, USA.

\subsubsection{Downstream - Distribution and storage}

With regards to the downstream supply chain covering distribution, storage and tanking of flights, new sustainable jet fuels will have several possible points of entry. Depending on the introduced amount of sustainable jet fuel, the integration will happen during the initial steps of distribution:

- Direct aircraft fueling: The first point of entry will, most likely, be to supply batch-size fuel by trucks directly from producer or storage facility to aircrafts for blending with conventional A-1. This will require no additional infrastructure and has already been done for an increasing number of demonstration flights around the world.

- On-field storage: The second point of entry will be to supply larger amounts of fuel to storage tanks located within airports. In an example case of Copenhagen airport, the storage tanks only hold a reported 24 hours' worth of fuel demand, which imposes a need for continuous feed-in if relying on blending in existing tanks. Depending on the ASTM certification of the specific sustainable jet fuels, different criteria for allowed blending ratios may exist, which could significantly limit the amount and the type of fuel that can be blended and stored. Furthermore, if delivered by trucks, an on-site 
storage scheme could bring about an impractical amount of additional traffic within the airport. Instead, dedicated sustainable jet fuel on-site storage tanks could be constructed, which would require more seldom refilling and allow for fueling of aircrafts with a multitude of different blends.

- Large off-field storage and distribution: The third and most impactful point of entry will be distribution and storage at large off-field facilities connected via pipelines to airports, such as the "Gasoline Island" outside Copenhagen Airport. Storage of the sustainable jet fuel can be blended directly with conventional jet A-1, though the same considerations as before on fuel type and blending ratios will have to be addressed. Alternately, large storage and distribution facilities dedicated to sustainable biofuels may be constructed, such as in the Bioport Karlstad and Holland projects.

Blending and storing sustainable jet fuel: One of the challenges associated with storage and blending of sustainable jet fuel with conventional jet fuel is the specific requirements to the final composition of the blended jet fuel. In the next chapter, different blend-ratios are given for sustainable jet fuel produced via different pathways, such as $50 \%$ blend ratio for HEFA-SPK or $10 \%$ for SIP-SPK (see chapter 8). However, these are the maximum blend ratios allowed as per the ASTM specifications, but the achievable blend ratios can in reality be used in lower percentages. Fossil jet fuels will have different profiles with respect to the amount of aromatics, cyclo-paraffins and iso-paraffins, and the ratios between these fraction directly affects parameters such as energy density, freezing point, lubricity, etc. which determine if the fuel can safely be used in an airplane. The highest blend ratios are then only achievably if blended with fossil Jet-A1 with an adequately compatible chemical profile, so that the final blend meets the required specifications.

In the longer term, as the consumption and thus blend ratio of sustainable jet fuel increases, airports may hit a blend-roof (below the maximum ASTM specified level), unless they change their supply of fossil jet fuel to one of different composition that will allow for higher blend ratios, closer to the maximum allowed level. 



\section{Technology pathways}

Several technology pathways exist for the conversion from feedstock to final jet fuel. This section describes different technology pathways on a country-level in the Nordic countries.

\subsection{Introduction to a sustainable jet fuel technology pathway}

A pathway can roughly be divided into three steps: pre-treatment, conversion-processing and refining, as shown in the figure below. In addition to these three steps focusing on the technology, a fourth step considering the resource base is included.

Figure 2: The four basic steps in a feedstock to fuel pathway

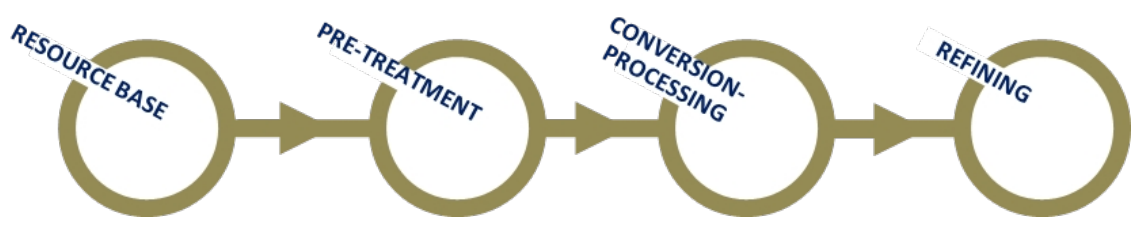

In the pre-treatment step the feedstock is first prepared for processing, e.g. by drying and chipping/pelletizing, and by isolating the intermediate products which will be converted to jet fuel. Different approaches exist for pre-treatment depending on the feedstock and the pathway. Starch and lignocellulosic biomass often undergo enzymatic hydrolysis during which the chemical structure is broken down to simple sugars which can be fermented. Pre-treatment can also include a more simple process such as pressing oil-seeds to extract lipids. Finally, pre-treatment includes gasification technologies if the pathway requires the feedstock to be in a gaseous form.

In the conversion and processing step, the intermediate products (sugar, lipid or gas) are further processed and converted into hydrocarbons. This can, for instance, be sugars that are fermented into alcohols, lipids which are hydrogenated or gas which is synthesized. 
In order to achieve a final product of jet A-1 grade, the hydrocarbons undergo refining into different fractions called distillates. Furthermore, impurities are removed during this final step. Other refining processes include cracking of carbon chains to achieve the desired length. The final products of each pathway will not only be jet fuel, but also a range of other hydrocarbon fuels as well as other byproducts, as illustrated in the figure below.

Figure 3: Overview of the different routes to produce biofuels and other products

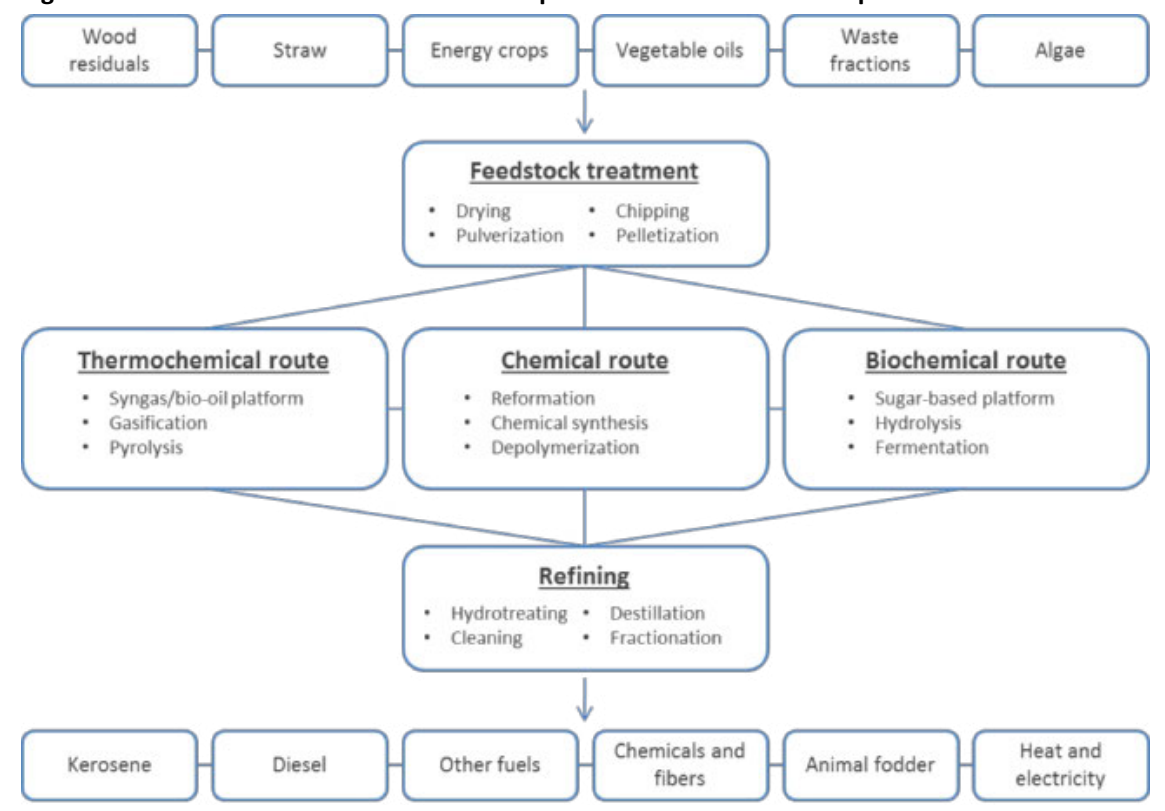

\subsubsection{Biorefining}

A biorefinery concept integrates the production of an array of energy products, transportation fuels and chemicals from biomass. Jet fuel produced in all the pathways listed above, can be considered as just one of many product streams in a Nordic biorefinery, which will ensure the most optimal utilization of the available biomass with respect to the economy of production, energy and conversion efficiency. In the Nordic countries, biorefining for chemicals and fibers made from wood-biomass is of a high technological maturity, but the integration with biofuel production at a commercial scale has yet to occur. Over longer time scales, biorefineries are an ideal candidate to replace all products, both fuels and chemicals produced in conventional petroleum refineries.

Two main types of biorefinery are based on a thermochemical route, using pyrolysis/gasification of biomass, or a biochemical conversion 
route, using fermentation of biomass, though a combination of both routes is also a possibility for more advanced future biorefineries. The extraction of chemicals and other products than biofuels happens at various stages in the biorefining processes. These include lower value commodity chemicals, higher value specialty chemicals and intermediates (e.g. for cosmetics or pharmaceuticals), fibers, feed, fertilizers, wastewater and steam/heat. For lignocellulosic biomass, the lignin fraction is another product, which has typically been used for co-firing in CHP production. Recent technological advancement has opened up for additional use of lignin for liquid biofuel production and as a source for many high value products.

\subsection{Recognized pathways}

Jet fuel is highly regulated and must meet strict specifications in order to be used in both commercial and military aviation. Jet fuels are approved by, among others, the American Society for Testing and Materials (ASTM) and are added as an annex to the ASTM D7566 standard. As of yet, three pathways have achieved an ASTM certification, three are under review, several are in the testing phase and others are in earlier stages of development. 
Table 12: ASTM certification of sustainable jet fuel pathways

\begin{tabular}{|c|c|c|}
\hline Pathway & Certification status & Feedstock \\
\hline Fischer-Tropsch (FT) & $\checkmark 50 \%$ blend & Any biomass or carbon source \\
\hline $\begin{array}{l}\text { Hydroprocessed esters and fatty } \\
\text { acids (HEFA) }\end{array}$ & $\checkmark 50 \%$ blend & $\begin{array}{l}\text { Vegetable oils, animal oils, and any other } \\
\text { bio-oils containing tri-glycerides }\end{array}$ \\
\hline Synthetic Parafinic kerosene (SIP) & $\checkmark 10 \%$ blend & Any sugar containing feedstock \\
\hline $\begin{array}{l}\text { Alcohol to Jet (AtJ) } \\
\text { (BASED ON ISOBUTANOL) }\end{array}$ & $\checkmark 30 \%$ blend & Any sugar containing feedstock \\
\hline $\begin{array}{l}\text { FT synthetic kerosene with } \\
\text { aromatics (FT-SKA) }\end{array}$ & $\begin{array}{l}\text { under review } \\
(100 \% \text { blend })\end{array}$ & Any biomass \\
\hline $\begin{array}{l}\text { Hydroprocessed depolymerized } \\
\text { cellulosic jet (HDCJ) }\end{array}$ & under review & Lignocellulosic \\
\hline HEFA+ & $\begin{array}{l}\text { testing (as annex to HEFA, } \\
\text { around } 10 \% \text { blend) }\end{array}$ & Same as HEFA \\
\hline $\begin{array}{l}\text { AtJ synthetic kerosene with } \\
\text { aromatics (AtJ-SKA) }\end{array}$ & $\begin{array}{l}\text { testing } \\
(100 \% \text { blend })\end{array}$ & Same as AtJ \\
\hline Catalytic hydrothermolysis $(\mathrm{CH})$ & testing & $\begin{array}{l}\text { Vegetable oils, animal oils, and any other } \\
\text { bio-oils containing tri-glycerides }\end{array}$ \\
\hline Hydrothermal liquefaction ( $\mathrm{HtL}$ ) & - & Any biomass \\
\hline Pyrolysis to jet (PtJ) & - & Any biomass \\
\hline Power to liquid (PtL) & - & Concentrated $\mathrm{CO}_{2}$ \\
\hline Microbial Conversion of $\mathrm{CO}_{2}$ & - & Concentrated $\mathrm{CO}_{2}$ \\
\hline
\end{tabular}

In addition to the pathways listed in the table above, a number of companies are pursuing and developing new pathways. These new pathways are often either variations or combinations of existing pathways, in which individual process steps are combined or even skipped entirely. While such new concepts are worthy of great interest, most are at an early stage of development, lacking substantial documentation in the form of:

- Detailed technical process descriptions.

- Proof of concept at pilot- or demonstration-scale.

- Operations and testing data, including energy and mass balances.

Many companies have made great efforts to portray their own emerging technology pathway as particularly advantageous to other conventional pathways, but until reliable documentation can be procured, the feasibil- 
ity of these new pathways is somewhat uncertain. Hence, this chapter and the scenarios described in chapter 9, only regard the more wellknown pathways, which hold up to the three criteria for substantial documentation and proof of concept as listed above. However, it is recognized that new pathways may emerge where technical innovations indeed prove to be advantageous to the pathways that are currently demonstrated at a high maturity level.

\subsubsection{Hydrotreated esters and fatty acids}

Hydrotreated esters and fatty acids (HEFA) is a lipid based technology and was approved by ASTM in 2011. The technology converts triglycerides and fatty acids from bio-oils, hence utilizing oil rich feedstocks. Impurities are initially removed by catalytic processes. The fatty acids are then hydrotreated and cracked in order to achieve the desired hydrocarbon length of 9-16 carbon atoms. HEFA is ASTM approved in up to $50 \%$ blend-in with conventional fossil fuel.

Figure 4: HEFA pathway

\section{HEFA pathway}

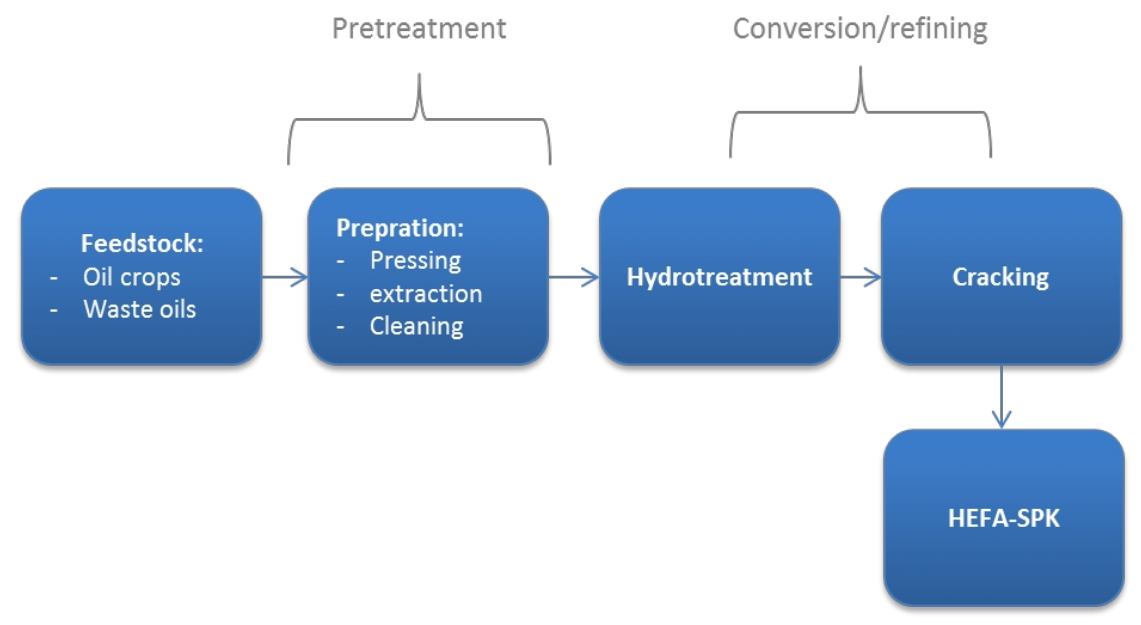

\subsubsection{HEFA+}

This pathway is known under a variety of different names, such as Green diesel, wider cut HEFA or advanced hydrotreated vegetable oil. The fuel in this pathway is produced using the same processes as the HEFA pathway. Chemically, HEFA+ consists of longer hydrocarbon chains, similar to renewable diesel which is used for road transport, and requires 
further hydroprocessing, cracking and isomerization in order to achieve the required jet A-1 grade properties. Such processing effectively constitutes the remaining steps of a HEFA pathway, meaning that HEFA+ is essentially unfinished HEFA-SPK. While HEFA can be blended in with up to $50 \%$, HEFA+ is restricted to a lower blending ratio with conventional jet fuel.44 HEFA+ is notably different from biodiesel used for road transport, which consists of fatty acid methyl esters (FAME) that are chemically distinct from both HEFA+ and jet A-1. HEFA+ is currently under testing for ASTM certification as an annex to HEFA.

The capacity of HEFA+ production in the US, Europe and Asia is 3 billion liters per annum, which is on a much larger scale compared to other alternatives to conventional fossil jet fuel (Boeing, 2014).

\subsubsection{Fischer-Tropsch Synthesis (FT)}

Fuels produced by Fischer-Tropsch synthesis (FT) were the first of their kind to receive certification as alternative fuels in aviation. A generic FT fuel certification was approved by ASTM as for up to $50 \%$ blending into conventional jetfuel in 2009. FT fuels are commercially produced from coal (CtL) and natural gas today (GtL). There is no commercial production of FT-SPK using biomass (BtL) yet. The Fischer-Tropsch synthesis was pioneered in 1920 by Franz Fischer and Hans Tropsch. A syngas consisting mainly of carbon monoxide $(\mathrm{CO})$ and hydrogen $\left(\mathrm{H}_{2}\right)$ is prepared through gasification of the solid feedstock in case of coal and biomass, or steam reforming of methane in case of natural gas. The syngas is cleaned and conditioned and then catalytically converted to hydrocarbons. The FT process can be adjusted to produce different products and is hence flexible. The FT-process is ASTM approved in up to $50 \%$ blendin with conventional fossil fuel. 


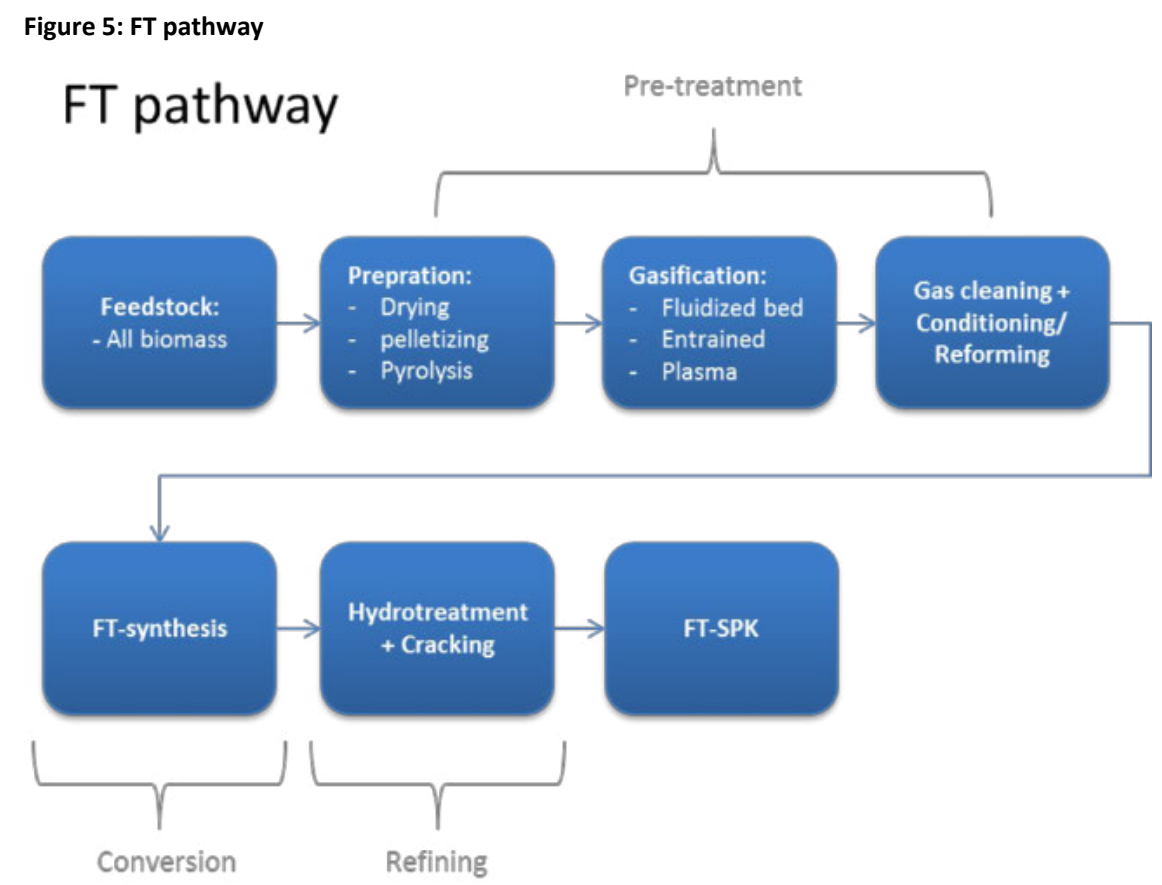

\subsubsection{Alcohol-to-jet (AtJ)}

In the alcohol-to-jet (AtJ) process, bio-alcohols are converted to hydrocarbons. Bioalcohol can be produced from both sugar/starch and lignocellulosic feedstocks. The most common alcohols used in the process are bioethanol and biobutanol (both n-butanol and isobutanol). The alcohols are dehydrated in a catalytic process at $300-500{ }^{\circ} \mathrm{C}$. The hydrocarbons are then converted through a number of steps including oligomerization, distillation and refining. At based on isobutanol was ASTM approved for 30\% blend in 2016 . 


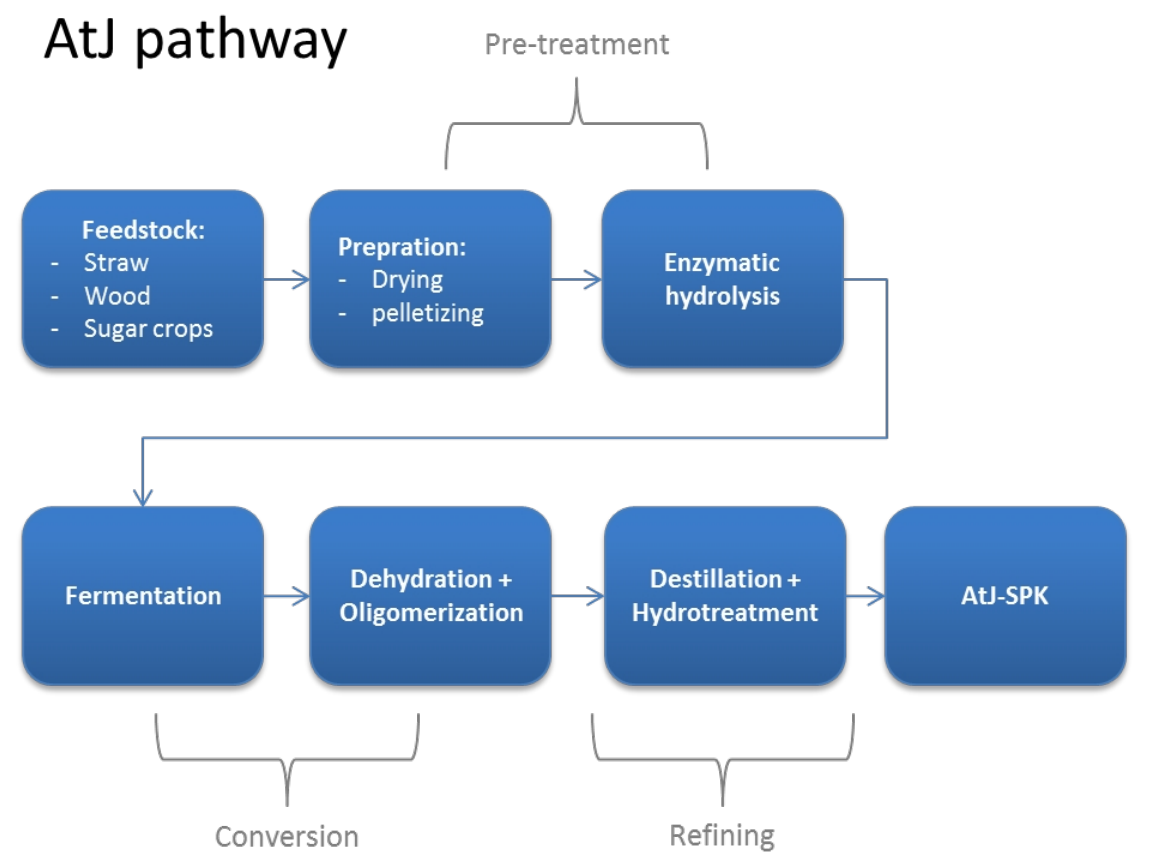

\subsubsection{Synthetic iso-paraffin}

Synthetic iso-paraffinic jet fuel (SIP), formerly known as direct sugar to hydrocarbons, is the most recently ASTM approved pathway. It was approved in 2014 with a blend-in ratio up to 10\% (IATA, 2014). The SIP pathway is based on sugar/starch feedstocks and pre-treatment very similar to the one of alcohol-to-jet and includes enzymatic hydrolysis to extract sugar molecules. However, unlike alcohol-to-jet the sugars are directly converted to hydrocarbon without an alcohol intermediate product. One advantage of the technology is that the microorganisms can be genetically modified to achieve a highly specialized fuel production. A downside to the technology is, that oxygen must be continuously supplied throughout the process since it is aerobic, which increases operating costs (NREL, 2013). 
Figure 7: SIP pathway

\section{SIP pathway}

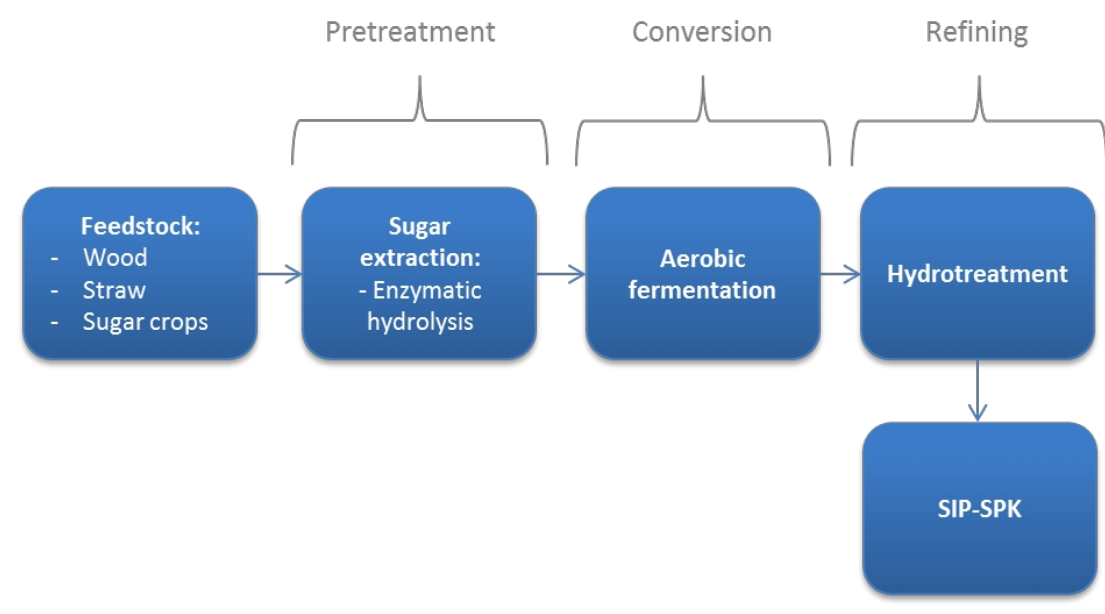

\subsubsection{Other pathways}

As mentioned previously, other pathways exist for the production of sustainable jet fuel. These processes are currently not ASTM certified and are still in early research and pilot scale.

Hydrothermal liquefaction (HtL) relies on wet biomass which is processed in a medium-temperature, high-pressure thermochemical reaction to produce a bio-crude. The HtL bio-crude has significantly lower oxygen content than bio-crude made from pyrolysis, but still requires further hydroprocessing and destillation to produce jet fuel. Unlike pyrolysis pathways, HTL can utilize a wider range of feedstocks, including lignocellulosic biomass, algae and a number of waste fractions, such as manure and sewage sludge. Catalytic hydrothermolysis $(\mathrm{CH})$ is pathway very similar to $\mathrm{HtL}$. Both $\mathrm{CH}$ and $\mathrm{HtL}$ can also produce relatively large amount of aromatics, which makes them an interesting supplement to other processes where no aromatics are formed (Li et al., 2009). 


\section{HTL pathway}

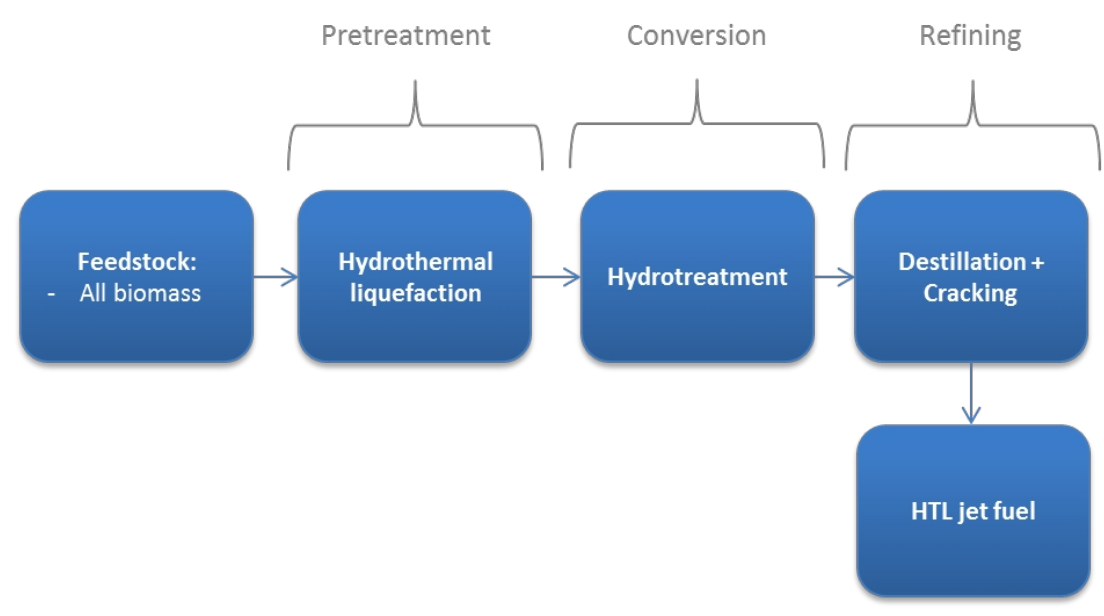

Pyrolysis pathways or pyrolysis-to-jet (PtJ) produce a solid biochar and a liquid bio-oil, usually from lignocellulosic feedstock. The pyrolysis can happen under different temperatures, fast pryrolysis, that gives maximum oil yields, is typically carried out around $500{ }^{\circ} \mathrm{C}$. The bio-oil is upgraded by deoxygenated before it can be considered as drop-in fuel. Deoxygenation is a catalytic process, with (hydroprocessing) or without (cracking) hydrogen addition. The upgraded bio-oil is then distilled into different ranges of fuel, including jet fuel. Pyrolysis and catalytic upgrading can be carried out in single step operation, however the maturity is lower in the single step case. 
Figure 9: Pyrolysis pathway

\section{Pyrolysis pathway}

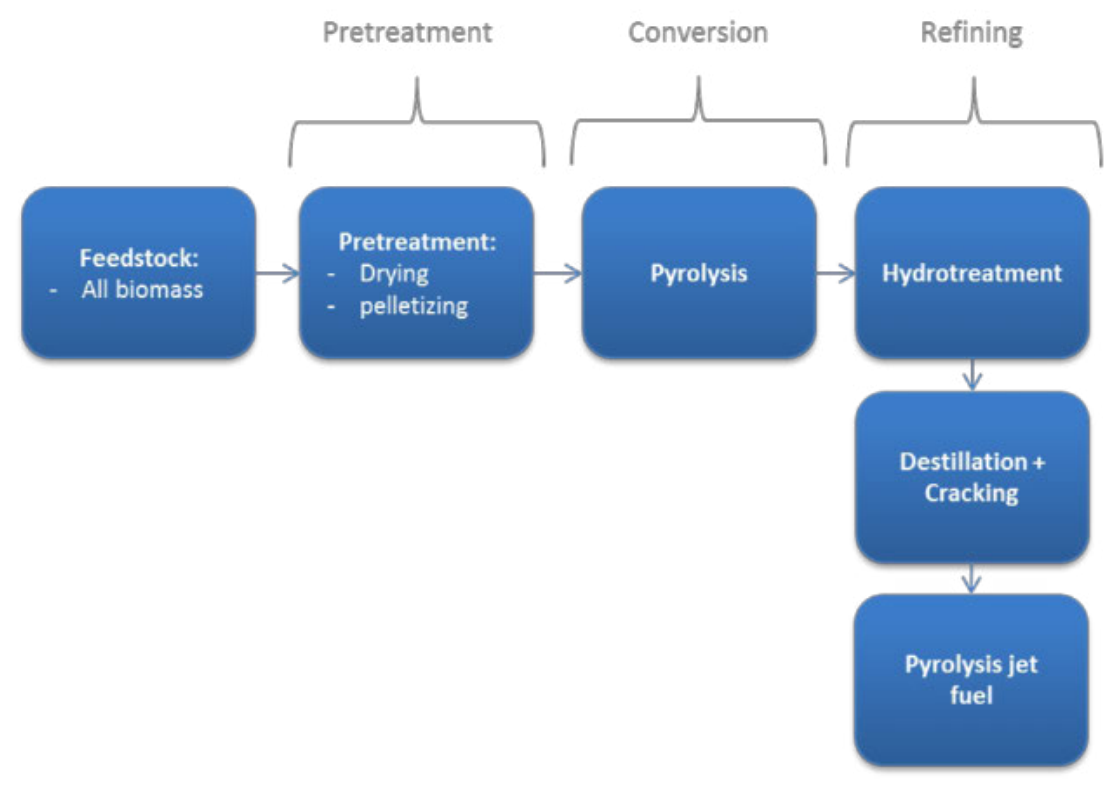

The power to liquid (PtL) (sometimes referred to as electro-fuels or synthetic fuels) is a pathway where hydrogen (produced e.g. by electrolysis or steam reforming) is used to reduce $\mathrm{CO}_{2}$ to $\mathrm{CO}$ and water. The $\mathrm{CO}$ is then combined with additional hydrogen to constitute a syngas, which can then be synthesized by the Fischer-Tropsch reaction into fuels. The PtL pathway is similar to another pathway, where $\mathrm{CO}_{2}$ is not reduced to $\mathrm{CO}$, but instead converted by engineered microbes to produce hydrocarbons, sometimes using sunlight as a catalyst.

While both these pathways have often been quoted as only requiring atmospheric air, water and electricity or sunlight, in reality a concentrated and pure source of $\mathrm{CO}_{2}$ is required as feedstock to produce significant amounts of fuel. This could be waste- $\mathrm{CO}_{2}$ from biogas production, industry or combustion plants, which may prove just as, or even more, difficult to obtain in sufficient amounts as any other (conventional) source of biomass feedstock that is required by other pathways. The PtL and microbial conversion pathways are currently at lower levels of technological maturity, and are thus unlikely to develop to a commercial scale before the other pathways described in this section. 


\section{Power-to-liquid pathway}

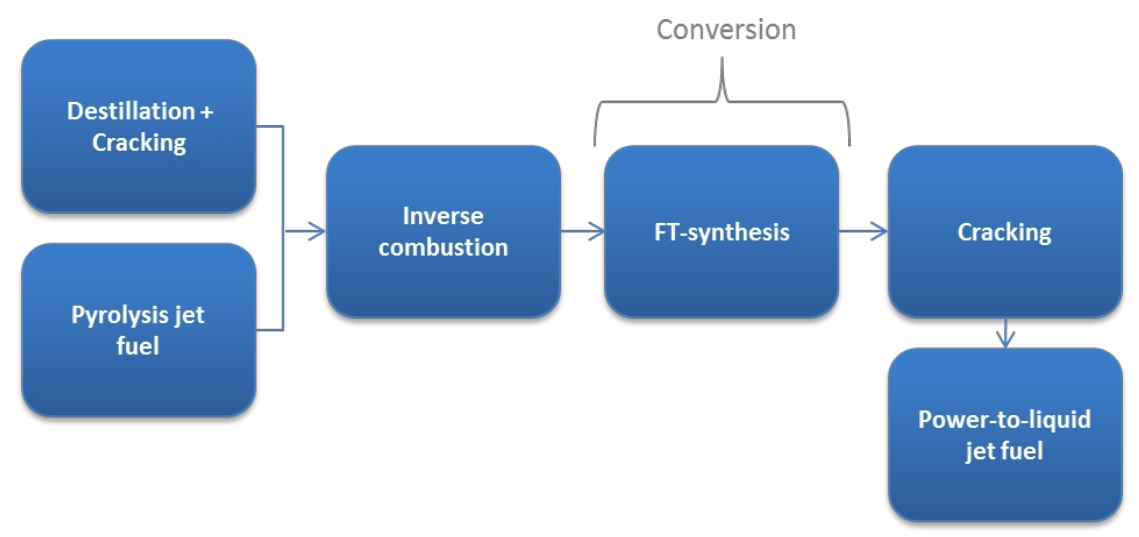

\subsection{Conversion efficiencies and product distribution}

The general conversion efficiency of a pathway determines how much of the original energy content in the feedstock can be converted to liquid hydrocarbon fuels (lhf). This conversion efficiency is different than the efficiency at which jet fuel can be produced, which depends on the size of the kerosene fraction of the produced lhf. Maximizing the general efficiency is critical to reduce the cost of the produced fuel and ensure a high degree of utilization from potentially limited available amounts of a given feedstock. The efficiency firstly depends on the content and properties of the feedstock and secondly on the physical/chemical processes and reactions involved in the pre-treatment and conversion.

The lignin content of a feedstock, e.g. in straw and forest residues, but also present in the husks of oil-crops like jatropha or palm oil, is harder to process and convert to lhf. Pathways relying on lignocellulosic feedstock will then produce a lignin fraction as a byproduct, which can contain as much as $50 \%$ of the original energy content in the feedstock (e.g. the approximate value for straw), lowering the general efficiency. The lignin fraction can, however, be used for other purposes, such as cofiring for heat and energy. An exception to this is pathways relying on gasification, pyrolysis and HtL. Depending on the temperature and pres- 
sure, a fraction of the lignin content can also be broken down and converted to $\mathrm{lhf}, 45$ increasing the general efficiency.

For the AtJ and the SIP pathways, $\mathrm{C}_{5}$ sugars have traditionally been harder to process and convert to fuels than $\mathrm{C}_{6}$ sugars, but new engineered types of yeast have successfully managed to also convert the $\mathrm{C}_{5}$ sugars from hemicellulose, eliminating $\mathrm{C}_{5}$-molasses as a by-product and increasing the general efficiency.

For the pathways relying only on the conversion step of hydroprocessing some kind of bio-oil, i.e. HEFA, HDCJ, pyrolysis and catalytic pathways, a higher oxygen to carbon and hydrogen content will increase the amount of hydrogen required. This will limit the amount that can realistically be processed into liquid fuels of sufficient quality, not only because of higher costs for hydrogen, but also resulting from a number of technical limitations related to processing bio-oils of high oxygen content and high consumption of hydrogen.

Considering the limitations imposed by feedstock composition and the pre-treatment and conversion steps of the different pathways, the general conversion efficiency from feedstock to $\mathrm{lhf}$ can span a very large range from as low as $20 \%$ and up to $80 \%$. The table below provides an overview of very general estimates for the expected efficiencies of pathways in combination with different feedstock.

While the general efficiency estimates the total amount of lhf that can be produced, the fraction of jet fuel (kerosene) in this amount depends on the product distribution. All pathways will produce different amounts of $\mathrm{lhf}$ ranging from lighter to heavier fuels, and the respective ratios between the fractions of gasoline (and lighter fuels), kerosene, diesel and heavier fuels, depends in particular on the catalyst used in the conversion step (i.e. the hydroprocessing reaction for HEFA, HTL, HDCJ and $\mathrm{CH}$, the Fischer-Tropsch reaction for FT, the oligomerization for At], the microbial conversion for SIP), but also on the feedstock content.

\footnotetext{
${ }^{45}$ Efforts to utilize lignin for production of biofuels is being investigated and pursued in a number of different projects, such as LignoJet and BioChemtex: http://www.biochemtex.com/sustainable-chemistry/moghi
} 


\begin{tabular}{|c|c|c|}
\hline Efficiency & Range & Pathways \\
\hline High end & $60-80 \%$ & $\begin{array}{l}\text { HEFA/HEFA+ } \\
\mathrm{FT}, \mathrm{HtL}, \mathrm{PtJ}, \mathrm{HDCJ} \text { and other pathways with a potential for high con- } \\
\text { version of lignin }\end{array}$ \\
\hline Medium & $35-60 \%$ & $\begin{array}{l}\mathrm{FT}, \mathrm{HtL}, \mathrm{PtJ}, \mathrm{HDCJ} \text { and other pathways with potential for some con- } \\
\text { version of lignin } \\
\text { AtJ and SIP based on sugar crops }\end{array}$ \\
\hline lower end & $20-35 \%$ & AtJ and SIP on lignocellulosic biomass \\
\hline
\end{tabular}

Regardless of pathway, the fraction of kerosene range $\mathrm{lhf}$ is generally quite small, typically in the range of $10-20 \%$, while the fractions of naphtha and diesel (and heavier fractions) are larger, around $20-30 \%$ and $40-70 \%$, respectively. The exact ranges depend on a variety of factors and will be different for each pathway. The production distribution can, however, be changed if it is desirable to increase a certain fraction. Increasing the kerosene fraction is done by fractioning (cracking), typically by hydrocracking. This splits longer hydrocarbon chains, such as longer diesel chains of 15-21 carbon atoms into one chain in the kerosene range, 9-16 carbon atoms, and one chain in the gasoline or lower naphtha- and gas range of 1-8 carbon atoms.

The resulting new product distribution has a higher fraction of kerosene, lower fraction of diesel, but also a higher fraction of short-range fuels of lower value, and an overall loss of middle-distillate. The cracking itself is an additional step incurring further costs and is from an economical perspective only favorable if the end products can be sold at higher profits than the intermediary products before cracking. 
Figure 11: Figure 1. Fractionation and product slate

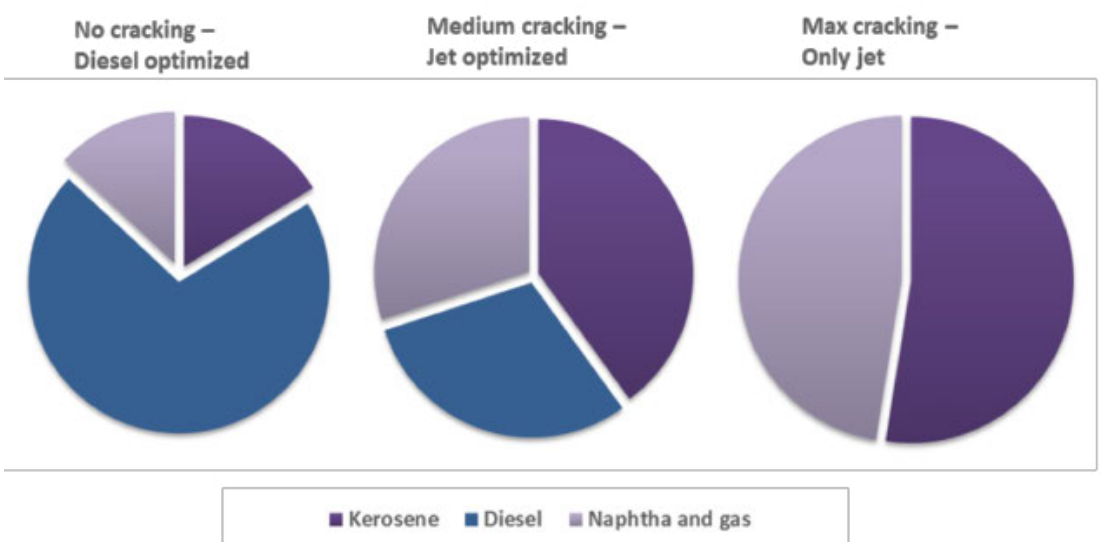

Note: The figure illustrates the concept of how cracking can increase the fraction of kerosene by decreasing the diesel fraction and increasing the fraction of naphtha and gas, resulting in a net loss of middle-distillate.

\subsection{Technical complexities in sustainable jet fuel production}

Compared to producing fossil jet fuel in a conventional petroleum refinery, producing jet fuel from biomass introduces a number of technical complexities. The higher oxygen content of the renewable feedstock results in a highly exothermic reaction during hydroprocessing and heat production up to 10 times as much as for an equal volume of fossil feedstock. Furthermore, the reaction produces higher amounts of water and gasses (methane, propane, $\mathrm{CO}$ and $\mathrm{CO}_{2}$ ), which must be removed to prevent a reduced catalyst activity and coke formation. As explained in the section above, the hydrogen requirement is also significantly higher, typically 5-10 times as much as for a fossil feed (as much as $400 \mathrm{Nm}^{3}$ per $\mathrm{m}^{3}$ processed feed), which can well constitute more than $10 \%$ of the total cost per liter of produced fuel. ${ }^{46}$ Moreover, infrastructure capable of providing such large amounts of hydrogen may not be available in locations that would otherwise be ideal for a production facility.

\footnotetext{
46 This calculation has been made on the assumption of a hydrogen price of about EUR $0.5 / \mathrm{Nm}^{3}$, a requirement of $300 \mathrm{Nm}^{3}$ per $\mathrm{m}^{3}$ of produced fuel and a final production cost of EUR $1.5 / \mathrm{l}$ jet fuel. The price of hydrogen is however, highly dependent on the method used to produce hydrogen, either steam methane reforming or electrolysis, and the price of natural gas or electricity respectively.
} 
Renewable feedstock, in particular bio-oils, with a high content of free fatty acids results in corrosion of pipes and other equipment, which must consequently be made of more durable, corrosive resistant and expensive material in order to handle such feed.

Finally, renewable feedstock contains a larger number of impurities, in particular metals, which can cause deactivation of reactions when accumulating. Removing such metals is a crucial pre-treatment step before further processing and conversion for many feedstocks.

For some of the complexities technical solutions exist, albeit at increased costs. However, for some feedstock and conversion technologies relatively little experience at large scale operations exists. This is especially the case for gasification of lignocellulosic feedstock, such as straw and forest residues, but also for the processes of lower maturity in general, such as hydrothermal liquefaction and catalytic hydrothermolysis. It is plausible that for such processes, additional, and as of yet unidentified, complexities could exist, and these represent a considerable risk for future producers of sustainable jet fuel and investors.

\subsection{Nordic technologies, role in pathways and maturity}

This section examines the Nordic technologies and suppliers which are considered relevant for a Nordic production of sustainable jet fuel, elaborating on their potential role in the different pathways and the individual processing steps, as well as on the technological maturity. The technologies and suppliers can be divided into four categories:

1. Producers of sustainable jet fuel. This includes only companies who are specifically pursuing the production of sustainable jet fuel.

2. Producers of other biofuels, e.g. diesel, ethanol, DME, gaseous fuels and others.

3. Producers of intermediates and technology components in biofuel production. This includes producers of bio-oils for further processing, but also any refining and pre-treatment technologies.

4. Petroleum refineries. This includes only the Nordic petroleum oil refineries. 
For the first category, only Finland, among the Nordic countries, possesses a complete and existing technological infrastructure for the production of sustainable jet fuel at a commercial level. Smaller initiatives for a full sustainable jet fuel production also exist, but these have only been demonstrated at lab or pilot scale (see table below). The majority of the Nordic technologies and suppliers, however, falls into the second, third and fourth categories.

\subsubsection{Technological maturity - Fuel Readiness level and Feedstock Readiness level}

For the first two categories, producers of sustainable jet fuel and producers of other biofuels, the technological maturity for production facilities can be assessed using the Fuel Readiness Level (FRL) tool, and the feedstock supply chain by the Feedstock Readiness Level (FSRL) tool, developed by CAAFI. Both tools are here presented in abbreviated versions.

The feedstock readiness level tool uses the same nine levels as the fuel readiness level tool, but with different process landmarks at the various levels, pertaining to the maturity of the feedstock supply chain rather than the biofuel conversion technology.

\begin{tabular}{|c|c|c|}
\hline \multicolumn{2}{|c|}{ Level } & \multirow{2}{*}{$\begin{array}{l}\text { Maturity } \\
\text { Feedstock /process principles identified }\end{array}$} \\
\hline 1 & $\begin{array}{l}\text { Basic principles observed and } \\
\text { reported }\end{array}$ & \\
\hline 2 & Technology concept Formulated & Feedstock /complete process identified \\
\hline 3 & Proof of concept & $\begin{array}{l}\text { Lab-scale fuel sample produced from realistic production feedstock. } \\
\text { Energy balance analysis executed for initial environmental assess- } \\
\text { ment. Basic fuel properties validated }\end{array}$ \\
\hline 4 & Preliminary technical Evaluation & $\begin{array}{l}\text { System performance and integration studies entry criteria/ } \\
\text { specification properties evaluated }\end{array}$ \\
\hline 5 & Process validation & Sequential scaling from laboratory to pilot plant \\
\hline 6 & Full-scale technical Evaluation & Fitness, fuel properties, rig testing and engine testing \\
\hline 7 & Fuel approval & Fuel class/type listed in international fuel standards \\
\hline 8 & Commercialization Validated & $\begin{array}{l}\text { Business model validated for production purchase agreements - } \\
\text { Facility specific GHG-assessment conducted to internationally ac- } \\
\text { cepted methodology }\end{array}$ \\
\hline 9 & Production capability established & Full-scale plant operational \\
\hline
\end{tabular}


Table 15: The 9 levels of the Feedstock Readiness Level tool

\begin{tabular}{|c|c|c|}
\hline \multicolumn{2}{|c|}{ Level } & \multirow{2}{*}{$\begin{array}{l}\text { Maturity } \\
\text { Identify potential feedstock for a specific conversion technology, } \\
\text { current producers, feedstock and coproduct users and wastes }\end{array}$} \\
\hline 1 & $\begin{array}{l}\text { Basic principles observed and } \\
\text { reported }\end{array}$ & \\
\hline 2 & Concept formulated & $\begin{array}{l}\text { Identify production processes, logistics and consequences of } \\
\text { commercial scale feedstock production }\end{array}$ \\
\hline 3 & Proof of concept & $\begin{array}{l}\text { Estimate feedstock production costs and evaluate current and a } \\
\text { Iternative future scenarios for establishing a feedstock sector }\end{array}$ \\
\hline 4 & Preliminary technical evaluation & $\begin{array}{l}\text { Compare performance of candidate feedstock with alternative choices. } \\
\text { Identify supply chains and logistics for feedstock }\end{array}$ \\
\hline 5 & Production system validation & $\begin{array}{l}\text { Develop and validate supply chain and budget for large scale } \\
\text { production }\end{array}$ \\
\hline 6 & Full-scale production initiation & Established feedstock production/collection and scale-up process \\
\hline 7 & Feedstock availability & $\begin{array}{l}\text { First commercial-scale collection/delivery of feedstock to production } \\
\text { facilities }\end{array}$ \\
\hline 8 & Commercializtion & Monitor and improve production system and supply chain \\
\hline 9 & $\begin{array}{l}\text { Sustainable feedstock produc- } \\
\text { tion capacity established }\end{array}$ & Market functions to support sustainable feedstock production \\
\hline
\end{tabular}

Note: Producers of jet fuel and other biofuels in the Nordic countries.

In the following table, the first category of technology suppliers, producers (or companies pursuing production) of sustainable jet fuel in the Nordic countries, is evaluated with respect to their fuel readiness and feedstock readiness level. 


\begin{tabular}{|c|c|c|c|}
\hline & Technological pathway & Feedstock & Readiness level \\
\hline Neste Oil & HEFA & $\begin{array}{l}\text { Multiple veg. waste-oils, animal fats, } \\
\text { used cooking oil, camelina }\end{array}$ & $\begin{array}{l}\text { FRL: } 7 \\
\text { FSRL: } 7\end{array}$ \\
\hline Cumulus Bio & AtJ & lignocellulosic feedstock & $\begin{array}{l}\text { FRL: } 2-3 \\
\text { FSRL: } 1\end{array}$ \\
\hline STEP & $\begin{array}{l}\text { Catalytic pressure less } \\
\text { depolymerisation }\end{array}$ & multiple organic wastes & $\begin{array}{l}\text { FRL: - } \\
\text { FSRL: - }\end{array}$ \\
\hline Swedish Biofuels & AtJ/FT & lignocellulosic feedstock & $\begin{array}{l}\text { FRL: - } \\
\text { FSRL: - }\end{array}$ \\
\hline GoBiGas & FT & lignocellulosic feedstock & $\begin{array}{l}\text { FRL: - } \\
\text { FSRL: - }\end{array}$ \\
\hline Synsel & Catalytic pyrolysis & lignocellulosic feedstock & $\begin{array}{l}\text { FRL: - } \\
\text { FSRL: - }\end{array}$ \\
\hline
\end{tabular}

Note: The readiness levels have been assessed according to own research and is only meant as guiding estimates. A dash - indicates that has not been possible to properly estimate the readiness level, though it is expected to be in the low end.

The next table evaluates the FRL and FSRL of the second category of the Nordic technology suppliers, producers of biofuels other than jet fuel. Additionally, the potential role and the pathways in which the technologies bear relevance to sustainable jet fuel are briefly summarized for each supplier.

The maturity of the Nordic technologies is an important indicator for their potential involvement in a pathway for sustainable jet fuel. However, most of the Nordic technologies are not aimed at producing jet fuel, and high technological maturity for any of the biofuel producers listed in the table above does not necessarily equate to an evident / obvious role in a pathway. 
Table 17: Technological and feedstock maturity of Nordic producers of biofuels

\begin{tabular}{|c|c|c|c|}
\hline Producers of Biofuels & Technology and role in pathway & $\begin{array}{l}\text { Relevant in } \\
\text { pathways }\end{array}$ & $\begin{array}{l}\text { Fuel and feedstock } \\
\text { readiness level }\end{array}$ \\
\hline \multicolumn{4}{|l|}{ Finland } \\
\hline Neste Oil (diesel) & $\begin{array}{l}\text { Production of renewable diesel from } \\
\text { vegetable oils, can potentially produce } \\
\text { HEFA+ for aviation if certified }\end{array}$ & HEFA/HEFA+ & $\begin{array}{l}\text { FRL: } 9 \\
\text { FSRL: } 9\end{array}$ \\
\hline UPM & $\begin{array}{l}\text { Production of renewable diesel from tall } \\
\text { oil. Know-how on biorefining and integra- } \\
\text { tion with forest industry and use of tall oil } \\
\text { as a feedstock }\end{array}$ & HEFA/HEFA+ & $\begin{array}{l}\text { FRL: } 9 \\
\text { FSRL: } 9\end{array}$ \\
\hline St1 & $\begin{array}{l}\text { Production of bioethanol from wastes and } \\
\text { residues to the transportation sector. } \\
\text { Potential for further processing into jet fuel. }\end{array}$ & AtJ, SIP & $\begin{array}{l}\text { FRL: } 6 \\
\text { FSRL: } 4\end{array}$ \\
\hline \multicolumn{4}{|l|}{ Denmark } \\
\hline Emmelev & $\begin{array}{l}\text { Production of biodiesel from rapeseed oil. } \\
\text { Know-how on large scale hydrotreating } \\
\text { and refining of vegetable oil }\end{array}$ & HEFA/HEFA+ & $\begin{array}{l}\text { FRL: } 9 \\
\text { FSRL: } 9\end{array}$ \\
\hline DAKA & $\begin{array}{l}\text { Production of biodiesel from animal fats } \\
\text { and wastes. Know-how on large scale } \\
\text { hydrotreating and refining of animal fats } \\
\text { and wastes }\end{array}$ & HEFA/HEFA+ & $\begin{array}{l}\text { FRL: } 9 \\
\text { FSRL: } 9\end{array}$ \\
\hline \multicolumn{4}{|l|}{ Sweden } \\
\hline $\begin{array}{l}\text { Lantmännen Agroeta- } \\
\text { nol }\end{array}$ & $\begin{array}{l}\text { Production of bioethanol from grain and } \\
\text { wastes. Potential further processing into } \\
\text { jet fuel and know how on large scale } \\
\text { production of bioethanol }\end{array}$ & AtJ, SIP & $\begin{array}{l}\text { FRL: } 9 \\
\text { FSRL: } 9\end{array}$ \\
\hline $\begin{array}{l}\text { Preem biorefinery, } \\
\text { Gothenburg }\end{array}$ & $\begin{array}{l}\text { Produces diesel with renewable content } \\
\text { from tall oil. Know how on retrofitting } \\
\text { concepts and utilization of existing fossil } \\
\text { refining capacity for biofuel production }\end{array}$ & $\begin{array}{l}\text { Multiple path- } \\
\text { ways, relying on } \\
\text { fossil retrofit- } \\
\text { ting concepts } \\
\text { for refining }\end{array}$ & $\begin{array}{l}\text { FRL: } 9 \\
\text { FSRL: } 9\end{array}$ \\
\hline Chemrec & $\begin{array}{l}\text { Gasification of black liquor to produce } \\
\text { syngas and further processing into DME } \\
\text { and biomethanol. Know-how and tech- } \\
\text { nology for black liqour gasification }\end{array}$ & FT & $\begin{array}{l}\text { FRL: - } \\
\text { FSRL: - }\end{array}$ \\
\hline SEKAB Biorefinery & $\begin{array}{l}\text { Know-how, technology and production of } \\
\text { bioethanol from wastes and residues. } \\
\text { Potential for further processing into jet fuel. }\end{array}$ & AtJ, SIP & $\begin{array}{l}\text { FRL: - } \\
\text { FSRL: - }\end{array}$ \\
\hline \multicolumn{4}{|l|}{ Norway } \\
\hline Borregaard & $\begin{array}{l}\text { Production of bioethanol from wood } \\
\text { residues. Potential further processing into } \\
\text { jet fuel, know how on biorefining con- } \\
\text { cepts from lignocellulosic biomass }\end{array}$ & AtJ, SIP & $\begin{array}{l}\text { FRL: } 9 \\
\text { FSRL: } 9\end{array}$ \\
\hline
\end{tabular}

Note: The readiness levels have been assessed according to own research and is only meant as guiding estimates. A dash - indicates that has not been possible to properly estimate the readiness level, though it is expected to be in the low end. 


\subsubsection{Producers of intermediates and technology components}

For the final two categories of the Nordic technology suppliers, Producers of intermediates and technology components and refineries, the FRL and FSRL tools bear less relevance. The feasibility of integrating these technology suppliers depend more strongly on other factors. Moreover, some of the intended roles of these suppliers will likely be in the form of supplying know-how rather than actual technologies. The following table lists the potential role and relevance in pathways for the different suppliers in the third category.

\begin{tabular}{|c|c|c|}
\hline & Technology and potential role in pathway & $\begin{array}{l}\text { Relevant in } \\
\text { pathways }\end{array}$ \\
\hline \multicolumn{3}{|l|}{ Denmark } \\
\hline Novozymes & Enzymes for hydrolysis of lignocellulosic biomass & AtJ, SIP \\
\hline Estibio & $\begin{array}{l}\text { Microorganisms for catalysing anaerobic fermentation of sugars to } \\
\text { ethanol }\end{array}$ & AtJ, SIP \\
\hline BIOGASOL & $\begin{array}{l}\text { Pretreatment technology for enzymatic hydrolysis of lignocellulosic } \\
\text { biomass }\end{array}$ & AtJ, SIP \\
\hline Terranol & Yeast cultures for ethanol fermentation & AtJ, SIP \\
\hline Inbicon/MEC & Biorefinery for production of bioethanol from straw & AtJ, SIP \\
\hline Haldor Topsøe & $\begin{array}{l}\text { Catalysts and refining technology, including hydrotreatment, } \\
\text { cracking and reforming/conditioning of syngas }\end{array}$ & $\begin{array}{l}\text { Potentially all } \\
\text { pathways }\end{array}$ \\
\hline Steeper Energy & $\begin{array}{l}\text { Production of bio-oil by hydrothermal liquefaction for further } \\
\text { processing }\end{array}$ & $\mathrm{HtL}$ \\
\hline Green Hydrogen & Technology for hydrogenproduction by electrolysis & $\begin{array}{l}\text { Potentially all } \\
\text { pathways }\end{array}$ \\
\hline TK Energy & Technology for feeder systems in gasification & FT \\
\hline \multicolumn{3}{|l|}{ Finland } \\
\hline Fortum & $\begin{array}{l}\text { Production of pyrolysis oil from wood residuals for further } \\
\text { processing and refining }\end{array}$ & $\begin{array}{l}\text { PtJ and other } \\
\text { new pathways }\end{array}$ \\
\hline Forchem & Processesing and refinering of tall oil to further products & HEFA \\
\hline Metgen & $\begin{array}{l}\text { Enzymes for biofuels and biochemicals production from } \\
\text { lignocellulosic feedstock. }\end{array}$ & AtJ \\
\hline Green Fuel Nordic & $\begin{array}{l}\text { Production of pyrolysis oil from wood residuals for further } \\
\text { processing and refining }\end{array}$ & $\begin{array}{l}\text { PtJ and other } \\
\text { new pathways }\end{array}$ \\
\hline Andritz & $\begin{array}{l}\text { Gasification technology and pre-treatment technology for wood } \\
\text { biomass }\end{array}$ & FT \\
\hline
\end{tabular}




\begin{tabular}{|c|c|c|}
\hline & Technology and potential role in pathway & $\begin{array}{l}\text { Relevant in } \\
\text { pathways }\end{array}$ \\
\hline Valmet & $\begin{array}{l}\text { Gasification technology, various technology components for bioe } \\
\text { thanol production, pre-treatment technology for wood biomass, } \\
\text { pyrolysis technology for bio-oil production }\end{array}$ & $\begin{array}{l}\mathrm{FT}, \mathrm{AtJ}, \mathrm{SIP}, \mathrm{PtJ} \\
\text { and other new } \\
\text { pathways }\end{array}$ \\
\hline Foster Wheeler & $\begin{array}{l}\text { Technology component for various refining steps, including } \\
\text { hydrotreatment and hydrocracking }\end{array}$ & $\begin{array}{l}\text { potentially all } \\
\text { pathways }\end{array}$ \\
\hline NesteJacobs & $\begin{array}{l}\text { Various technology components for both thermochemical and } \\
\text { biochemical biorefinery concepts }\end{array}$ & $\begin{array}{l}\text { potentially all } \\
\text { pathways }\end{array}$ \\
\hline \multicolumn{3}{|l|}{ Sweden } \\
\hline GoBiGas & Technology and know-how for gasification of forest residuals & FT \\
\hline Sunpine & $\begin{array}{l}\text { Production of tall oil diesel from tall oil for further processing and } \\
\text { refining into biofuels }\end{array}$ & HEFA \\
\hline RenFuel $2 \mathrm{~KB} A B$ & $\begin{array}{l}\text { Production of catalytic lignin oil for further processing and refining } \\
\text { into biofuels }\end{array}$ & $\begin{array}{l}\text { PtJ and other } \\
\text { new pathways }\end{array}$ \\
\hline
\end{tabular}

\subsubsection{Technology profiles and new biofuel initiatives by country}

\section{Denmark}

Most of the Danish technologies are related to bioethanol production, such as the enzymes and fermentation technology provided by Novozymes, Biogasol and Estibio. Within refining technology, Haldor Topsøe represents a strong asset relevant in all pathways.

Inbicon and MEC are also near-commercial and commercial technologies. The final element of MEC, notably the bioethanol production facility, remains to be constructed before MEC can be a part of a Nordic pathway of sustainable jet fuel production.

All the Danish technologies listed have not been used in any relation to the production of jet fuel, with the exception of Cumulus Bio, who is at an early concept stage for developing a full pathway, and Haldor Topsoe, whose refining technology and catalysts have been used in a number of actual jet fuel productions globally.

\section{Finland}

In Finland, the technology for producing aviation biofuels already exists in the form of Neste's production facilities. Neste has also been active in developing ASTM standard specifications for renewable aviation fuel, and put resources on research and development on the field, including, 
for example, a EUR 10 million EU project aiming at developing a full value chain to use camelina for providing jet fuel at large scale. ${ }^{47}$ So far, sustainable jet fuel has only been produced in batches by Neste and further investments are needed to enable continuous production.

In addition to Neste, several other companies are producing transportation biofuels, but have so far indicated no interest to invest in aviation fuels at the current stage of commercialization.

Finland also has a strong network of technology providers (machinery and equipment) and engineering companies with an extensive track record within bioenergy and forest industry. They have been closely involved in the development of biofuels in partnerships with their customers. For example, Fortum, UPM and Valmet together are developing catalytic pyrolysis technology for upgrading bio-oil to higher value bio liquids. Also several engineering companies have specific expertise on the field. In 2007-2012 an innovation programme worth of EUR 242 million was run by the National Innovation Agency (Tekes) on biorefining. It focused on biofuels production (especially gasification) including also several projects on future raw material sources such as microbial oil.

Metsä Fibre, part of forest-company Metsä Group, has in 2015 decided to build a bioproduct mill in Äänekoski, near an existing pulp mill, which will be the largest forest industry investment ever in Finland (Bioproductmill 2015). The mill is scheduled to be completed in 2017. The annual pulp production will be around 1.3 million tons. In addition to pulp, it will produce a broad range of bioproducts, such as tall oil, turpentine, lignin products, electricity and wood fuel. All side streams are planned to be utilized in the ecosystem that will be formed by various companies around the mill.

The Finnish potential biofuel producers have also shown a strong interest in developing the technologies. In addition to the already mentioned companies, examples include Green Fuel Nordic and Chempolis. Although not considering aviation biofuel production as such, all these companies are looking for further refinement and higher value added products as potential further revenue streams.

The Finnish pathway is lacking actors (outside forest industry) especially in the start of the value chains (in the raw material production and pre-treatment). Despite of research and development devoted to this area, availability and price of feasible raw materials is a challenge (from

47 Over 1,000 tons of biokerosene, the project was running years 2012-2015. For Lufthansa, Neste provided 800 tons of biokerosene during 6 months for the flights between Frankfurt and Hamburg. More information https://www.neste.com/na/en/customers/products/renewable-products/nexbtl-renewable-aviation-fuel-0 
the fuel producers' point of view). Currently the forest companies are opening their ecosystems and side streams to potential partners. For example the upcoming Äänekoski pulp mill is looking for partners interested in utilizing their saw dust, tall oil, lignin and sludge for further processing and production of new products.

\section{Norway}

The abundance of oil and gas on the one side and water on the other side explain that the energy use in Norway is primarily covered by hydropower and fossil fuels, contributing with a share of up to $92 \%$ of the total energy consumption. In this scenario, bioenergy represents only $7 \%$ of the total energy use. In contrast to the other Nordic countries, this fact in combination with the need for high investment costs as well as the lack for long-term stable policies and strong incentives have been major barriers for the development of a strong bioenergy and biofuel market in Norway.

As of today, Norway only has one producer of biofuel (Borregaard) that produces bioethanol, which is, however, only a byproduct of other production.

Looking ahead, there are four planned and upcoming industrial initiatives for production of biofuels. The first one is a joint venture agreement between Statkraft and Södra through the establishment of a new company for production of second generation biofuels for sectors with few sustainable alternatives such as heavy transport and aviation. Heavy duty road transport will be the main focus in the first phase. The planned production plant will have a capacity between 50-100 million 1/year. The production plant will be located at Tofte, Eastern Norway, where Södra Cell Tofte had their old cellulose factory (NRK, 2015), taking advantage of this existing infrastructure, with easy access to large quantities of local wood and a port for potential imports of biomass.

The second major industrial initiative is led by Viken Skog and their subsidiary company Treklyngen (Treklyngen, 2015). The latter has since 2011 owned the property where Norske Skog had their paper mill located at Follum, also Eastern Norway (TU, 2014). Their main goal is to develop a new sustainable future oriented forest industry cluster, where production of second generation biofuels is among their main activities along with other bioenergy purposes, sawmill operations and cellulose production.

In order to speed up the realization of these industrial initiatives, a so called national incubator, Pan Innovasjon A/S, was established in 2011 (Pan Innovasjon, 2015). In particular Pan Innovasjon aims at encouraging entrepreneurship and assisting new businesses in developing and commercialising new technology and innovative products within the forestry based industry. 
At smaller scale there are two additional initiatives under development and worth mentioning. One of them is developed by Synsel Scandinavia AS (Synsel, 2015), based in Larvik, Norway and owned by Bergene Holm AS (Saw Mill Company) and Synsel Energy INC from Chicago. Synsel is aiming to commercialize a catalytic thermochemical conversion process for production of synthetic fuels. The initial focus will be on production of biodiesel, biogasoline and biojetfuel. Four production plants are planned in Scandinavia and the first plant is expected to be in the region of Amli next to an existing saw mill in the Aust Agder province, in Southern Norway, with the intention to provide second generation biofuels to all the municipalities in this region. The company has the ambition to start building up their first commercial facility, use 1,000 BDT feedstock with a production capacity of about 342,000 liters/day (TA, 2015), by 2019.

The fourth planned initiative in Norway for production of sustainable biofuels is from the company Biofuel Development (FB, 2015). It is planned a feasibility study that will evaluate whether it is economically feasible to establish a sustainable jet fuel production plant based on municipal waste at Fredrikstad (Østfold province), Southern Norway. The production plant would process up to 2,000 t/day of municipal waste with plasma gasification conversion technology.

It is also worth noting the establishment of a national R\&D laboratory for biorefining, known as NorBioLab. This laboratory shall contribute to the development of future technologies for conversion of both land (forestry and agricultural) based biomass as well as marine biomass. The most conceivable and promising conversion routes will be tested and simulated, both at lab and pilot scale. NorBioLab was funded by the Research Council of Norway in October 2013, with a total investment of NOK 37.5 million and duration of 8 years (2014-2021).

\section{Sweden}

As of today there is no existing commercial production of sustainable jet fuel in Sweden. The amounts of biojet used in Sweden are imported and produced on-demand. However, there are a number of facilities currently producing biofuel for the transportation sector such as ethanol, biodiesel and biogas from biomass feedstock. Moreover, existing industry capacity is often integrated in clusters where various types of chemicals and products are produced in an efficient way.

Available industry clusters, refineries and biorefineries in Sweden provide a good basis for developing a sustainable jet fuel production chain in Sweden. For example, renewable diesel is produced from tall oil which is a residue from the forest industry. The tall oil is transported by 
ship From Piteå in Northern Sweden to the Port of Gothenburg. At the refinery in Gothenburg, the tall oil is refined together with fossil diesel, making the final product identical to fossil fuel, but with renewable content. The refinery in Gothenburg could theoretically be used to produce bio jet fuel as well, given that the production of bio jet fuel is commercially viable. 


\section{Most Promising Pathway Scenarios}

This section focuses on discussing the most promising pathway scenarios. First, the pathway scenarios which are most promising in terms of market and technology maturity are presented (chapter 9). This is followed by a discussion on the Nordic comparative advantages for these pathway scenarios (chapter 10) and how international actors may contribute to strengthen the development of sustainable jet fuel in the Nordic countries (chapter 11). 



\section{Most promising pathway scenarios for Nordic collaboration}

This chapter will identify three of the most promising pathway scenarios for a Nordic production of sustainable jet fuel. First, we present a set of evaluation criteria against which the feasibility of any pathway scenario can be gauged. These criteria are based on the findings of chapter 3-8. Secondly, the different feedstock and conversion technologies found in chapter 6 and 8 are considered in light of these criteria and unfeasible options are sorted out. Finally, three pathway scenarios are chosen, based on the most feasible candidates of feedstock and conversion technologies.

\subsection{Evaluation criteria}

- Feedstock price: Chapter 6 lists estimates of some of the potential Nordic feedstock, with prices ranging from about EUR 5-8/GJ, though many cost estimates are uncertain and highly depending on competing utilization. The cost structure has been estimated for a number of pathways and feedstock generally comprises a major fraction for all pathways, e.g. about $50 \%$ for Atj using Norwegian wood (Avinor 2013) and up to 70\% for a US based HEFA (MASBI 2013). The cost pr. liter for sustainable jet fuel is currently (as of mid 2016) very high relative to fossil fuel with estimates ranging from $2-$ 5 times as high, and using a cheap feedstock is one of the key measures for reducing this price gap.

- Feedstock availability: A dedicated commercial sustainable jet fuel production requires a stable and sufficient flow of feedstock to sustain production. Securing the required amounts may prove highly challenging. Chapter 6 mentioned studies that have attempted to quantify the amount of feedstock available for sustainable jet fuel production, such as straw or wood residuals. Some feedstock is seen as more promising than others. Feedstock estimates are often theoretical and the real availability may be significantly different, e.g. 
due to considerations of economy, transportation distances, sustainability and competing markets. Moreover, the availability may also change over time.

- Competing markets for feedstock: All the feedstock candidates in a Nordic perspective face existing competing markets. Biofuel production for road transport shares the same feedstock base as sustainable jet fuel, and this base is also used for heat and power production. For instance, wood-biomass from Norway, Sweden and Finland is currently being used also for renewable diesel production, heat and power production, processing to wood pellets for heating or into wood-fibre board. A high demand for all the attractive feedstock candidates is expected to persists, and the share available for sustainable jet fuel production should be considered in this light.

- Sustainability of feedstock and production: Depending on the chosen feedstock and production pathway, the GHG intensity of a sustainable jet fuel may be highly variable. Chapter 4 lists estimates ranging from a $30-90 \%$ GHG-reduction relative to conventional fossil jet fuel. Feedstock cultivated with an associated large land use change impact is especially considered unfavourable from a sustainability point of view. Other factors of influence on the GHG intensity regard the use of other inputs, such as energy, hydrogen, the efficiency of the conversion process itself and possible substitution effects from byproducts. In addition to GHG intensity, other parameters of sustainability also influence the choice of feedstock and production (see chapter 3).

- Conversion technology cost, maturity and complexity: Chapter 8 showed more than 13 possible conversion technology pathways. Some have been demonstrated at a commercial level, while others are only operating at pilot scale or at earlier stages of development. It is important to be aware of the uncertainties and risks associated with conversion technologies of lower maturity, which investors and the production companies themselves may be unwilling to accept. This can for instance be complexities like accumulation of metals and other impurities, corrosion of equipment or excess heat production. An important factor is the consumption of hydrogen, which is very costly and energy-intensive to produce, and the required amounts may not be available in locations that would otherwise be ideal for a production facility, which necessitates the construction of nearby hydrogen production capacity, further increasing costs. 
- Conversion efficiency and product distribution: The different pathways presented in chapter 8 have different conversion efficiencies and different byproducts can be produced depending on the choice of feedstock. Most pathways will produce only a very small amount of kerosene, and fractionation is required to increase this amount, introducing a trade-off between higher yields of jet quality fuel and lower value products.

\subsection{Most promising feedstock}

Table 7 in chapter 5 estimated the demand for feedstock for sustainable jet fuel to be around $15 \mathrm{PJ} /$ year by 2020 and increasing to around $470 \mathrm{PJ} / \mathrm{yr}$ by 2050 (corresponding to around 1 million tons in 2020 and 31 million tons in 2050). ${ }^{48}$ The choice of the different feedstock used must be able to match this demand on the aggregate level. Table 8 in chapter 6 summarizes the availability of the Nordic feedstock candidates. Compared to the demand it is clear that more than one source of feedstock is required.

Wood residuals are deemed the feedstock of the most promising availability with estimates well over a few hundred PJ, though such estimates are highly variable when taking into account the technical and economic limitations. Currently, most Nordic forests are in net growth, producing more than is harvested, representing a large potential for utilization. Prices are likely to be highly dependent on the country and area from which the feedstock is sourced, the transportation distances and any competing utilization, such as for heat and energy. Among the locations of existing and planned bio-production facilities in Finland, Norway and Sweden, a common denominator is proximity to large concentrations of forest biomass as well as infrastructure related to forestry and pulp and paper industry. Placing a sustainable jet fuel production facility in such key locations should also be regarded as a vital measure to secure easy access to feedstock and take advantage of existing infrastructure to reduce costs and simplify logistics.

For straw, the estimated availability is also promising, albeit lower than for wood residuals, with a total potential around 36 PJ in Denmark and Sweden combined. In both countries a significant amount of straw is already harvested and utilized for heat and power production. A large

\footnotetext{
${ }^{48}$ The feedstock amount in tons is calculated on the assumption of an average value of $15 \mathrm{GJ} /$ ton for the energy content of feedstock.
} 
fraction, though, is still left to compost on fields, which may be claimed for biofuel production.

Much attention has been given to the use of smaller waste fractions, such as waste oils (also known as used-cooking oil). The availability of these fractions in the Nordic countries is very small compared to the required demand, and any pathway relying only on waste oils will thus depend on import from other countries. It is, however, still considered an attractive feedstock as it requires very little processing and is considered relatively cheap.

Although Municipal solid waste (MSW) amounts to over 40 million tons annually in the Nordic countries, it is not considered a viable feedstock. This is especially true within the shorter timeframe. The vast majority is currently used for incineration for heat and energy production as well as recycling, and MSW is even imported in Denmark and Sweden due to an existing over-capacity of incineration plants. Diverting larger amounts of MSW away from its current utilization in the Nordic countries and towards biofuel production is unlikely to happen within a short timeframe. On the longer term it is, however, possible that the organic fraction of MSW may become available for biofuel production in the wake of cheap and efficient sorting technologies for MSW emerging on the market.

At the moment, a few projects have successfully managed to utilize the organic fraction of MSW for biogas production and as both sorting and biofuel production technologies mature, this fraction could eventual$l y$ be utilized for biofuel production.

Energy crops are grown on only small number of hectares in Sweden and Denmark which amounts to less than $5 \mathrm{PJ}$ annually. Most of this is currently used for generating heat and energy, and while the total cultivation area could be expanded, this would be in direct competition with agricultural land for food production and is thus deemed unlikely. This feedstock is then not considered as a viable option, though it may constitute a side-stream to a pathway relying on wood-residuls and straw. 


\subsection{Most promising conversion technology pathways}

Out of the pathways presented in chapter 8 , three options emerge as advantageous to the others: The first two are HEFA ${ }^{49}$ and FT, which are already ASTM-certified, and demonstrated at a high technological maturity. Following is AtJ, with an expected ASTM-certification in 2016, and similarly high technological maturity. Moreover, several Nordic technology suppliers relevant for these three pathways in particular have been identified in chapter 7.

The SIP pathway is also certified and demonstrated at near commercial scale, but is in a Nordic context unlikely to be economically feasible if using anything other than high sugar-content crops such as sugarcane or beet.

The remaining pathways, i.e. HDCJ, HtL, CH, PtL and PtJ (and microbial conversion of $\mathrm{CO}_{2}$ ) are currently not certified. The certification time for FT and HEFA took several years, but a shorter processing time is generally expected for future pathways. In addition to not being certified, these remaining pathways have not been demonstrated at a level greater than pilot scale. They are thus of much lower technological maturity, and associated with greater uncertainties and risks. It will consequently take several years, if not decades, before these pathways can be realized at a commercial level, while the AtJ, FT and HEFA/HEFA+ pathways could be realized much earlier.

\subsection{Identification of the most promising scenarios}

From the reasoning in the previous sections, the best feedstock candidates are wood residuals, straw and waste oils, and the best technology candidates are AtJ, FT and HEFA. The most promising pathway scenarios for a Nordic production of sustainable jet fuel are then chosen to be:

- HEFA/HEFA+ based on waste-oils and oil crops.

- Fischer-Tropsch (FT) on wood residuals.

- Alcohol-to-Jet (AtJ) on straw and wood residuals.

${ }^{49} \mathrm{HEFA}+$, is considered to be at least as equally mature as HEFA once ASTM-certified (expected in 2016/2017). 
These scenarios are not considered mutually exclusive and can theoretically be implemented simultaneaously in the Nordic countries. For each scenario, the following topics are investigated in the following sections:

- Feedstock: The ideal feedstock is discussed for each scenario along with an estimated price and availability.

- Processes and infrastructure: Discusses the different stages and technology maturity for each scenario, along with the considerations of the location of production facilities. A general range for the conversion efficiency from feedstock to fuel is also estimated, while recognizing that more precise efficiency estimates will require a more detailed examining of a potential production facility, which is beyond the scope of this report.

- Product slate and bio-refining opportunities: This section discusses the different by-products that can be produced in each scenario, including other fuels and other higher- and lower value products, as well as the possibility for integrating the production of sustainable jet fuel in a bio-refining concept.

- Cost estimates: This section gives general considerations on the production costs for each scenario comprised of the three categories: feedstock costs, investment costs and operations costs. Price estimates are introduced based on the findings of this report, along with estimates from available literature. The scope of this report does not allow for precise cost estimates of each scenario, and the listed figures should not be relied upon to directly differentiate between the economic advantageousness of one scenario over another.

- Nordic Technology suppliers: Potential Nordic suppliers of technology and their role in the different stages of the scenarios are identified.

\subsection{Scenario 1: HEFA/HEFA+}

The following figure illustrates the process of the HEFA/HEFA+ pathway scenario. The different technology suppliers listed at the different stages are meant as examples and drawn from the full list of potential suppliers, shown in the end of this section. 
Figure 17: Process-diagram of Scenario 1

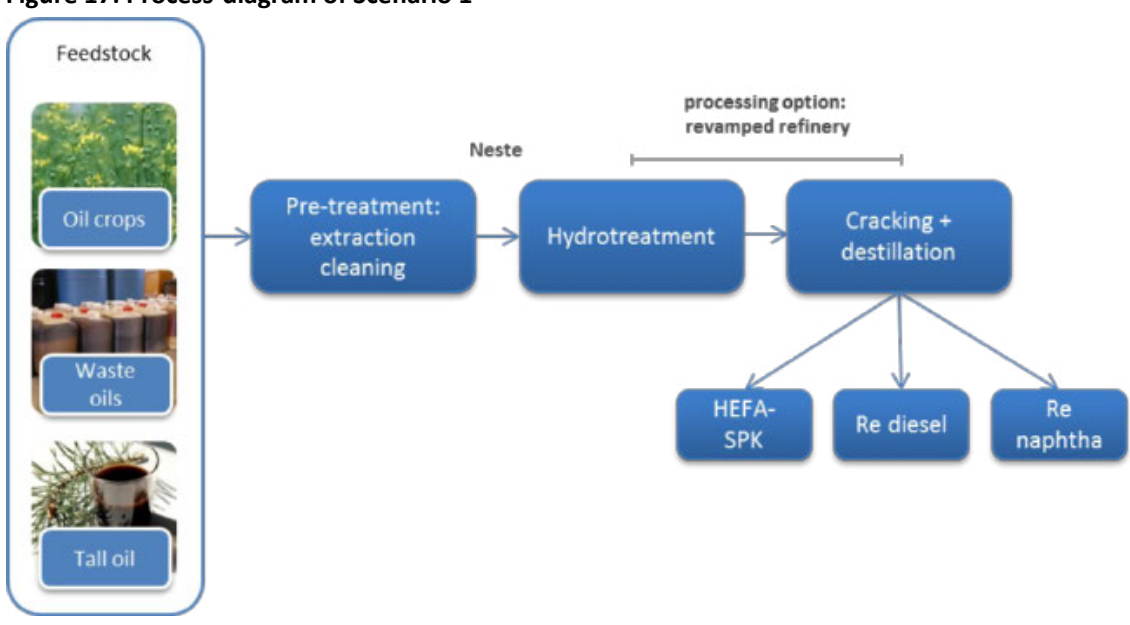

The first scenario utilizes waste oil (used cooking oil, animal fats, vegetable oils, etc), tall oil and oil-crops which are converted to jet fuel via the HEFA pathway. HEFA-SPK is ASTM-certified to a $50 \%$ blend-in. If HEFA+ is ASTM-certified as an annex to HEFA (see chapter 8 on HEFA+), this scenario could equally produce HEFA+ jet fuel for blending, albeit at a lower ratio around 10\% (IATA 2015). This scenario differs from the other two scenarios by relying mainly on imported feedstock.

\subsubsection{Feedstock}

This scenario relies on a multitude of different feedstocks in the form of waste oils and oil crops. The advantages of utilizing many smaller streams of feedstock are generally lower prices (an important aspect of reducing the overall production cost), along with a degree of independency from a single source of feedstock and resilience against volatile price fluctuations of feedstock. Due to a limited availability of waste oils and oil crops in the Nordic countries, this scenario relies heavily on import of feedstock, as opposed to the other scenarios.

Waste-oils can be found in many forms, such as used cooking oil, animal fats, but also side-streams from vegetable oil production or from biofuel production, such as corn oil from bioethanol production. Sourcing enough feedstock streams from waste oils to feed a large scale production of sustainable jet fuel may prove to be a significant logistical challenge and requires production facilities to be flexible enough to han- 
dle the different feedstock. Moreover, the availability of such feedstock 50 may simply become insufficient, due to competing use for diesel production as demand increases.

Crude tall oil is currently being processed into renewable diesel (for ground transportation) in Sweden and Finland. The crude tall oil contains a large fraction of fatty acids, and could also be used to produce HEFA-SPK/HEFA+ under more optimistic assumptions of its availability.

Imported oil crops, such as camelina is also considered as possible feedstock sources. Camelina could in theory be grown in southern Sweden and Denmark depending on the yield, and if cultivation in rotation is possible so as to avoid competition with land for food production. This scenario, however, considers import from e.g. plantations in central and southern Europe as a more likely option.

\subsubsection{Processes and infrastructure}

Out of the three scenarios, the HEFA/HEFA+ scenario is the simplest and the only one with existing facilities in the Nordic countries for an actual jet fuel production, in the form of Neste's NEXBTL fuel which can be produced at the Porvoo refinery. In addition, Neste also owns a refinery in Rotterdam, Netherlands, which could also be considered a part of this scenario. The technology to produce HEFA-SPK made from bio-oils (both oil-crops and waste-oils) is also of a high maturity with small risks regarding technical complexities in production, and the existing facilities represent a significant advantage in terms of investment costs and know-how. However, the projected demand for sustainable jet fuel will entail a market-size nowhere near saturated by Neste's current production capacity and an integral part of the first scenario hence considers new production facilities, possibly involving other suppliers than Neste. If HEFA+ is certified, the market opportunity for producers will be even greater, as HEFA+ will be less costly and simpler to produce. While the blending level will be limited to between $10-15 \%$, a Nordic HEFA+ scenario may represent the simplest and most cost-effective way to satisfy the immediate demand for sustainable jet fuel.

The lower energy density of oil-crops necessitates some kind of pretreatment facilities for oil-extraction close to the feedstock source, be-

\footnotetext{
${ }^{50}$ Ecofys 2013 estimated a maximum of 927,000 tons of waste oils (roughly equivalent to 37 PJ) collectable within the $\mathrm{EU}$, of which at least $90 \%$ was already used for biodiesel production at the time of the analysis. The theoretical potential was significantly higher, around $3 \mathrm{Mt}$, though this included waste oil from households, which is considered unfeasible to collect: http://www.ecofys.com/files/files/ecofys-2013-low-ilucpotential-of-wastes-and-residues.pdf
} 
fore transportation to Nordic HEFA facilities for further processing. Long transportation distances to a Nordic facility must, however, be justified by some kind of economical or technical advantage pertaining to the Nordic facility over an alternative located closer to the feedstock source. In that sense, the first scenario may be at a disadvantage compared to the two other scenarios, where the feedstock is transported, prepared and processed over smaller distances. This disadvantage may be eliminated if a Nordic feedstock is used.

\subsubsection{Product slate and bio-refining opportunities}

The HEFA pathway produces renewable diesel, naphtha and kerosene. Cracking can increase the kerosene fraction, albeit at the expense of a middle distillate loss.

The HEFA/HEFA+ scenario can also be considered part of an integrated biorefinery concept. The Finnish UPM biorefinery is an example of an integration of pulp production with renewable diesel made from crude tall oil. Such a concept can be seen as highly inspirational for a potential jet fuel production.

For the imported oil crops, biorefining for multiple products in a Nordic facility, other than fuels, is limited to any chemicals that may be contained in the extracted jatropha or camelina oil which is imported for Nordic processing. The residual waste from the full crop after oil extraction, i.e. the press cake and husks, will most likely be used closer to the cultivation site for purposes such as energy/heat or animal fodder. In this sense a Nordic biorefinery using imported oil crops is more limited with regards to the array of products than in the other scenarios, where the entirety of the feedstock can be utilized in an integrated concept.

\subsubsection{Cost estimates}

The production cost of the HEFA/HEFA+ scenario will be dominated by feedstock costs accounting for about $60-80 \%$. The conversion efficiency of the energy in the feedstock to biofuels is expected to be higher than the other scenarios, in the range of 50-70\%.

The processing technology is less complex than in the following two scenarios, and both the investment costs and operations costs will likely be correspondingly lower. The total cost per liter produced HEFA jet fuel from oil crops and waste oils has been investigated several times in the literature, with estimates generally in the range of EUR 0.8-1.5/l, though such estimates are again highly dependent on the feedstock cost. For 
HEFA+, the price will be pushed further down in the lower end of the range and closer to price-competitive levels with fossil jet fuel.

\subsubsection{Nordic technology suppliers/actors and roles}

Chapter 7 identified several possible Nordic candidates for technology suppliers for the scenario within technology for hydrotreatment of biooils and refining technolgy. These suppliers and their potential role within the different processes of the second scenario are listed here. In the figure below, some of these suppliers are shown at their possible respective stages in the FT-scenario.

\begin{tabular}{|c|c|}
\hline Suppliers/Actors & Possible roles \\
\hline Neste (Fi) & $\begin{array}{l}\text { Producer of sustainable jet fuel, know-how and technology for hydropro- } \\
\text { cessing of bio-oils and refining capacity and infrastructure }\end{array}$ \\
\hline UPM Biofuels (FL) & $\begin{array}{l}\text { Technology and refining capacity of crude tall oil into an intermediary product } \\
\text { suited for jet fuel production + integration of forestry and biorefining }\end{array}$ \\
\hline Sunpine (SWE) & $\begin{array}{l}\text { Technology and refining capacity of crude tall oil into an intermediary product } \\
\text { suited for jet fuel production }\end{array}$ \\
\hline RenFuel 2KB AB (SWE) & Technology and production for lignin oil for further processing into biofuels \\
\hline $\begin{array}{l}\text { Preem Refinery Gothenburg } \\
\text { (SWE) }\end{array}$ & Know-how on retrofitting of hydrotreatment units to handle renewable feed \\
\hline Haldor Topsøe (DK) & Catalysts and technology for hydroprocessing of bio-oils \\
\hline Green Hydrogen (DK) & Hydrogen production for refining steps \\
\hline $\begin{array}{l}\text { Nordic petroleum refineries } \\
\text { (SWE, DK, NO, FI) }\end{array}$ & $\begin{array}{l}\text { Production integration, refining in retrofitted units and infrastructure for } \\
\text { storage and distribution to airports }\end{array}$ \\
\hline
\end{tabular}

\subsubsection{Climate impact}

The life-cycle GHG estimates of HEFA-SPK on camelina ranges from about $63-86 \%$, with the highest estimate attributed to a high yield of camelina per hectare. Cultivation accounts for the majority of the GHG inventory, but this scenario will also need to consider increased transportation emissions from import. Most of the camelina estimates did also not include the effects of LUC and iLUC, which will be more relevant in this scenario. Camelina grown in crop-rotation e.g. with winter wheat will in this case be a more advantageous feedstock from a climate perspective. If tall oil or waste-oils are used as a feedstock, the climate im- 
pact of HEFA/HEFA+ will likely be higher, comparable to the FT-SPK from the second scenario, around an $80-90 \%$ GHG reduction per MJ fuel.

\subsection{Scenario 2: FT Forest industry integration}

The following figure illustrates the process of the FT pathway scenario. The different technology suppliers listed at the different stages are meant as examples and drawn from the full list of potential suppliers, shown later in this section.

Figure 18: Process-diagram of Scenario 2

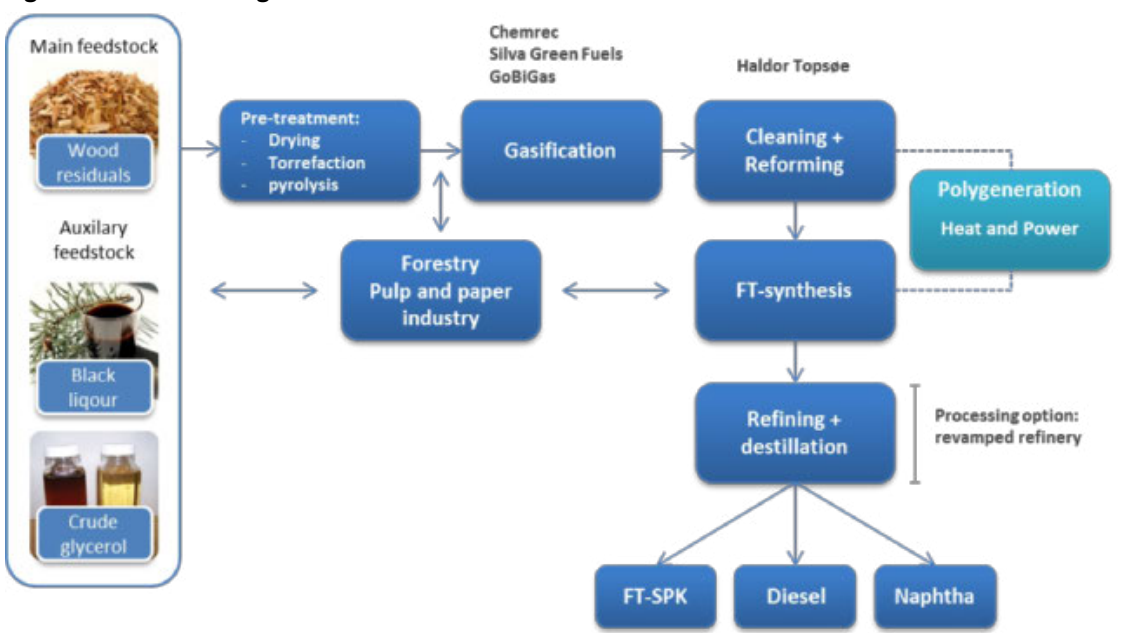

The FT pathway scenario draws upon advantages of wood residuals as a feedstock in supposedly ample availability among the Nordic countries, close connection to the forestry and pulp-and-paper industry and infrastructure, as well as technology and know-how within gasification. FTSPK jet fuel has been ASTM-certified since 2011 for up to $50 \%$ blend in, though a certification for a $100 \%$ drop-in FT-SKA with aromatic content is currently under review.

\subsubsection{Feedstock}

Wood residuals exist in a wide variety of shapes and content from many side-streams of forestry and pulp and paper production. The specific content of moisture, bark, lignin and other components can have an important effect on the quality of the syngas produced, and hence how suitable it is for synthesizing to fuels. The FT pathway scenario can then most likely only utilize a narrow and more homogenous range of wood 
residuals, though it is possible that certain gasification technologies will be able to handle a higher feedstock variety.

Another option is to gasify black liquor if technically feasible and abundant in availability. The access to black liquor as a feedstock depends on its current use in pulp mills. Pulp mills with no paper production have a large excess heat and electricity production from burning black liquor, and in such cases a fraction may be available for biofuel production if this can be substituted with another energy source. Another option is to co-gasify crude glycerol, a by-product of biodiesel production, which has been shown to increase the quality of syngas in small scale tests.

In the short term, fossil natural gas could also be used as an auxiliary feedstock for syngas production, in order to improve the initial cost competitiveness of the FT-SPK, which would be at the expense of a reduced climate benefit of the fuel. Over time, as forest biomass gasification technology matures, fossil gas would then be outfaced in a transition towards a $100 \%$ renewable feed.

\subsubsection{Processes and infrastructure}

A key aspect in utilizing forest feedstocks is to locate production facilities close to the feedstock resource, which is likely to come from saw mills or pulp and paper mills. This gives rise to several possible advantages: minimizing transportation distances, use of existing infrastructure, and integrated production with synergies e.g. between process heat, energy and steam. The distance to airports, where the produced fuel will eventually be stored and tanked, is deemed of lesser importance as it is much more economically efficient to transport a high energy-density fuel than the feedstock.

For wood residuals as the main feedstock, additional pre-treatment e.g. drying, torrefaction or even pyrolysis will likely be required before gasification. These steps also increase the energy density of the feedstock, and if advantageous could take place in stand-alone facilities, from which the treated feedstock is sent to a larger gasification facility.

The main challenge for a large scale biomass gasification facility is related to feedstock handling and the tar in the gasification step as well as the cleaning/reforming of the syngas. The cleaning/reforming is the most costly process in an FT-pathway which can amount to as much as $60-70 \%$ of the final product cost (Tunå, 2013). The specific choice of gasification technology and temperature is highly important, not only for the type of feedstock that can be processed, but also the tar accumula- 
tion and the syngas quality. Generally, high-temperature gasification will have a lower tar production and higher conversion of feedstock to gas, hence reducing the amount of by-products and increasing the biofuel potential. The conversion efficiency from biomass energy content to syngas is typically $45-65 \%$ (Energistyrelsen, 2015) out of which 10$20 \%$ can be synthesized to jet fuel, before additional cracking, implying a biomass to jet fuel efficiency of about $5-13 \%$.

One of the important advantages of using FT-technology is an already existing commercial scale industry for coal and natural gas to liquid fuels. Currently there is still no large scale biomass gasification technology for the production of syngas suited for biofuel production, though several both small and large facilities for gasification to fuel-gas for heat/power generation exist. The complexities in producing fuel-gas are much lower than syngas for biofuel production, with regards to reforming and cleaning for tar and impurities, but there is still an expected cross-over of technological know-how which adds to the advantageousness of this scenario. Another interesting possibility is polygeneration of both liquid biofuels and heat and power rather than standalone production. Polygeneration uses a fraction of the unreacted syngas to directly generate power and heat or to produce synthetic natural gas, which allows for greater flexibility and higher overall conversion efficiency of the biomass energy (Heidenreich \& Foscolo, 2015).

In general, gasification is in many aspects a mature technology, but the field of biomass gasification is at the same time in rapid development, which in the near future could address existing complexities regarding process and economy.

The FT-synthesis following gasification produces an oil fraction and an FT-wax with content depending on the gasification steps and the feedstock used. While the oil can be distilled directly into biofuels, maximizing the yield requires further refining of the FT-wax by cracking into the desired fuel ranges and isomerization. This refining step could potentially utilize existing infrastructure in the existing Nordic petroleum refineries.

\subsubsection{Product slate and bio-refining opportunities}

An FT production facility will not exclusively produce jet fuel, but also renewable diesel and naphtha. The specific product slate depends on a range of factors including the feedstock, syngas quality, the FT-synthesis catalyst, reaction time, temperature and pressure. Cracking can increase the jet fuel fraction, albeit at the expense of a middle distillate loss. In 
addition to liquid fuels, gasses, such as propane and methane but also CO and $\mathrm{CO}_{2}$ will also be produced. Biochar (containing nutrients) is another common byproduct, which can be used as a soil supplement to prevent nutrient-leaching and increase the carbon stock.

The forestry-industry integration described above constitutes an advanced biorefinery concept, where the production facilities for both pulp and paper, biofuels, chemicals and other products are coupled to some extent. Integrating a thermochemical biofuel production has yet to be demonstrated, though the wood-based biorefineries in Norway and Finland, Borregaard and UPM respectively, could serve as inspiration for a Nordic thermochemical forest biorefinery producing FT-SPK.

\subsubsection{Cost estimates}

Avinor 2013 estimated the production cost of FT jet fuel from a hypothetical 50 million l/yr FT-biofuel plant, using Norwegian wood residuals as feedstock to about EUR 2.2/l. Of this cost, 31\% was investment, $56 \%$ feedstock and $13 \%$ operations cost. If the sale of by-products (diesel and naphtha) was included, the effective production cost dropped to about EUR 1.5/l. In the price estimate, the feedstock price was assumed to be about EUR 5.5/GJ including transport and terminal costs, which is comparable to the estimates for the price of wood residuals presented in chapter 6.

Such price estimates are very sensitive to a set of assumptions, in particular regarding the feedstock price and the value of by-products. As gasification of wood biomass for biofuel production matures as a technology, it is likely that the production cost will decrease, mainly as a result of improved conversion efficiency and the potential for sale of high value byproducts, such as specialty chemicals.

\subsubsection{Nordic technology suppliers and actors}

Chapter 7 identified several possible Nordic candidates for technology suppliers in the FT-scenario within biomass gasification, refining and gas reforming. The Nordic suppliers and their potential role within the different processes of the first scenario are listed here. Below, some of these suppliers are listed by their possible respective stages in the FT-scenario. 


\begin{tabular}{|c|c|}
\hline Suppliers/Actors & Possible role \\
\hline Andritz Carbona (FL) & Technology for gasification and pre-treatment of wood biomass \\
\hline Valmet (FL) & Technology for gasification and pre-treatment of wood biomass \\
\hline GoBigas (SWE) & $\begin{array}{l}\text { Know-how on gasification of wood residuals to produce synthesis gas } \\
\text { (currently only aimed at generating gas-fuel for road transport) }\end{array}$ \\
\hline Chemrec/LTU green fuels (SWE) & Technology and know-how on gasification of black liquor \\
\hline $\begin{array}{l}\text { Silva Green Fuels/Statkraft and } \\
\text { Södre (NO) }\end{array}$ & $\begin{array}{l}\text { Know-how and technology on gasification and possibly opportunities for } \\
\text { biorefining of high-value products from wood residuals }\end{array}$ \\
\hline T/K Energy (DK) & Technology for gasification, in particular energy efficient feeder systems \\
\hline Haldor Topsøe (DK) & $\begin{array}{l}\text { Catalysts and technology for refining processes and cleaning/reforming of } \\
\text { syngas }\end{array}$ \\
\hline $\begin{array}{l}\text { Nordic petroleum refineries } \\
\text { (SWE, DK, NO, FI) }\end{array}$ & $\begin{array}{l}\text { Refining in retrofitted units + infrastructure for storage and distribution to } \\
\text { airports }\end{array}$ \\
\hline Green hydrogen (DK) & Hydrogen production for refining steps \\
\hline
\end{tabular}

\subsubsection{Climate impact}

Within LCA literature only a few estimates exist on the GHG-intensity of FT-SPK using forest residuals. Avinor 2013 is one of them, with a listed value of an $80 \% \mathrm{CO}_{2}$ reduction relative to fossil jet A-1 (no LUC or iLUC included in this estimate). For FT-SPK fuel using energy crops, such as willow or switchgrass estimates are comparable in the range of $80-90 \%$ reduction (SWAFEA 2011, Partner 2010). The dominant source of emissions for the FT-scenario will be attributed to processing, but the substitution effects from byproducts will also have a significant effect on the overall climate benefit.

\subsection{Scenario 3: Lignocellulosic At]}

The following figure illustrates the process of the AtJ pathway scenario. The different technology suppliers listed at the different stages are meant as examples and drawn from the full list of potential suppliers later in this section. 
Figure 19: Process-diagram of Scenario 3

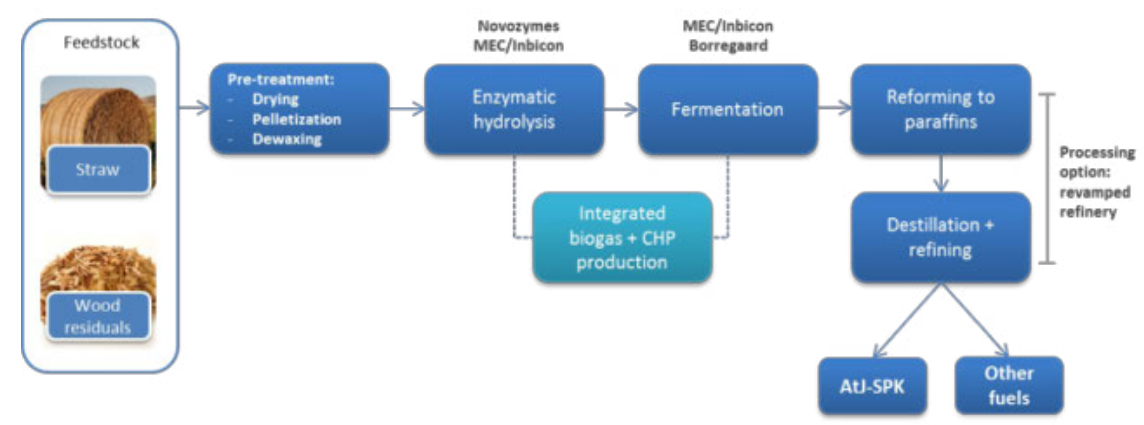

The third scenario is based on fermentation of straw and/or wood residuals bioalcohols and further processing to jet fuel via an AtJ pathway. The main advantages of this scenario are straw and wood residuals as feedstock of ample availability and strong Nordic competencies within hydrolysis and fermentation technologies. AtJ-SPK fuel is not certified yet, but has been under review since the end of 2014 and is most likely certified within 2016 for up to $50 \%$ blend.

\subsubsection{Feedstock}

The total amount of straw available in Denmark for biofuel production has been estimated to about $22 \mathrm{PJ}$ annually and $15 \mathrm{PJ}$ in Sweden, though competition with heat and power production using straw is a threat to the availability. The potential utilized for biofuel production would most likely be taken from the straw fraction left to compost at the fields, which will require that the nutrients in the straw can be recycled out of the process and returned to the fields.

For wood residuals, many of the considerations found in the second scenario are similarly relevant in this scenario, though the hydrolysis and fermentation process will likely be less sensitive to the requirements of homogeneity of the wood residuals than for gasification.

\subsubsection{Processes and infrastructure}

The straw feedstock is likely to be gathered from many suppliers, as opposed to one or a few suppliers in the form of pulp/paper mills, and the logistics of feedstock sourcing will thus be more complex. The location of a straw ethanol plant will ideally be within short distances of as many farms as possible where the straw can be sourced and transported by truck at a low cost. In the case of Denmark, the feedstock transportation 
distances will generally be very small, while for straw in Sweden the distances and logistics will be greater.

For wood residuals, the same proximity and integration with forestry and pulp and paper industry and infrastructure as in the second scenario, will likewise be of equal importance in this scenario.

The AtJ scenario can use a number of different bioalcohols as intermediary products, the most likely candidates being ethanol and butanol (and variations thereof, such as isobutanol or n-butanol), but throughout this section, ethanol is referred to as the used intermediary alcohol.

Hydrolysis converting almost all but the lignin fraction of lignocellulosic feedstock to sugars has been demonstrated in a number of biorefineries, such as Inbicon, and engineered yeast cultures are now able to ferment both the $\mathrm{C}_{5}$ and $\mathrm{C}_{6}$ sugars produced by enzymatic hydrolysis. Based on the operations at Inbicon, the conversion efficiency of the energy in straw to ethanol is about $37 \%$ (Larsen \& Henriksen 2015). With development in more advanced enzymes for hydrolysis and yeast for fermentation, the conversion efficiency can be expected to increase, and the $37 \%$ is thus a conservative estimate. The conversion of ethanol to jet fuel is more complicated and depends on the process of oligomerization/reforming. The available literature lists a wide range of estimates from about 2 to $8 \mathrm{l}$ ethanol per $\mathrm{l}$ jet fuel (Avinor 2013), which suggests a total conversion efficiency of the energy in straw to jet fuel of about 4$18 \%$ (based on the $37 \%$ straw-energy to ethanol efficiency).

Bioethanol has a reasonably high energy density and can be transported over longer distances for further processing without significant cost. The steps of dehydration to olefins, oligomerization to paraffins and distillation and hydrotreatment to fuels are all known from petrochemical industry, which opens up the opportunity for processing in retrofitted units in one or several of the Nordic petroleum refineries.

\subsubsection{Product slate and biorefining opportunities}

The AtJ scenario can similarly to the first scenario produce a number of hydrocarbon fuels, depending on the oligomerization process and the intermediary alcohol. Using butanol (and its isomers) will mainly produce $\mathrm{C}_{12}$ and $\mathrm{C}_{16}$ chains, which sit well in the kerosene range, and may in this regard be favourable for jet fuel production compared to ethanol, which produces a broader range of C-chains and thus also other biofuels.

Integrating the AtJ scenario in a biorefining concept is a highly advantageous measure, ensuring full utilization of the feedstock and the production of higher value products which can increase the price com- 
petitiveness of the produced biofuels. Such a concept could draw inspiration and know-how from existing facilities in the Nordic countries, in particular Norwegian Borregaard and Danish Inbicon and the planned MEC. Straw contains about $2 \%$ wax by dry-matter weight, consisting of a multitude of chemicals, suited e.g. for medical purposes, such as sterols and polycosanols, or wax esters for cosmetics and coatings (Deswartes 2007). Other possible products from a lignocellulosic alcohol biorefinery include concentrated $\mathrm{CO}_{2}$, polymers (e.g. PVC or PET), fibers and other biochemicals. In the case of Norwegian Borregaard, the biochemicals and fibers extracted from the wood feedstock actually constitute the highest value in the production, and the bioethanol is really a byproduct. Whether the produced biofuels of a lignocellulosic biorefinery will similarly be regarded as lower-value by-products depends on the respective values of all the product streams.

Out of the straw content, about $15 \%$ is lignin, and for wood biomass the number ranges between $20-30 \%$. This fraction is typically not converted to liquid biofuels, but both the climate effect and the economy of lignocellulosic AtJ-SPK is very dependent on the utilization of this byproduct. The typical application is co-firing in a CHP plant for green energy, but it may also be used in a thermochemical process, such as gasification or hydrothermal liquefaction, to produce additional liquid biofuels.

\subsubsection{Cost estimates}

In comparison to the first scenario, the cost structure of an AtJ pathway is expected to be even more heavily dominated by the feedstock costs, and with relatively lower investment costs. Avinor 2013 estimated that for an AtJ pathway, bioethanol as a feedstock comprises near $90 \%$ of total production costs while operations and investment costs are at $10 \%$. A price estimate (se chapter 6 ) for straw at about EUR 5.7/GJ and wood residuals around EUR 5-6/GJ, and based on an expected average conversion efficiency around $12 \%$, the feedstock costs alone comes out at between EUR 1.5-1.8/l jet fuel. Under the assumption that the feedstock costs account for $90 \%$ of production costs, and operations and investments the remaining 10\%, the final price of AtJ-SPK would be EUR 1.7-2/l.

The final price of jet fuel will however also include the two components of operations and investment costs which will slightly increase the total price per 1 jet fuel. From a producer's point of view, any further processing of the bio-alchohol must also increase the value of the final product, and upgrading any bio-alcohol into jet fuel is still not seen as economically rational if the AtJ-SPK cannot be sold at a price higher than the bio-alcohol. 


\subsubsection{Nordic technology suppliers/actors and roles}

Chapter 7 identified several possible Nordic candidates for technology suppliers for the second scenario within hydrolysis, fermentation and refining. These suppliers and their potential role within the different processes of the third scenario are listed here. Below, some of these suppliers are listed by their possible respective stages in the FT-scenario.

Table 21: Suppliers for the AtJ pathway

\begin{tabular}{|c|c|}
\hline Suppliers/actors & Possible roles \\
\hline Lantmannen Agroetanol (SWE) & $\begin{array}{l}\text { Know-how on large scale ethanol production and } \mathrm{CO} 2 \text { capture, knowledge } \\
\text { on logistics of agricultural feedstock sourcing }\end{array}$ \\
\hline SEKAB (SWE) & $\begin{array}{l}\text { Know-how and technology for bioethanol production and biorefining } \\
\text { opportunities }\end{array}$ \\
\hline St1 (Fi) & $\begin{array}{l}\text { know-how on integration of ethanol production and dehydration with } \\
\text { petroleum refinery infrastructure }\end{array}$ \\
\hline Metgen (Fi) & Enzymes for hydrolysis of lignocellulosic feedstock \\
\hline Borregaard (NO) & Know how on biorefining and co-production of high-value products \\
\hline Novozymes (DK) & Enzymes for hydrolysis of lignocellulosic feedstock \\
\hline Inbicon/MEC (DK): & $\begin{array}{l}\text { existing ethanol from straw demo plant and planned full scale production } \\
\text { facility }\end{array}$ \\
\hline Biogasol (DK) & Straw pre-treatment and enzymatic hydrolysis technology \\
\hline Estibio (DK) & Microbial catalysts for ethanol fermentation \\
\hline Terranol (DK) & Yeast cultures for ethanol fermentation \\
\hline Haldor Topsoe (DK) & Catalysts and technology for refining processes of ethanol to jet \\
\hline Green Hydrogen (DK) & Hydrogen production for refining steps \\
\hline $\begin{array}{l}\text { Nordic petroleum refineries } \\
\text { (SWE, DK, NO, FI) }\end{array}$ & $\begin{array}{l}\text { Production integration, refining in retrofitted units and infrastructure for } \\
\text { storage and distribution to airports }\end{array}$ \\
\hline
\end{tabular}

\subsubsection{Climate impact}

The literature review (see in chapter 12) identifies only one estimate of an AtJ pathway, using wood residuals as feedstock with a $66 \%$ GHGreduction compared to fossil jet A-1, but other well-to-gate estimates for bioethanol from straw were also included showing $-69 \mathrm{~g} \mathrm{CO}_{2} \mathrm{eq} / \mathrm{MJ}$ in the low end and $34 \mathrm{~g} \mathrm{CO}_{2} \mathrm{eq} / \mathrm{MJ}$ in the high end. The large discrepancy resulted from different substitution effects of co-products, in particular in the negative estimate from using produced $\mathrm{C}_{5}$-molasses as animal feed substituting imported soy bean fodder and avoiding associated iLUC. It 
is possible that an AtJ producer would prefer to eliminate $\mathrm{C}_{5}$-molasses as a by-product by converting the $\mathrm{C}_{5}$ sugars to additional biofuel, reducing the climate benefits from such product substitution. The $34 \mathrm{~g} \mathrm{CO}_{2} \mathrm{eq} / \mathrm{MJ}$ is then a more likely estimate, but due to the further processing required, the emissions from Straw-AtJ-SPK are expected to be somewhat higher, in the area of $30-45 \mathrm{~g} \mathrm{CO}_{2}$ eq/MJ, corresponding to a $66-45 \%$ $\mathrm{CO}_{2}$ reduction compared to conventional fossil jet. In the absence of very high substitution effects, such as imported soy bean fodder replacement, the climate benefit of the straw jet fuel will likely be slightly less favourable than the wood-FT jet fuel in the first scenario.

\subsection{Comparison of the three scenarios}

When comparing the three pathway scenarios, they perform similarly in terms of sustainability and costs of the final fuel product. However, these estimates are very uncertain. The estimated production costs are highly dependent on the assumptions made on the degree of utilization of byproducts and feedstock prices. Similarly, the estimations of GHG reductions are based on a number of different assumptions concerning feedstock, substitution effects and LUC/ILUC. 
Table 22: Comparison of the three pathway scenarios

\begin{tabular}{|c|c|c|c|}
\hline & $\begin{array}{l}\text { Scenario 1: } \\
\text { HEFA/HEFA+ } \\
\text { (waste oils and oil crops) }\end{array}$ & $\begin{array}{l}\text { Scenario 2: } \\
\text { FT (wood residuals) }\end{array}$ & $\begin{array}{l}\text { Scenario 3: AtJ } \\
\text { (straw and wood residuals) }\end{array}$ \\
\hline ASTM certified & $\begin{array}{l}\text { Yes, } 50 \% \text { blend in (HEFA+ } \\
\text { expected in 2016/2017) }\end{array}$ & Yes, $50 \%$ blend in & No, expected in 2016 \\
\hline $\begin{array}{l}\text { Estimated price } \\
\text { range of jet fuel } \\
\text { produced }\end{array}$ & $\begin{array}{l}\text { EUR } 0.8-1.5 / 1 \\
\text { (HEFA+ price expected in } \\
\text { the lower range) }\end{array}$ & $\begin{array}{l}\text { EUR } 1.5-2.2 / l \\
\text { (lower range if sale of by- } \\
\text { products is included) }\end{array}$ & $\begin{array}{l}\text { EUR } 1.7-2 / \text { I } \\
\text { (lower range if sale of by- } \\
\text { products) }\end{array}$ \\
\hline $\begin{array}{l}\text { Feedstock } \\
\text { availability }\end{array}$ & $\begin{array}{l}\text { Uncertain availability of } \\
\text { waste oils and oil crops. } \\
\text { Depends largely on import } \\
\text { and availability in other } \\
\text { countries } \\
\text { Competition with diesel } \\
\text { production for road } \\
\text { transport }\end{array}$ & $\begin{array}{l}\text { Promising availability of } \\
\text { wood residuals in general } \\
\text { in Norway, Sweden and } \\
\text { Finland. } \\
\text { Prices and availability are } \\
\text { likely to be highly variable } \\
\text { on a regional basis } \\
\text { Competition with CHP } \\
\text { production }\end{array}$ & $\begin{array}{l}\text { Promising availability of } \\
\text { straw in Denmark and } \\
\text { wood residuals in Sweden, } \\
\text { Norway and Finland. } \\
\text { Competition with heat and } \\
\text { power production }\end{array}$ \\
\hline Infrastructure & $\begin{array}{l}\text { Existing infrastructure } \\
\text { capable of producing sus- } \\
\text { tainable jet fuel } \\
\text { New production capacity } \\
\text { required after demand } \\
\text { increases beyond existing } \\
\text { capacity. } \\
\text { Can potentially utilize exist- } \\
\text { ing petroleum refinery } \\
\text { infrastructure }\end{array}$ & $\begin{array}{l}\text { Some biomass gasification } \\
\text { plants exist, though not for } \\
\text { syngas production for } \\
\text { biofuels at large scale } \\
\text { Requires new production } \\
\text { facilities from start. } \\
\text { Can potentially utilize exist- } \\
\text { ing petroleum refinery } \\
\text { infrastructure }\end{array}$ & $\begin{array}{l}\text { Some bioethanol produc- } \\
\text { tion plants exist, though } \\
\text { mostly for road transport } \\
\text { fuel. } \\
\text { Requires new production } \\
\text { facilities from start } \\
\text { Can potentially utilize exist- } \\
\text { ing petroleum refinery } \\
\text { infrastructure }\end{array}$ \\
\hline $\begin{array}{l}\text { CO2 reduction } \\
\text { compared to } \\
\text { fossil alternative }\end{array}$ & $\begin{array}{l}63-90 \% \\
\text { (High savings if using waste- } \\
\text { oils, lower if using cultivat- } \\
\text { ed oil crops) }\end{array}$ & $80-90 \%$ & $45-66 \%$ \\
\hline
\end{tabular}

If HEFA+ is certified by ASTM, the first scenario offers a more simple conversion technology than the other pathways, which in the short term is likely to be the most economically feasible, as the technology is already commercially available and more mature. However, both FT and AtJ are promising technologies in the long run, due to the potentials for producing jet fuel as part of biorefineries, producing a range of highvalue products.

The HEFA/HEFA+ scenario is deemed the most likely to develop within the short timeframe, from 2020 and onwards, while the FT and AtJ are more likely to develop from 2025-2030 and onwards. After this period, from 2030 towards 2050, it is possible that other scenarios, based on some of the emerging pathways described in chapter 8 may become feasible, but it has not been possible to fully investigate such possibilities in this report. 
The three scenarios all utilize feedstock that is in competition with utilization in other sectors. Thus, their realization will to a large extent be influenced by feedstock prices and political priorities concerning the allocation of the available biomass. Nevertheless, the three scenarios are not mutually exclusive with regards to feedstock and it is theoretically possible to implement all three scenarios simultaneously, which may even allow for synergetic effects between the scenarios.

The location of production facilities will differ between the scenarios as the initial conversion steps should be located close to the feedstock source, in order to reduce logistic costs. Thus, facilities for initial treatment in the FT-based scenario will most likely be in Norway, Sweden or Finland in proximity of key areas with available forest biomass and forestry/pulp and paper infrastructure. The AtJ scenario will be most strongly based in Denmark or Sweden, due to the utilization of straw. Finally, the HEFA/HEFA+ scenario will most likely be physically located in Finland, due to the already existing Neste refinery. However, if the capacity should be expanded by new facilities, these can in principle be located in either of the Nordic countries (possibly with the exception of Denmark, if tall oil is used rather than imported oil crops as feedstock). The location of the final processing steps of refining can, theoretically, also be located in either of the Nordic countries, as the transportation costs of the more energy dense intermediate products are low, compared to the costs of transporting pure feedstock. 


\section{Nordic comparative advantages}

Chapter 9 has presented three different scenarios for a Nordic production of sustainable jet fuel. As previously mentioned, the scenarios have been selected based on a number of different criteria, such as feedstock prices and availability, sustainability, etc. This section will briefly summarize and compare the different scenarios, with a special emphasis on the Nordic comparative advantages pursuant to the respective scenarios.

The Nordic countries have a number of comparative advantages relevant for the three scenarios. This section will summarize the Nordic strengths in each of the scenarios and within a production of sustainable jet fuel in general.

\subsection{Nordic strengths on feedstock and infrastructure}

The second and third scenarios utilize forest biomass in Finland, Norway and Sweden, which represents the largest forest resource in Europe, with an existing, well-established industry and infrastructure for collection and utilization of the feedstock. In addition, the Nordic countries have strong competencies and technological know-how within advanced utilization of forest biomass, such as gasification and extraction of higher value products in biorefining. Further investments in pulp production (also in renewal of existing pulp mills) are made with new concepts and technologies that allow for synergies in production and the flexibility to produce a variety of biofuels and biochemicals, thus advancing the opportunities for future biorefining concepts on forest biomass.

The AtJ scenario is based on fermentation and enzymatic technologies in the conversion step, with similarly strong technological competencies and know-how within the Nordic countries, especially from Novozymes, Inbicon, Borregaard and St1. Thus, the Nordic strengths are within the production of the alcohol that will be further converted to jet fuel and producing within an integrated biorefinery concept with a wide array of product streams and synergies in production. 
In the first scenario commercial scale production facilities already exist (Neste's refinery in Porvoo, Finland, and potentially the refinery in Rotterdam as well). Neste possesses experience and know-how within the conversion of lipids to jet fuel. With an ASTM certification of HEFA+, Neste will be in a favorable position to produce sustainable jet fuel at competitive prices. A major drawback in this scenario is the very limited availability of lipids as a feedstock in the Nordic countries and generally poorer conditions for cultivating e.g. jatropha or camelina compared to warmer countries. Thus, the scenario is dependent on import of feedstock as discussed in chapter 9 with regards to international actors who could be instrumental in establishing an imported feedstock supply chain. For the refining phase, relevant in all the scenarios, the Nordic petroleum refineries provide an opportunity to not only solve a rising problem of over-capacity, but also to save investment costs and utilize existing infrastructure, by placing the refining steps of biofuel production in retrofitted units or integrated close by. Two examples from Gothenburg in Sweden provide know-how and experience on such concepts, namely the St1 Etanolix ethanol plant integrated in the St1 refinery, and the revamped hydrotreatment unit in the Preem refinery for coprocessing renewable tall oil diesel. Further, Haldor Topsoe holds a strong position internationally within catalytic technologies for refining.

As mentioned earlier, the three scenarios are able to exist in parallel. The flexibility in production pathways illustrates the Nordic strengths and know-how within a number of different biotechnologies and especially within fermentation and gasification. This know-how is continuously developed and made available from the different universities and research institutes (such as VTT in Finland), which are an important Nordic advantage in bridging R\&D with the commercial stage, helping to overcome technical challenges and barriers and opening up for new byproduct streams and utilizations.

The biorefinery concept is already well-established in Nordic energy production and is closely linked to an increasing awareness of circular economy and the utilization of by-products. Although not focusing on fuels for aviation, the Borregaard biorefinery is an example of how the biorefinery concept has been well integrated producing both high-value products and bulk products such as bioethanol. Maabjerg Energy Concept (MEC) is also based on integrating bioethanol production with biogas production and the use of lignin for heat and electricity production.

With a decreasing demand for fossil petroleum products, an overcapacity of existing refineries and crude oil infrastructure is expected in the future (Janssens \& Fitzgibbon, 2015). The Nordic refineries and pe- 
troleum industry are likely to explore new options for saturating the capacity made available, and refining of sustainable jet fuel in retrofitted units is a promising opportunity to utilize existing infrastructure.

\subsection{Initiatives}

Chapter 8 revealed a number of Nordic companies, who are actively pursuing the production of sustainable jet fuel via other pathways than the ones presented in the three scenarios. These companies include Synsel (US/NO), Swedish Biofuels (SWE), Step (SWE), Steeper Energy Aps (DK) and Cumulus Bio (DK). While they are all in the earlier stages of development, with only limited documentation available on proof-of-concept and technical descriptions of the involved conversion processes, they represent an interesting asset for new technical innovations that could strengthen any of the three scenarios.

The Nordic countries have ambitious climate policies and in some areas are front-runners in the transition towards a fossil-free energy sector.

In 2016, the Norwegian government agreed to investigate a proposal to reduce landing fees by $25 \%$ for all flights flying on a $25 \%$ blend with sustainable jet fuel from 2018 and onwards (Stortinget, 2015).

In Finland, an economically viable concept on introducing sustainable jet fuel was studied by the Ministry of Transport and Communications, the Ministry of Employment and the Economy, Finnai, Neste and Finavia. The study emphasized the key issue remaining on how to cover the premium of sustainable jet fuel compared to conventional fossil jet. Initiatives on finding financial support mechanisms and attractive business models to create a demand are equally as supporting the supply side.

In Finland, the Government has taken steps to promote bioeconomy and clean energy solutions, and will be supporting the area with EUR 300 million during the years 2016-2018, including, for new biofuel pilot- and demonstration plants.

Such initiatives show how political priorities in the Nordic countries can create incentives and establish a market demand for sustainable jet fuel. The active involvement of the Nordic governments in providing a stable policy framework for sustainable biofuel as well as facilitating and supporting initiatives across stakeholders is a critical element in commercializing sustainable jet fuel, regardless of the scenarios and the pathway chosen for sustainable jet fuel production.

Initiatives from the Nordic Universities within $R \& D$, in particular in collaboration with the bioenergy industries, have also played an im- 
portant role in accelerating biofuel technologies in general. New initiatives, such as the recently established Center for Science of Sustainable Fuels and Chemicals at the Danish Technical University, or the Norwegian Norbiolab collaboration between the Fibre Research Institute, SINTEF and two Norwegian universities, will equally be a strong asset in realizing the technological side of a sustainable Nordic jet fuel production. 


\section{International actors}

This section will discuss how including international actors from outside the Nordic countries can strengthen the three scenarios presented in Chapter 9. It also discusses the experience that can be made from cases from other countries where a planned sustainable jet fuel production was stopped due to various reasons.

The three scenarios illustrate how there is not a single company that can provide a full supply chain from feedstock to aircraft. Instead, a supply chain consists of a range of different stakeholders, including feedstock producers, technology suppliers, refineries, investors, airports and airlines. Thus, a complete production to consumption pathway is not possible without some degree of collaboration between the relevant sectors and across country borders. This report has provided three different scenarios, which can help identify the relevant Nordic technology suppliers within the different pathways. In addition to the Nordic stakeholders, there are a number of international actors that can be included to potentially strengthen a Nordic sustainable jet fuel pathway. The following paragraphs will discuss these based on the findings in the previous sections.

In the forest-resource-based FT scenario, the feedstock, as well as the know-how and technology, is already available in the Nordic countries. Similarly, the AtJ scenario could be realized based exclusively on Nordic feedstock, technology and know-how. However, the question of whether the straw resource will be available for a large scale production of sustainable jet fuel is more uncertain than it is with the forest resource of the FT scenario, when considering other industries in direct competition for utilization of the available amounts of biomass.

The HEFA based scenario is dependent on input from other countries than the Nordics, which is also illustrated in the SkyNRG, Neste and Avinor and Air BP partnership. This is due to the limited amounts of lipid feedstocks within the Nordic countries, which makes import of feedstock from abroad a necessity for a large scale production. Thus, in order for this scenario to be viable, lipid rich feedstocks, such as camelina, jatropha or used cooking oil, will either have to be imported or the production facilities must be located in other countries closer to the feed- 
stock production. Many of the feedstocks discussed in the previous sections are commodities traded between different countries.

The ITAKA project is working with $\mathrm{R} \& \mathrm{D}$ to promote a European production of camelina. Trial plantations have been established in Spain and Romania, utilizing the warmer climate for the production of feedstock. The import of feedstock provides flexibility, compared to being reliant solely on locally produced feedstocks, which can increase supply security.

A cost effective production of e.g. camelina can make the import of feedstock economically feasible. Camelina and jatropha have the possibility of growing in areas where it is difficult to cultivate crops for food production, which from a sustainability point of view has some benefits in terms of reduced ILUC effects. On the other hand, import of feedstock is most likely associated with longer transport distances, which can offset some of this positive effect.

Several large international airports exist in the Nordic countries and hence international airlines are also potential partners in a Nordic sustainable jet fuel pathway as fuel consumers. An example of this is the previously mentioned partnership between SkyNRG, Avinor, Air BP, Lufthansa, KLM and SAS. The partnership is based at Oslo Airport, Gardermoen, and will utilize imported camelina from the ITAKA project and HEFA technology from Neste. Based on their previous engagement in sustainable jet fuels, the airlines Finnair, KLM, Lufthansa and SAS are identified as potential partners in the establishment of a Nordic supply chain. Including both airlines domestic to the Nordic countries and international airlines will serve to ensure a market demand suitable for commercial scale production. Furthermore, international airlines should be included in the supply chain, given the higher cost of acquiring sustainable vis-à-vis conventional jet fuel, so as to not impose undue higher operating costs on Nordic airlines, putting them at a competitive disadvantage.

International fuel suppliers are the main jet fuel suppliers and distributors in most of the Nordic airports and are relevant to include from a logistical point of view. As previously mentioned, none of the existing pathways are ASTM certified for blend-in ratios higher than 50\%. Furthermore, the international airports will most likely face a transition period, where only a fraction of the airlines, fueling in the airport, are willing to purchase sustainable fuels instead of conventional fossil jet A-1. Thus, including the fuel suppliers from an early phase is a necessity for ensuring adequate infrastructure in the final distribution of the sustainable jet fuel. 


\subsection{Experience from other countries}

Not only successful stories exist for the completion of a pathway for production of sustainable jet fuel. According to Kevin Weiss, Chief Executive in the California based Byogy Renewables; the main reason for failure is the inability of delivering fuels at competitive prices. This is mainly due to feedstock costs as they can make up a large percentage of the costs of the final fuel as illustrated in Chapter 9. In addition to the reasons stated by Weiss, a cost competitive production of sustainable jet fuel is also dependent on the price of fossil oil and not only the production costs of the sustainable alternative. Another issue is challenges arising when scaling up technologies from pilot/demonstration scale to commercial scale. Further, the infrastructure to blend in sustainable jet fuels has in some cases proven to be a difficult challenge to overcome. Finally, it is difficult to initiate a production of sustainable jet fuel without some degree of government support.

One example of a project that came to an end before being realized is the partnership between British Airways and Solena Fuels. The aim was to build a USD 500 million facility converting municipal solid waste into sustainable jet fuel with an annual production of 60 million l. However, it was not possible for Solena to raise the required finance for the project and produce fuel at competitive prices. This was explained by the decreasing prices of fossil oil, but also a lack of government support in terms of incentivizing sustainable jet fuel in the same way as sustainable fuels for e.g. land transport (GreenAir Online, 2015).

In the US there are also a number of cases where sustainable jet fuel projects have come to an end before the construction of a large scale production facility. One of them is Range Fuel who set out to build a biorefinery for ethanol from pine trees with an annual capacity of 380 million 1 . The project succeeded in getting funding from both the government and private investors; hence construction of the refinery began in 2007. In 2010, Range Fuel produced the first batch of bioethanol, but filed for bankruptcy the following year. During the scale up, Range Fuel faced technical challenges in scaling up their production (National Geographic, 2012).

The cases from other countries emphasize the great importance of choosing a low cost feedstock with a promising availability. It is important to be aware that many byproducts from the forest industry currently are utilized, making the availability of forest resources a key issue if choosing the FT based scenario. The same is the case for the straw based scenario. The stories of failure also illustrates that a partnership 
between the fuel supplier and an airline company is not a guarantee of success in itself. However, these partnerships indicate that there is a market for sustainable jet fuel, yet often under the condition that it is price competitive with conventional fossil fuels.

Some of the successful cases from abroad involve long term agreements with airlines to supply large amounts of sustainable jet fuel. Thus, in addition to political willingness the airlines can play a crucial part in ensuring a long term demand for sustainable jet fuel.

One of the most significant stories of success within the bioenergy sector is the Brazilian production of bioethanol. The global oil crisis in the 1970s caused the Brazilian government to launch the ProAlcool program with the scope of strengthening a national production of bioethanol and gain independence from imported fossil oil. Unlike biofuels produced in the US and Europe, the Brazilian production of bioethanol is no longer subsidized by the government. Today, Brazil is a global leader within the production of bioethanol, which accounts for $40 \%$ of transport fuels. However, despite the political willingness, the current bioethanol infrastructure took 30 years to establish, which illustrates the complexity in establishing a new supply chain for alternative fuels.

The USA also makes an interesting case, with regards to political support for the development of biofuel markets and incentivizing producers. The Energy Policy Act of 2005 introduced the Renewable Fuel Standard, which was later expanded in the Energy Independence and Security Act of 2007. These acts authorize the Environmental Protection Agency (EPA) to set Renewable Volume Obligations (RVO) for producers and refiners of transportation-, heating- and jet fuel (EPA, 2016). Each producer has to fulfill their RVO, by producing fuel using pathways that are approved under the RFS by the EPA. The production of a gallon of renewable fuel triggers the issuance of a Renewable Identification Number (RIN), which demonstrates compliance with the RFS and can be used as proof of compliance with the RVO (EPA, 2016). Surplus RINs can be sold to producers who have not been able to fulfill their RVO, thus producers are incentivized to increase production, in order to increase revenue through the sale of RINs. This system, in congruence with a range of financial support schemes for biofuel research and production (incl. loan guarantees, direct funding and tax credits [US Department of Energy, 2016])), could help explain the substantial production of biofuels in the USA, which ranks as one of the largest biofuel producers worldwide in terms of volume (UNCTAD, 2016). However, if such a system is transferable to a Nordic context requires further exploration. 
Within the production of sustainable jet fuel, a number of large scale productions such as Fulcrum and GEVO are still to be realized. Whether or not these projects are realized will depend on the above mentioned aspects and their progress should be monitored in order for a Nordic production pathway to be able to overcome some of the many challenges. 



\section{Impact on Climate Change and Economy}

This last section focuses on discussing the environmental and economic effects for the Nordic region in scaling-up sustainable jet fuel production. First the consequenses of scaling up the production for the climate change mitigation (chapter 12) and then the socio economic factors are discussed (chapter 13). The section is wrapped up by a discussion on the identified challenges for the Nordic, including barriers and steps to take (chapter 13). 



\section{Climate change mitigation impact}

Aviation is globally responsible for about $11 \%$ of all transport associated $\mathrm{CO}_{2}$ equivalent emissions, which is equivalent to $2 \%$ of all anthropogenic $\mathrm{CO}_{2}$ equivalent emissions (AR5 WGII CH8). Forecasts on Aviation growth shows that emissions will almost triple by 2050 with over $2.6 \mathrm{Gt} / \mathrm{yr}$ in a baseline scenario (ICAO, 2013).

To address this increasingly large GHG emissions and the associated climate impact, the aviation industry has set forth voluntary emissiontargets described in section 3.3 Sustainable jet fuel has been recognized as a key measure for fulfilling these targets and reducing the climate impact of aviation GHG emissions (ICAO, 2014).

This chapter is based on the identified Nordic market demand and the three most promising production conversion pathways from conventional to sustainable aviation fuel. It assesses the climate effects of this conversion. Before doing so, the chapter establishes an overview of the existing knowledge on the climate impact of conversion to sustainable technology in aviation. The relevant assumptions and considerations regarding different approaches in system boundaries will also be highlighted, as well as the non- $\mathrm{CO}_{2}$ climate effects of alternative fuels currently not investigated in existing LCA literature will also be discussed.

\subsection{How to measure the climate impact of aviation fuel}

Many studies have attempted to quantify the GHG mitigation potential of existing and hypothetical sustainable jet fuels production pathways, in particular by life cycle assessments (LCA), yielding a wide range of results.

Life cycle assessments of sustainable jet fuel production identify GHG emission sources from the entire supply chain, typically from feedstock cultivation, transportation, treatment and processing and end use in flight. However, many studies have investigated the same production pathways and feedstock choice, yet ended up with different results. The discrepancies are due to different system boundaries and sensitivity of assumptions, 
e.g. on the source of energy input used, processing technology and conversion factors, biomass yield and fertilizer input, which complicates intercomparison. The wide range of results is in many cases largely accounted for by the effects of LUC and ILUC, but there is currently no consensus on a recognized methodology of quantifying those effects, in particular for ILUC, which is not even considered in most studies.

Depending on the scope, an LCA may include substitution effects if a byproduct of the process is considered to displace another product, in which case the associated emissions are allocated as credits to the lifecycle fuel emissions. This is for instance the case if residual biomass can be used for animal feed or fertilizer, and the emissions related to the replaced feed or fertilizer are then subtracted from the fuel emissions. Many of the processes also produce significant excess heat and/or byproducts suited for heat and electricity generation, which similarly have associated substitution effects. The value of the substitution emissioncredits depends highly on the individual country or even region in which the substitution takes place. If a solid lignin byproduct is co-fired to produce electricity, the emission-credit will for instance be much greater in a country/region with a fossil-dominated energy supply than for a renewable energy supply. Extrapolation of LCA GHG-estimates to other countries/regions should therefore be treated with caution.

The comparison of life-cycle GHG emissions of alternative jet fuel made from biomass to fossil jet fuel is conventionally done on a wellto-tank basis. In this case, the combustion emissions of biojet are assumed to be negated by the uptake of $\mathrm{CO}_{2}$ during cultivation of the biomass, as opposed to a well-to-wake basis where the combustion emissions are included.

Below is a list of GHG LCA estimates from seven different studies on a range of production pathways accounting for feedstock use, process technology and whether or not LUC and ILUC effects have been considered. The functional unit reported in the table is the commonly adopted $\mathrm{g} \mathrm{CO}_{2}$ equivalent over a 100 year period per MJ of fuel. To compare the $\mathrm{CO}_{2}$ emissions from the alternative pathways, similar estimates for conventional fossil jet A-1 are also listed. 
Table 23: GHG mitigation impact on various production pathways

\begin{tabular}{|c|c|c|c|c|c|}
\hline Study & Pathway & LUC & iLUC & $\begin{array}{l}\mathrm{g} \mathrm{CO}_{2} \text { eq. / } \\
\mathrm{MJ} \text { fuel }\end{array}$ & $\begin{array}{r}\mathrm{CO}_{2} \\
\text { reduction }\end{array}$ \\
\hline \multirow{4}{*}{$\begin{array}{l}\text { Kadambari Lokesh et al. (2015) } \\
\text { Life cycle greenhouse gas anal- } \\
\text { ysis of biojet fuels with a tech- } \\
\text { nical investigation into their } \\
\text { impact on jet engine } \\
\text { performance }\end{array}$} & Camelina HEFA-SPK & & & 31.4 & $63 \%$ \\
\hline & Microalgae HEFA-SPK & & & 40.1 & $52 \%$ \\
\hline & Jatropha HEFA-SPK & & & 38 & $55 \%$ \\
\hline & Conventional Jet A-1 & & & 106.1 & \\
\hline $\begin{array}{l}\text { Moreira et al. (2014) } \\
\text { Life Cycle Greenhouse Gas } \\
\text { Emissions of Sugar Cane Re- } \\
\text { newable Jet Fuel }\end{array}$ & Sugarcane SIP-SPK & $x$ & $x$ & 21 & $75 . \%$ \\
\hline Li and Mupondwa (2014) & Camelina (high yield) HEFA-SPK & & & 12 & $86 \%$ \\
\hline $\begin{array}{l}\text { Life cycle assessment of came- } \\
\text { lina oil derived biodiesel and jet } \\
\text { fuel in the Canadian Prairies }\end{array}$ & Camelina (low yield) HEFA-SPK & & & 32 & $62 \%$ \\
\hline \multirow{2}{*}{$\begin{array}{l}\text { Marie-Odile P. Fortier et al. } \\
\text { (2014) } \\
\text { Life cycle assessment of bio-jet } \\
\text { fuel from hydrothermal lique- } \\
\text { faction of microalgae }\end{array}$} & Microalgae R-HTL & & & 35.2 & $58 \%$ \\
\hline & Microalgae WWTP-HTL & & & 86.5 & $-3.0 \%$ \\
\hline \multirow{3}{*}{$\begin{array}{l}\text { Avinor (2013) } \\
\text { BAEREKRAFTIG BIODRIVSTOFF } \\
\text { FOR LUFTFART }\end{array}$} & Wood-residuals FT-SPK & & & 16 & $81 \%$ \\
\hline & Wood-residuals AtJ-SPK & & & 29 & $66 \%$ \\
\hline & Conventional Jet A-1 & & & 84 & \\
\hline $\begin{array}{l}\text { Poritosh \& Dutta (2012) } \\
\text { Life Cycle Assessment of Etha- } \\
\text { nol Produced from Wheat } \\
\text { Straw }\end{array}$ & Bioethanol Straw & & & 34 & - \\
\hline Concito (2013) & Bioethanol Maize & & & 49 & - \\
\hline $\begin{array}{l}\text { Klimapåvirkningen fra biomasse } \\
\text { og andre energikilder }\end{array}$ & Bioethanol Straw & & & -69 & - \\
\hline \multirow{7}{*}{$\begin{array}{l}\text { SWAFEA (2011) } \\
\text { Sustainable Way for Alternative } \\
\text { Fuels and Energy in Aviation - } \\
\text { Final Report }\end{array}$} & Rapeseed HEFA-SPK & $x$ & & 41 & $51 \%$ \\
\hline & Camelina HEFA-SPK & $x$ & & 24 & $70 \%$ \\
\hline & Jatropha HEFA-SPK & $x$ & & 38 & $55 \%$ \\
\hline & Miscanthus HEFA-SPK & $x$ & & 10 & $88 \%$ \\
\hline & Switchgrass HEFA-SPK & $x$ & & 15 & $82 \%$ \\
\hline & Short rotation wood-crops FT-SPK & $x$ & & 12 & $86 \%$ \\
\hline & Conventional Jet A-1 & & & 84 & \\
\hline \multirow{5}{*}{$\begin{array}{l}\text { Partner (2010) } \\
\text { Life Cycle Greenhouse Gas } \\
\text { Emissions from Alternative Jet } \\
\text { Fuels }\end{array}$} & Switchgrass FT-SPK & & & 17.7 & $80 \%$ \\
\hline & Switchgrass FT-SPK & & $x$ & -2.0 & $102 \%$ \\
\hline & Rapeseed oil HEFA (no LUC) & & & 54.9 & $37 \%$ \\
\hline & Rapeseed oil HEFA & $x$ & & 97.9 & $-12 \%$ \\
\hline & Jet $A-1$ & & & 87.5 & \\
\hline
\end{tabular}


Explanatory note to the table above: FT: Fischer-Tropsch. HEFA: Hydropocessed Esters and Fatty Acids (also known as HRJ). R-HTL: Refinery Hydrothermal Liquefaction. SIP: Synthetic Iso-paraffin. WWTP-HTL: Wastewater Treatment Plant integrated with Hydrothermal Liquefaction. SPK: synthetic paraffinic kerosene. The listed $\mathrm{CO}_{2}$ reduction is estimated with reference to a value of $84 \mathrm{~g} \mathrm{CO}_{2}$ eq / MJ (Novelli, 2011) for conventional jet fuel. The table is non-exhaustive and does not include certain feedstock types, such as palm and soy oil and Salicornia which are not considered relevant for a potential Nordic production pathway.

The table above demonstrates the wide range of estimates for life cycle GHG emissions of production pathways. In many studies (not accounting for LUC and ILUC) the dominant emission sources can be attributed to biomass cultivation, while processing emissions are greater in others. The more promising $\mathrm{CO}_{2}$ reduction potentials range from about $60-80 \%$, but the mitigation benefit could well change significantly if LUC and ILUC scenarios relevant for an actual feedstock cultivation scheme are applied.

If included, the effects of LUC and ILUC can entirely dominate the total GHG emissions. Any climate mitigation benefit for a pathway may be fully offset, e.g. if land of high carbon stock is converted for feedstock cultivation (SWAFEA, 2011), as is for instance seen in the Partner 2010 study, where rapeseed oil HEFA has a $37 \%$ reduction without LUC effects, but a $12 \%$ increase for the considered LUC scenario. For other types of feedstock the LUC impacts can be even more pronounced, as demonstrated in the Partner 2010 study, where a considered scenario for palm oil (not listed in table) resulted in GHG emissions more than seven times higher than conventional jet fuel. LUC impacts may also be positive, for instance if converted grassland is used for growing perennial crops (SWAFEA, 2010).

The available literature has mostly investigated the HEFA and FT production pathways. Only one study was found on the AtJ pathway, with Norwegian wood residuals as feedstock, yielding a 66\% reduction, with the majority of emissions (excluding combustion) attributed to processing (Avinor, 2013). For bioethanol, several well-to-gate GHG estimates exist, and the emission categories included in such studies are comparable to the emissions for a full AtJ pathway (excluding the processing step from bioethanol to jet fuel). Three of such estimates have been included in the table to serve as proxies for the emissions of an AtJ pathway. The negative value for bioethanol from straw is due to an assumed displacement of animal feed from a $\mathrm{C}_{5}$-molasse by-product. 
Most studies available have also only explored hypothetical production pathways, and little can be found on existing fuel production. The Moreira et al. (2014) studies the sugarcane SIP-SPK fuel produced by Amyris and found a 75\% CO2 reduction, but for the rest of known commercially produced alternative jet fuels, only non-LCA estimates exist. These estimates cannot be fully relied upon, in particular as some may be the producers own estimates. Generally, such estimates list anywhere from 50\% to 80\% reduction (United, 2013; Fulcrum Bioenergy, 2015; IATA, 2015).

\subsection{Non- $\mathrm{CO}_{2}$ climate effects of sustainable jet fuels}

Most LCAs have focused purely on quantifying $\mathrm{CO}_{2}, \mathrm{CH}_{4}$ and $\mathrm{N}_{2} \mathrm{O}$ emissions, expressed in $\mathrm{CO}_{2}$ equivalents. However, other climate impacts from aviation known as non- $\mathrm{CO}_{2}$ effects exist. The aviation non- $\mathrm{CO}_{2}$ effects can be broken down into radiative forcing (RF) components from contrails and induced cirrus cloudiness, aerosols (black carbon and sulfate), water vapor, and possibly also surface albedo changes from feedstock cultivation (Myhre, et al. 2013). These effects are far more uncertain and less studied, in particular the effects of aerosols and cloudiness. The total anthropogenic RF from aviation have been estimated to be as high as $5 \%$ (compared to the $2 \%$ of anthropogenic $\mathrm{CO}_{2}$ emissions accounted for by aviation) (Lee et al., 2009), due to non- $\mathrm{CO}_{2}$ effects.

Recently, a number of studies have shown that the chemical composition of alternative jet fuel gives rise to altered non- $\mathrm{CO}_{2}$ effects compared to those adhering to conventional jet fuel. A traditional GHG inventory assessment may therefore not fully account for the actual climate impact of alternative jet fuels. Stratton et al. (2011) found that non$\mathrm{CO}_{2}$ combustion emissions of SPK fuels led to a reduced life cycle climate merit relative to conventional jet fuel, but did not investigate the effects of contrails and contrail cirrus clouds. Rojo et al. (2014) investigated the effect of aerosols from jet A-1, FT- and HEFA-fuel and found significant alterations in the optical properties of aircraft contrails, but did not quantify this in terms of a RF effect. Raymond et al. (2014) analyzed black carbon (BC) emissions and found a proportional relationship with the aromatic content of alternative jet fuels. The RF of aviation BC emissions is approximately $34 \%$ of the aviation $\mathrm{CO}_{2} \mathrm{RF}$ (Stettler et al., 2013), which indicates an increased climate benefit (and air quality) from lowaromatics alternative fuels. 
The non- $\mathrm{CO}_{2}$ effects have mostly been examined in isolation. The results indicate a need for further research and development of a holistic framework for quantification, as an extension to the current GHG metric, before absolute comparisons of the climate impact of alternative jet fuels can be fully trusted.

\subsection{Climate impacts of the three pathway scenarios}

\subsubsection{Climate impact of the HEFA pathway (scenario 1)}

The life-cycle GHG estimates of HEFA-SPK on camelina range from about $63-86 \%$, with the highest estimate attributed to a high yield of camelina per hectare. Cultivation accounts for the majority of the GHG inventory, but the first scenario will also need to consider increased transportation emissions from importing either camelina. Most of the camelina estimates did also not include the effects of LUC and ILUC. Camelina grown in crop-rotation e.g. with winter wheat will in this case be a more advantageous feedstock from a climate perspective. If tall oil or waste-oils are used as a feedstock, the climate impact of HEFA/HEFA+ will likely be comparable to the FT-SPK from the second scenario around an $80-90 \%$ GHG reduction per MJ fuel.

\subsubsection{Climate impact of the Fisher Tropsch pathway (scenario 2)}

Within LCA literature only a few estimates exist on the GHG-intensity of FT-SPK using forest residuals. Avinor 2013 is one of them, with a listed value of an $80 \% \mathrm{CO}_{2}$ reduction relative to fossil jet A-1 (no LUC or ILUC included in this estimate). For FT-SPK fuel using energy crops, such as willow or switchgrass estimates are comparable in the range of 80-90\% reduction (SWAFEA 2011, Partner 2010). The dominant source of emissions for the FT-scenario will be attributed to processing, but the substitution effects from byproducts will also have a significant effect on the overall climate benefit. 


\subsubsection{Climate impact of the Lignocellulosic AtJ pathway (scenario 3)}

The literature review found only one estimate of an AtJ pathway, using wood residuals as feedstock with a $66 \%$ GHG-reduction compared to fossil jet A-1, but other well-to-gate estimates for bioethanol from straw were also included showing $-69 \mathrm{~g} \mathrm{CO}_{2} \mathrm{eq} / \mathrm{MJ}$ in the low end and $34 \mathrm{~g} \mathrm{CO}_{2}$ eq/MJ in the high end. The large discrepancy resulted from different substitution effects of co-products, in particular in the negative estimate from using produced $\mathrm{C}_{5}$-molasses as animal feed substituting imported soy bean fodder and avoiding associated ILUC. It is possible that an AtJ producer would prefer to eliminate $\mathrm{C}_{5}$-molasses as a by-product by converting the $\mathrm{C}_{5}$ sugars to additional biofuel, reducing the climate benefits from such product substitution. The $34 \mathrm{~g} \mathrm{CO}_{2} \mathrm{eq} / \mathrm{MJ}$ is then a more likely estimate, but due to the further processing required, the emissions from Straw-AtJ-SPK are expected to be somewhat higher, in the area of 30-45 $\mathrm{g} \mathrm{CO}_{2} \mathrm{eq} / \mathrm{MJ}$, corresponding to a $66-45 \% \mathrm{CO}_{2}$ reduction compared to conventional fossil jet. In the absence of very high substitution effects, such as imported soy bean fodder replacement, the climate benefit of the straw jet fuel will likely be slightly less favorable than the wood-FT jet fuel in the second scenario.

\subsection{The impact from $2020-2050$}

Based on the projected demand of sustainable jet fuel in the Nordic countries, as presented in chapter 5 , the climate impact following a substitution of fossil jet fuel with sustainable jet fuel, as produced in the different scenarios, can be estimated. This impact is quantified in terms of avoided $\mathrm{CO}_{2}$ equivalent emissions.

The estimates are based on the assumption that the demand for sustainable jet fuel by year is fully covered by one of the three pathway scenarios, with associated life-cycle GHG estimates mentioned above, and an assumed reference value for fossil jet fuel of $84 \mathrm{~g} \mathrm{CO}_{2} / \mathrm{MJ}$. It should be noted that the calculations assume that the life-cycle GHG-intensity for each pathway will stay constant from 2020-2050.

The values in the graph are based on the average value of the range of GHG intensity listed for each pathway above, with the error bars showing the savings using the highest and lowest values. The wide range seen towards 2040 and 2050 reflects the uncertainty in the lifecycle GHG inventory for the different pathways, where feedstock, conversion 
efficiency, inputs and byproducts can have a highly significant effect on the climate impact.

Figure 20: Annual GHG savings by pathway scenario

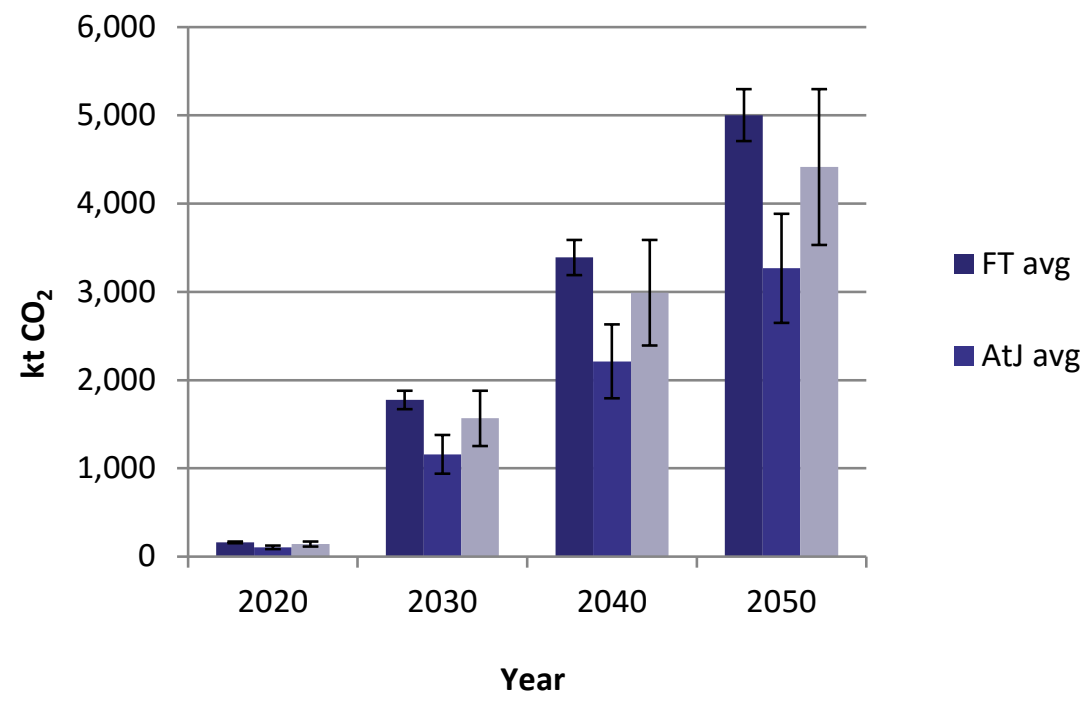

The three scenarios have different effects for the climate. The annual possible GHG savings are highest for the Fisher-Tropsch pathway scenario, which are likely to save between 152-171 kt in 2020, increasing to between 4,700-5,300 kt in 2050. This will generate a total saving of 76-85 Mt.

The HEFA pathway has the second highest climate impact, with 114$171 \mathrm{kt} \mathrm{CO} \mathrm{CO}_{2}$ equivalent annual emissions in 2020 and 3,500-5,300 kt in 2050. This will provide a likely aggregated reduction of 57-85 $\mathrm{Mt} \mathrm{CO}_{2}$ from 2020 to 2050. The Alcohol-to-Jet pathway scenario will in comparison only reach an aggregated reduction between 43-62 $\mathrm{Mt} \mathrm{CO}_{2}$ in 2050.

The following graph below illustrates the aggregate climate impact from an initial $1 \%$ in 2020 to a $37.5 \%$ blend-in scenario in 2050 . 
Figure 21: Total GHG savings from 2020-2050 by pathway

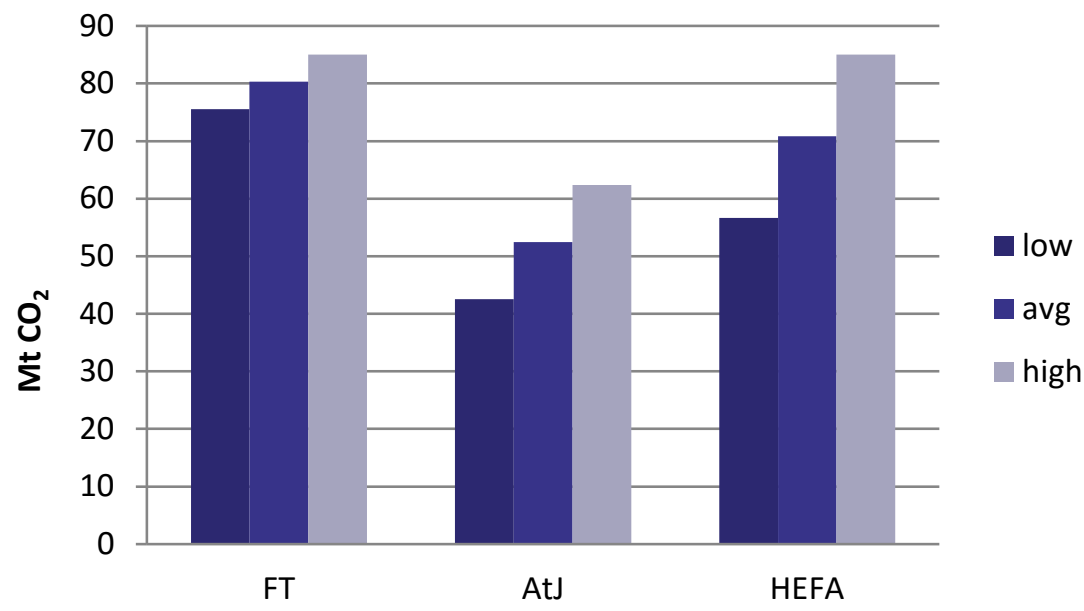

\subsection{Discussion}

The analysis of the climate impact of the three scenarios shows that the FT scenario in average is likely to create the highest climate impact. In the analysis, the GHG-intensity has been assumed fixed on the current level. However this intensity is likely to change over time due to a number of factors.

Firstly, the increasing maturity of the conversion technology will improve conversion efficiency and reduce $\mathrm{CO}_{2}$ intensity per produced l sustainable jet fuel. Also, the energy inputs in the production (electricity, heat/steam) is likely to come from an increasingly decarbonized energy supply as coal and natural gas are outfaced in the Nordic power mix, reducing the $\mathrm{CO}_{2}$ intensity. Thirdly, the application of by-products and associated substitution effects can change over time. For instance, co-firing lignin for CHP production can no longer displace fossil energy sources in the Nordic countries as they are outfaced, or vinasse, a by-product in bioethanol production, may suddenly shift its application, e.g. away from biogas production towards animal fodder instead for economic or environmental reasons. Fourth, feedstock cultivation/sourcing or composition may change over time. For instance, certain waste fractions (e.g. waste-oils or wood residuals) may become less or more available.

It is most likely that the aggregate effect of these factors will result in a decreasing GHG-intensity for all pathways over time. However, both the magnitude and the speed of reduction will be different for each 
pathway. For the FT and the AtJ scenarios, the lower technological maturity than in the HEFA scenario is most likely to result in a higher potential for increasing the conversion efficiency and a correspondingly higher potential for reducing the GHG intensity. The disadvantageousness of the AtJ scenario with regards to the climate impact does, hence, not take into account this potential.

Taking account of these altering factors and more precisely estimating the climate impact would require a scrutinous investigation of technological forecasting as well as projections on the availability and prices of feedstock and the future utilization possibilities of by-products. Such an analysis is beyond the scope of this report, and the results illustrated above should therefore only serve as an indicator for the expected order of magnitude of the climate impact. 


\section{Socio-economic and business impact}

A shift from fossil fuel towards a Nordic sustainable bio jet fuel market will have a positive impact on those business entities involved in the development and deployment of the new value chain for biofuel, and a negatively impact those businesses, which gains from the current deliveries of fossil fuel to the aviation industry, insofar as they will not be redirecting their current production and services towards the sustainable jet fuel value chain.

In general, the business sectors which will be most affected belong to the value chains of energy production, transportation of fuel (e.g. changed level of sea and land transportation), waste management and agriculture, depending on the feedstock scenario (e.g. forestry residues for FT synthesis). Some businesses within certain sectors, such as refining and transportation, may be able to adapt from the old to the new production line and thereby be more neutral to the technology shift.

Additionally, other economic effects will also involve the derived value chains, through employment, administrative and support services, such as research and monitoring agencies and certifying bodies, auditing the sustainability of the value chain. The effect of implementing a production of sustainable jet fuels will also vary geographically across the Nordic region, depending on market development and the choice of technological pathway.

This chapter seeks to flesh out the possible consequences for business and social economy, as well as for employment, with sustainable jet fuel. The analysis will focus on the three production scenarios outlined in chapter 9 and the likely implementation pathways.

The estimates used for illustrating the pathways are based on rough, partial numbers and do not include indirect production effects in for example the agricultural sector and the utility sector. For example, an increased production and demand of forestry residuals or straw is likely to alter the current market price and thereby result in a substitution effect for the heat sector from bio-energy towards more wind- and waterbased energy production. Also in agriculture, a shift in production, for example, may result in an altered composition of the total crop produc- 
tion, caused by altered crop rotation and the organization of sowing, harvesting, etc., as well as integration of biomass production on farms or new opportunities for processing of manure could lead to adjustments of livestock production on these farms.

\subsection{Production costs of sustainable jet fuel}

The socio-economic impact for each of the three feedstock-scenarios will depend on the aggregated production cost. The estimated demand from 2020 to 2050 was estimated in chapter 5. Chapter 9 provided an estimate of the costs of producing sustainable jet fuel. The cost of fuel produced through a FT synthesis was estimated within an interval of 1.5EUR 2.2/l, whereas the costs of producing sustainable jet fuels using an AtJ approach falls within the range of EUR 1.7-2/l, and in the range of EUR 0.8-1.5/l when employing a HEFA pathway. The following subsection identifies the costs associated with producing the estimated quantity of sustainable jet fuel, given these prices.

It should be noted that the assumed costs of producing sustainable jet fuel does not necessarily imply comparability across the pathway scenarios. As described in chapter 8 , the various pathways sport a range of technological variance, meaning that the costs of the individual fuels do not necessarily correlate. For instance, the cost of the HEFA pathway scenario might be situated in the lower end of the spectrum while AtJ scenario exhibit high costs, dependent on the chosen method of production. Furthermore, it should be noted that the low/high cost-efficiency scenarios are extreme points at either end of a spectrum. In reality, both cost and conversion efficiency are likely to be placed somewhere in between these two poles.

Table 24: Costs of producing sustainable jet fuels in the low-cost scenario (2016 prices)

\begin{tabular}{lrrrrrr} 
Million EUR & $\mathbf{2 0 2 0}$ & $\mathbf{2 0 2 5}$ & $\mathbf{2 0 3 5}$ & $\mathbf{2 0 4 5}$ & $\mathbf{2 0 5 0}$ & $\begin{array}{r}\text { Cumulative costs } \\
\mathbf{2 0 2 0} \mathbf{2 0 5 0}\end{array}$ \\
\hline HEFA & 52 & 328 & 831 & 1,351 & 1,611 & 25,853 \\
FT & 98 & 615 & 1,559 & 2,533 & 3,020 & 48,474 \\
ATJ & 111 & 697 & 1,767 & 2,871 & 3,423 & 54,937 \\
FOSSIL REFERENCE & 16 & 103 & 260 & 422 & 503 & 8,079 \\
\hline
\end{tabular}


In the low cost scenario, the annual cost of utilizing a FT synthesis pathway starts at roughly EUR 98 million in 2020, rising progressively towards an annual cost of EUR 3 billion in 2050, in order to satisfy the quota obligations outlined in chapter 5 . The cumulative costs of the FT pathway reach roughly 48.5 billion EUR over the 30 year period of analysis.

The HEFA pathway scenario starts with an annual cost of EUR 52 million in 2020, which increases to EUR 1.6 billion in 2050, which is coarsely equivalent to a cumulative cost of EUR 26 billion.

For the AtJ pathway scenario, annual costs initiate at approximately EUR 111 million. Over the period of analysis, these costs gradually increase to roughly EUR 3.5 billion in 2050, corresponding to a cumulative cost of EUR 55 billion.

Table 25: Costs of producing sustainable jet fuels in the high-cost scenario

\begin{tabular}{lrrrrrr} 
Million EUR & $\mathbf{2 0 2 0}$ & $\mathbf{2 0 2 5}$ & $\mathbf{2 0 3 5}$ & $\mathbf{2 0 4 5}$ & $\mathbf{2 0 5 0}$ & $\begin{array}{r}\text { Cumulative costs } \\
\mathbf{2 0 2 0}-\mathbf{2 0 5 0}\end{array}$ \\
& & & & & \\
HEFA & 98 & 615 & 1,559 & 2,533 & 3,020 & 48,474 \\
FT & 143 & 902 & 2,286 & 3,715 & 4,430 & 71,095 \\
AtJ & 130 & 820 & 2,079 & 3,378 & 4,027 & 64,632 \\
Fossil reference & 16 & 103 & 260 & 422 & 503 & 8,079 \\
\hline
\end{tabular}

In the high cost scenario, the annual cost of employing the FT pathway increases to approximately EUR 143 million in 2020 and further to roughly EUR 4.5 billion in 2050 . Thus, the cumulative cost of producing sustainable biofuels increases to circa EUR 71 billion over the 30 year period.

The initial annual cost of producing sustainable jet fuels using the AtJ pathway increases to approximately EUR 130 million in the high cost scenario. Over the period of analysis this cost increase to a final EUR 4 billion in 2050, equal to a cumulative cost of roughly EUR 65 billion from 2020-2050. It is worth noting, that while the AtJ pathway scenario is the most expensive option in the low cost scenario, costs decrease relative to the FT pathway in the high cost scenario, due to a more narrow range of estimated costs.

Before concluding this sub-section, it should be stressed that the estimates above should not serve as a basis for conclusions concerning the optimal pathway for a Nordic production of sustainable jet fuel in and of themselves. Rather, they should serve as a point of departure for further analysis. To illustrate this point, one should consider the costs estimated above. As previously mentioned, while the costs are assumed to be rather similar across the technological pathways, the composition of the costs is not. This fact carries with a series of implications that should be considered. 
For instance, investment in production facilities make up a larger fraction of costs in the FT pathway than its contemporaries, as it is a technically more demanding process. This carries with it the risk of technical lock-in, once the investments are made. On the other hand, the AtJ might require lower initial investment, yet feedstock makes up a larger proportion of the total costs, which increases vulnerability to fluctuations in the market. Finally, while the HEFA pathway seems superior with regards to investment costs and efficiency, one should consider the fact that choosing this path makes the Nordic countries highly dependent upon imported feedstock. Furthermore, as the production of feedstock and the first processing (making the feedstock into a high energycontent product suitable for long-haul transportation) would take place abroad, the socio-economic effects of sustainable jet fuel production in the Nordics would be diminished.

Finally, it should be kept in mind that fuel prices are fixed to 2016 level in the calculations above. This may not reflect the real fluctuations and expectance in the market. For instance, the price of fossil fuels is currently at a historic low and could increase again in the future, thus diminishing the price gap between sustainable and conventional jet fuel. Furthermore, commercial scale production of sustainable jet fuels could lead to a steeper decrease in costs over time, as potential gains from learning and economies of scale are realized. As a consequence, the estimates above should be treated with care.

\subsection{The socio-economic effect}

The direct socio-economic effect following the estimated demand is measured in income, net exports and employment. It should be noted that this demand will only be realized, implementing the right instruments for realizing the market. Two main effects will influence the Nordic producers and service providers, including the reduction of demand for fossil jet fuel and the increase of the demand for biofuel. In the following, these effects are described.

\subsubsection{The decrease of fossil jet fuel production}

Following the estimated annual substitution from 2020 to 2050 of fossil jet fuel to sustainable bio jet fuel (as estimated in chapter 5.2), the decrease of fossil jet fuel demand will especially affect the Nordic import ratio of energy, as the current jet fuel demand in the Nordics is roughly cov- 
ered through imports from overseas producers via maritime transportation. The conversion into locally produced bio jet fuels will have a profound effect on the current production line, income level and -distribution, as well as the employment balance between the Nordic region, the remainder of EU Member States and other jet fuel producing countries.

The decrease of fossil jet fuel imports in the Nordics will especially affect overseas producers, but should inter alia also have an effect on maritime transportation, where the majority share is from the Nordic shiptanks.

\subsubsection{The increase of sustainable jet fuel production}

Given the high ratio of feedstock production in each of the pathway scenarios, the effect of biofuel products is primarily generated through their direct effect on agriculture and forestry production. Further effects could be generated through the multiplication effects to other businesses within and outside the agricultural sector.

According to a Danish study, 51 about $42 \%$ of the indirect effects from agriculture are generated within the sector. The remaining 58\% mainly affects the following sectors: industry (17\%) (mainly production of farming equipment), financial (14\%), transportation (9\%) and trade (7\%). The effect on the energy and construction sectors makes up less than $5 \%$ respectively. Although not fully adaptable to the other Nordic countries, these findings indicate that an increased feedstock production will have a multiplication effect on a broad range of sectors across the Nordic region.

Quantifying the total socio-economic impact is not within the scope of this report. However, using currently available literature on the current direct and indirect sector-based impact on Denmark, one may approximate how each of the pathway scenarios may affect the Nordic region as a whole. It must be emphasized that the estimates only works as an illustrative example on how a gradual implementation of sustainable jet fuel may turn out. The example is illustrated in the table above. Note, that for the HEFA process, two different effects are identified illustrating the impact of either imported HEFA or domestically produced feedstock.

In the table below, the annual approximated impact - measured in EUR per liter - is an aggregate of the direct and indirect benefits, as well as the socio-economic costs, caused by loss of fossil jet fuel consumption and including the socio-economic benefits of the environmental impact, estimated to EUR 7.5/Tons $\mathrm{CO}_{2}$.

${ }^{51}$ See i.e. 10 mio planen, Universities of Copenhagen and Aarhus. 
Table 26: Annual approximated socio-economic impact of the scenarios

\begin{tabular}{|c|c|c|c|c|}
\hline Annual effect (EUR/liter) & $\begin{array}{r}\text { Scenario 1a: } \\
\text { HEFA }\end{array}$ & $\begin{array}{r}\text { Scenario1b: } \\
\text { HEFA } \\
\text { (imported) }\end{array}$ & Scenario 2: FT & Scenario 3: AtJ \\
\hline Gross socio-economic benefit & 3.0 & 0.2 & 3.9 & 4.8 \\
\hline Agriculture, forestry etc. & 1.4 & - & 1.6 & 2.6 \\
\hline Energy and water supply & 0.3 & - & 0.4 & 0.4 \\
\hline Industry and Construction & 0.7 & - & 1.2 & 1.0 \\
\hline Transport etc. & 0.3 & 0.1 & 0.3 & 0.3 \\
\hline Others & 0.3 & 0.1 & 0.4 & 0.5 \\
\hline Environmental benefit & 0.016 & 0.016 & 0.019 & 0.012 \\
\hline Gross socio-Economic cost & 0.4 & - & 0.4 & 0.4 \\
\hline Net Socio-Economic Benefit & 2.6 & 0.3 & 3.5 & 4.4 \\
\hline $\begin{array}{l}\text { Annual sector-based employment effect } \\
\text { (EUR/mio. litre) }\end{array}$ & 7.0 & 0.6 & 9.1 & 11.2 \\
\hline
\end{tabular}

Source: Own estimates, based on Department of Food and Resource Economics, 2012, Blooberg 2012 and Larsen et al. 2008.

According to this illustrated example, the gross benefit of the production of a liter sustainable jet fuel will be in the range of EUR 3-4.8, not including the scenario $1 \mathrm{~b}$, where the HEFA feedstock is entirely imported. Because almost the entire production will be placed abroad in the latter scenario, it will hardly have any gross benefit on the Nordic sectors, aside from the transportation sector.

The negative impact on the current fossil based jet fuel pathway is estimated to be 0.4 euro per liter, especially due to the loss of shiptanks in the transportation sectors. Hence, the net socio-economic impact is reduced from EUR 2.6 to 4.4 per liter.

The derived impact on employment of a sustainable jet fuel production is estimated to 7-11.2 annual full-time employed per million liters, once again ignoring the diminutive impact on a HEFA $1 \mathrm{~b}$ scenario.

The example, which is based on direct and indirect sector-based multiplication effects involved in biofuel production and distribution, does not include the cost of implementing an incentive system (neither as loss of tax-incomes, tariffs etc.). Also, it does not take into account the specific local multiplication effect, nor does it include the specific engineering technology used downstream to further a biofuel production into jet-fuel. The estimates are also based on current agricultural production technologies and infrastructure. Scaling up production into an efficient production line for a 2050 -level of $37.5 \%$ of the total jet fuel demand is likely to affect the farmers production level and choice of crop, depending on future price on fossil fuel and biofuel.

However, one may get an idea of on what scale a sustainable jet-fuel production may have an impact. For example, using the rough estimates 
and extrapolating to a 2050-level of production in the Nordic countries, and assuming a blend-in level of $37.5 \%$ (in order to fulfill the $25 \% \mathrm{GHG}$ emission reduction target, see chapter 5.2 ), the socio-economic net impact would annually be between EUR 5.2-8.8 billion, depending on the mixture of the three pathway scenarios and assuming that all sustainable jet fuel will be produced within the Nordic region. Such level will be followed by 14,000-22,500 additional employed, depending on the production mixture of the three pathways.

\subsection{The impact on business sectors}

The table below illustrates the most affected businesses, divided along the lines of the three most promising pathway scenarios, respectively HEFA, FT and AtJ. The analysis in chapter 9 reveals the HEFA-based scenario as the most realizable within the short term, from around 2020. Thus, it is likely that the majority of the feedstock for this scenario, i.e. waste oils or oil crops, will initially be imported. However, if feedstock availability will enable a Nordic collection of residual oils or production of camelina, the import will be lowered respectively. Later on, from 2025-2030 and onwards, as the FT and AtJ scenarios can start to develop, the feedstock is likely to come from Nordic sources. 
Table 27: The directly benefitting sectors of biofuel jet production

\begin{tabular}{|c|c|c|c|}
\hline & Scenario 1: HEFA & Scenario 2: FT & Scenario 3: AtJ \\
\hline $\begin{array}{l}\text { Construction } \\
\text { And Planning }\end{array}$ & $\begin{array}{l}\text { Construction and } \\
\text { engineering industry } \\
\text { (and expansion of existing) } \\
\text { Advisory services from the } \\
\text { engineering industry }\end{array}$ & $\begin{array}{l}\text { Construction and engineer- } \\
\text { ing industry } \\
\text { Advisory services from the } \\
\text { engineering industry }\end{array}$ & $\begin{array}{l}\text { Construction and engineer- } \\
\text { ing industry } \\
\text { Advisory services from the } \\
\text { engineering industry }\end{array}$ \\
\hline $\begin{array}{l}\text { Feedstock } \\
\text { Production }\end{array}$ & $\begin{array}{l}\text { Oil residual industry to be } \\
\text { expanded in all Nordic } \\
\text { countries } \\
\text { For the imported share, no } \\
\text { impact will be traced in the } \\
\text { Nordic economy. }\end{array}$ & $\begin{array}{l}\text { Wood residual industry to } \\
\text { be expanded in general in } \\
\text { Norway, Sweden and Fin- } \\
\text { land. } \\
\text { Current demand of biofuel } \\
\text { from wood residues to CHP } \\
\text { will shift into renewable } \\
\text { electricity (wind and water- } \\
\text { based energy production). }\end{array}$ & $\begin{array}{l}\text { Straw production in the } \\
\text { agricultural sector in Den- } \\
\text { mark and to some extent } \\
\text { Sweden. Wood residual } \\
\text { production in Norway, } \\
\text { Finland and Sweden. } \\
\text { Current demand of biofuel } \\
\text { from ethanol to CHP will } \\
\text { shift into renewable elec- } \\
\text { tricity (wind and water). }\end{array}$ \\
\hline $\begin{array}{l}\text { Transportation } \\
\text { Infrastructure }\end{array}$ & $\begin{array}{l}\text { The Nordic tankships are } \\
\text { likely to have a large share } \\
\text { in transportation of the } \\
\text { imports from Central- and } \\
\text { Southern Europe. }\end{array}$ & $\begin{array}{l}\text { Transportation, including } \\
\text { feedstock collection and } \\
\text { fuel distribution via rail- } \\
\text { ways, trucks and tankships. }\end{array}$ & $\begin{array}{l}\text { Transportation includes } \\
\text { feedstock collection and } \\
\text { fuel distribution via rail- } \\
\text { ways, trucks and tankships. }\end{array}$ \\
\hline $\begin{array}{l}\text { Conversion } \\
\text { And Biorefinery }\end{array}$ & $\begin{array}{l}\text { Hydrotreatment and refin- } \\
\text { ery plants in Finland and } \\
\text { possibly the other Nordic } \\
\text { countries }\end{array}$ & $\begin{array}{l}\text { Gasification and refinery } \\
\text { plants in the Energy sector } \\
\text { in Norway, Sweden and } \\
\text { Finland }\end{array}$ & $\begin{array}{l}\text { Enzyme and biomass pre- } \\
\text { treatment, gasification and } \\
\text { refinery plants in the Energy } \\
\text { sector in Denmark, Norway, } \\
\text { Sweden and Finland }\end{array}$ \\
\hline $\begin{array}{l}\text { Blending } \\
\text { And Distribution }\end{array}$ & $\begin{array}{l}\text { Nordic petroleum refinery } \\
\text { plants close to the Nordic } \\
\text { Airports }\end{array}$ & $\begin{array}{l}\text { Nordic petroleum refinery } \\
\text { plants close to the Nordic } \\
\text { Airports }\end{array}$ & $\begin{array}{l}\text { Nordic petroleum refinery } \\
\text { plants close to the Nordic } \\
\text { Airports }\end{array}$ \\
\hline
\end{tabular}

Table 28: The effected sectors by decreased fossil jet fuel production

\begin{tabular}{ll} 
SECTOR & EFFECT \\
Production & $\begin{array}{l}\text { The production is fully imported. The Nordic oil producers will not be affected } \\
\text { The Nordic Tankships value chain will lose their current import shipping of oil, } \\
\text { between the Nordic countries as well as from abroad }\end{array}$ \\
$\begin{array}{l}\text { Transportation } \\
\text { Blending And Distribution }\end{array}$ & Nordic petroleum refinery plants close to the Nordic Airports \\
\hline
\end{tabular}


The increase of biofuel demand will affect each of the Nordic countries' economy differently, depending on which production scenario the fuel will be based upon. Scenario 2 and 3, where the production pathway is entirely Nordic, will benefit the Nordic economies relatively more than Scenario 1, where a share of the input factors may initially be imported from Southern Europe.

\subsubsection{Agriculture and Forestry Sector}

Agriculture and forestry will experience a new, high demand for straw and forest residue. Since large parts of the feedstock is already utilized by the heating, electricity and biofuel industries and given the fact that the resource is limited and that it is relatively more expensive to extract the part of the feedstock that is not already utilized, the price of the feedstock should inter alia increase.

\subsubsection{Transportation Sector}

The demand for both land transportation and logistics will increase, especially with regards to the transportation of fuel on land in all the stages from feedstock to refinery. Land transportation is important, especially when considering wood as the feedstock, and the amount of trucks that will be needed to transport large quantities of wooden biomass. In addition, railway and tankship transportation will need to be part of an efficient production pathway, although this will largely be on the same level as for conventional fuels. Also businesses specialized in land transportation and fuel logistics will experience a higher demand after their services.

\subsubsection{Industry and Construction Sector}

Initially, the market will need construction of new processing and storage facilities. Such investment will primarily benefit the construction and engineering industry. These facilities need to be built, as well as storage facilities, housing for workers, and roads if not already established. A thorough planning of the full production and processing pathway is also needed before the construction phase is initiated.

A dominant share of the equipment and machinery needed for feedstock collection, pretreatment, refineries, fermentation and distillation are likely to be developed and produced in the Nordic region, as the countries already have a world leader position on clean-tech equipment. This will call for an increased demand for engineering and operation 
managers, as well as facility employees, depending on the level of automation in the production. Furthermore, when the production line is operational, facilities and machinery need to be maintained. Buildings, roads and machinery need to be maintained continuously and can therefore create long term employment within the sector.

\subsubsection{Other sectors}

Public and private services will be needed to ensure quality in production and processes, including environmental assessments.

Constructing and maintaining a level of sustainable jet fuel production sufficient to meet internal demand in the Nordic region, will need a continuing stream of knowledge from the universities and research institutions on how to safeguard and make the pathway more efficient, and potentially lead to new and more efficient pathways. Having a large scale production can help researchers to get a better understanding about the practicalities, they can use in their theoretical studies.

Because of the geographical distribution of the feedstock production, the Nordic production pathway will create special opportunities for small and medium sized businesses, in comparison to large businesses. Small to medium sized businesses are more likely to employ and generate wealth at a local level.

Because of the income generated in relation to the feedstock production, the HEFA scenario, if based on partly imported feedstock, the socioeconomic impact will be lower than fuel based on the Nordic feedstock reserves. The income generated from the imported feedstock share will instead benefit other countries, likely within the EU borders. However, even if the feedstock is imported, the Nordic countries may still benefit from income generated by the transportation sector and to some extent from the export of know-how and technical solutions, ensuring a sustainable and efficient fuel production by the HEFA technology.

\subsection{Employment}

The work force needed to produce sustainable jet fuel has an unusual composition in comparison to other emerging technologies. About $80-90 \%$ of the jobs will be created in the agriculture and forestry sector, and in the transportation sector. The jobs are mainly non-urban and geographically distributed to more remote areas, and thereby benefit the rural communities, which are suffering from the general urbanization of the job-market. 
Table 29: Nordic region annual employment impact in 2050 (at 37.5\% blend-in requirement), by business sector and highest education

\begin{tabular}{|c|c|c|c|c|c|}
\hline & $\begin{array}{r}\text { Secondary/ } \\
\text { Unskilled }\end{array}$ & $\begin{array}{r}\text { Vocational } \\
\text { training }\end{array}$ & $\begin{array}{r}\text { Short/medium- } \\
\text { term higher } \\
\text { education }\end{array}$ & $\begin{array}{r}\text { Long-term } \\
\text { higher } \\
\text { education }\end{array}$ & Total \\
\hline \multicolumn{6}{|l|}{ Scenario 1: HEFA } \\
\hline Agriculture, forestry etc. & 1,800 & 3,400 & 600 & 200 & $6 ; 000$ \\
\hline Energy and water supply & 200 & 300 & 100 & - & 600 \\
\hline Industry and Construction & 700 & 1,200 & 700 & 400 & 3,000 \\
\hline $\begin{array}{l}\text { Transport, post and } \\
\text { telecommunications }\end{array}$ & 400 & 1,600 & 200 & - & 2,200 \\
\hline Others & 1,400 & 100 & 800 & 100 & 2,400 \\
\hline \multicolumn{6}{|l|}{ Scenario 2: FT } \\
\hline Agriculture, forestry etc. & 2,300 & 4,400 & 800 & 200 & 7,800 \\
\hline Energy and water supply & 200 & 400 & 100 & 100 & 700 \\
\hline Industry and Construction & 900 & 1,600 & 900 & 500 & 3,900 \\
\hline $\begin{array}{l}\text { Transport, post and } \\
\text { telecommunications }\end{array}$ & 600 & 2,000 & 300 & - & 2,900 \\
\hline Others & 1,800 & 100 & 1,000 & 100 & 3,000 \\
\hline \multicolumn{6}{|l|}{ Scenario 3: AtJ } \\
\hline Agriculture, forestry etc. & 2,900 & 5,400 & 1,000 & 300 & 9,600 \\
\hline Energy and water supply & 200 & 400 & 200 & 100 & 900 \\
\hline Industry and Construction & 1,200 & 1,900 & 1,100 & 600 & 4,800 \\
\hline $\begin{array}{l}\text { Transport, post and } \\
\text { telecommunications }\end{array}$ & 700 & 2,500 & 300 & - & 3,500 \\
\hline Others & 2,200 & 100 & 1,300 & 200 & 3,800 \\
\hline
\end{tabular}

Own extrapolated estimates based on table $\mathrm{X}$, and crossed with branch statistics data from Statistics Denmark.

In the table above, we have estimated how the number of job in the four main job-categories would be distributed across sectors, with an inblend ratio of $37.5 \%$ (corresponding to the aviation industry objectives of year 2050). The production level for each pathway scenario is based on the same assumption as in figure 13.2. In addition, it should be noted that the labour market structure on education follows the 2014 level.

As the table imply, a transition to sustainable jet fuel production within the Nordic region will create jobs specifically for the feedstock processing and production in the agriculture and forestry sectors. The 
employment impact in these sectors will, at a $37.5 \%$ blend-in scenario, be between 6,000 and 9,600 new jobs dominated by an increased hire of people with a vocational training. More than $50 \%$ of the job creation would be vocational training. In transportation alone, three out of four jobs would require a vocational training background.

The second highest job-category is low-skilled jobs for people without tertiary education levels. About $30 \%$ of the jobs in the agricultural and forestry sector, $27 \%$ in the energy sector, and $25 \%$ in the industry sector, are likely to be low-skilled employment. Altogether between 4,500 and 7,200 full time jobs are likely to be created with a blend-in requirement of $37.5 \%$, depending on the combination of the three scenarios.

About $35 \%$ of the jobs within the industry and construction sectors are likely to require technicians and engineers with a higher education. For the energy sector, one out of four must have a higher educational background. Apart from these sectors, only a small fragment of the jobs will require either short or long term higher education. Altogether, between 2,400 and 3,900 full time jobs with a short-to-medium term high educational background are likely to be created in a $37.5 \%$ blend-in scenario, depending on the combination of the three scenarios. Similarly, $700-1,200$ jobs with a long-term higher educational background are a likely estimate for the same production level.

The production of sustainable jet fuel is most economically produced close to the feedstock reservoir. Therefore, in contrast to the general urbanization trends, the geographical distribution of the jobs in a sustainable jet fuel production value chain is likely to favor the rural areas, especially for the forestry and agriculture feedstock pathways. 


\section{Barriers and steps to take}

This report has investigated the potential for a Nordic production of sustainable jet fuel, with regards to the available technologies and infrastructure, feedstock and political landscape.

A Nordic production of sustainable jet fuels has potential benefits stemming from the reduction of GHG emissions and negative environmental impacts, the development of new technology, as well as economic growth and job creation.

Furthermore, the Nordic countries possess a series of comparative advantages with regards to producing sustainable jet fuels, including:

- The vastest forest resource in Europe, with a well-established industry and infrastructure.

- Strong competencies and technical know-how with regards to utilization of forest biomass.

- Strong competencies in fermentation and enzymatic technologies, relevant for production under the AtJ pathway.

- Already existing commercial scale facilities for production under a HEFA pathway, combined with technical expertise in converting lipids to jet fuel.

- Existing infrastructure poised for retrofitting to production of sustainable jet fuels.

- The aviation industry has shown high willingness to introduce biofuel in aviation.

Yet, a number of barriers to implementing such a production exist, which are deemed insurmountable without proper political action to support market creation and investment in sustainable jet fuels. The following section summarizes and discusses these barriers and gives recommendations as to how they could be overcome. 


\subsection{Price differential on fossil and sustainable jet fuels}

One of the main barriers to implementing a Nordic production and use of sustainable jet fuel is the contemporary price differential between available biofuels and fossil-based jet A-1. Sustainable jet fuel could be produced at a price of EUR 0.8-2.2/liter, dependent on choice of pathway and the feedstock-to-fuel efficiency. Compared to a fossil reference of EUR 0.25/liter, the cost of sustainable jet fuel falls within a price range that is roughly 3-9 times higher than conventional jet A-1. Considering that fuel costs make up $31 \%$ of airlines operating expenses, such an increase in the fuel price creates disincentives for airline operators to demand sustainable jet fuel. Consequently, it should be explored how this disincentive could be mitigated.

A policy aiming to mitigate an economic disincentive should introduce a corresponding (or exceeding) incentive, in order to level the playing field of the various fuels. It would seem an apparent choice to impose taxes upon fossil jet fuels, in order to increase their price to the level of their sustainable counterparts. However, under the auspices of article 14 of the EU Energy Taxation Directive, ${ }^{52}$ all fuels used for aviation are exempt from energy taxation. It should be noted, that the EU ETS already impose a de facto taxation on $\mathrm{CO}_{2}$, which airline carriers could reduce by increasing the share of sustainable jet fuel in their fuel mix. Furthermore, it should be noted that the EU ETS presently only covers flights within the European Economic Area (EEA).

Thus, it is the recommendation of this report to lessen the cost differential by tying economic benefits to the use of sustainable jet fuel. One need not look beyond the Nordic region for inspiration as to how such benefits could be constructed. For instance, as outlined in section 4.4, Norway has proposed a reduction of owed landing fees owed by airlines for airplanes using a minimum blend-in of $25 \%$ sustainable jet fuel. Iceland, on the other hand, has lowered VAT on sustainable fuels.

An alternative approach to lessen the price differential between fossil and sustainable bio jet fuel, could be the implementation of the Directive (EU) 2015/1513, the so-called ILUC Directive. The ILUC Directive amends article $7 \mathrm{a}$ of the FQD, allowing Member States to include sustainable biofuels used in aviation towards the 6\% reduction target (see section 3.2). Thus far, the Nordic countries have not implemented this amendment to the FQD (CE Delft, 2015). By allowing sustainable jet fuel

52 Directive 2003/96/EC, art. 14. 
to count towards reaching the $6 \%$ target, a credit system could be introduced among energy suppliers, much like the one already in place allowing the trade of surplus blends of biofuels in fuel for land transport. Effectively, such a system increase the price of sustainable jet fuels, as credits can be sold to bolster income, thus helping in mitigating the price differential.

\subsection{Lack of congruent sustainability requirements}

Another barrier for a Nordic production of sustainable jet fuel is the current lack of global agreement with regards to what constitutes sustainability, as outlined in section 3.1. For instance, the Roundtable on Sustainable Biomaterials (RSB), which is considered to be one of the most comprehensive certification schemes in the world, has had to develop separate certification requirements for products destined for the EU, in order to comply with sustainability requirements defined in the EU Renewable Energy Directive (RED). Furthermore, there is still an ongoing scientific debate regarding the sustainability issues linked to the various generations of biofuels, such as the unsustainability of $1 \mathrm{G}$ vis-à-vis $2 \mathrm{G}$.

While the recent ISO 13065 standard establishes globally applicable standards, these standards are developed with the objective of specifying principles, criteria and indicators, as well as the methodology set indicators, however, the standard does not establish any limits or thresholds. Consequently, while the standard can serve as a basis for comparison, it cannot in and of itself serve as sustainability standard, as it does not define what levels of the identified indicators can be considered to be sustainable.

Consequently, it is of singular importance to work towards the establishment of appropriate and globally recognized sustainability requirements. The reason for this is twofold. First, it is a necessity for producers of biofuel for aviation worldwide to have an internationally agreed upon standard to adhere to, in order to ensure the production of truly sustainable jet fuels. Second, regional asymmetries with regards to the sustainability standards that producers should achieve could impose competitive disadvantages on firms situated in regions subject to the strictest demands. Thus, producers of sustainable jet fuel within the EU could face unfair global competition.

While the effects described above could be mitigated by lowering sustainability requirements nationally, such an approach could prove detrimental to the efforts towards mitigating the effects of climate 
change. Therefore, it is the recommendation of this report that the Nordics continue working towards globally applicable standards for sustainability, in line with current policies for climate change mitigation.

\subsubsection{Lack of political support for sustainable jet fuels}

The Nordic countries are characterized by a lack of political backing for forwarding the agenda of sustainable jet fuel. When reviewing the policies and regulatory frameworks of the Nordics (see chapter 4), one of the striking features is that most countries do not have any specific targets for the use of sustainable fuels in aviation. The exception to this observation is Finland, which have a declared goal of a $40 \%$ share of RES in aviation by 2050 . On the other hand, Every Nordic country has set blendin requirements for the use of RES in land transport and most have also introduced tax regimes that are favorable to this end.

Another feature of the Nordics, revealing an apparent lack of political support for sustainable jet fuels, is the fact that only two of the Nordics have introduced national initiatives towards their deployment. In Finland, the government sponsored a compilation of business models that could feasibly include the use of sustainable jet fuel and in Norway, the partially state-owned company Avinor supported the establishment of a biohub at Oslo Airport, Gardermoen (a feature that has been replicated at the municipal level in Sweden, with the establishment of Karlstad BioPort).

The missing political support for sustainable jet fuels contributes to a range of barriers to the implementation of their production in that:

- there are very few explicit political goals, which reduce investor confidence in the future market

- policy mechanisms and incentive structures become skewed towards electricity production and land transport

- schemes are unaligned, causing different levels of incentive/disincentive in different countries.

The first barrier relates to the lack of politically set targets for the use of sustainable jet fuels outlined above. This fact contributes to reducing investor confidence that there will be a market for such fuels in the future and could serve to reduce investments in the development of a value chain for sustainable jet fuel. This argument is underscored by the fact that Norwegian stakeholders in the aviation industry have requested more concrete framework conditions for the industry. 
It is the recommendation of this report that specific targets for the share of RES in aviation are set. Specific targets will have a strong signal value to private investors and will thus contribute to spurring investment in the development of sustainable jet fuels. Furthermore, having set targets could help design incentive structures, which will further spur the development and use of sustainable jet fuel.

The second challenge relates to building up an efficient incentive structure across the different sectors, competing for biomass. The current incentive structure is implemented to promote the use of RES in land transport and electricity production, in order to reach set targets and blend-in requirements, without considering the challenges of aviation and lack of sustainable alternatives. One may argue that this incentive structure already seeks to reduce GHG emissions in the most cost efficient way and address the least expensive emissions first. However, if the aviation targets for 2050 are to be realized, this argument is likely to lack the consideration of cumulative costs over many years (and only focus on the marginal costs), including those which reflect the fact that avaiation currently does not have viable sustainable fuel alternatives and as a consequence must be forced to limit its activities.

The Nordic countries have implemented blend-in requirements in various degrees for the use of RES in road transport. In addition, tax exemptions or rebates exist in most countries for environmentally friendly cars. Subsidies for electricity production based on biomass are also common across the Nordics. The argument can be made that energy produced from biomass or other form of renewable energy should be subject to the same subsidies or tax breaks, due to a principle of technological neutrality. However, such an argument exhibits one inherent flaw. Unlike power sources such as wind and solar, biomass is a renewable and yet limited resource, at least if it is to be sustainable. This is due to the fact that only a limited supply of land is available for the production of biomass and care must be taken not to disrupt ecosystem services and biodiversity in the exploitation of biomass. Thus, it is necessary to prioritize the allocation of biomass towards sectors that currently have no viable alternatives, such as heavy road transport, maritime shipping and aviation.

Following this train of thought, it is the recommendation of this report that support schemes are implemented, which give priority to biomass for the abovementioned sectors. Such schemes could seek inspiration in the Icelandic model, where electric and hydrogen-powered cars are exempt from VAT, allowing Iceland to prioritize its limited biomass resources towards the production of bio fuels for its fishing fleet, as mar- 
itime transport, much like aviation, does not currently have any viable, sustainable alternatives to biofuels.

The final barrier is a mismatch of incentive structure across the Nordics. For instance, blend-in requirements for land transport vary from $5-$ $20 \%$ in the region. While such variance is not problematic in and of itself, it becomes a challenge when it affects the market for sustainable jet fuels. For example, Finland is the only Nordic country to set blend-in requirements for the aviation industry, which means that biomass inter alia would be directed towards covering the blend-in requirements for land transport in the other Nordic countries, thus limiting available feedstock. Given the barrier of cost differentials between sustainable and conventional jet fuels mentioned above, policy measures should seek to mitigate the cost differential in the short run and create a demand for sustainable products, which can spur commercial scale production and arguably help bring down costs due to economies of scale in the long run.

It is the recommendation of this report that incentive structures are coordinated, so that the desired effects will be achieved across the region. This could for example be done through an agreement on minimum national target share of RES in aviation across the Nordic countries, thus ensuring a sizable future market. As a supplement to blend-in requirements, future demand for sustainable jet fuel could also be spurred through military procurement, which could provide a small market to kick-start production of sustainable jet fuel whilst increasing security of supply and reducing dependency on imported fossil jet fuels in national defense. However, military aviation has not been included within the scope of this report.

\subsection{Business challenges}

\subsubsection{Low market demand}

The price gap between sustainable and fossil jet fuels means that market demand for the sustainable product is rather limited. Thus, it can be difficult for producers of sustainable jet fuel to find buyers for their products, which in turn can keep potential producers from entering the market, as the current demand does not warrant additional supply. Thus, investments are stifled, due to an expectation of low market demand and a high perceived risk associated with investments in a product that might be unsellable. 
Fuel costs constitute up to $30 \%$ of airlines' operating costs and the airline industry is rather competitive. The price sensitivities of demand facing the airline industry were examined in chapter 5 . It was found that while the demand for interregional and -national flights were rather inelastic, individual routes were subject to a high level of elasticity, meaning that consumers will readily shift from one airline to another based on price differentials. In such a competitive industry, it cannot be expected that any single airline carrier will assume the incremental cost of shifting from conventional to sustainable jet fuel, thus forgoing business to its competitors.

The uncertain future demand and the high risk of first-movers adopting sustainable jet fuel among the airline carriers forms the basis of an environment, which is detrimental to investments. As a consequence, it becomes necessary to find a way to pool risk between the various stakeholders of the industry.

One way of compiling risk and secure finance for investment in the development of sustainable jet fuels is through innovative business models, such as SkyNRG and the Fly Green Fund. SkyNRG is a broker of sustainable jet fuel that has engaged in multi-stakeholder initiatives, called BioPorts, which aim to ensure a demand for sustainable jet fuel. One such BioPort already exists in the Nordic region in Karlstad, Sweden. The Fly Green Fund is a collaborative, counting a range of stakeholders of the aviation industry among its members. The Fund is comprised of payments from its corporate members, which in turn receive annual statements that a certain fraction of their air travel was conducted with sustainable fuels. The Fund is used to finance research in new technology and supply chain development.

It is the recommendation of this report that possible sustainable business models, which can support the development of sustainable jet fuel supply chains, are explored further. Finland has already compiled a range of models, which could serve as a basis for further development.

In addition to exploring possible business models, it is recommended that the perceived risk of investing in sustainable jet fuels is lowered through the formation and facilitation of public-private partnership, between airline carriers, jet fuel producers, universities and other public entities. 


\subsubsection{Competing uses for feedstock}

There are currently a range of competing uses for feedstock, including the production of biofuels for land transport, electricity generation and food production (with recent technological developments, such competition is also valid with regards to $2 \mathrm{G}$ biofuels). Thus, there is a high level of competition for feedstock, which could lead to volatile feedstock prices.

Feedstock has been assessed to constitute a substantial part of the the fuel price, depending on the chosen technological pathway. This makes the production highly vulnerable to fluctuations in feedstock prices. This vulnerability constitutes a barrier to producers of sustainable jet fuel, as high feedstock prices held in congruence with a highly competitive airline industry (in which fuel costs represent a significant fraction of operating costs) could present the producers with dual pressures, squeezing profit margins.

Increased support for R\&D could help to increase the feedstock-tofuel conversion ratio, thus decreasing the amount of feedstock required to produce a given quantity of sustainable jet fuel and vulnerability to feedstock prices.

\subsubsection{Challenges from upscaling to commercial production}

One of the main challenges towards establishing a supply chain for sustainable jet fuels is the transition from demonstration to commercial scale production. Many companies fail at this stage, due to difficulties in attracting investors.

An example of this can be found in the Green Sky London project, in which the company Solenas was to build a commercial scale FT plant, supplying British Airways with a quantity of sustainable jet fuel equivalent to $2 \%$ of British Airways total fuel consumption. Announced in 2010, the project failed in 2015, when Solenas filed for bankruptcy. The reasons were low fossil fuel prices, which meant that the company could not keep its promise of competitive prices, which caused investment jitters.

In order to overcome this crucial barrier to the establishment of commercial scale production, it is recommended that loan guarantees are given to producers of sustainable jet fuels, in order to secure investment capital. Other financial instruments that can be brought to bear in this regard include providing tax incentives either for producers or investors, grants and co-financing of facilities with public institutions, which could limit initial capital requirements for private actors. 


\subsubsection{Higher value products can be derived from feedstock}

The fact that products with higher value than jet fuels can be derived from feedstock constitutes a barrier to establishing a production of sustainable jet fuels.

For the AtJ pathway, the current market price of pure alcohol (ethanol and butanol) as a product in itself exceeds the value jet fuel minus the incremental cost required to upgrade alcohol to jet. Thus, there is an incentive to simply sell alcohol rather than undergoing the process of producing biojet. The same logic applies to both the HEFA and FT pathways were it might be more viable to produce higher fractions of biodiesel than jet fuel from the feedstock.

\subsection{Steps to take}

In order to improve the Nordic potential to develop and use sustainable jet fuel, the Nordic countries need to target the identified market barriers, including the price structure, the feedstock supply, the technology development and the financial availability, as well as the very definition on what constitutes sustainable alternatives for aviation fuels. Some of the optional recommendations are best implemented on a national level and others internationally in a Nordic, EU or global policy context.

A commercialization of the sustainable jet fuel market, which can meet the sector's blend-in commitments from 2020 and onwards, and at the same time can position the enterprises in the Nordic countries with a first-mover advantage, is dependent on stimulus from the public and private sector. A series of recommended actions are listed below to further the introduction of sustainable fuels for aviation.

The recommendations are divided into steps to take for national policy makers, public-private partnerships and international action.

Recommendations to national policy makers:

- Recognize that focused jet fuel targeted strategies are needed to kick start and develop a market for sustainable fuel alternatives in the Nordic countries.

- Launch national and international initiatives which can kick-start and stimulate the maturing and upscaling of the market for sustainable jet fuel. An example could be to tie economic benefits to the use of sustainable jet fuel in order to reduce the cost differential. An inspiration could be the proposed Norwegian reduction of owed landing fees for airplanes using a minimum blend-in of $25 \%$ 
sustainable jet fuel. Iceland has lowered VAT on sustainable fuels. Other initiatives could be to give prioritization to national biomass resources into sectors, which does not have any sustainable alternatives.

- Explore possibilities to make specific targets for the share of RES in aviation on global, European and Nordic level in order to create a strong signal value to private investors and design a more streamlined incentive structures.

- Explore and stimulate possibilities for co-processing with existing facilities, especially oil refineries.

Recommendation to policy makers and private sector in terms of enhancing public-private collaboration:

- Organize the individual technologies and their developers in collaboration around specific production pathways throughout the value chain and with a strong lead partner to facilitate and drive the development.

- Intensify innovation and research on sustainable jet fuel across the Nordic countries. For example, launch initiatives which can enable the collaboration between the forestry industry and R\&D institutions to enhance the utilization of by-products and raw materials. Also, initiatives to bring professional entrepreneurship assistance to startup companies in the sustainable jet fuel value chain.

- Promote public-private partnership, between airline carriers, jet fuel producers, universities and other public entities, in order to increase transparency and lower the risk in investing in sustainable business models.

- Explore new, sustainable business models in support of the development of sustainable jet fuel supply chains, such as the Fly Green Fund and the multi-stakeholder initiative BioPort.

- Policy makers should explore possibilities for establishing a loan guarantee mechanism for producers of sustainable jet fuels, in order to secure transition investment capital. 
Recommendations for policy makers directed towards of international collaboration:

- Nordic collaboration and policy makers should work on the international level through ICAO and other channels, towards an incentive structure for the use of sustainable jet fuel.

- Nordic collaboration and policy makers should continue work towards globally applicable standards for sustainability, in line with current policies for climate change mitigation.

- Explore the possibility to develop globally accepted mandatory blending levels.

- Support and advocate for more streamlined and time-efficient ASTM acceptance processes of new pathways in support of sustainable jet fuel. 



\section{Table Units and Conversion}

Throughout the report, amounts of jet fuel are reported in the units of 1 million or 1 billion $\mathrm{l}$. In other literature, other units are found, such as $1,000 \mathrm{t}, 1,000 \mathrm{~m}^{3}$ (which is equivalent to 1 million l), $1 \mathrm{TJ}$ or $1 \mathrm{PJ}$. To allow for easy comparison between estimates of different units, the following conversion table is provided, along with the adopted assumptions of jet fuel specifications in the form of density and lower heating value.

Table 30: Jet fuel specifications

\begin{tabular}{lrr} 
Density [kg/l] & $\begin{array}{r}\text { Lower heating value per mass } \\
{[\mathrm{MJ} / \mathrm{kg}]}\end{array}$ & $\begin{array}{r}\text { Lower heating value per volume } \\
{[\mathrm{M} / \mathrm{l}]}\end{array}$ \\
\hline 0.8 & 43.5 & 34.8 \\
\hline
\end{tabular}

Source: Danish Energy Agency.

Table 31: Unit conversion

\begin{tabular}{lrrrr} 
Unit & $\mathbf{1 ~ T J}$ & $\mathbf{1}$ PJ & $\mathbf{1}$ million I & $\mathbf{1 , 0 0 0 ~ t}$ \\
$1 \mathrm{TJ}$ & & 0.001 & 0.029 & 0.023 \\
$1 \mathrm{PJ}$ & $1,000.0$ & & 28.740 & 22.990 \\
1 million I & 34.8 & 0.035 & & 0.800 \\
$1,000 \mathrm{t}$ & 43.5 & 0.044 & 1.250 & \\
\hline
\end{tabular}

Source: Danish Energy Agency. 



\section{References}

Abengoa (2015). Abengoa Newsarchive 2015. URL: http://www.abengoa.com/web/ en/noticias_y_publicaciones/noticias/historico/2015/05_mayo/ abg_20150505.html [Accessed 10.09.2015].

Air Transport Action Group (ATAG) (2015). Aviation climate solutions. Geneva, September 2015.

Air Transport Action Group [ATAG] (2013). Reducing Emissions from Aviation through Carbon-Neutral Growth from 2020, URL: https://www.iata.org/policy/ environment/Documents/atag-paper-on-cng2020-july2013.pdf [Accessed 11.09.2015].

AIREG, Aviation Initiative for Renewable Energy in Germany (2012). U.S.-German bilateral agreement on the development of sustainable alternative aviation fuel.

AltAir Fuels (2015). AltAir Fuels About. URL: http://altairfuels.com/about/ [Accessed 07.09.15].

Althingi (2011). The Strengthening of the Green Economy in Iceland: Sustainable Prosperity - A Model Society. Report of the Parliamentary Committee on the Strengthening of the Green Economy. September 2011.

Analyse\&Strategi (2013). Bærekraftig biodrivstoff til sivil luftfart i Norge: Delutredning 3 - Lokalisering av prosessanlegg for produksjon av biodrivstoff, inklusive logistikkanalyse. Oslo, October 2012.

ASA, N. a. s. (2014). Annual Report. https://www.norwegian.no/globalassets/global/ english/aboutnorwegian/ir/doc/annualreports/nas-annual-report-2014.pdf.

AU, Aarhus University (2015). Fremtidens landbrug kombinerer bæredygtighed med produktivitet og effektivitet. URL: http://agro.au.dk/aktuelt/nyheder/vis/artikel/ fremtidens-landbrug-kombinerer-baeredygtighed-med-produktivitet-og-effektivitet/ [Accessed 11.09.2015].

Avfall Sverige (2014). Swedish waste management 2014.

Aviation Week \& Space Technology (2014). HEFA+ is potential path to aviation's CO2 goal. Online. URL: http://aviationweek.com/awin/green-diesel-potential-pathaviation-s-co2-goal [Accessed 13.10.2015].

Avinor (2013). Utredning - Bærekraftig biodrivstoff for luftfart. Killingland, M.; Aga P.; Grinde, M.; Saunes, I.; Melbye, A. M.; Vevatne, J.; Christophersen, E. B., Rambøll.

Avinor (2015). Nasjonal Transportplan 2018-2027. Perspektivanalyse mot 2015. Oslo, March 2015.

Avinor statistics (2015). Monthly transport statistics. URL: https://avinor.no/ konsern/om-oss/trafikkstatistikk/trafikkstatistikktrafikkstatistikk [Accessed 9.12.2015].

Avinor (2014). CSR report. URL: https://avinor.no/globalassets/_konsern/ om-oss/rapporter/en/avinors-csr--report-2014.pdf [Assessed October 2015]. BAD, Biojet Abu Dhabi (2014). Biojet Abu Dhabi: Flight Path to Sustainability The Roadmap. 
Bansal, S.; Durrett, T. P. (2015) Camelina sativa: An ideal platform for the metabolic engineering and field production of industrial lipids. Department of Biochemistry and Molecular Biophysics, Kansas State University, Manhattan, US. June 2015.

Becidan M. et al. (2015). Norwegian waste-toenergy (wte) in 2030: challenges and opportunities. Chemical Engineering Transactions, 43, 2401-2406.

URL: http://dx.doi.org/10.3303/CET1543401

Berlinske (2015). Opinion: Klog klimaudmelding fra regeringen.URL: http://www.b.dk/kommentarer/klog-klimaudmelding-fra-regeringen [Accessed 06.10.2015].

Bernhard, P. \& Bugge, L. (2006). Biomasse - nok til alle gode formål? . Kanenergi, Oslo.

Biodiesl Magazine (2012). Neste Oil to produce biojet as part of EU-funded Itaka project. URL: http://www.biodieselmagazine.com/articles/8848/neste-oil-toproduce-biojet-as-part-of-eu-funded-itaka-project [Accessed 17.03.2016].

Bioenergy Australia (2014). ISO 13065: Sustainability Criteria for Bioenergy - Update Sept. 2014. URL: http://www.bioenergyaustralia.org/data/

BEA_18_Sep_2014_ISO_Sustainability_Criteria_-_OConnell.pdf [Accessed 24.08.2015].

Biofuels Digest (2014 a). HSBC to join Virgin Atlantic, LanzaTech partnership for low carbon jet fuel. URL: http://www.biofuelsdigest.com/bdigest/2014/10/24/ hsbc-to-join-virgin-atlantic-lanzatech-partnership-for-low-carbon-jet-fuel/ [Accessed 06.09.2015].

Biofuels Digest (2014 b). Solazyme: Biofuels Digest's 2014 5-Minute Guide. URL: http://www.biofuelsdigest.com/bdigest/2014/02/17/solazyme-biofuels-digests2014-5-minute-guide/ [Accessed 09.09.2015].

Biofuels Digest (2014). 100\% Drop-in Aviation Biofuels "closer" to reality. Online. URL: http://www.renewableenergyworld.com/articles/2014/03/100-drop-inaviation-biofuels-closer-to-reality.html [Accessed 23.10.2015].

Biofuels Digest (2015a). Alaska Airlines, Gevo to demonstrate renewable Alcohol-to-Jet fuel in upcoming flight. URL: http://www.biofuelsdigest.com/bdigest/2015/ 05/07/alaska-airlines-gevos-to-demonstrate-renewable-alcohol-to-jet-fuel-flight/ [Accessed 06.09.2015].

Biofuels Digest (2015b). Flagship invests in Red Rock, cost-competitive aviation biofuels come closer. URL: http://www.biofuelsdigest.com/bdigest/2015/03/17/ flagship-invests-in-red-rock-cost-competitive-aviation-biofuels-come-closer/ [Accessed 06.09.2015].

Biofuels Digest (2015c). FedEx, Southwest Airlines combine to buy entire jet fuel output of Red Rock biorefinery, through 2024. URL: http://www.biofuelsdigest.com/ bdigest/2015/07/21/fedex-southwest-airlines-combine-to-buy-entire-jet-fueloutput-of-red-rock-biorefinery-through-2024/ [Accessed 08.09.2015].

Biofuels Digest (2015d). United to start flying biofuels out of LAX in 2015; AltAir to supply 15 million gallons in 3-year deal. URL: http://www.biofuelsdigest.com/ bdigest/2015/06/30/united-to-start-flying-biofuels-out-of-lax-in-2015-altair-tosupply-15-million-gallons-in-3-year-deal/ [Accessed 09.09.2015].

Biofuels Digest (2012). Audi, Joule ink partnership, as Joule heads for scale with $\$ 1.28$ per gallon advanced fuels. URL: http://www.biofuelsdigest.com/bdigest/ 2012/09/17/audi-joule-ink-partnership-as-joule-heads-for-scale-with-1-28-pergallon-advanced-fuels/ [Accessed 14.09.2015].

Biofuels Digest (2013). Fly the (environmentally) friendly skies: United to commence wide-scale aviation biofuels flights in 2014. URL: http://www.biofuelsdigest.com/ bdigest/2013/06/05/fly-the-environmentally-friendly-skies-united-to-commencewide-scale-aviation-biofuels-flights-in-2014/ [Accessed 08.09.2015]. 
BioM (2015). Evalueringsrapport Pil. BioM Projektet. AgroTech, Denmark. URL: http://agrotech.dk/projekter/project/biom-projektet [Accessed 02.10.2015]. BioM (2015b). Følsomhedsanalyser for driftsøkonomi ved dyrkning af energipilBioM Projektet. AgroTech, Denmark. URL: http://agrotech.dk/sites/agrotech.dk/files/ public/uploads/Projects/BioM/folsomhedsanalyseforpiledyrkning_pil.pdf [Accessed 02.10.2015].

Biomassmagazine (2016). Gevo's biobased jet fuel can now fuel commercial flights. URL: http://www.biomassmagazine.com/articles/13130/gevoundefinedsbiobased-jet-fuel-can-now-fuel-commercial-flights [Accessed 14.04.2016].

Biopact (2007). A quick look at 'fourth generation' biofuels. URL: http://news.mongabay.com/bioenergy/2007/10/quick-look-at-fourthgeneration.html [Accessed 02.10.2015].

Bioproductmill (2015). Metsä group to build next-generation bioproduct mill in Äänekoski. URL: http://bioproductmill.com/articles/metsa-group-to-build-nextgeneration-bioproduct-mill-in-aanekoski

BioRefining Alliance (2015). Bioøkonomipanel anbefaler iblanding af avancerede biobrændstoffer. URL: http://biorefiningalliance.com/biooekonomipanelanbefaler-iblanding-af-avancerede-biobraendstoffer/ [Accessed 06.10.2015].

Bloomberg (2012): Moving Towards a Next-Generation Ethanol Economy, Bloomberg New Energy Finance January 2012.

Boeing (2014). Boeing conducts World's first test flight with "HEFA+". Online. URL: http://boeing.mediaroom.com/2014-12-03-Boeing-Conducts-Worlds-First-Flightwith-Green-Diesel-as-Aviation-Biofuel\#assets_117:19654 [Accessed 13.10.2015].

Borkowska, S. (2009). Biodiesel potential in Iceland. Akureyri, February 2009.

Borregaard (2013). Presentation on BALITM demo plant for co-production of bioethanol and green chemicals. Nordic Baltic Bioenergy, Oslo 2013.

Brancheforeningen Dansk Luftfart (2015). Danmark som attraktivt luftfartsland. Copenhagen Economics. Dansk Luftfart, May 2015.

Broch et al. (2013). Aquaculture Environment Interactions, 2013;4(2):187-206.

Cathay Pacific (2014). Press release: Cathay Pacific invests in sustainable biojet fuel developer. URL: http://www.cathaypacific.com/cx/en_DK/about-us/ press-room/press-release/2014/Cathay-Pacific-invests-in-sustainable-biojet-fueldeveloper.html [Accessed 08.09.2015].

CE Delft (2015). Assessing progress towards implementation of the ILUC Directive. URL: http://www.theicct.org/sites/default/files/publications/

CE_Delft_4H38_Assessing_progress_towards_implementation_ILUC_dir.pdf [Accessed 31.05.2016].

Chalmers Tekniska Högskola (2015). https://www.chalmers.se/sv/institutioner/ ee/nyheter/Sidor/GoBiGas-nu-i-full-drift.aspx [Accessed 27.10.2015].

Chalmers Tekniska Högskola (2015). https://www.chalmers.se/sv/institutioner/ ee/nyheter/Sidor/GoBiGas-nu-i-full-drift.aspx [Accessed 27.10.2015].

Chemrec (2015). URL: http://www.chemrec.se/ [Accessed 23.11.2015].

Cintas, O., Berndes, G., Cowie, A. L., Egnell, G., Holmström, H., \& Ågren, G. I. (2015). The climate effect of increased forest bioenergy use in Sweden: Evaluation at different spatial and temporal scales. Wiley Online Library. URL http://dx.doi.org/10.1002/wene.178 [Accessed 06.01:2016].

CleanTech Iceland [CTI] (2015). Clean Tech Iceland - CTI. URL: http://www.si.is/ starfsgreinahopar/graen-taekni/clean-tech-iceland---cti/ [Accessed 23.10.2015] 
Cooper, J. \& Dobson, H. (2007). The benefits of pesticides to mankind and the environment. Crop Protection (26) p. 1337-1348. http://dx.doi.org/10.1016/ j.cropro.2007.03.022

Copenhagen Economics (2015). Beskæftigelsespotentialer i udrulning af bioøkonomi. CPH, Copenhagen Airports A/S (2014). Københavns Lufthavn skal kunne håndtere 40 mio. passagerer årligt. URL: https://www.cph.dk/om-cph/presse/ nyheder/expanding-cph [Accessed 30.10.2015].

CPH, Copenhagen Airports A/S (2015). FACTS \& FIGURES 2014 COPENHAGEN AIRPORTS. Copenhagen Airports, Denmark.

Danish Energy Agency (2012). Aftale mellem regeringen (Socialdemokraterne, Det Radikale Venstre, Socialistisk Folkeparti) og Venstre, Dansk Folkeparti, Enhedslisten og Det Konservative Folkeparti om den danske energipolitik 20122020. Energistyrelsen. 22.03.20102.

Danish Energy Agency (2013). Energistatistik 2013.URL: http://www.ens.dk/sites/ ens.dk/files/info/tal-kort/statistik-noegletal/aarlig-energistatistik/ energistatistik2013.pdf [Accessed 05.10.2015].

Danish Energy Agency (20132014). Energistatistik 2013-2014. Danish Energy Agency, Copenhagen.

Danish Energy Agency (2014). Energiscenarier frem imod 2020, 2035 og 2050. Energistyrelsen. 2014.

Danish Energy Agency (2015). Tilskud til Biogas. URL: http://www.ens.dk/ undergrund-forsyning/vedvarende-energi/bioenergi/tilskud-biogas [Accessed 09.10.2015].

Department of Food and Resource Economics (2012) Sektor-og samfundsøkonomisk vurdering af 3 scenarier for en udvidet dansk produktion og raffinering af biomasse, Fødevareøkonomisk Institut. Det Natur- og Biovidenskabelige Fakultet, Københavns Universitet.

Det Nationale Bioøkonomipanel (2015). Anbefalinger: Det gule guld halmressourcens uudnyttede potentiale. http://naturerhverv.dk/fileadmin/ user_upload/NaturErhverv/Filer/Tvaergaaende/Biooekonomi/Biooekonomipanel ets_anbefalinger_ved_anvendelse_af_gul_biomasse.pdf [Accessed 15.09.2015].

Deswarte, F.E., Clark, J.H., Wilson, A.J., Hardy, J.J., Marriott, R., Chahal, S.P., Jackson, C., Heslop, G., Birkett, M., Bruce, T.J. \& Whiteley, G. (2007). Toward an integrated straw-based biorefinery. Biofuels, Bioproducts and Biorefining, 1(4), pp.245-254. http://dx.doi.org/10.1002/bbb.32

Directive 2014/94/EU of the European Parliament and of the Council of 22 October 2014 on the deployment of alternative fuels infrastructure.

E.on (2011). Press release. http://www.eon.se/press\#/pressreleases/e-onavvaktar-med-storskaligt-biogasprojekt-i-skaane-817068 [Accessed 11.11.2015].

E3M-Lab (2016). URL: http://www.e3mlab.ntua.gr/e3mlab/ index.php?option=com_content $\&$ view=category\&id=35\&Itemid=80\&lang=en

EA, Energy Analyses (2014). Biomassepriser an forbrugssted. URL: http://www.ea-energianalyse.dk/reports/1430_biomassepriser_an_forbrugssted.pdf [Accessed 29.09.2015].

EC, European Commision (2014). Case No COMP/M.7387 - BP/STATOIL FUEL AND RETAIL AVIATION. Office for Publications of the European Union, Luxembourg. December, 2014.

Ekbom, T. et al. (2009). Pilot study of Bio-jet A-1 fuel production for StockholmArlanda Airport, Värmeforsk report 1125. 
Energi Styrelsen (2015). Målsætninger og aftaler vedr. transportens energiforbrug. URL: http://www.ens.dk/klima-co2/transport/maalsaetninger-aftaler-vedrtransportens-energiforbrug [Accessed 05.10.2015].

Energiaftalen (2012). Aftale mellem regeringen (Socialdemokraterne, Det Radikale Venstre, Socialistisk Folkeparti) og Venstre, Dansk Folkeparti, Enhedslisten og Det Konservative Folkeparti om den danske energipolitik 2012-2020. URL: http://www.ens.dk/sites/ens.dk/files/politik/dansk-klima-energipolitik/ politiske-aftaler-paa-energiomraadet/energiaftalen-22-marts-2012/ Aftale_22-03-2012_FINAL_ren.doc.pdf [Accessed 5.10.2015].

Energimyndigheten (2015). Energiläget 2015.

Energimyndigheten (2015). URL: http://www.energimyndigheten.se/en/ [Accessed 14.10.2015].

Energistyrelsen (2015). Teknologivurdering af udvalgte energiteknologier: Termisk forgasningsteknlogi.

Enova (2016). Støtte til biogass og biodrivstoff. URL:

http://www.enova.no/finansiering/naring/transport/ stotte-til-biogass-og-biodrivstoff/1044/0/ [Accessed 17.03.2016].

EPA, Environmental Protection Agency (2016). Renewable Fuels Standard Program. URL: https://www.epa.gov/renewable-fuel-standard-program/ program-overview-renewable-fuel-standard-program [Accessed 15.06.2016].

Eriksen, J., Nordemann Jensen, P., \& Jacobsen, B.H. (2014). Virkemidler til realisering af 2. Generations vandplaner og målrettet arealregulering. DCA Rapport. URL: http://dnmark.org/wp-content/uploads/2015/01/Virkemiddelkatalog.pdf [Accessed 01.10.2015].

EUC, European Commission (2011). 2 million tons per year: A performing biofuels supply chain for EU aviation.

EU-commission (2014). Press Release: From sunlight to jet fuel: EU project makes first "solar" kerosene. URL: http://europa.eu/rapid/ press-release_IP-14-481_en.htm?locale=en [Accessed 14.09.2015].

European Commission (2015a). Technical assessment of the EU biofuel sustainability and feasibility of $10 \%$ renewable energy target in transport. Commission staff working document. \{COM(2015) 293 final\}.

European Commission (2015b). Voluntary schemes. URL: https://ec.europa.eu/ energy/en/topics/renewable-energy/biofuels/voluntary-schemes [Accessed 16.09.2015].

European Union (2015). Advanced biofuels in Europe. URL: http://www.biofuelstp.eu/ advancedbiofuels.htm [Accessed 11.09.2015].

Eurostat (2013). URL: http://ec.europa.eu/eurostat/statistics-explained/index.php/ Energy_from_renewable_sources [Accessed 13.10.2015].

ExxonMobile (2015). Raffinering og logistikk. URL: http://www.exxonmobil.no/ Norway-Norwegian/PA/about_what_refining.aspx

FAO (2010). Jatropha: A Smallholder Bioenergy Crop - The Potential for Pro-Poor Development. Brittaine, R.; Lutaladio, N., Rome.

Fethers, B. et al. (2014). Aviation biofuel production in Sweden - an insight into the potential of forestry biomass as a feedstock, IIIEE

Fethers, B. (2014). Aviation Biofuel Production in Sweden - An Insight into the Potential of Forestry Biomass as a Feedstock, IIIEE, Lund University, September 2014.

Finavia Traffic Statistics (2014) https://www.finavia.fi/en/finavia-corporation/ statistics/Statistics-2014/ 
Finish Transport Safety Agency (2015) 2015 State Action Plan of Finland. URL: http://www.google.dk/url?sa=t\&rct=j\&q=\&esrc=s\&frm=1\&source=web\&cd=3\&ca $\mathrm{d}=$ rja\&uact $=8 \&$ ved $=0 \mathrm{CC} 0 \mathrm{QFjACahUKEwi2q5HNtY3JAhWEhiwKHegzDBY \& url}=\mathrm{http}$ \%3A\%2F\%2Fwww.trafi.fi\%2Ffilebank\%2Fa\%2F1435659226\%2F1f1aad3a6c5ba bd175c5c5629634ab1a\%2F17994-1_2015_State_Action_Plan_of_Finland.pdf \&usg=AFQjCNFs7auNBs7tgVpSbrAfEC0s5Xy5mA\&sig2=P6rOt4M4V8rJirop9_0V_Q [Accessed 13.11.2015].

Finish Forest Association (2016). URL: http://www.smy.fi/en/forest-fi/forest-facts/ finnish-forests-owned-by-finns/ [Accessed 20.05.2016].

Finnish Transport Safety Agency [Trafi] (2015). State Action Plan of Finland: International Aviation CO2 Emissions. Trafi Publications. Helsinki. 2015.

Finnish Transport Safety Agency (2015). State Action Plan of Finland, International Aviation CO2 Emissions, Trafi Publications 5/2015.

Fløjgaard, E. (2012). Tekniske muligheder for at bjerge en større del af den producerede halm. Baggrundsnotat til +10 mio. tons planen. URL: www.foi.life.ku.dk/Publikationer/specielle_FOI-udgivelser/10miotons.aspx

Follo G., Nybakk E., Barstad J., \& Talbot B. (2015) Forest Land Ownership Change in Norway.COST Action FP1201 FACESMAP Country Report. European Forest Institute Central-East and South-East European Regional Office, Vienna. 43 pages. [Online publication].

Fortier, M. O. P., Roberts, G. W., Stagg-Williams, S. M., \& Sturm, B. S. (2014). Life cycle assessment of bio-jet fuel from hydrothermal liquefaction of microalgae. Applied Energy, 122, 73-82. http://dx.doi.org/10.1016/j.apenergy.2014.01.077

Fredrikstad Blad (FB, 2015). Britisk søppel kan bli flybiodrivstoff i ny megafabrikk her. URL: http://www.f-b.no/arbeidsliv/britisk-soppel-kan-bli-flydrivstoff-i-nymegafabrikk-her/s/5-59-100446 [Accessed 15.12.2015].

Fulcrum Bioenergy (2015). Fulcrum bioenergy facilities. URL: http://fulcrum-bioenergy.com/facilities/ [Accessed 07.09:2015].

Fulcrum Bioenergy (2015). Fulcrum Bioenergy Low Carbon, Renewable Fuels. URL: http://fulcrum-bioenergy.com/benefits/low-carbon-renewable-fuels/ [Accessed 16.09.2015].

Gaia Consulting Oy (2014). Deployment of aviation biofuels in Finland, URL: http://clean.web02.beon.dk/media/704658/Julkaisuja-34-2014.pdf [Accessed 09.11.2015]

Gas Technology Institute (GTI 2015). Using thermal catalytic processes to produce gasoline and diesel transportation fuels from renewable resources. URL: http://www.gastechnology.org/Solutions/Pages/Using-thermal-catalyticprocesses-to-produce-gasoline-and-diesel-fuels.aspx [Accessed 09.12.2015]

GreenAir Online (2015). Low oil price and current lack of government support stalls British Airways' waste to jet biofuel project. URL: http://www.greenaironline.com/ news.php?viewStory=2163 [Accessed 08.02.2016].

Greenwood, N. N. \& Earnshaw, A. (1997). Chemistry of the elements. Oxford: Butterworth-Heinemann.

Gundersen et al. (2011). Utredning om CO2-opptak i marine naturtyper. NIVA, RAPPORT LNR 6070-2010. 
Gylling, M. (2015). Notat om halm og andre celluloseholdige biprodukter, med henblik på anvendelse i den kommende behandling af gule værdikæder i Det Nationale Bioøkonomipanel. http://naturerhverv.dk/fileadmin/user_upload/NaturErhverv/ Filer/Tvaergaaende/Biooekonomi/IFRO_-_Baggrundsnotat _om_halm_og_andre_celluloseholdige_biprodukter.pdf [Accessed 15.09.2015].

Gylling, M., Jørgensen, U., Bentsen, N. S., Kristensen, I. T., Dalgaard, T., Felby, C., \& Johannsen, V. K. (2012) + +10 mio. tons planen: Muligheder for en øget dansk produktion af bæredygtig biomasse til bioraffinaderier. Fødevareøkonomisk Institut, University of Copenhagen.

Heidenreich, S. \& Foscolo, P.U. (2015). New concepts in biomass gasification. Progress in energy and combustion science, 46, pp.72-95.

http://dx.doi.org/10.1016/j.pecs.2014.06.002

Heineman, K. (2013). Researchers take non-edible parts of plants and turn them into food we can eat. URL: https://www.insidescience.org/content/ turning-wood-chips-nutritious-food/1380 [Accessed 19.11.2015].

IATA (2008). Air travel demand.

IATA (2013). Factsheet: Fuel. December 2013, Montreal.

IATA (2014) URL: https://www.iata.org/pressroom/facts_figures/fact_sheets/ Documents/fact-sheet-alternative-fuels.pdf

IATA, International Air Transport Association (2013). Report on Alternative Fuels 2013. ISBN 978-92-9252-259-9.

IATA, International Air Transport Association (2014). Report on Alternative Fuels 2014. ISBN 978-92-9252-508-8.

IATA, International Air Transport Association (2015). Sustainable Aviation Roadmap. ISBN 978-92-9252-704-4.

ICAO, International Civil Aviation Organisation (2014). Fuel producers cooperation or fuel supply agreement. URL: http://www.icao.int/environmental-protection/ GFAAF/Pages/airlines.aspx [Accessed 08.09.2015].

ICAO, International Civil Aviation Organization (2013). Environmental Report 2013

ICAO, International civil aviation organization (2014). Approaches to the Sustainability of Alternative Fuels in Aviation.

IEA Bioenergy (2012). Theoretical versus market available supply of biomass for energy from long-rotation forestry and agriculture - Swedish experiences, IEA Bioenergy Task 43, 2012:2

IEA (2013). Energy policies of IEA countries - Sweden - 2013 review, Excerpt.

INAF, Initiative for Next Generation Aviation Fuels (2015). Roadmap for Establishing Supply Chain for Next-Generation Aviation Fuels Aiming to Commence Utilization by the 2020 Tokyo Olympics and Paralympics.

Inbicon and Terranol collaboration demonstrates a fast, high yielding process for $2 \mathrm{G}$ bioethanol production (n.d.). URL:

https://assets.dongenergy.com/DONGEnergyDocuments/Inbic/TerranolInbicon\%20EUDP\%20conclusion\%20(16\%2004\%202015)\%20EUDP.pdf [Accessed 13.10.15].

Intergovernmental Panel on Climate Change (IPCC) (1999). IPCC Special Report on Aviation and the Global Atmosphere. Cambridge University Press.

International air transport association IATA (2015). FACT SHEET: Alternative Fuels.

International Organisation for Standarisation (2015). ISO 13065 :2015. URL:

http://www.iso.org/iso/catalogue_detail.htm?csnumber=52528 [Accessed 02.10.2015]. 
ITAKA (2015). WP1. Feedstock. URL: http://www.itaka-project.eu/nav/ pages/progress_results.aspx [Accessed 09.10.15].

IUCN National Committee of the Netherlands (2013). Betting on best quality: A comparison of the quality and level of assurance of sustainability standards for biomass, soy and palmoil. Report.

IUCN, World Resource Institute [WRI] (2007). Business and Ecosystems: Ecosystem challenges and Business Implications. Report.

Janssens, T. \& Fitzgibbon, T. (2015). Profitability in a World of over Capacity. McKinsey \& Company.

Johnston, P., Everad, M., Santillo, D., \& Robèrt, K. H. (2007). Reclaiming the Definition of Sustainability, Environmental Science and Pollution Research, 14(1), p. 60-66. http://dx.doi.org/10.1065/espr2007.01.375

Joule Unlimited (2014). Press Releases: Joule Achieves ASTM Specifications for Sustainable Diesel, Jet Fuel. URL: http://www.jouleunlimited.com/joule-achievesastm-specifications-sustainable-diesel-jet-fuel [Accessed 14.09.2015].

Jørgensen, U et al. (2013). Biomasseudnyttelse i Danmark - Potentielle Ressourcer og Bæredygtighed. DCA Rapport nr. 033.

Karyd, A. (2012). Fossilfri flygtrafik? Underlagsrapport till utredningen om fossiloberoende fordonsflotta, N2012:05.

Killingland, M. et al. (2013). Bærekraftig biodrivstoff for luftfart. Oslo, Rambøll.

Klima- Energi- og bygningsministeriet [KEBMIN] (2015). Energipolitisk Redegørelse 2015. 29.04.2015.

Klima og Energiminsteriet (2010). National Action Plan for Renewable Energy in Denmark. Denmark.

Københavns Lufthavn (2014). Expanding CPH - The Gateway of Northern Europe. URL: https://www.cph.dk/globalassets/om-cph/profil/ cph_21x21_expandingcphbook_digital.pdf [Accessed 19.11.2015].

Larsen (2008): The IBUS Process - Lignocellulosic Bioethanol Close to Commercial Reality, Chemical Engineering \& Technology.

Larsen, J.\& Henriksen, N. (2015). Status for the Inbicon technology by end of 2014. Dong Energy.

Lee, D. S., Fahey, D. W., Forster, P. M., Newton, P. J., Wit, R. C., Lim, L. L., ... \& Sausen, R. (2009). Aviation and global climate change in the 21st century. Atmospheric Environment, 43(22), 3520-3537. http://dx.doi.org/10.1016/j.atmosenv.2009.04.024

Lee, D. S., Pitari, G., Grewe, V., Gierens, K., Penner, J.E., Petzold, A., Prather, M.J., Schumann, U., Bais, A., Berntsen, T., Iachetti, D., Lim, L. L. and Sausen, R. (2010). Transport impacts on atmosphere and climate: Aviation. University of California. 2010. LFV (2015). URL: http://www.lfv.se/en/ [Accessed 14.10.2015].

Li, L., Coppola, E., Rine, J., Miller, J.L., \& Walker, D. (2010). Catalytic Hydrothermal Conversion of Triglycerides to Non-ester Biofuels. Energy fuels, 24, pp. 1305-1315. http://dx.doi.org/10.1021/ef901163a

Li, X., \& Mupondwa, E. (2014). Life cycle assessment of camelina oil derived biodiesel and jet fuel in the Canadian Prairies. Science of the Total Environment, 481, 17-26. http://dx.doi.org/10.1016/j.scitotenv.2014.02.003

Lindegaard, A. et al., (2014). Kunnskapsgrunnlag for lavutslippsutvikling, Miljødirektoratet, Oslo, Norway, p. 345.

Lokesh, K., Sethi, V., Nikolaidis, T., Goodger, E., \& Nalianda, D. (2015). Life cycle greenhouse gas analysis of biojet fuels with a technical investigation into their impact on jet engine performance. Biomass and Bioenergy, 77, 26-44. 
Lufthansa Group (2014). Press release: Lufthansa Group backs research into innovative biokerosene. URL: http://www.lufthansagroup.com/nc/en/ responsibility/news/press-releases/singleview/archive/2014/april/23/ article $/ 2920$.html?cHash=49a05528321e962ca2d67362e8cbd4d2\&sword_list\%5B 0\%5D=gevo [Accessed 07.08.2015].

Luke, Natural Reources Institute Finland (2015). Total wood consumption. URL: http://statdb.luke.fi/PXWeb/pxweb/en/LUKE/LUKE_04\%20Metsa_04\%20Talou s_14\%20Puun\%20kokonaiskaytto/?tablelist=true\&rxid=001bc7da-70f4-47c4a6c2-c9100d8b50db [Accessed 10.11.2015].

Luke, Natural Resources Institute Finland (2014). Finnish Statistical Yearbook of Forestry.

Luke, Natural Resources Institute Finland (2015). Wood in energy generation. URL: http://statdb.luke.fi/PXWeb/pxweb/en/LUKE/LUKE_04\%20Metsa_04\%20Talou s_10\%20Puun\%20energiakaytto/?tablelist=true\&rxid=001bc7da-70f4-47c4a6c2-c9100d8b50db [Accessed 10.11.2015].

Luleå Tekniska Universitet (2015). http://www.ltu.se/ltu/media/news/LTU-GreenFuels-ratt-i-tiden-1.106301 [Accessed 27.10.2015].

Luleå Tekniska Universitet (2015) http://www.ltu.se/ltu/media/news/LTU-GreenFuels-ratt-i-tiden-1.106301 Accessed 27.10.2015].

Maniatis, K., Weitz, M., \& Zshocke, A. (2013). 2 million tons per year: A performing biofuels supply chain for EU aviation. European Commission. Technical Paper. August 2013 Update.

Marklund, G. (1988). Biomass functions for pine, spruce and birch in Sweden. Swedish University of Agricultural Sciences. Department of Forest Survey Report 45.71

Masbi, Midwest Aviation Sustainable Biofuel Initiative (2013). Fueling a Sustainable Future for Aviation.

ME, Mannvit Engineering (2010). Biofuel production in Iceland - Survey of potential raw materials and yields to 2030. Sundberg, M.; Guðmundsson, J.; Guðmundsson, M., Reykavik, October 2010.

Miljødirektoratet (2014). Kunskapsgrunnlag for lavutslippsutvikling. Rapport M229. Miljødirektoratet. Norge.

Miljøstyrelsen (2013). Affaldsstatistik 2013. Toft, R., Fischer, C., Bøjesen, N. Aa., \& Kristensen, E. URL: https://dakofa.dk/vidensbank/data-statistikker/ [Accessed 29.09.2015].

Miljøstyrelsen (2015). Affaldsstatistik 2013. Toft, R., Fischer, C., Aasted Bøjesen, N., \& Kristensen, E. Miljøstyrelsen, 2015.

Ministry for Environment and Nautral Resources [MENR] (2015). Tasks - Ministry for the Environment and Natural Resources. URL: http://eng.umhverfisraduneyti.is/ ministry/tasks/ [Accessed 22.10.2015].

Ministry of Employment and the Economy (2010). Finland's national action plan for promoting energy from renewable sources pursuant to Directive 2009/28/EC. Finland.

Ministry of Employment and the Economy (2014). The Finnish Bioeconomy Strategy. URL: https://www.tem.fi/files/40366/The_Finnish_Bioeconomy_Strategy.pdf [Accessed 09.11.2015].

Ministry of Employment and the Economy (2014). Energy and Climate Roadmap 2050, Report on the Parliamentary Committee on Energy and Climate Issues on 16th October 2014, URL: https://www.tem.fi/files/41483/

Energy_and_Climate_Roadmap_2050.pdf [Accessed 09.11.2015]. 
Ministry of Industry and Innovation [MII] (2014). The Icelandic Renewable Energy Action Plan for the promotion of the use of energy from renewable sources in accordance with Directive 2009/28/EC and the Commission Decision of 30 June 2009 on a template for the national renewable energy action plans. Policy document. 2014.

Ministry of Petroleum and Energy (2013). National Renewable Energy Action Plan under Directive 2009/28/EC. Norway.

Ministry of Transport and Communications (2013). Future power sources. URL: http://www.lvm.fi/c/document_library/get_file?folderId=2497123\&name=DLFE21539.pdf\&title=Julkaisuja\%2024-2013 [Accessed 09.11.2015].

Ministry of Transport and Communications (2015). Alternative fuels infrastructure a proposal for a national framework until 2020/2030. URL: https://www.lvm.fi/docs/fi/3759144_DLFE-27022.pdf [Accessed 09.11.2015].

Ministry of Transport and Communications (2015). Finland's Air Transport Strategy 2015-2030. URL: https://www.lvm.fi/docs/en/3759144_DLFE-26373.pdf [Accessed 09.11.2015].

Ministry of Transport and Communications (2013). Alternative propulsion for the transport of the future - Final report by working group, Publications 15/2013.

Ministry of Transport and Communications (2015). Finland's Air Transport Strategy 2015-2030, Publications 3/2015.

Moreira, M., Gurgel, A. C., \& Seabra, J. E. (2014). Life Cycle Greenhouse Gas Emissions of Sugar Cane Renewable Jet Fuel. Environmental science \& technology, 48(24), 14756-14763. URL: http://dx.doi.org/10.1021/es503217g

MTC, Ministry of transport and Communications (2013). Future transport power sources - Executive summary. Working group on alternative propulsion. Rautavirta, M. \& Jääskeläinen, S., Helsinki, 9th September 2013.

MTC, Ministry of transport and Communications (2014). Deployment of aviation biofuels in Finland. Luoma, P., Bröckl, M., Pursula, T., \& Nyman, H., Helsinki, 28th November 2014.

Myhre, G. et al. (2013) Anthropogenic and Natural Radiative Forcing. In: Climate Change 2013: The Physical Science Basis. Contribution of Working Group I to the Fifth Assessment Report of the Intergovernmental Panel on Climate Change. Cambridge University Press, Cambridge.

National Energy and Climate Strategy (2013). National Energy and Climate Strategy Government Report to Parliament on 20th March 2013.

National Geographic (2012). Second try: LanzaTech grabs failed biofuel refinery in Georgia Pine. URL: http://news.nationalgeographic.com/news/energy/2012/ 01/12019-range-lanzatech-cellulosic-biofuel-ethanol/ [Accessed 08.02.2016].

National Resources Defense Center (2014). Biofuel Sustainability Performance Guidelines. Report.

NASA (2016). Ozone and its Precursors and Sinks. URL: http://tes.jpl.nasa.gov/ mission/O3SourceSink/ [Accessed 30.05.2016].

Naturerhvervstyrelsen (2014). Arealstatistik for ordningen Enkeltbetaling 2014. URL: http://naturerhverv.dk/fileadmin/user_upload/NaturErhverv/Filer/Tilskud/ Arealtilskud/Enkeltbetaling/Arealstatistik_for_ordningen_Enkeltbetaling_2014.pdf [Accessed 01.10.2015].

NEA (2015). Orkustonfun National Energy Authority (2015). URL: http://www.nea.is/fuel/ [Accessed 0810.2015].

NIRAS (2014). Sustainable Fuels for Aviation - An Analysis of Danish Achievements and Opportunities. Wormslev, E., Tang, C., \& Eriksen, C., Denmark. 
NIRAS (2014). Sustainable Fuels for Aviation - An Analysis of Danish Achievements and Opportunities. Wormslev, E.; Tang, C.; Eriksen, C., Denmark.

NIRAS (2014). Sustainable Fuels for Aviation: An Analysis of Danish Achievements and Opportunities, Brancheforeningen Dansk Luftfart, 2014.

NISA (2015). Nordic Initiative for Sustainable Aviation. URL: http://clean.web02.beon.dk/Nisa/ [Accessed 06.01.2016].

Nordic Council of Ministers (2012). Nordic Environmental Action Plan 2013-2018, Nordic Council of Ministers, Copenhagen, 2012. http://dx.doi.org/10.6027/ANP2012-766

Nordic Council of Ministers (2012b). Socio-economic importance of ecosystem services in the Nordic Countries, Nordic Council of Ministers, ch. 10, p. 129-183, 2012. URL: http://dx.doi.org/10.6027/TN2012-559

Nordic Energy Research, I. E. A. (2013). Nordic energy technology perspectives Pathways to a carbon neutral energy future. Paris.

NordRegio (2016). State of Nordic Region 2016. URL: http://urn.kb.se/ resolve?urn=urn:nbn:se:norden:org:diva-4328

Norsk Petroleumsinstitutt (NP 2014). Statistics on sales of jet fuel in Norway since 1952. URL: http://www.np.no/getfile.php/Filer/Statistikk/Salg/ Salg\%20tilbake\%20til\%201952-web.xls. [Accessed 09.12.2015].

Norwegian Agricultural Agency (n.d.) URL: https://www.slf.dep.no/no/statistikk/ skogbruk/tommeravvirkning [Accessed October 2015].

Novelli, P. (2011). Sustainable Way For Alternative Fuels and Energy in Aviation-Final Report. SWAFEA formal report D, 9, v1.

NREL, National Renewable Energy Laboratory (2013). Biological conversion of sugars to hydrocarbons technology pathway. Davis, R., Biddy, M., Tan, E., Tao, L., \& Jones, S.

NRK (2015). Nytt liv på Tofte. URL: http://www.nrk.no/buskerud/vil-produserebiodrivstoff-1.12213019.NRK (2015) [Accessed 09.12.2015].

NVE rapport nr 41. (2014). http://webby.nve.no/publikasjoner/rapport/ 2014/rapport2014_41.pdf [Accessed November 2015].

Organization for Cooperation and Development (2012). OECD Environmental Outlook to 2050: The Consequences of Inaction, OECD Publishing, ch. 5, p. 207-274.

Organization for Economic Cooperation and Development [OECD] (2014). OECD Environmental Performance Reviews: Iceland. OECD Publishing, Paris. 2015.

Owens, S. (2003). Is there a meaningful definition of sustainability?, Cambridge Journals, April 2003.

Oxford Economics (2011). Flygets ekonomiska betydelse för Sverige.

Pan Innovasjon (2015). Pan Innovasjon AS homepage. URL: http://www.paninnovasjon.no/en/ [Accessed 09.12.2015].

Parajuli, R., Dalgaard, T., Jørgensen, U., Adamsen, A.P.S., Knudsen, M.T., Birkved, M., Gylling, M., \& Schjørring, J.K., (2015b). Biorefining in the prevailing energy and materials crisis: a review of sustainable pathways for biorefinery value chains and sustainability assessment methodologies. Renew. Sustain. Energy Rev. 43, 244-263. URL: http://dx.doi.org/10.1016/j.rser.2014.11.041

Parajuli, R., Knudsen, M.T., Dalgaard, T., (2015a). Multi-criteria assessment of yellow, green, and woody biomasses: pre-screening of potential biomasses as feedstocks for biorefineries. Biofuels Bioprod. Biorefining 9, 545-566 . URL: http://dx.doi.org/10.1002/bbb.1567 
Parajuli, R., Sperling, K., Dalgaard, T. (2015c). Environmental Performance of Miscanthus as a Fuel Alternative for District Heat Production. Biomass and Bioenergy 72: 104-16. URL: http://dx.doi.org/10.1016/j.biombioe.2014.11.011

PC AirBP (2015). Personal communication with Erik Hatlebackk, AirBP, December 2015.

PC Avinor (2015). Personal communication with Olav M.Larsen, Avinor, December 2015.

PC Borregaard (2015). Personal communication with Gisle Johansen, Borregaard, December 2015.

PC ExxonMobile (2015). Personal communication with Ingar Lindheim, ExxonMobile, December 2015.

PC MotorOil (2015). Personal communication with Michalis Pachnos, MotorOil, December 2015.

PC Synsel (2015). Personal communication with Magnus Torp, Synsel, November 2015.

PC Treklynge (2015). Person communication with Rolf Jarle Aaberg, Treklynge, December 2015.

Politiko (2015). Nyheder: "Regeringen kalder det grøn realisme, men det er snarere grøn kamikaze”. URL: http://www.politiko.dk/nyheder/regeringen-kalder-detgroen-realisme-men-det-er-snarere-groen-kamikaze [Accessed 06.10.2015].

Politiko (2015). Nyheder: Tidligere klimaminister ryster på hovedet over skrottede mål. URL: http://www.politiko.dk/nyheder/tidligere-klimaminister-ryster-paahovedet-over-skrottede-maal [Accessed 06.10.2015].

Politiko (2015). Tal for tal: Her er overblikket over regeringens finanslovsforslag. URL: http://www.politiko.dk/nyheder/tal-for-tal-her-er-overblikket-over-regeringensfinanslovsforslag [Accessed 06.10.2015].

PR Newswire (2010). Solazyme Delivers 100\% Algal-Derived Renewable Jet Fuel to U.S. Navy. URL: http://www.prnewswire.com/news-releases/solazyme-delivers100-algal-derived-renewable-jet-fuel-to-us-navy-98721799.html [Accessed 07.09.2015].

Preem (2015). https://www.preem.se/om-preem/om-oss/vad-vi-gor/raff/ preemraff-goteborg/ [Accessed 13.11.2015].

Project Solaris (2016). Sustainability. URL: http://www.projectsolaris.co.za/ p/sustainability.html [Accessed 31.05.2016].

Regeringen (2013). Danmark uden affald: Genanvend mere - forbrænd mindre. October 2013.

Regeringskansliet (2010). The Swedish National Action Plan for the promotion of the use of renewable energy in accordance with Directive 2009/28/EC and the Commission Decision of 30.06.2009. Sweden.

Regeringskansliet (2013). Fossilfrihet på väg (SOU 2013:84), Government Offices of Sweden.

Retsinformation (2011). Bekendtgørelse af lov om bæredygtige biobrændstoffer og om reduktion af drivhusgasser fra transport. URL: https://www.retsinformation.dk/ forms/r0710.aspx?id=137888 [Accessed 06.10.2015].

Retsinformation (2011). Lov om bæredygtige brændstoffer (LOV nr 468 af 12/06/2009). URL: https://www.retsinformation.dk/Forms/

r0710.aspx?id=125469 [Accessed 05.10.2015].

Retsinformation (2012). Lov om CO2-kvoter [LOV 1095 28/11/2012]. URL: https://www.retsinformation.dk/Forms/R0710.aspx?id=144102 [Accessed 06.10.2015]. 
Reuters (2014). Boeing aims to seek approval for HEFA+ as jet fuel. URL: http://www.reuters.com/article/boeing-biofuelidUSL6N0K02NU20140114\#KpbSfDvX14IKqx0I.97 [Accessed 17.03.2016].

Ribeiro, S. K., Kobayashi, S., Beuthe, M., Gasca, J., Greene, D., Lee, D. S., Muromachi, Y., Newton, P. J., Plotkin, S., Sperling, D., Wit, R., \& Zhou, P. J. (2007). Transport and its infrastructure. In Climate Change 2007: Mitigation. Contribution of Working Group III to the Fourth Assessment Report of the Intergovernmental Panel on Climate Change [Metz, B., Davidson, O. R., Bosch, P. R., Dave, R., Meyer, L. A. (eds)]. Cambridge University Press, Cambridge, United Kingdom and New York, NY, USA.

Rojo, C., Vancassel, X., Mirabel, P., Ponche, J. L., \& Garnier, F. (2015). Impact of alternative jet fuels on aircraft-induced aerosols. Fuel, 144, 335-341. URL: http://dx.doi.org/10.1016/j.fuel.2014.12.021

Rossi et al. (2014). Pursuing aviation biofuels - A diagnistic analysis of the Swedish biojet innovation system, IIIEE.

Rossi, R. (2014). Pursuing Aviation Biofuels - A Diagnostic Analysis of the Swedish Biojet Innovation System, IIIEE, Lund University, September 2014.

Roundtable on Sustainable Biomaterials (2015a). Roundtable on Sustainable Biomaterials. URL: http://rsb.org/pdfs/reports/RSB_Brochure_Web\%202015.pdf [Accessed 24.08.2015].

Roundtable on Sustainable Biomaterials (2011). Consolidated RSB EU RED Principles \& Criteria for Sustainable Biofuel Production. RSB, Geneva.

Roundtable on Sustainable Biomaterials (2014). Annual Report 2014. Report.

Roundtable on Sustainable Biomaterials (2015b). RSB Standard for EU market access.

Roundtable on Sustainable Biomaterials (2015c). Member List. URL: http://rsb.org/about/organization/member-list/ [Accessed 24.08.2015].

Roy, P.\& Dutta, A. (2012). Life cycle assessment of ethanol produced from wheat straw. Journal of Biobased Materials and Bioenergy, 6(3), pp.276-282. URL: http://dx.doi.org/10.1166/jbmb.2012.1219

Rubens, C. (2008). WTF Are Fourth-Generation Biofuels? GIGAOM. URL: https://gigaom.com/2008/03/04/wtf-are-fourth-generation-biofuels/ [Accessed 02.10.2015].

SA, Sustainable Aviation (2014). Sustainable Fuels UK Road-Map.

Scarlat, N., Dallemand, J.-F., Skjelhaugen, O.J., Asplund, D., \& Nesheim, L. (2011). An overview of the biomass resource potential of Norway for bioenergy use. Renewable and Sustainable Energy Reviews 15, 3388-3398. URL: http://dx.doi.org/10.1016/j.rser.2011.04.028

SEGES (2015). URL: http://www.inbiom.dk/Files//Files/Pr\%C3\%A6sentationer2015/Halmlogistik_Lone-Abildgaard.pdf [Accessed 09.10.2015].

SER, SINTEF Energy Research (2012). Benchmark of conversion and production technologies for synthetic biofuels for aviation. Matas Güell, B., Bugge, M., Kempegowda, R. S., Anthe, G., \& M. Paap, S.

Sims R. et al. (2014). Transport. In: Climate Change 2014: Mitigation of Climate Change. Contribution of Working Group III to the Fifth Assessment Report of the Intergovernmental Panel on Climate Change. Cambridge University Press.

Skjermo, J. et al. (2014). A new Norwegian bioeconomy based on cultivation and processing of seaweeds: Opportunities and $R \& D$ needs. Innovation Norway (ISBN 978-82-14-05712-6).

Skogsindustrierna (2014). The Swedish forest industries - facts and figures 2014. 
SkyNRG (2015). Technology Selection. Online. URL: http://skynrg.com/ technology-section/ [Accessed 23.10.2015].

SkyNRG (2016). SkyNRG, Avinor and Air BP make first volumes of sustainable jet fuel a feality for Lufthansa, KLM and SAS at Oslo Gardermoen Airport. URL: http://skynrg.com/wp-content/uploads/2016/01/20160122_PressRelease_SkyNRG-Avinor-and-Air-BP-make-first-volumes-of-sustainable-jet-fuel-areality-for-Lufthansa-KLM-and-SAS-at-Oslo-Gardermoen-Airport.pdf [Accessed 17.03.2016].

SPBI (2015). SPBI Branschfakta 2015. URL: http://spbi.se/wp-content/uploads/ 2015/06/SPBI_branschfakta_2015_WEBB_NY.pdf [Accessed 14.10.2015].

Speth, R. L., Rojo, C., Malina, R., \& Barrett, S. R. (2015). Black carbon emissions reductions from combustion of alternative jet fuels. Atmospheric Environment, 105, 37-42. URL: http://dx.doi.org/10.1016/j.atmosenv.2015.01.040

Spöttle, M., Alberici, S., Toop, G., Peters, D., Gamba, L., Ping, S., Steen, H. \& Bellefleur, D. (2013). Low ILUC potential of wastes and residues for biofuels. Straw, forestry residues, UCO, corn cobs. ECOFYS Project Number: BIEDE, 13386.

Staffas, L. et al. (2013). Alternative sources for competing with forest based biofuel - a pre-study.

Statens Energimyndighet (2015). Transportsektorns Energianvänding 2014. URL: https://energimyndigheten.a-w2m.se/Home.mvc?ResourceId=3057. [Accessed 19.11.2015].

Statens Energimyndighet (2014). Scenarier över Sveriges energisystem 2014 års långsiktiga scenarier, ett underlag till klimatrapporteringen. URL: https://energimyndigheten.a-w2m.se/Home.mvc?ResourceId=3000

Statens vegvesen (2010). Sektoranalyse for transport Klimakur 2020 - tiltak og virkemidler for å nå norske klimamål mot 2020. Oslo.

Statistics Iceland (2015). Installed capacity and generation in public power plants 1976-2013. URL: http://www.statice.is/?PageID=1230\&src=https:// rannsokn.hagstofa.is/pxen/Dialog/varval.asp?ma=IDN02101\%26ti=Installed+capa city+and+generation+in+public+power+plants+1976-2013+\%26path=../ Database/idnadur/orkumal/\%26lang=1\%26units=Megawatt/Gigawatt $\% 20$ hour $\%$ 20/percent [Accessed 25.09.2015].

Statistics Iceland (2015). Oil use 1983-2013. URL: http://www.statice.is/ ?PageID=1230\&src=https://rannsokn.hagstofa.is/pxen/Dialog/varval.asp?ma=IDN 02105\%26ti=Oil+use+1983-2013+\%26path=../Database/idnadur/orkumal/ \%26lang=1\%26units=Kilotonnes [Accessed 08.10.2015].

Statistics Norway homepage (n.d.) http://www.ssb.no/en/natur-og-miljo/ statistikker/avfregno [Assessed October 2015].

Statistics Norway (n.d.) http://www.ssb.no/energi-og-industri/ statistikker/petroleumsalg/aar [Accessed October 2015].

Statkraft (2015). Statkraft og Södra oppretter biodrivstoffselskap. URL: http://www.statkraft.no/media/pressemeldinger/2015/ statkraft-og-sodra-oppretter-biodrivstoffselskap [Accessed 09.12.2015].

Statoil (2015). Mongstad refinery. URL: http://www.statoil.com/en/ OurOperations/TerminalsRefining/ProdFacilitiesMongstad/Pages/ Mongstadraffineri.aspx [Accessed 09.122015].

Stettler, M. E., Boies, A. M., Petzold, A., \& Barrett, S. R. (2013). Global civil aviation black carbon emissions. Environmental science \& technology, 47(18), 10397-10404. URL: http://dx.doi.org/10.1021/es401356v 
Stortinget (2016). Komiteens tilrådning. URL: https://www.stortinget.no/no/ Saker-og-publikasjoner/Publikasjoner/Innstillinger/Stortinget/2015-2016/ inns-201516-002/8/ [Accessed 18.03.2016].

Stortinget (2015). Nasjonalbudsjettet 2016 Meld. St. 1 (2015-2016), Innst. 2 S (20152016). URL: https://www.stortinget.no/no/Saker-og-publikasjoner/Vedtak/ Vedtak/Sak/?p=63610

Stratton, R. W., Wolfe, P. J., \& Hileman, J. I. (2011). Impact of aviation non-CO2 combustion effects on the environmental feasibility of alternative jet fuels. Environmental science \& technology, 45(24), 10736-10743. URL: http://dx.doi.org/10.1021/es2017522

Stratton, R. W., Wong, H. M., \& Hileman, J. I. (2010). Life cycle greenhouse gas emissions from alternative jet fuels. Partnership for AiR Transportation Noise and Emission Reduction, Partner Project, 28.

Sunfire (2015). Press releases: Sunfire now produces synthetic fuel from air, water and green electrical energy. URL: http://www.sunfire.de/wp-content/uploads/ sunfire-INTERNATIONAL-PM-2015-alternative-fuel.pdf [Accessed 08.09.2015].

Sunpine (2015). URL: http://www.sunpine.se/en/tecknology/ [Accessed 23.11.2015]. Svenskt Flyg (2014). Sverige inom räckhåll.

Swedavia (2015). Annual and sustainability report 2014. Swedavia.

Swedavia (2015). URL: https://www.swedavia.com/ [Accessed 14.10.2015].

Swedish Energy Agency (2013). Transportsektorns energianvändning, ES2014:01

Swedish Energy Agency (2015). Energipriser. URL: https://www.energimyndigheten.se/ statistik/energipriser/?currentTab=1\#mainheading [Accessed 02.02.2016].

Synsel (2015). Synsel homepage. URL: http://www.synsel.net [Accessed 09.12.2015]. Teknisk Ukeblad (TU 2014). Dette er et av norgeshistoriens største rivingsprosjekter. URL: http://www.tu.no/bygg/2014/03/22/dette-er-et-av-norgeshistoriensstorste-rivingsprosjekter [Accessed 09.12.2015].

Telemarkavisa (TA 2015). Bedriften Synsel vil tilby biodrivstoff til kommunene i Grenland. URL: http://www.ta.no/nyheter/bamble/okonomi-og-naringsliv/vil-selgebiodrivstoff/s/5-50-127194127194 [Accessed 25.09.2015].

Tellnes, L. G. F. et al. ( 2011). Material flows in the Norwegian sawmilling industry. URL: http://www.skogoglandskap.no/filearchive/rapport_15_11_proceedings_ 7th_meeting_nordic_baltic_network_in_wood_material_science_engineering.pdf s113 [Accessed October 2015].

The Norwegian Government's homepage (n.d.) https://www.regjeringen.no/ globalassets/upload/OED/Bioenergistrategien2008w.pdf [assessed October 2015].

The State of Sustainable Initiatives Review (2014). Standards of the Green Economy. Report.

The Swedish forest agency (n.d.) http://www.skogsstyrelsen.se/ Myndigheten/Statistik/ [27.10.2015].

The Swedish Transport Agency - Maritime and Civil Aviation Department (2015). ICAO State Action Plan on CO2 Emissions Reduction Activities. Lindell A., Sweden.

The Water Framework Directive: In Norway, NIVA homepage (n.d.). http://www.niva.no/en/vanndirektivet [Accessed November 2015].

Tnå, P. (2013). Generation of synthesis gas for fuels and chemicals production (Doctoral dissertation, Lund University).

Trafi (2014). URL: http://www.trafi.fi/filebank/a/1412058290/ 69a45c179b03229549f209e6828aa5f3/15448-Trafi_Liikenteen_ ymparistovaikutusten_tila_2014_epdf_FIN.pdf [Accessed 20.11.2015]. 
Trafi (2015). State Action Plan of Finland International Aviation CO2 Emissions, Finnish Transport Safety Agency.

Transportstyrelsen (2015). URL: https://www.transportstyrelsen.se/en/aviation/, [Accessed 14.10.2015].

Treklyngen (2015). Treklynge homepage. URL: http://www.viken.skog.no/ om-oss/strategi [Accessed 09.12.2015].

Trømborg, E. et al. (2012). Bærekraftig biodrivstoff til sivil luftfart i Norge Biomassetilgang fra landbaserte ressurser. Oppdragsrapport for Avinor, October 2012.

UK SHEC (2012). A review of hydrogen production technologies for energy system models - UKSHEC Working Paper No. 6. Dodds, P. E. \& McDowall, W., UCL Energy Institute, University College London.

UNCTAD (2016). Second Generation Biofuel Markets: State of Play and Developing Country Perspectives. United Nations Publication.

UNECE (2000). Terms and definitions applied in the UN-ECE/FAO Temperate and Boreal Forest Resources Assessment 2000. URL: http://www.unece.org/forests/ fra/definit.html [Accessed 19.11.2015].

United Airlines (2013). News: United Airlines and AltAir Fuels to Bring CommercialScale, Cost-Competitive Biofuels to Aviation Industry. URL: http://ir.united.com/ phoenix.zhtml?c=83680\&p=irol-newsArticle\&ID=1826859 [Accessed 16.09.2015].

United Airlines (2015) New releases: United Airlines Purchases Stake in Fulcrum BioEnergy with $\$ 30$ Million Investment. URL http://newsroom.united.com/ 2015-06-30-United-Airlines-Purchases-Stake-in-Fulcrum-BioEnergy-with-30Million-Investment [Accessed 08.09.2015].

United Nations (2004). Freshwater Country Profile: Norway, URL: http://www.un.org/ esa/agenda21/natlinfo/countr/norway/waterNorway04f.pdf [Accessed 17.09.2015].

Universitet for Miljø- og Biovitenskap (NMBU 2012). Bærekraftig biodrivstoff til sivil luftfart i Norge - Biomassetilgang fra landbaserte ressurser. Ås, October 2012.

US Department of Energy (2016). Federal Laws and Incentives for biodiesel. URL: http://www.afdc.energy.gov/fuels/laws/BIOD/US [Accessed 15.06:2016].

UOP (2014). Press Release: Honeywell's UOP Green Fuels Technology Selected By Petrixo To Produce Renewable Jet Fuel And Diesel. URL: https://honeywell.com/ News/Pages/Honeywell\%E2\%80\%99s-UOP-Green-Fuels-Technology-Selected-ByPetrixo-To-Produce-Renewable-Jet-Fuel-And-Diesel.aspx [Accessed 09.09.2015].

World Nuclear Organization (2015). http://www.world-nuclear.org/ [Accessed 11.11.2015].

Worldwide Fund for Nature (2013). Searching for Sustainability: Comparative Analysis of Certification Schemes for Biomass used for the Production of Biofuels. Report. 
Nordic Council of Ministers

Ved Stranden 18

DK-1061 Copenhagen K

www.norden.org

\section{Sustainable jet fuel for aviation}

The study assesses to what extent the production and use of advanced sustainable jet fuel may contribute to GHG reduction and mitigation, and identifies the commercial potential for initiating and scaling up advanced sustainable jet fuel production at a Nordic level. The report explores as well on how to most efficiently use the available Nordic know-how, feedstock and production facilities. The report draws on the latest available reports and statistics, as well as interviews with stakeholders and experts across the Nordic countries, concludes on identifying the most matured technologies, the Nordic opportunities and challenges, and ideas to mitigate the barriers within the Nordic private and public sectors.

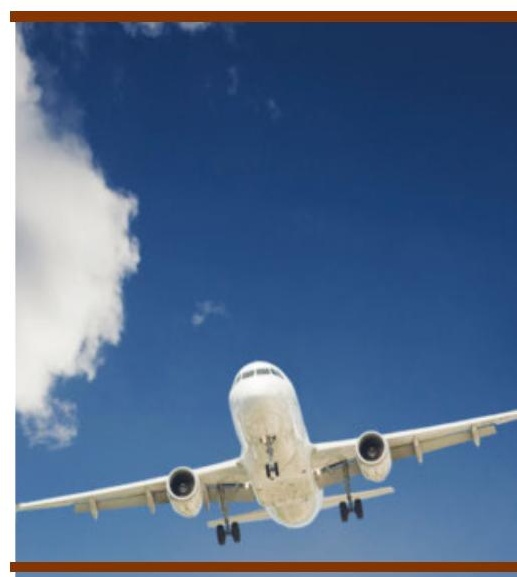

TemaNord 2016:538

ISBN 978-92-893-4661-0 (PRINT)

ISBN 978-92-893-4662-7 (PDF)

ISBN 978-92-893-4663-4 (EPUB)

ISSN 0908-6692

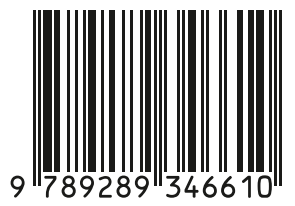

